\title{
ipen
}

Instituto de Pesquisas Energéticas e Nucleares

AUTARQUIA ASSOCIADA À UNIVERSIDADE DE SÃO PAULO

\section{ESTUDO COMPARTIMENTAL E DOSIMÉTRICO DO ANTI-CD20 MARCADO COM ${ }^{188} \mathrm{Re}$}

\section{GRACIELA BARRIO KURAMOTO}

Tese apresentada como parte dos requisitos para obtenção do grau de Doutor em Ciências na Área de Tecnologia Nuclear - Aplicações.

Orientador:

Dr. João Alberto Osso Jr. 


\section{Instituto de Pesquisas Energéticas e Nucleares}

AUTARQUIA ASSOCIADA À UNIVERSIDADE DE SÃO PAULO

\section{ESTUDO COMPARTIMENTAL E DOSIMÉTRICO DO ANTI-CD20 MARCADO COM ${ }^{188} \mathrm{Re}$}

\section{GRACIELA BARRIO KURAMOTO}

Tese apresentada como parte dos requisitos para obtenção do grau de Doutor em Ciências na Área de Tecnologia Nuclear - Aplicações.

Orientador:

Dr. João Alberto Osso Jr. 
Dedico este trabalho ao meu pai, Gonzalo Barrio Vilar (em memória). 


\section{AGRADECIMENTOS}

Ao meu pai Gonzalo Barrio Vilar, que lá de cima deve estar muito orgulhoso de ver onde sua filha mais velha chegou, graças a tudo que ele construiu em vida para sua família. Serei eternamente grata a oportunidade que ele deu a mim e a minha irmã, com relação a estudar em uma boa escola, fazer uma boa faculdade, sempre nos mostrando o quanto é importante ser uma pessoa estudada, para que não nos tornássemos pessoas ignorantes de conhecimento. Saudades eternas!

À minha mãe Terezinha com carinho sempre, hoje formada como assistente social, graças a oportunidade que teve de poder voltar aos estudos após quase 40 anos. Oportunidade que agarrou após se espelhar em mim e em minha irmã, formadas e profissionais. Este trabalho é fruto de todos os esforços por ela, juntamente ao meu pai, dedicados durante toda a minha vida, mostrando sempre a importância do estudo para a formação do ser humano.

À minha irmã Ofelia, que sempre torce pelo meu crescimento, me apoiando mesmo de longe em qualquer decisão que tomo, sejam nos melhores momentos ou até nos mais difíceis ao longo da minha vida.

Ao meu marido Renato, que sempre me acompanha, me apóia, me aconselha, me incentiva, em todos os momentos, ao longo desta jornada para quem tenho profunda gratidão e admiração.

Aos meus sogros Regina e Satoru, meus cunhados André e Priscilla que sempre torceram pelo sucesso da minha carreira acadêmica.

Ao Dr. João Alberto Osso Júnior, por acreditar no meu trabalho e em mim principalmente (que em várias vezes eu mesma desacreditava), me encorajando a nunca desistir, apesar das diversas dificuldades encontradas, pela confiança ao longo desses 10 anos de orientação e amizade, minha sincera gratidão. 
À Dra. Margareth Mie Nakamura Matsuda em aceitar participar como coorientadora deste trabalho, enriquecendo-o ainda mais graças à sua experiência e competência, minha sincera gratidão e respeito.

A Comissão Nacional de Energia Nuclear (CNEN) pela concessão da bolsa de doutorado.

Ao Instituto de Pesquisas Energéticas e Nucleares juntamente com o Centro de Radiofarmácia pela infraestrutura proporcionada para o desenvolvimento deste trabalho.

Às queridas amigas: Carla, Kátia, Samanta e Tânia - por todos os momentos felizes (e tristes também) que convivi junto com vocês dentro e fora da Radiofarmácia ao longo desses 10 anos. As também queridas Daphne e Marcela pelos momentos divertidos passados juntas. Que nossa amizade continue mesmo com a distância e os compromissos de cada uma.

Aos funcionários Peterson Squair Lima e Lorena Pozzo pela contribuição do trabalho na área de dosimetria com sugestões, críticas e ensinamentos que enriqueceram meus conhecimentos na área.

Ao Dr. Ignacio Hernández Gonzáles, do Centro de Isótopos (CENTIS), pela contribuição do trabalho na área de radiofarmacocinética, com sugestão do uso do programa monolix, enriquecendo meus conhecimentos na área e neste trabalho.

Aos demais Pesquisadores, Funcionários e Colegas de Trabalho do Centro de Radiofarmácia que contribuíram direta ou indiretamente para a consolidação deste trabalho. 
"Lute, se esforce, vença e continue lutando. Assim como as lutas não tem fim, a vitória pode ser sem limites".

Aleff Lavoisier 


\title{
Estudo compartimental e dosimétrico do Anti-CD20 marcado com ${ }^{188} \mathrm{Re}$
}

\author{
Graciela Barrio Kuramoto
}

\section{RESUMO}

A radioimunoterapia (RIT) faz uso de anticorpos monoclonais conjugados com radionuclídeos emissores $\alpha$ ou $\beta^{-}$, ambos para terapia. $O$ tratamento baseia-se na irradiação e destruição do tumor, preservando os órgãos normais quanto ao excesso de radiação. Radionuclídeos emissores $\beta{ }^{-}$como ${ }^{90} Y,{ }^{131} \mathrm{I},{ }^{177} \mathrm{Lu}$ e ${ }^{188} \mathrm{Re}$, são úteis para o desenvolvimento de radiofármacos terapêuticos e, quando associados a AcM como o Anti-CD20 são importantes principalmente para o tratamento de Linfomas Não Hodgkin's $(L N H) .{ }^{188} R e\left(E_{\beta-}=2,12 \mathrm{MeV} ; E_{\gamma}=155 \mathrm{keV} ; t_{1 / 2}=16,9 \mathrm{~h}\right)$ é um radionuclídeo atrativo para RIT. O Centro de Radiofarmácia do IPEN possui um projeto que visa a produção do radiofármaco ${ }^{188} \mathrm{Re}$-Anti-CD20. Com isso,este estudo foi proposto para avaliar a eficácia desta técnica de marcação para tratamento em termos compartimentais e dosimétricos. O objetivo deste trabalho consistiu na compararação da marcação do AcM anti-CD20 com ${ }^{188}$ Re com a marcação do anticorpo com ${ }^{90} \mathrm{Y},{ }^{131} \mathrm{I},{ }^{177} \mathrm{Lu}$ e ${ }^{99 \mathrm{~m} T c}$ (pelas suas características químicas similares) e ${ }^{211} \mathrm{At},{ }^{213} \mathrm{Bi},{ }^{223} \mathrm{Ra}$ e ${ }^{225} \mathrm{Ac}$. Através do estudo de técnicas de marcação relatadas em literatura, foi proposto um modelo compartimental para avaliação de sua farmacocinética e estudos dosimétricos, de alto interesse para a terapia. A revisão de dados publicados na literatura, possibilitou demonstrar diferentes procedimentos de marcação, rendimentos de marcação, tempo de reação, impurezas e estudos de biodistribuição. O resultado do estudo mostra uma cinética favorável para o ${ }^{188} \mathrm{Re}$, pelas suas características físicas e químicas frente aos demais radionuclídeos avaliados. O estudo compartimental proposto descreve o metabolismo do ${ }^{188} \mathrm{Re}$-antiCD20 através de um modelo compartimental mamilar, que pela sua análise farmacocinética, realizada em comparação aos produtos marcados com emissores $\beta^{-}$: ${ }^{131} \mathrm{I}$-antiCD20, ${ }^{177} \mathrm{Lu}$-anti-CD20, o emissor $\gamma{ }^{99 m} \mathrm{mc}$-anti-CD20 e o emissor $\alpha{ }^{211}$ At-Anti-CD20, apresentou uma constante de eliminação de aproximadamente 0,05 horas $^{-1}$ no sangue do animal. A avaliação dosimétrica do ${ }^{188}$ Re-Anti-CD20 foi realizada através de duas metodologias: pelo método de Monte Carlo e pelo uso de uma fonte pontual $\beta^{-}$através da Fórmula de Loevinger via programa Excel. Através da Fórmula de Loevinger fez-se a validação do método de Monte Carlo para a dosimetria do ${ }^{188} \mathrm{Re}-\mathrm{Anti}-\mathrm{CD} 20$ e dos demais produtos. As doses e as taxas de doses obtidas pelos dois métodos foram avaliadas em comparação à dosimetria do ${ }^{90}$ Y-Anti-CD20, ${ }^{131} \mathrm{I}$-Anti-CD20 e do ${ }^{177} \mathrm{Lu}$-Anti-CD20, obtidas pela mesma metodologia. $O$ estudo de dose foi realizado utilizando modelos matemáticos considerando um camundongo nude de $25 \mathrm{~g}$, simulando diferentes tamanhos de tumor e diferentes formas de distribuição do produto dentro do animal. De acordo com os resultados obtidos, pela energia de emissão $\beta,{ }^{188}$ Re-Anti-CD20 apresenta maior deposição de energia para tumores volumosos em relação aos demais 
produtos avaliados. Em uma simulação com $100 \%$ do produto captado pelo tumor, $89 \%$ da dose total manteve-se absorvida pelo tumor, preservando a integridade de ógãos críticos como coração (2\%), pulmões $(5 \%)$, coluna $(4 \%)$, fígado $(0,014 \%)$ e rins $(0,0007 \%)$. Em uma simulação onde há uma biodistribuição do produto no organismo do animal, $38 \%$ da dose total é absorvida pelo tumor e $>3 \%$ é absorvida pela coluna. Nessa situação mais próxima da realidade, a extrapolação dos dados para um humano de $70 \mathrm{~kg}$, mostrou que a dose absorvida no tumor corresponde a cerca de 33\%; na coluna 7\% e o coração receberia uma dose de $35 \%$ do total. A análise compartimental e dosimétrica apresentada neste trabalho, realizada através do uso de um modelo animal para $0{ }^{188}$ Re-Anti-CD20 mostra que o produto desenvolvido e apresentado em literatura é candidato promissor para a RIT.

Palavras-chave: Radioimunoterapia, Anti-CD20, ${ }^{188}$ Re, Método de Monte Carlo, Radiofarmacocinética. 


\title{
Compartmental and Dosimetric Studies of Anti-CD20 labelled with ${ }^{188} \mathrm{Re}$
}

\author{
Graciela Barrio Kuramoto
}

\begin{abstract}
The radioimmunotherapy (RIT) uses MAbs conjugated to radionuclides $\alpha$ or $\beta^{-}$emitters, both for therapy. Your treatment is based on the irradiation and tumor destruction, preserving the normal organs as the excess radiation. Radionuclides $\beta$ emitters as ${ }^{131}$, ${ }^{90 Y},{ }^{188} \mathrm{Re}{ }^{177} \mathrm{Lu}$ and are useful for the development of therapeutic radiopharmaceuticals and, when coupled with MAb and Anti-CD20 it is important mainly for the treatment of non-Hodgkin's lymphomas $(\mathrm{NHL}) .{ }^{188} \mathrm{Re}\left(\mathrm{E}_{\beta-}=2.12 \mathrm{MeV}\right.$; $\mathrm{E}_{\gamma}=155 \mathrm{keV} ; \mathrm{t}_{1 / 2}=16.9 \mathrm{~h}$ ) is an attractive radionuclide for RIT. However, ${ }^{188} \mathrm{Re}$ can be obtained from a radionuclide generator of ${ }^{188} \mathrm{~W} /{ }^{188} \mathrm{Re}$, commercially available, making it convenient for use in research and for clinical routine. The CR of IPEN has a project aimed at the production of radiopharmaceutical ${ }^{188} \mathrm{Re}-\mathrm{Anti}-\mathrm{CD} 20$, where the radionuclide can be obtained from a generator system ${ }^{188} \mathrm{~W} /{ }^{188} \mathrm{Re}$. With this proposed a study to assess the efficiency of this labeling technique for treatment in accordance compartmental and dosimetry. The objective of this study was to compare the marking of anti-CD20 MAb with ${ }^{188}$ Re with the marking of the antibody with ${ }^{90} \mathrm{Y},{ }^{131}$, ${ }^{177} \mathrm{Lu}$ and ${ }^{99 \mathrm{~m}} \mathrm{Tc}$ (for their similar chemical characteristics) and ${ }^{211} \mathrm{At},{ }^{213} \mathrm{Bi},{ }^{223} \mathrm{Ra}$ and ${ }^{225} \mathrm{Ac}$ ); through the study of labeling techniques reported in literature, the proposal of a compartmental model to evaluate its pharmacokinetic and dosimetric studies, high interest for therapy. The result of the study shows a favorable kinetics for ${ }^{188} \mathrm{Re}$, by their physical and chemical characteristics compared to the other evaluated radionuclides. The compartment proposed study describes the metabolism of ${ }^{188} \mathrm{Re}$ anti-CD20 through a compartment mammillary model, which by their pharmacokinetic analysis, performed compared to products emissores $\beta^{-}:{ }^{131} \mathrm{I}$-labeled antiCD20, ${ }^{177} \mathrm{Lu}$ anti-CD20, the $\gamma$ emitter ${ }^{99 m}$ Tc-Anti-CD20 and $\alpha$ emitter ${ }^{211}$ At-Anti-CD20 presented a elimination constant of approximately 0.05 hours $^{-1}$ in the animal's blood. The dosimetric evaluation of ${ }^{188} \mathrm{Re}-$ Anti-CD20 was performed using two methodologies: the Monte Carlo method and the use of a point source $\beta^{-}$by Formula Loevinger by Excel program. In the Formula Loevinger, there was a validation of the Monte Carlo method for dosimetry of ${ }^{188} \mathrm{Re}-\mathrm{Anti}-\mathrm{CD} 20$ and other products. The doses and dose rates obtained by the two methods were evaluated in comparison with ${ }^{90} \mathrm{Y}$-Anti-CD20, ${ }^{131}$ I-Anti-CD20 and ${ }^{177}$ Lu-Anti-CD20 dosimetry, obtained by the same methodology. The dose study was conducted using mathematical models considering a nude mouse $25 \mathrm{~g}$, simulating different tumor sizes and different forms of distribution of the product within the animal. According to the results, the energy emission $\beta^{-},{ }^{188} \mathrm{Re}$ Anti-CD20 has a higher energy deposition for large tumors when compared to other products evaluated. In a simulation with $100 \%$ of the product uptake by tumor, $89 \%$ of the total dose remained absorbed by the tumor, while preserving the integrity of critical ógãos as heart ( $2 \%)$, lung $(5 \%)$, column $(4 \%)$, liver $(0.014 \%)$ and kidneys
\end{abstract}


$(0.0007 \%)$. In a simulation where there is a biodistribution of the product in the animal organism, $38 \%$ of the total dose absorbed by the tumor and $>3 \%$ is absorbed by the column. In this situation closer to reality, the extrapolation of the data for a $70 \mathrm{~kg}$ human, showed that the absorbed dose to tumor corresponds to about $33 \%$; In column $7 \%$ and the heart would receive a dose of $35 \%$ of the total. The compartmental analysis and dosimetric presented in this work, performed through use of an animal model for the ${ }^{188} \mathrm{Re}$-anti-CD20 shows that the product developed and presented in the literature is promising candidate for RIT.

Key words: Radioimunotherapy, Anti-CD20, ${ }^{188} \mathrm{Re}$, Monte Carlo Method, Radiopharmacokinetic. 


\section{SUMÁRIO}

Página

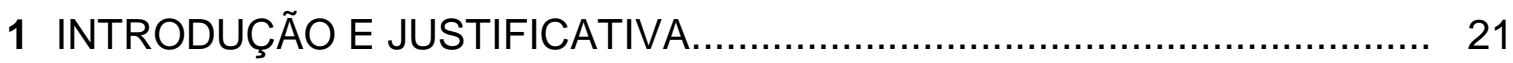

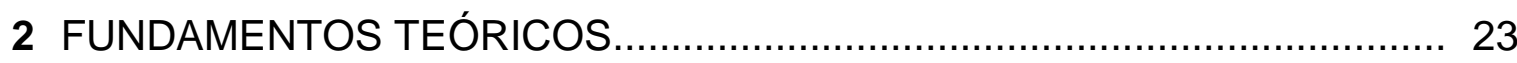

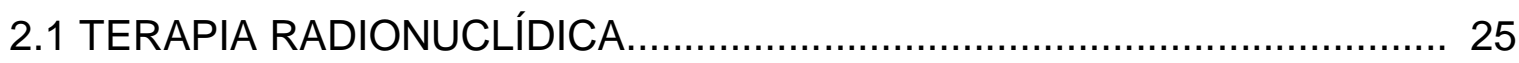

2.1.1 RADIONUCLÍDEOS PARA ENDOTERAPIA....................................... 27

2.1.2 CARACTERÍSTICAS DE UM RADIONUCLÍDEO IDEAL PARA

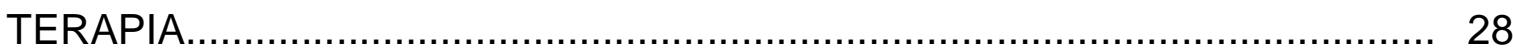

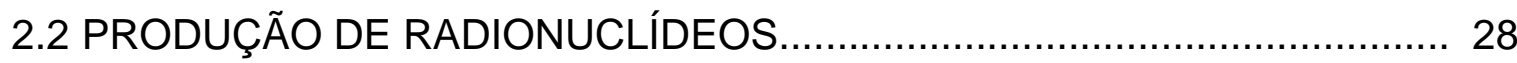

2.2.1 RADIONUCLÍDEOS PRODUZIDOS POR REATORES............................ 29

2.2.2 RADIONUCLÍDEOS PRODUZIDOS POR ACELERADORES OU

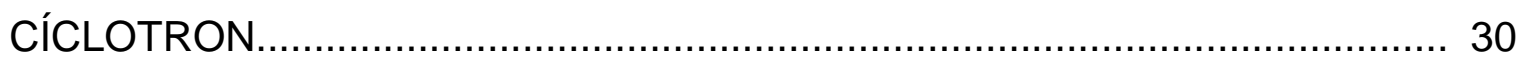

2.2.3 RADIONUCLÍDEOS PRODUZIDOS POR SISTEMAS

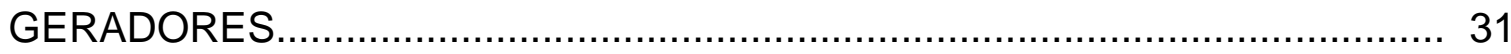

2.2.3.1 GERADORES DE RADIONUCLÍDEOS.......................................... 32

2.3 O PRINCÍPIO DA RADIOIMUNOTERAPIA (RIT) .................................. 33

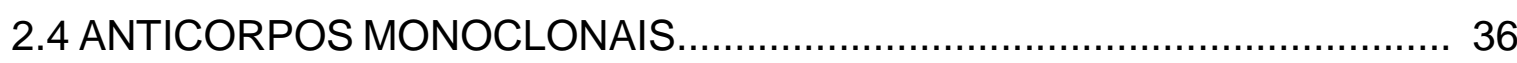

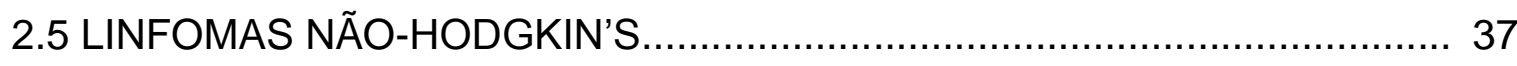

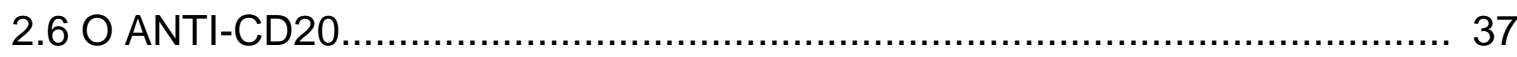

2.7 PROPRIEDADES FÍSICAS E DOSIMÉTRICAS DO ${ }^{188}$ Re-ANTI-CD20_....... 42

2.8 ESTUDOS DE BIODISTRIBUIÇÃO, FARMACOCINÉTICA E DOSIMETRIA COMO FERRAMENTAS ALIADAS À TERAPIA............................................ 46

2.8.1 PROGRAMAS COMPUTACIONAIS PARA ESTUDOS FARMACOCINÉTICOS COM RADIOFÁRMACOS......................................... 46

2.8.2 PROGRAMAS COMPUTACIONAIS PARA ESTUDOS DE DOSIMETRIA INTERNA DE RADIOFÁRMACOS EM MODELO ANIMAL................................. 48

2.8.2.1 MODELOS ANTROPOMÓRFICOS................................................. $\quad 50$

2.8.2.2 O MÉTODO DE MONTE CARLO................................................... 51

2.8.2.3 DOSIMETRIA POR FONTE PONTUAL PARA EMISSORES $\beta$-........... 53 
2.8.3 EXTRAPOLAÇÃO DE DADOS DE ESTUDOS EM ANIMAIS PARA

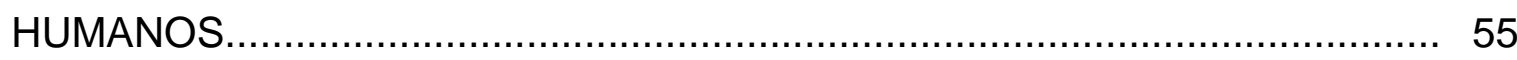

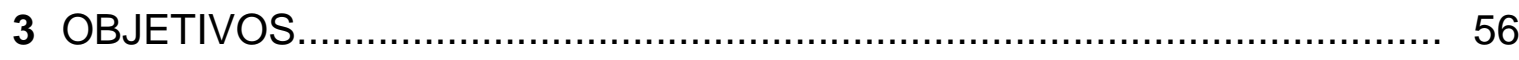

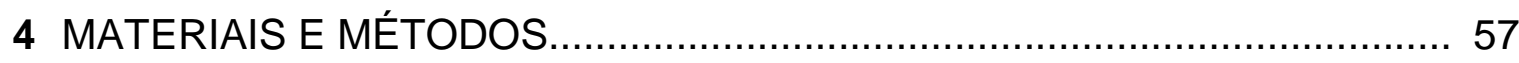

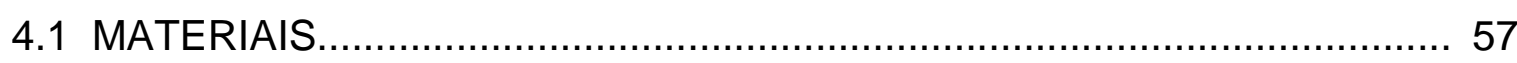

4.1.1 INFRAESTRUTURA E EQUIPAMENTOS........................................... 57

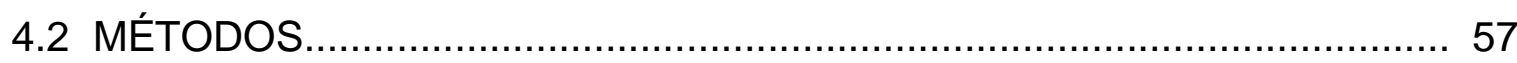

4.2.1 ESTUDO DAS PROPRIEDADES FÍSICAS DOS RADIONUCLÍDEOS..... 57

4.2.2 ESTUDO DA PUREZA RADIOQUÍMICA DOS RADIOFÁRMACOS.......... 57

4.2.3 AVALIAÇÃO DA FARMACOCINÉTICA DO ANTI-CD2O MARCADO COM PRINCIPAIS RADIONUCLÍDEOS EMISSORES $\alpha$ E $\beta$ - PARA RIT .................... 58

4.2.3.1 MODELO COMPARTIMENTAL PARA ESTUDOS CINÉTICOS............ 58

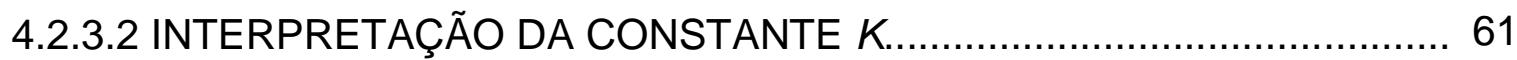

4.2.3.3 SIMULAÇÃO DOS DADOS A PARTIR DO MONOLIX........................... 62

4.2.4 AVALIAÇÃO DA DOSIMETRIA NO TUMOR E EM TECIDOS NORMAIS EM RIT COM ANTI-CD20 MARCADO COM EMISSORES $\beta$............................ 62

4.2.4.1 USO DE MODELOS MATEMÁTICOS.................................................. 63

4.2.4.2 MÉTODO POR MONTE CARLO PARA ESTUDOS DE DOSIMETRIA ................................................................................ 66

4.2.4.3 MÉTODO POR USO DE UMA FONTE PONTUAL PARA ESTUDOS

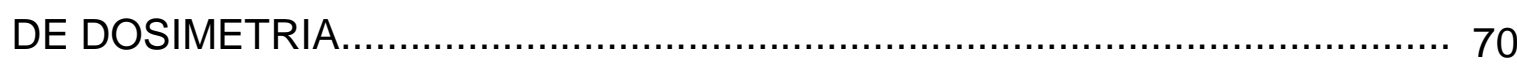

4.2.4.4 EXTRAPOLAÇÃO DE DADOS ANIMAIS PARA HUMANOS................. 71

5 RESULTADOS E DISCUSSÃO............................................................ 73

5.1 PROPRIEDADES FÍSICAS DOS RADIONUCLÍDEOS PARA APLICAÇÃO

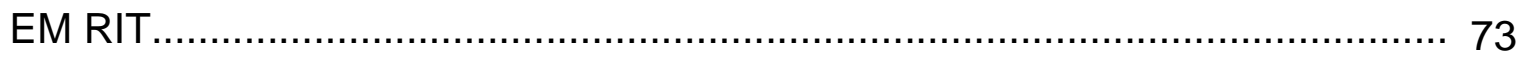

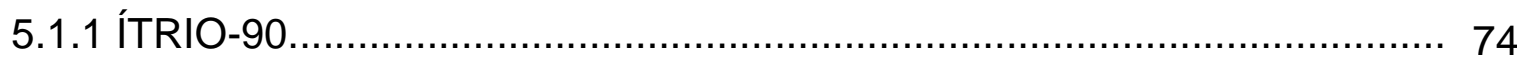

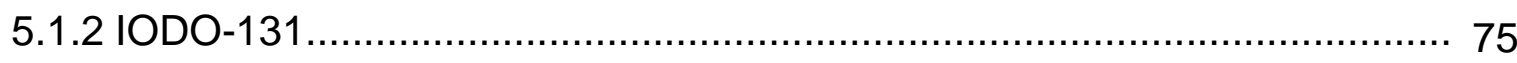

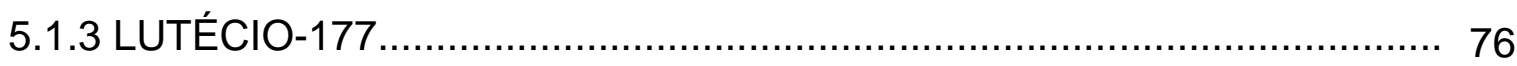

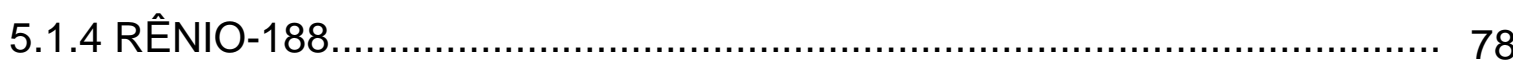

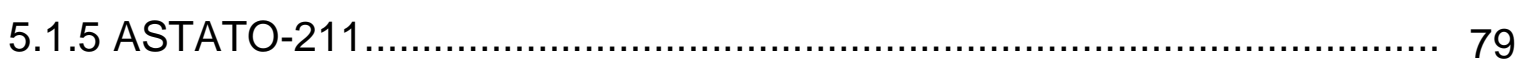

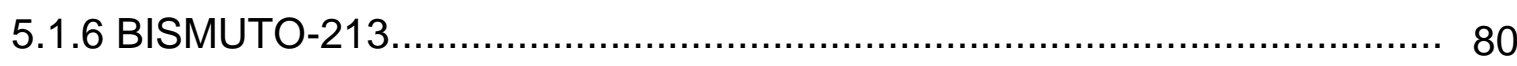

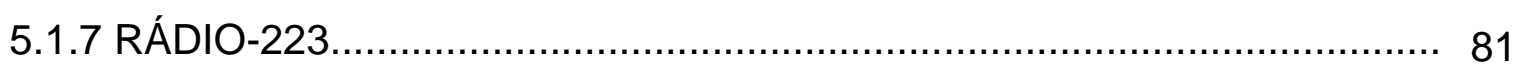

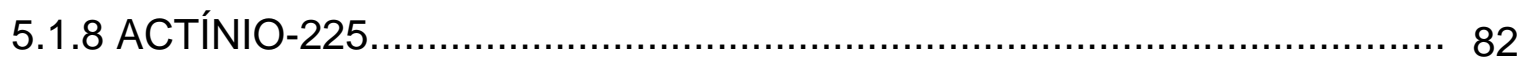


5.1.9 CONSIDERAÇÕES SOBRE AS CARACTERÍSTICAS FÍSICAS DOS RADIONUCLÍDEOS PARA APLICAÇÃO EM RIT ........................................... 83

5.2 MARCAÇÃO DO ANTI-CD20 COM RADIONUCLÍDEOS $\alpha$ e $\beta$-................ 86

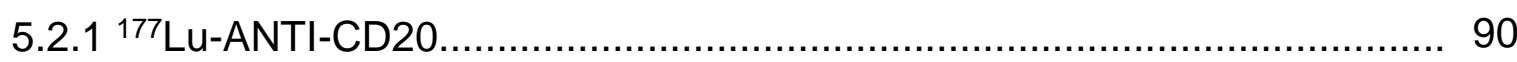

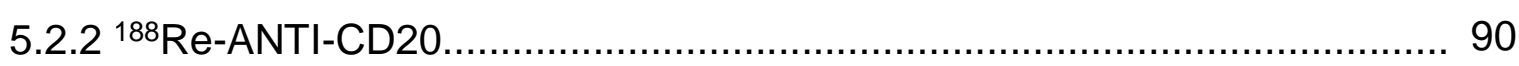

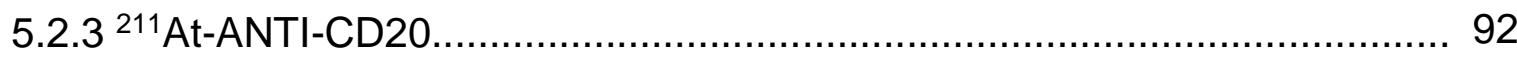

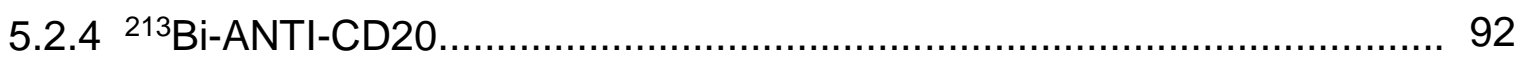

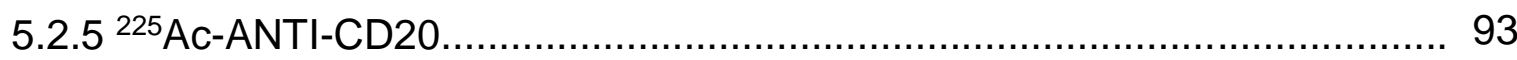

5.3 AVALIAÇÃO DA FARMACOCINÉTICA DO ANTI-CD20............................. 93

5.4 AVALIAÇÃO DOS ESTUDOS DE DOSIMETRIA COM

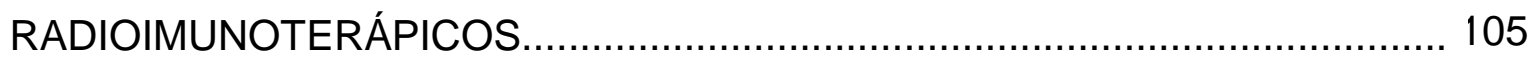

5.4.1 AVALIAÇÃO DOSIMÉTRICA PELO MÉTODO DE MONTE CARLO......... 105 5.4.2 AVALIAÇÃO DA DOSE ABSORVIDA PELO MÉTODO POR FONTE

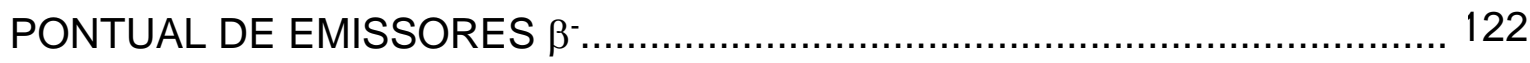

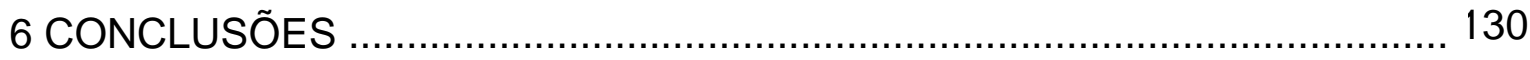

REFERÊNCIAS BIBLIOGRÁFICAS ............................................................ 132 


\section{LISTA DE TABELAS}

Página

TABELA 1 - Principais radioisótopos utilizados na técnica PET...................... 24

TABELA 2 - Principais radioisótopos utilizados na técnica SPECT.................. 24

TABELA 3 - Vantagens e limitações da terapia radionuclídica......................... 25

TABELA 4 - Radioisótopos utilizados para Endoterapia................................ 27

TABELA 5 - Rota de produção dos principais radionuclídeos terápicos comumente utilizados

TABELA 6 - Principais sistemas de geradores de radionuclídeos usados para aplicações em medicina nuclear

TABELA 7 - Anticorpos Anti-CD20 em ensaios clínicos e clinicamente aprovados

TABELA 8 - Características terapêuticas dos principais radionuclídeos $\beta$ utilizados para terapia

TABELA 9 - Equações diferenciais dos onze compartimentos para o modelo compartimental mamilar do Anti-CD20.

TABELA 10 - Relação das equações utilizadas para definição do modelo matemático dos órgãos do camundongo, usados como dados de entrada para calcular a dose absorvida nos órgãos normais e tumor, no estudo da dosimetria com emissores $\beta^{-}$em RIT

TABELA 11 - Densidades dos pulmões, coluna (medula óssea), além dos demais órgãos e tumor, usados como dados de entrada para a determinação da dose absorvida, com os radionuclídeos emissores $\beta^{-}$

TABELA 12 - Massa dos órgãos do camundongo e massa do tumor utilizados como dados de entrada, para a determinação da dose absorvida, com os radionuclídeos emissores $\beta$ -

TABELA 13 - Energias máximas de emissão dos radionuclídeos emissores $\beta$ usados nas simulações com MCNP para determinação da dose absorvida nos tecidos. 
TABELA 14 - Tamanho de tumor (raio) usado nas simulações para avaliar a variação tumoral em relação à sua dosimetria

TABELA 15 - Valores de referência para massa de órgãos, considerando um ser humano de $70 \mathrm{~kg}$.

TABELA 16 - Radionuclídeos emissores $\beta^{-}$e $\alpha$ e suas respectivas meiasvidas.

TABELA 17 - Comparação da farmacologia dos radiofármacos comerciais preparados com o AcM Anti-CD20, e o próprio imunoterápico Anti-CD20.

TABELA 18 - Metodologias de marcação com AcM com radionuclídeos emissores $\beta$ - promissores para RIT.

TABELA 19 - Metodologias de marcação com AcM com radionuclídeos emissores $\alpha$ promissores para RIT.

TABELA 20 - Taxa de eliminação (k) e meia-vida biológica obtidas para o Anti-CD20 radiomarcado com ${ }^{188} \mathrm{Re}$, em comparação com ${ }^{131} \mathrm{I}$, ${ }^{177} \mathrm{Lu}$ e 99mTc.

TABELA 21 - Massas dos órgãos do camundongo calculadas pelo MCNP, comparadas às massas dos mesmos órgãos utilizadas em literatura

TABELA 22 - Relação entre o tamanho do tumor dentro do corpo do camundongo (através do seu raio), e suas respectivas massas tumorais, calculadas pelo MCNP

TABELA 23 - Doses absorvidas em cada órgão e no tumor em simulações com MCNP, com Anti-CD20 e cada um dos radionuclídeos ${ }^{188} \mathrm{Re},{ }^{177} \mathrm{Lu},{ }^{131} \mathrm{I} \mathrm{e}$ ${ }^{90} \mathrm{Y}$, para tumores de $\mathrm{r}=0,4 \mathrm{~cm}$. Tempo para cada simulação: $300 \mathrm{~min}$. Atividade simulada do radiofármaco: $85 \mathrm{~Bq}$.

TABELA 24 - Extrapolação da dose de ${ }^{188}$ Re-Anti-CD20, obtido por meio de simulações de Monte Carlo em um camundongo de 25g, para um homem de $70 \mathrm{~kg}$.

TABELA 25 - Doses absorvidas em tumores de diferentes dimensões radiais, calculados pela fórmula de Loevinger. Atividade considerada: $85 \mathrm{~Bq}$. Tempo total considerado: 5 horas.

TABELA 26 - Taxas de doses absorvidas no tumor de diferentes dimensões radiais, calculados pela fórmula de Loevinger. Atividade considerada: $85 \mathrm{~Bq}$. Tempo total considerado: 5 horas. 


\section{LISTA DE FIGURAS}

Página

FIGURA 1 - Expressão do CD20 no desenvolvimento das células-B. O antígeno CD20 é expresso primeiro durante um desenvolvimento inicial da précélula-B e perdido durante diferenciação terminal das células do plasma

FIGURA 2 - A molécula humana CD20.

FIGURA 3 - Poder de penetração dos radionuclídeos emissores de partículas $\beta^{-}$usados em terapia em função da energia $(\mathrm{MeV})$ para diferentes espessuras teciduais.

FIGURA 4 - Exemplo de uma Imagem bidimensional de uma Tomografia Computadorizada (TC) onde corresponde a uma fatia tridimensional de um corpo humano. Cada pixel na imagem corresponde a um voxel. O voxel tem as duas dimensões do pixel no plano da imagem e a terceira dimensão representa a espessura da fatia da varredura TC

FIGURA 5 - Modelo mamilar utilizado para estudos farmacocinéticos com AntiCD20. O modelo descreve a interação do radiofármaco entre o sangue e cada um demais compartimentos, correspondendo aos órgãos e tumor. A perda de material pela urina foi consideranda irreversível de material.

FIGURA 6 - Modelo matemático do corpo de um camundongo, proposto pelo código de Monte Carlo MCNP-4C. Este modelo foi utilizado para estabelecer a geometria dos órgãos e do tumor, dentro de um corpo simulado de um camundongo, na determinação da dose absorvida.

FIGURA 7 - Curvas de decaimento radioativo dos principais radionuclídeos emissores $\beta^{-}$e $\alpha$ usados em RIT, obtidas teoricamente.

FIGURA 8 - Produção alternativa do ${ }^{90} Y$ a partir da irradiação de alvos naturais de ${ }^{89} Y$. 
FIGURA 9 - Esquema de produção do ${ }^{90} \mathrm{Y}$ a partir do processo de decaimento do ${ }^{90} \mathrm{Sr}$ produzido via reator e seu decaimento para o ${ }^{90} \mathrm{Zr}$ (estável)

FIGURA 10 - Produção do ${ }^{131}$ | a partir de dois métodos: como produto de fissão do ${ }^{235} \mathrm{U}$ ou pela ativação de alvos de telúrio natural. 76

FIGURA 11 - Esquema de decaimento do ${ }^{131}$ I.

FIGURA 12 - Representação esquemática da produção do ${ }^{177} \mathrm{Lu}$ pelo método 'direto' através da irradiação do alvo de ${ }^{176}$ Lu enriquecido e o método 'indireto' pela irradiação dos alvos de ${ }^{176} \mathrm{Yb}$.

FIGURA 13 - Esquema de decaimento do ${ }^{177} \mathrm{Lu}$

FIGURA 14 - Esquema de produção e decaimento para o ${ }^{188} \mathrm{Re}$ a partir da irradiação do alvo de ${ }^{186} \mathrm{~W}$ enriquecido com nêutrons.

FIGURA 15 - Esquema de produção do ${ }^{188} \mathrm{Re}$ a partir do processo de decaimento do ${ }^{188} \mathrm{~W}$ e seu decaimento para o ${ }^{188} \mathrm{Os}$ (estável)

FIGURA 16 - Cascata de decaimento do ${ }^{211} \mathrm{At}$, com decaimento de partículas associadas e meias-vidas

FIGURA 17 - Produção do ${ }^{211}$ At via cíclotron

FIGURA 18 - Cascata de decaimento do ${ }^{213} \mathrm{Bi}$ com decaimento de partículas associadas e meias-vidas

FIGURA 19 - Cascata de decaimento do ${ }^{223}$ Ra com decaimento de partículas associadas e meias-vidas

FIGURA 20 - Cascata de decaimento do ${ }^{225} \mathrm{Ac}$ com decaimento de partículas associadas e meias-vidas

FIGURA 21 - Ajustes das curvas de concentração do AcM Anti-CD20 marcado com os radionuclídeos, no sangue, em função do tempo: ${ }^{188} \mathrm{Re}$ (com dois métodos de marcação); ${ }^{177} \mathrm{Lu}$; ${ }^{131}$; ; $99 \mathrm{~m} \mathrm{Tc}$ e ${ }^{211} \mathrm{At}$.

FIGURA 22 - Correlação entre as concentrações das atividades de todos os produtos Anti-CD20 marcado com os radionuclídeos ${ }^{188} \mathrm{Re}$ (com dois métodos de marcação); ${ }^{177} \mathrm{Lu},{ }^{131} \mathrm{I},{ }^{99 \mathrm{mTC}}$ e ${ }^{211} \mathrm{At}$, injetados no animal, obtidos por literatura e previstos por simulação.

FIGURA 23 - Estudo compartimental para o ${ }^{188}$ Re-Anti-CD20 ......................... 98

FIGURA 24 - Estudo compartimental para o ${ }^{131}$ I-Anti-CD20............................ 99

FIGURA 25 - Estudo compartimental para o ${ }^{177} \mathrm{Lu}$-Anti-CD20 ........................... 100

FIGURA 26 - Estudo compartimental obtido para o 99mTc-Anti-CD20................. 101 
FIGURA 27 - Estudo compartimental obtido para o ${ }^{211}$ At-Anti-CD20..

FIGURA 28 - Visão lateral da geometria do corpo do camundongo, envolvida por uma superfície esférica vazia, para que não haja perda de partículas durante o processo de simulação. Órgãos visualizados pelas superfícies de volume: coração (53), pulmão esquerdo (54), fígado (56), rim esquerdo (57), bexiga (60) e testículo esquerdo (61).

FIGURA 29 - Representação geométrica do corpo do camundongo, no Plano $\mathrm{XY}$, visualizando o tumor pela superfície de volume 69 , posicionado entre os pulmões (54 e 55) e coluna (63).

FIGURA 30 - Representação geométrica do corpo do camundongo no plano YZ. Órgãos visualizados pelas superfícies de volume: coração (53), pulmões (54), fígado (56 e 67), rins (57), bexiga (60), testículos (61) e coluna (63).

FIGURA 31 - Representação geométrica do corpo do camundongo no plano XZ. Órgãos visualizados pelas superfícies de volume: glândula tireóide (51 e 52), coração (53), pulmões (54 e 55), rins (57 e 58), bexiga (60), testículos (61 e 62), coluna (63) e o tumor (69)

FIGURA 32 - Energia no tumor em função do seu raio, determinados pela simulação por Monte Carlo, utilizando Anti-CD20 marcado com ${ }^{90} \mathrm{Y},{ }^{131} \mathrm{I},{ }^{177} \mathrm{Lu}$ e ${ }^{188} \mathrm{Re}$, simulados com o material situado totalmente dentro do tumor. Tempo de cada simulação: 300 minutos.

FIGURA 33 - Dose absorvida para tumores de $r=0,01 \mathrm{~cm}$, calculada por método de Monte Carlo para cada radiofármaco. Considerou-se $45 \%$ de captação do produto dentro do tumor e restante distribuído no organismo do camundongo. Tempo de cada simulação: 300 minutos. Atividade simulada do radiofármaco: $85 \mathrm{~Bq}$.

FIGURA 34 - Dose absorvida para tumores de $r=0,4 \mathrm{~cm}$, calculada por método de Monte Carlo para cada radiofármaco. Considerou-se $45 \%$ de captação do produto dentro do tumor e restante distribuído no organismo do camundongo. Tempo de cada simulação: 300 minutos. Atividade simulada do radiofármaco: $85 \mathrm{~Bq}$.

FIGURA 35 - Dose absorvida nos órgãos, considerando um tumor de $r=0,4$ $\mathrm{cm}$. A simulação foi feita com cada radiofármaco, situado totalmente dentro do 
tumor (100\%). Tempo de cada simulação: 300 minutos. Atividade simulada do radiofármaco: $85 \mathrm{~Bq}$.

FIGURA 36 - Dose absorvida nos principais órgãos e tumor, com simulações de diferentes tamanhos de tumor, para simulações com ${ }^{188} \mathrm{Re}$-anti-CD20 situado $100 \%$ dentro da região do tumor. Tempo de cada simulação: 300 minutos. Atividade simulada do radiofármaco: $85 \mathrm{~Bq}$.

FIGURA 37 - Dose absorvida nos principais órgãos e tumor, com simulações de diferentes tamanhos de tumor, para ${ }^{177} \mathrm{Lu}$-Anti-CD20 situado $100 \%$ dentro da região do tumor. Tempo de cada simulação: 300 minutos. Atividade simulada do radiofármaco: $85 \mathrm{~Bq}$.

FIGURA 38 - Dose absorvida nos principais órgãos e tumor, com simulações de diferentes tamanhos de tumor, para ${ }^{131}$ I-Anti-CD20 situado $100 \%$ dentro da região do tumor. Tempo de cada simulação: 300 minutos. Atividade simulada do radiofármaco: $85 \mathrm{~Bq}$.

FIGURA 39 - Dose absorvida nos prinicpais órgãos e tumor, com simulações de diferentes tamanhos de tumor, para ${ }^{90} \mathrm{Y}$-Anti-CD20 situado 100\% dentro da região do tumor. Tempo de cada simulação: 300 minutos. Atividade simulada do radiofármaco: $85 \mathrm{~Bq}$

FIGURA 40 - Dose absorvida nos principais órgãos e tumor (para $r=0,01 \mathrm{~cm}$ ) simulando uma condição em que Anti-CD20 marcado com ${ }^{90} \mathrm{Y},{ }^{131} \mathrm{I}$, ${ }^{177} \mathrm{Lu}$ e ${ }^{188} \mathrm{Re}$ injetado no animal biodistribuido pelo corpo. Tempo de simulação: 300 minutos. Atividade simulada do radiofármaco: $85 \mathrm{~Bq}$.

FIGURA 41 - Dose absorvida nos principais órgãos e tumor (para $r=0,4 \mathrm{~cm}$ ) simulando uma condição em que Anti-CD20 marcado com ${ }^{90} \mathrm{Y},{ }^{131} \mathrm{I},{ }^{177} \mathrm{Lu} \mathrm{e}$ ${ }^{188} \mathrm{Re}$ injetado no animal foi biodistribuído pelo corpo. Tempo de simulação: 300 minutos. Atividade simulada do radiofármaco: $85 \mathrm{~Bq}$

FIGURA 42 - Corte horizontal do corpo de um camundongo, construído a partir da união de diversas planilhas no programa excel, correspondendo a cada estrutura do corpo do animal, pelo uso de equações matemáticas

FIGURA 43 - Representação gráfica da estrutura do corpo de um camundongo construído por meio do conjunto de planilhas do excel, através do uso de equações geométricas, representando órgãos e tumor dentro do animal. 
FIGURA 44 - Comparação dos resultados da taxa de dose obtidos via forma analítica (pela fórmula de Loevinger) e o método de Monte Carlo para ${ }^{188} \mathrm{Re}$ Anti-CD20, em diferentes tamanhos de tumores.

FIGURA 45 - Comparação dos resultados da taxa de dose obtidos via forma analítica (pela fórmula de Loevinger) e o método de Monte Carlo para ${ }^{177} \mathrm{Lu}$ Anti-CD20, em diferentes tamanhos de tumores

FIGURA 46 - Comparação dos resultados da taxa de dose obtidos via forma analítica (pela fórmula de Loevinger) e o método de Monte Carlo para ${ }^{131}$ I-AntiCD20, em diferentes tamanhos de tumores.

FIGURA 47 - Comparação dos resultados da taxa de dose obtidos via forma analítica (pela fórmula de Loevinger) e o método de Monte Carlo para ${ }^{90} \mathrm{Y}$-AntiCD20, em diferentes tamanhos de tumores. 


\section{LISTA DE ABREVIATURAS E SIGLAS}

$\begin{array}{ll}\text { ACM } & \text { Anticorpo Monoclonal } \\ \text { ADN } & \text { Ácido Desoxirribonucleico } \\ \text { CCDA } & \text { Citoxicidade Celular Dependente do Anticorpo } \\ \text { CDC } & \text { Citoxicidade Dependente Complementar } \\ \text { CE } & \text { Captura Eletrônica } \\ \text { CR } & \text { Centro de Radiofarmácia } \\ \text { ICRP } & \text { International Commission on Radiological Protection } \\ \text { ICRU } & \text { International Commission on Radiation Units and Measurements } \\ \text { EBR } & \text { Efeito Biológico Relativo } \\ \text { ERT } & \text { Endoterapia } \\ \text { FC } & \text { Fragmento Cristalizável } \\ \text { FDA } & \text { Food and Drug Administration } \\ \text { FDP } & \text { Funções de Densidade de Probabilidade } \\ \text { INCA } & \text { Instituto Nacional do Câncer } \\ \text { IgG1 } & \text { Imunoglobulina } \\ \text { IPEN } & \text { Instituto de Pesquisas Energéticas e Nucleares } \\ \text { LLC } & \text { Leucemia Linfócita Crônica } \\ \text { LET } & \text { Linear Transfer Energy } \\ \text { LNH } & \text { Linfomas Não-Hodkin's } \\ \text { MCNP } & \text { Monte Carlo N-Particle } \\ \text { PET } & \text { Tomografia por Emissão de Pósitron } \\ \text { RIT } & \text { Radioimunoterapia } \\ \text { SAEM } & \text { Stochastic Approximation of Expectation Maximization } \\ \text { SPECT } & \text { Tomografia Computadorizada por Emissão de Fóton Único } \\ \text { TC } & \text { Tomografia Computadorizada } \\ \text { TRRP } & \text { Terapia com Radionuclídeos em Receptores de Peptídeos } \\ & \end{array}$




\section{INTRODUÇÃO E JUSTIFICATIVA}

A terapia de alvos moleculares tem se tornado uma estratégia relevante para terapia de câncer, pelo uso de anticorpos monoclonais (AcM) específicos a antígenos. Com isso, a imunoterapia se tornou uma alternativa para o tratamento de linfomas não-Hodgkin's (LNH) através do uso de AcM comerciais. Rituximabe, um anticorpo direcionado junto ao antígeno CD20, é o primeiro AcM terapêutico disponível para tratamento de $\mathrm{LNH}$ e de primeira linha para pacientes com linfoma indolente [NECSOIU et al., 2002].

A radioimunoterapia (RIT) faz uso de AcM conjugados a radionuclídeos emissores $\alpha$ ou $\beta^{-}$. Seu tratamento baseia-se na irradiação e destruição do tumor, preservando os órgãos normais quanto ao excesso de radiação. A atividade terapêutica específica a ser injetada num paciente é baseada em informações prévias em estudos de dosimetria [NECSOIU et al., 2002].

O desenvolvimento da Medicina Nuclear levou a um aumento na demanda da produção de radionuclídeos, com propriedades físicas e químicas adequadas para uma variedade de tratamentos. Alguns compostos marcados com radiometais como ítrio-90 $\left({ }^{90} \mathrm{Y}\right)$, estrôncio-89 $\left({ }^{89} \mathrm{Sr}\right)$ e rênio-186-188 $\left({ }^{186,188} \mathrm{Re}\right)$ têm recebido uma atenção especial para a terapia em virtude não somente às suas características físicas, mas por sua capacidade inerente de se combinar com uma grande variedade de ligantes [NECSOIU et al., 2002].

Radionuclídeos emissores $\beta$ - como iodo-131 ( $\left.{ }^{131} \mathrm{I}\right)$, rênio-188 $\left({ }^{188} \mathrm{Re}\right)$, ítrio$90\left({ }^{90} \mathrm{Y}\right)$ e lutécio-177 $\left({ }^{177} \mathrm{Lu}\right)$ são úteis para o desenvolvimento de radiofármacos terapêuticos. Dentre estes, ${ }^{188}$ Re tem ganhado importância nos projetos de pesquisa do Centro de Radiofarmácia (CR) do Instituto de Pesquisas Energéticas e Nucleares (IPEN-CNEN/SP) e grande interesse pela classe médica, pelas suas propriedades físicas adequadas para RIT, e pela emissão de raios $\gamma$, permitindo a obtenção de imagens, tornando isso uma vantagem em relação aos demais radionuclídeos usados em terapia. 
Métodos de marcação do rituximabe com ${ }^{188}$ Re têm sido desenvolvidos pelo grupo de pesquisa do Centro de Radiofarmácia (CR). Rituximabe é um AcM quimérico anti-CD20 produzido por tecnologia recombinante. Ele é composto de duas cadeias pesadas de 451 aminoácidos e duas cadeias leves de 213 aminoácidos, tendo um peso molecular de aproximadamente $145 \mathrm{kDa}$. Sua afinidade de ligação para o antígeno CD20 é de aproximadamente $8,0 \mathrm{nmol} . \mathrm{L}^{-1}$, ligando-se especificamente à este antígeno (expressado pela maioria dos linfócitos $\mathrm{B}$ humano) [SCHEINFELD, 2006; CARTRON et al., 2004].

O CR do IPEN possui um projeto que visa a produção do radiofármaco ${ }^{188} \mathrm{Re}$-Anti-CD20, onde o radionuclídeo pode ser obtido a partir de um sistema gerador de ${ }^{188} \mathrm{~W} / 188 \mathrm{Re}$, disponível no Instituto.

Nos últimos anos, muitas tecnologias desenvolvidas para obtenção de imagens in vivo tem sido dirigidas aos estudos em pequenos animais de laboratório, tornando-se uma ferramenta de pesquisa fundamental para estudo de doenças humanas, avaliação de terapias potenciais e principalmente, dosimetria em estudos pré-clínicos. Estes estudos dosimétricos são realizados a partir do conhecimento e desenvolvimento de modelos animais combinados com simulações matemáticas.

O uso de radionuclídeos emissores $\alpha$ como ${ }^{211} \mathrm{At},{ }^{213} \mathrm{Bi},{ }^{223} \mathrm{Ra}$ e ${ }^{225} \mathrm{Ac}$ para a RIT vem crescendo de maneira rápida nos últimos anos, em consequência das vantagens das suas características de emissão e alcance nos tecidos [DADACHOVA, 2010; MULDORF et al, 2005; AURLIEN et al, 2000; SGOUROS, 2008; SONG et al, 2008; PARK et al, 2010; HENRIKSEN et al, 2002; MIEDERER et al, 2008; MCDEVITT et al, 1999; MCDEVITT et al, 2002]. Há interesse por parte da classe médica brasileira em introduzir também esses radionuclídeos para RIT, pelos resultados promissores apresentados em eventos científicos de âmbito nacional e internacional. O Centro de Radiofarmácia possui interesse no estudo da implementação destes "novos" radionuclídeos para terapia. 


\section{FUNDAMENTOS TEÓRICOS}

A Medicina Nuclear é uma especialidade médica que utiliza radionuclídeos na forma não selada com finalidades diagnóstica e terapêutica. Os materiais radioativos são administrados normalmente in vivo e apresentam biodistribuição para determinados órgãos ou tecidos. Essa distribuição, pode ser ditada por características do próprio elemento radioativo ou estar associado por um grupo químico ou biomolécula ligado, formando um radiofármaco com finalidades específicas [SAHA, 1998].

Os radionuclídeos com finalidades diagnósticas são utilizados como ferramenta para diagnosticar por meio de imagens resultantes de exames. A escolha da técnica a ser utilizada no diagnóstico está relacionada com o tipo de emissão eletromagnética e corpuscular do radionuclídeo durante o seu decaimento radioativo. Dentre as técnicas utilizadas estão a Tomografia por Emissão de Pósitron (PET) e a Tomografia Computadorizada por Emissão de Fóton Único (SPECT) [SAHA, 1998].

$\mathrm{Na}$ técnica $\mathrm{PET}$, o pósitron é uma partícula beta que possui uma carga positiva associada $\left(\beta^{+}\right)$e uma massa idêntica ao do elétron. A técnica é baseada na detecção em coincidência de dois fótons de $511 \mathrm{keV}$ emitidos em direções opostas, após a aniquilação de um pósitron e um elétron do meio. Os dois fótons são detectados por dois detectores conectados em coincidência no mesmo eixo. Os radionuclídeos utilizados na técnica PET de diagnóstico estão descritos na TAB. 1 [OLIVEIRA et al., 2006]. 
TABELA 1 - Principais radioisótopos utilizados na técnica PET [OLIVEIRA et al., 2006].

\begin{tabular}{cc}
\hline Radioisótopo & $\mathbf{T}_{\mathbf{1} / 2}$ \\
\hline${ }^{11} \mathrm{C}$ & $20,40 \mathrm{~min}$ \\
${ }^{13} \mathrm{~N}$ & $9,96 \mathrm{~min}$ \\
${ }^{15} \mathrm{O}$ & $2,07 \mathrm{~min}$ \\
${ }^{18} \mathrm{~F}$ & $109,80 \mathrm{~min}$ \\
${ }^{64} \mathrm{Cu}$ & $13,00 \mathrm{~s}$ \\
${ }^{68} \mathrm{Ga}$ & $68,10 \mathrm{~min}$ \\
${ }^{89} \mathrm{Zr}$ & $78,41 \mathrm{~h}$ \\
${ }^{124} \mathrm{I}$ & $4,20 \mathrm{~d}$ \\
\hline
\end{tabular}

Para o diagnóstico utilizado na técnica SPECT uma das características mais importantes é a meia-vida física do elemento químico. É ideal que este tempo seja curto o suficiente para que sua permanência dentro do corpo até sua eliminação seja o mais breve possível. A faixa de energia para que se tenha uma boa imagem está entre 100 e $300 \mathrm{keV}$. Atualmente, o radionuclídeo mais utilizado para o diagnóstico é o ${ }^{99 \mathrm{~m}} \mathrm{Tc}$, porque possui uma meia-vida física de 6 horas e sua energia de emissão $\gamma$ é de $140 \mathrm{keV}$ [SAHA, 1998; WEINER \& THAKUR, 1995]. A maioria dos sistemas SPECT possuem uma gama câmara contendo de 1 a 3 detectores de Nal (TI), que estão acoplados a um sistema computadorizado para aquisição e processamento das imagens. $\mathrm{Na}$ TAB. 2, estão relacionados os radionuclídeos utilizados [OLIVEIRA et al., 2006].

TABELA 2 - Principais radioisótopos utilizados na técnica SPECT [OLIVEIRA et al., 2006].

\begin{tabular}{cc}
\hline Radioisótopo & $\mathbf{T}_{\mathbf{1 / 2}}$ \\
\hline${ }^{67} \mathrm{Ga}$ & $78,30 \mathrm{~h}$ \\
${ }^{99 \mathrm{~m} T \mathrm{Tc}}$ & $6,00 \mathrm{~h}$ \\
${ }^{111} \mathrm{In}$ & $67,90 \mathrm{~h}$ \\
${ }^{123} \mathrm{I}$ & $13,00 \mathrm{~h}$ \\
${ }^{131} \mathrm{I}$ & $8,04 \mathrm{~d}$ \\
${ }^{201} \mathrm{TI}$ & $73,00 \mathrm{~h}$ \\
\hline
\end{tabular}




\subsection{TERAPIA RADIONUCLIIDICA}

A terapia radionuclídica faz uso de fontes de radiação não-seladas para liberação seletiva da radiação aos tumores ou órgãos alvos. No tratamento do câncer, pode ser usada como parte de uma estratégia terapêutica com intenção curativa, controle de doença e paliativa. A toxicidade geralmente é limitada ao tecido hematopoético e poucos efeitos colaterais são observados. Com isso, as principais vantagens e limitações da terapia radionuclídica estão descritas na TAB. 3 [CHATAL \& HOEFNAGEL, 1999]:

TABELA 3 - Vantagens e limitações da terapia radionuclídica [CHATAL \& HOEFNAGEL, 1999].

\section{Vantagens}

- Especifidade (dose de radiação limitada ao alvo)

- Eficácia

- Baixa toxicidade

- Aplicação sistêmica ou loco-regional

- Excelente paliação

- Consequências limitadas a longo prazo

- Pré-avaliação da captação e retenção (traçador - quando for possível gerar imagens com o próprio radioisótopo)

- Custo moderado para o exame (a maioria das aplicações)

- Possibilidade de tratamentos múltiplos

- Novas indicações emergentes

\section{Limitações}

- Estocagem do lixo radioativo

- Disponibilidade

- Alto custo (na produção do radioisótopo)

- Enfoque mutidisciplinar requerido

- Necessidade de cálculos dosimétricos

- Mecanismo não totalmente compreendido 
A escolha de um radionuclídeo para ser usado em um tipo particular de terapia está baseada nas suas características físicas que incluem: energia de emissão, meia-vida física, disponibilidade, abundância de radiação $\gamma$ associada, atividade específica, além de sua rota de produção e características químicas para possível marcação [PILLAI \& DAS, 2013]. O que a dosimetria exige de um candidato "ideal" é a razão entre a radiação não-penetrante (partícula) e a radiação penetrante ser a maior possível. Ou seja, distribuir a radiação exclusivamente ao órgão-alvo mas não ao tecido saudável circunvizinho. Esta razão por sua vez, é alta para emissores $\beta$ - "puros", como por exemplo para o ${ }^{90} \mathrm{Y}$ ( 1000) [SAHA, 1998].

Os radionuclídeos que decaem por emissão $\beta$ - são os mais utilizados para aplicações terapêuticas na prática clínica, possuindo um alcance no tecido apropriado e baixa transferência linear de energia (LET - Linear Energy Transfer). Os radionuclídeos que emitem partículas $\alpha$ tem um alcance limitado no tecido (50-

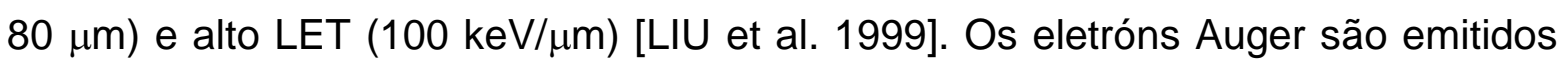
durante os processos de captura eletrônica e conversão interna, depositam grandes quantidades de energia sobre dimensões subcelulares, resultando em destruição mais eficiente das células tumorais nos locais onde os emissores Auger estão localizados [VOLKERT \& HOFFMAN, 1999]. Em virtude do baixo alcance, o radiofármaco contendo emissores Auger deve penetrar na célula.

Quanto à administração direta de radionuclídeos terápicos, dois métodos são utilizados: a radioterapia e a endoterapia (injetáveis) [STÖCKLIN et. al, 1995].

- A braquiterapia (uma modalidade da radioterapia) consiste da introdução intraarterial ou intracavitária de partículas não degradáveis contendo os radionuclídeos, numa forma selada, permanecendo na mesma posição dentro do corpo ao longo do tempo [STÖCKLIN et. al, 1995].

- A endoterapia (ERT) ou injetáveis, consiste na administração intravenosa de radiofármacos contendo radioisótopos, que se acumulam seletivamente no tecidoalvo correspondente, de acordo com as interações biomoleculares específicas. Há várias rotas principais de ação, como a incorporação dentro da célula (ex. ${ }^{131}$ Iiodeto, [ $\left.{ }^{131} 1\right] \mathrm{MIBG}$ ), ou na superfície da célula (por exemplo, anticorpos 
monoclonais - AcM, peptídeos e outras moléculas receptoras ligantes) [STÖCKLIN et. al, 1995].

\subsubsection{RADIONUCLÍDEOS PARA ENDOTERAPIA}

As propriedades físicas de decaimento dos principais radionuclídeos estudados e/ou empregados em terapia estão listados na TAB. 4 [OLIVEIRA et. al, 2006].

TABELA 4 - Radioisótopos utilizados para Endoterapia [OLIVEIRA et. al, 2006].

\begin{tabular}{lllll}
\hline Radioisótopo & \multicolumn{1}{c}{$\mathbf{T}_{1 / 2}$} & $\mathbf{E}_{\text {máx }}(\mathrm{MeV})$ & Emissão $\gamma(\mathrm{MeV})$ & $\begin{array}{l}\text { Alcance máximo } \\
\text { nos tecidos }(\mathbf{m m})\end{array}$ \\
\hline${ }^{32} \mathrm{P}$ & $14,3 \mathrm{~d}$ & $1,71\left(\beta^{-}\right)$ & - & 8,7 \\
${ }^{67} \mathrm{Cu}$ & $2,6 \mathrm{~d}$ & $0,57\left(\beta^{-}\right)$ & $0,185(48 \%)$ & 1,2 \\
& & $0,092(23 \%)$ & 8,0 \\
${ }^{89} \mathrm{Sr}$ & $50,5 \mathrm{~d}$ & $1,46\left(\beta^{-}\right)$ & - & 12,0 \\
${ }^{90} \mathrm{Y}$ & $2,7 \mathrm{~d}$ & $2,27\left(\beta^{-}\right)$ & - & 0,3 \\
${ }^{117 m} \mathrm{Sn}$ & $13,6 \mathrm{~d}$ & $0,13\left(\mathrm{e}^{-}\right.$Auger $)$ & $0,158(87 \%)$ & $10,0 \mathrm{~nm}$ \\
${ }^{125} \mathrm{I}$ & $60,3 \mathrm{~d}$ & $0,4 \mathrm{keV}\left(\mathrm{e}^{-}\right.$Auger $)$ & $25-35 \mathrm{keV}$ & 2,4 \\
${ }^{131} \mathrm{I}$ & $8,0 \mathrm{~d}$ & $0,81\left(\beta^{-}\right)$ & $0,364(81 \%)$ & 3,0 \\
${ }^{153} \mathrm{Sm}$ & $1,9 \mathrm{~d}$ & $0,81\left(\beta^{-}\right)$ & $0,103(29 \%)$ & 8,4 \\
& & & $0,081(6,24 \%)$ & \\
${ }^{166} \mathrm{Ho}$ & $1,1 \mathrm{~d}$ & $1,85\left(\beta^{-}\right)$ & $1,379(0,93 \%)$ & 1,2 \\
& & & $0,113(6,4 \%)$ & \\
${ }^{177} \mathrm{Lu}$ & $6,7 \mathrm{~d}$ & $0,5\left(\beta^{-}\right)$ & $0,208(11 \%)$ & 5,0 \\
${ }^{186} \mathrm{Re}$ & $3,8 \mathrm{~d}$ & $1,07\left(\beta^{-}\right)$ & $0,137(9 \%)$ & 10,8 \\
${ }^{188} \mathrm{Re}$ & $0,71 \mathrm{~d}$ & $2,11\left(\beta^{-}\right)$ & $0,155(15 \%)$ & $65,0 \mathrm{~nm}$ \\
${ }^{211} \mathrm{At}$ & $0,3 \mathrm{~d}$ & $6,0(\alpha)$ & $0,670(0,3 \%)$ & $70,0 \mathrm{~nm}$ \\
${ }^{212} \mathrm{Bi}$ & $1 \mathrm{~h}$ & $6,0(\alpha)$ & $0,727(7 \%)$ & 0,1 \\
${ }^{213} \mathrm{Bi}$ & $0,76 \mathrm{~h}$ & $8,0(\alpha)$ & $0,440(17 \%)$ & \\
\hline
\end{tabular}




\subsubsection{CARACTERÍSTICAS DE UM RADIONUCLÍDEO IDEAL PARA TERAPIA}

Os radionuclídeos que possuem uma meia-vida física entre algumas horas e cerca de 70 dias são os mais adequados. Os radionuclídeos devem decair emitindo radiação $\alpha, \beta^{-}$ou elétrons Auger. A quantidade de raios $\gamma$ emitidos deve também ser considerada nos cálculos de transferência de energia linear (TEL) total no processo [PILLAI \& DAS, 2013].

Para um radionuclídeo "ideal”, o produto de decaimento deve ser estável. Formação de produtos de meia-vida física longa (meia-vida na ordem de dias) é inaceitável. A formação de produtos de decaimento de meia-vida física muito curta (meia-vida na ordem de poucos minutos ou menos) podem ser tolerados, se o isótopo resultante não emitir partículas no seu decaimento. Se o produto de decaimento não for somente de meia-vida física muito curta, mas além disso emitir outros tipos de radiação (radiação $\gamma$ de baixa energia ou pósitrons de alta energia), estes podem ser usados para obter imagens qualitativas do terápico via técnica SPECT ou imagens quantitativas via técnica PET. Se o próprio produto de decaimento é propício para endoterapia, este pode ser considerado como um gerador in vivo, proveniente do decaimento do radioterápico primário, permitindo que o produto de decaimento fique dentro do alvo e/ou dentro do ambiente da ação terapêutica [PILLAI \& DAS, 2013].

Somente alguns radionuclídeos são adequados para uma rotina clínica, podendo ser produzidos com altos rendimentos e subsequentemente, serem distribuídos para hospitais. A incorporação destes radionuclídeos necessita de uma coordenação efetiva entre o produtor (um reator ou cíclotron), a instalação (infraestrutura) para processamento radioquímico, o distribuidor e os hospitais. A distribuição de geradores torna bastante conveniente a aplicação clínica dos radionuclídeos. Um pequeno número de sistemas geradores com potencial para uso em terapia existem, a saber: ${ }^{90} \mathrm{Sr} /{ }^{90} \mathrm{Y},{ }^{188} \mathrm{~W} /{ }^{188} \mathrm{Re},{ }^{166} \mathrm{Dy} /{ }^{166} \mathrm{Ho}$ e ${ }^{212} \mathrm{~Pb} /{ }^{212} \mathrm{Bi}[\mathrm{IAEA}$, 2010].

\subsection{PRODUÇÃO DE RADIONUCLÍDEOS}

Os radionuclídeos para uso clínico são produzidos em reatores nucleares, cíclotrons, aceleradores lineares ou sistemas de geradores. O critério para a 
produção de radioisótopos são as altas pureza radionuclídica, pureza radioquímica e atividade específica. A rota de produção dos radionuclídeos comumente utilizados em terapia estão listados na TAB. 5 [QAIM, 2001].

TABELA 5 - Rota de produção dos principais radionuclídeos terápicos comumente utilizados [QAIM, 2001].

\begin{tabular}{|c|c|c|c|}
\hline Radionuclídeo & $\begin{array}{l}\text { Fonte de } \\
\text { Produção }\end{array}$ & $\begin{array}{l}\text { Tipo de } \\
\text { Emissão }\end{array}$ & Reação nuclear \\
\hline${ }^{32} \mathrm{P}$ & & $\beta^{-}$ & ${ }^{31} P(n, \gamma)^{32} P /{ }^{32} P(n, p){ }^{32} P$ \\
\hline${ }^{67} \mathrm{Cu}$ & & $\beta^{-}$ & ${ }^{67} \mathrm{Zn}(n, p){ }^{67} \mathrm{Cu}$ \\
\hline${ }^{89} \mathrm{Sr}$ & & $\beta^{-}$ & ${ }^{88} \mathrm{Sr}(n, \gamma){ }^{89} \mathrm{Sr}$ \\
\hline $131 \mid$ & Reatores & $\beta^{-}$ & ${ }^{235} U(n, f){ }^{131} I /{ }^{130} T e(n, \gamma){ }^{131} T e \stackrel{\beta^{-}}{\rightarrow}{ }^{131} I$ \\
\hline${ }^{153} \mathrm{Sm}$ & & $\beta^{-}$ & ${ }^{152} \mathrm{Sm}(n, \gamma){ }^{153} \mathrm{Sm}$ \\
\hline${ }^{177} \mathrm{Lu}$ & & $\beta^{-}$ & ${ }^{176} L u(n, \gamma){ }^{177} L u$ \\
\hline${ }^{186} \mathrm{Re}$ & & $\beta^{-}$ & ${ }^{185} \operatorname{Re}(n, \gamma){ }^{186} \operatorname{Re}$ \\
\hline${ }^{64} \mathrm{Cu}$ & Aceleradores & raios-X/e Auger & ${ }^{64} \mathrm{Ni}(p, n){ }^{64} \mathrm{Cu}$ \\
\hline $111 / n$ & ou & raios-X/e- Auger & ${ }^{111} C d(p, n)^{111} \operatorname{In}$ \\
\hline${ }^{211} \mathrm{At}$ & Cíclotron & raios-X/e- Auger & ${ }^{207} B i(\alpha, 2 n){ }^{211} A t$ \\
\hline${ }^{90} \mathrm{Y}$ & & $\beta^{-}$ & ${ }^{235} U(n, f){ }^{90} \mathrm{Sr} \stackrel{\beta^{-}}{\rightarrow}{ }^{90} Y$ \\
\hline${ }^{188} \mathrm{Re}$ & & $\beta^{-}$ & ${ }^{186} W(2 n, \gamma){ }^{188} W \stackrel{\beta^{-}}{\rightarrow}{ }^{188} R e$ \\
\hline${ }^{212} \mathrm{Bi}$ & Geradores & $\alpha$ & ${ }^{228} \mathrm{Th} \rightarrow \ldots \rightarrow{ }^{224} \mathrm{Ra} \rightarrow{ }^{212} \mathrm{~Pb} \stackrel{\beta^{-}}{\rightarrow}{ }^{212} \mathrm{Bi}$ \\
\hline${ }^{213} \mathrm{Bi}$ & & $\beta^{-}$ & ${ }^{229} \mathrm{Th} \rightarrow \ldots \rightarrow{ }^{225} \mathrm{Ac} \stackrel{\propto}{\rightarrow}{ }^{221} \mathrm{Fr} \stackrel{\propto}{\rightarrow}{ }^{217} \mathrm{At} \stackrel{\propto}{\rightarrow}{ }^{213} \mathrm{Bi}$ \\
\hline
\end{tabular}

\subsubsection{RADIONUCLÍDEOS PRODUZIDOS POR REATORES}

Uma variedade de radionuclídeos são produzidos em reatores nucleares. Nesses reatores, o elemento combustível é composto de materiais físseis enriquecidos, como ${ }^{235} \mathrm{U}$ e ${ }^{239} \mathrm{Pu}$. Em sua maioria, são produzidos através da interação de nêutrons térmicos ( 0,025 eV) [SAHA, 1998].

As principais características deste tipo de produção estão na facilidade de irradiação e preparo dos alvos, que podem ser enriquecidos isotopicamente. Os portas-alvos utilizados, geralmente são de alumínio contendo ou não recipiente interno de quartzo ou polietileno. A vantagem de produção em reatores está na 
possibilidade de irradiação de grandes massas, obtenção de altas atividades com baixa seção de choque [SAHA, 1998].

As reações mais comuns que ocorrem em reatores nucleares na produção de radionuclídeos são [SAHA, 1998]:

- Reações $(n, \gamma)$ - é o processo mais usado para produção. O maior interesse nesta reação está no uso de nêutrons de baixa energia, sendo limitada pelo fluxo de nêutrons no reator.

- Reações $(n, p)$ e $(n, \alpha)$ - neste processo, há a necessidade do uso de nêutrons rápidos para a produção de radionuclídeos livres de carregador.

- Reações $(n, f)$ - os radioisótopos formados por este processo necessitam de uma separação química complexa (resinas cromatográficas, extração por solventes, etc). Com isso, é necessário um gerenciamento dos rejeitos formados. Os principais radionuclídeos usados clinicamente são o ${ }^{99} \mathrm{Mo} \mathrm{e}{ }^{131} \mathrm{I}$, que são produtos de fissão de ${ }^{235} \mathrm{U}$.

- Reações secundárias - radionuclídeos produzidos por este processo são de baixa atividade.

Os radionuclídeos produzidos por reatores são ricos em nêutrons, em geral não são livres de carregador, decaem por partículas $\beta^{-}$e são usados para finalidades terapêuticas [SAHA, 1998].

\subsubsection{RADIONUCLÍdEOS PRODUZIDOS POR ACELERAdORES OU CÍCLOTRON}

Na produção de radionuclídeos por aceleradores lineares, as reações que ocorrem são do tipo espalhamento sob energias elevadas, similares à fissão nuclear. Os valores das seções de choque são baixas e requerem o uso de alvos complexos [SAHA, 1998]. 
Em um cíclotron, partículas carregadas como prótons, dêuterons, partículas $\alpha$ e ${ }^{3} \mathrm{He}$ são aceleradas em uma trajetória circular em meio a vácuo num campo magnético. Estas partículas aceleradas podem possuir desde baixas energias $(\mathrm{keV})$ até altas energias $(\mathrm{MeV})$, dependendo da configuração e tipo de cíclotron. Quanto maior o movimento das partículas sob a trajetória circular provocada por um campo magnético cuja energia aumenta gradualmente, maior será o raio da trajetória desta partícula e maior a sua energia. Esta relação entre a energia e o raio é estabelecida para cada cíclotron [SAHA, 1998].

As reações que ocorrem durante este tipo de produção exigem muita complexidade. Além disso, a energia e a corrente do feixe são variáveis. Em geral, a seção de choque da reação é baixa - fazendo com que os alvos sejam enriquecidos isotopicamente. Devido à alta quantidade de calor dissipada em uma pequena área, há necessidade de refrigeração dos alvos. Estes alvos e porta alvos utilizados exigem complexidade, pois devem possuir elevado ponto de fusão (ou ebulição) e boa condutividade térmica. A espessura do alvo define a degradação de energia - podendo assim selecionar a faixa de maior rendimento e menor nível de impurezas radionuclídicas [SAHA, 1998].

Radionuclíeos produzidos por aceleradores cíclotrons geralmente são livres de carregador e apresentam altas atividades específicas. Além disso, são deficientes de nêutrons e decaem por pósitrons $\left(\beta^{+}\right)$ou captura eletrônica (CE), com finalidades diagnósticas. Exemplos de radioisótopos produzidos por cíclotrons são o ${ }^{11} \mathrm{C},{ }^{13} \mathrm{~N},{ }^{15} \mathrm{O},{ }^{18} \mathrm{~F}$ e ${ }^{123}$ [SAHA, 1998].

\subsubsection{RADIONUCLÍDEOS PRODUZIDOS POR SISTEMAS GERADORES}

$\mathrm{Na}$ Medicina Nuclear, uma das questões mais enfrentadas é utilizar radionuclídeos de meia-vida física curta (horas, ao contrário de dias ou semanas) e ao mesmo tempo que possam ser entregues de forma comercial em hospitais ou clínicas. Uma forma de contornar este problema é o sistema de geradores de radionuclídeos. Este sistema consiste num radionuclídeo pai de meia-vida física longa e que a partir do seu decaimento, produz um radionuclídeo filho de meia-vida física curta, adequado para aplicações clínicas. Com esta combinação, o gerador pode ser entregue em lugares distantes. As propriedades químicas dos dois radionuclídeos devem ser distintas, para que sejam facilmente separados. 
Geradores de radionuclídeos continuam a desempenhar um papel importante no fornecimento de radionuclídeos para medicina nuclear [HORTON, 1982].

\subsubsection{GERADORES DE RADIONUCLÍDEOS}

Um gerador de radionuclídeos é um dispositivo utilizado para uma separação radioquímica efetiva de um radionuclídeo filho formado pelo decaimento de um radionuclídeo pai. Este radionuclídeo filho deve possuir em sua forma alta pureza radioquímica e radionuclídica [HORTON, 1982].

Geradores de radionuclídeos geram frequentemente radionuclídeos sem a necessidade de um acelerador ou um reator de pesquisa. Utilizando um sistema de gerador, é possível obter um radionuclídeo filho com uma pureza radioquímica adequada mediante adaptação de uma técnica de separação adequada e eficiente [HORTON, 1982].

Os radionuclídeos terápicos derivados de geradores possuem inúmeras características quanto às propriedades de decaimento, podendo emitir partículas beta, elétrons Auger, partículas alfa e fótons de baixa energia. Os principais exemplos de geradores de radionuclídeos terápicos cujos radionuclídeos pai são produzidos por reatores são o ${ }^{90} \mathrm{Sr} /{ }^{90} \mathrm{Y}$ e ${ }^{188} \mathrm{~W} /{ }^{188} \mathrm{Re}$. A TAB. 6 mostra exemplos dos principais geradores de radionuclídeos que produzem radionuclídeos filhos para aplicações diagnósticas ou terapêuticas em Medicina Nuclear [IAEA, 2010]. 
TABELA 6 - Principais sistemas de geradores de radionuclídeos usados para aplicações em medicina nuclear [IAEA, 2010].

\begin{tabular}{|c|c|c|c|c|}
\hline Equilíbrio & Pai $\left(T_{1 / 2}\right)$ & Filho $\left(T_{1 / 2}\right)$ & $\begin{array}{l}\text { Modo de } \\
\text { decaimento } \\
\text { do filho }\end{array}$ & $\boldsymbol{T}_{\frac{1}{2}, 1}: T_{\frac{1}{z^{2}}, 2}$ \\
\hline \multirow[t]{6}{*}{ Secular } & $62 Z n(9,26 h)$ & ${ }^{62} \mathrm{Cu}(9,74 \mathrm{~min})$ & $\overline{\beta^{+}}$ & $5,7 \times 10^{1}$ \\
\hline & ${ }^{68} \mathrm{Ge}(270 \mathrm{~d})$ & ${ }^{68} \mathrm{Ga}(68 \mathrm{~min})$ & $\beta^{+}$ & $5,7 \times 10^{2}$ \\
\hline & ${ }^{81} \mathrm{Rb}(4,58 \mathrm{~h})$ & ${ }^{81} \mathrm{Kr}(13 \mathrm{~s})$ & $\gamma$ & $1,3 \times 10^{2}$ \\
\hline & ${ }^{82} \mathrm{Sr}(25,6 \mathrm{~d})$ & ${ }^{82} \mathrm{Rb}(1,27 \mathrm{~min})$ & $\beta^{+}$ & $2,9 \times 10^{2}$ \\
\hline & ${ }^{90} \mathrm{Sr}(28,5 \mathrm{a})$ & ${ }^{90} \mathrm{Y}(64,1 \mathrm{~h})$ & $\beta^{-}$ & $3,9 \times 10^{2}$ \\
\hline & 188W (69 d) & ${ }^{188} \operatorname{Re}(16,9 \mathrm{~h})$ & $\beta^{-}$ & $9,8 \times 10^{1}$ \\
\hline \multirow[t]{2}{*}{ Transiente } & ${ }^{99} \mathrm{Mo}(2,75 \mathrm{~d})$ & 99mTc (6 h) & $\gamma$ & $1,1 \times 10^{1}$ \\
\hline & ${ }^{166}$ Dy $(3,4 d)$ & ${ }^{166} \mathrm{Ho}(1,117 \mathrm{~d})$ & $\beta^{-}$ & $3,0 \times 10^{0}$ \\
\hline
\end{tabular}

\subsection{O PRINCÍPIO DA RADIOIMUNOTERAPIA (RIT)}

A radioimunoterapia $(\mathrm{RIT})$ faz uso de anticorpos monoclonais (AcM) marcados com radionuclídeos emissores $\alpha$ ou $\beta^{-}$para propósitos terapêuticos, levando a irradiação no tumor e sua destruição total, preservando órgãos normais do excesso de radiação [IZNAGA-ESCOBAR, 1998; JACOBI \& DÖRNER, 2010].

A RIT pode ser benéfica particularmente para o tratamento de tumores que não são facilmente passíveis de controle cirúrgico e para o tratamento de recorrência precoce e metástase remota. Diferente de drogas e toxinas, imunoconjugados de AcM radiomarcados, podem destruir células que estão distanciadas do sítio alvo, dependendo da escolha do radionuclídeo, sem o conjugado do anticorpo ser internalizado. Teoricamente, a RIT possui o potencial de direcionar a radiação de uma forma mais seletiva para o tumor, em relação a um feixe de radiação externa [GLENNIE et. al, 2007; IZNAGA-ESCOBAR, 1998].

Existem três tipos de radiações particuladas importantes para a RIT: partículas $\alpha$, que são essencialmente núcleos de hélio, com um curto alcance (irradiação de volumes de tecidos com dimensões celulares) porém alta toxicidade; partículas $\beta$, com um maior alcance no tumor (com irradiação de volumes de tecidos com dimensões multicelulares), porém menor toxicidade do que as partículas $\alpha$; elétrons Auger, que possuem um alcance muito curto (com irradiação de volumes de 
tecidos com dimensões subcelulares) e são somente tóxicos quando liberados na célula, preferencialmente próximo do núcleo. Os radionuclídeos mais usados em RIT são os emissores $\beta$ - [ZALUTSKY et al, 2007; DEARLING \& PEDLEY, 2007].

Emissores $\alpha$ com meia-vida física curta vêm sendo sugeridos para a RIT. Seu potencial terapêutico faz da RIT com partículas $\alpha$ uma abordagem atrativa para o tratamento de doenças mínimas ou citoreduzidas [MIEDERER et. al, 2008, MCDEVITT et. al, 2002, ROSENBLAT et al, 2010, MULDORF et al, 2005].

A dependência do Efeito Biológico Relativo (EBR) e do LET são explicados pelas diferenças no tipo e extenção do dano celular. A relativa meia-vida física curta com o alcance limitado nos tecidos (50-80 $\mu \mathrm{m}$ ), juntamente com 0 alto LET $(100 \mathrm{keV} / \mu \mathrm{m})$, distingue a sua dosimetria dos emissores $\beta^{-}$. De fato, a radiação de alto LET induz maiores quebras irreparáveis na fita dupla de ácido desoxirribonucleico (ADN) e mais danos cromossômicos profundos nos processo de mitose e rearranjos cromossômicos complexos numa alta frequência, do que no caso de radiação de baixo LET (emissores $\beta^{-}$). A taxa máxima da quebra da fita dupla de ADN ocorre com LETs entre 100-200 keV/ $\mu \mathrm{m}$. Emissores $\alpha$ que foram avaliados em animais em oncologia clínica incluem, entre outros, Actínio-225 (225Ac), Astato-211 $\left({ }^{211} \mathrm{At}\right)$ e Bismuto-213 $\left({ }^{213} \mathrm{Bi}\right)$ [HAMOUDEH et. al, 2008, MIEDERER et. al, 2008, MCDEVITT et. al, 2002, MULDORF et al, 2005].

As características físicas das partículas $\alpha$ podem proporcionar uma citoxicidade ideal para pequenos focos de células tumorais resistentes à quimioterapia, minimizando $O$ dano aos tecidos normais circundantes na determinação de doenças residuais mínimas [PARK et al, 2010, DADACHOVA, 2010].

O mérito relativo dos emissores $\alpha$ versus $\beta^{-}$em diversas configurações tumorais pode ser discutido a partir de um ponto de vista teórico. No tratamento de tumores intraperitoneais, por exemplo, com um radioisótopo ligado a microesferas, comparações experimentais diretas mostram que partículas $\alpha$ do ${ }^{211} \mathrm{At}$ tornam-se superior ao ${ }^{90} \mathrm{Y}$, em virtude das diferenças nas suas propriedades físicas [KENNEL et al, 1999].

Uma vez que 0 alcance dos emissores $\beta^{-}$se extende para vários milímetros, como na terapia com isótopos como ${ }^{131} \mathrm{I},{ }^{90} \mathrm{Y}$ e ${ }^{188} \mathrm{Re}$, pode-se criar um cross-fire ("efeito de fogo cruzado"), destruindo as células do tumor, onde o 
radioimunoconjugado não é ligado diretamente. Emissões $\beta^{-}$de longo alcance podem produzir efeitos citotóxicos não específicos, pela destruição das células normais circundantes. Essas características fazem da terapia com partículas $\beta^{-}$mais adequadas para tumores volumosos. Em contrapartida, partículas $\alpha$ são adequadas para o tratamento de doenças microscópicas ou de pequenos volumes devido ao curto alcance e energias potencialmente altas, oferecendo a destruição específica das células tumorais de forma mais eficiente. Num modelo dosimétrico utilizando condições de células únicas, um decaimento de um emissor $\alpha{ }^{211} \mathrm{At}$ na superfície da célula, resulta um grau de morte celular de aproximadamente 1000 decaimentos de superfície celular em relação ao emissor $\beta^{-}$como o ${ }^{90} Y$ [MULDORF et al, 2005].

Radionuclídeos emissores de partículas $\beta^{-}$, alguns usados para planejamento em RIT, podem não ser ideais para irradiação de tumores microscópicos e células de tumores isolados. Estima-se que a fração de energia depositada num tumor medindo $200 \mu \mathrm{m}$ de diâmetro é de somente 1,5\% e 17\% para anticorpos marcados com ${ }^{90} \mathrm{Y}$ e ${ }^{131} \mathrm{I}$, respectivamente. $\mathrm{O}$ restante desta energia é depositada nos tecidos normais circundantes, resultando em toxicidades que limitam a dose injetada. Além disso, a energia de decaimento relativamente baixa das partículas $\beta^{-}$, resulta numa destruição inferior ao esperado das células tumorais, contribuindo para uma reincidência na maioria dos pacientes tratados. Estas características físicas das partículas $\alpha$ podem proporcionar uma citoxicidade ideal para pequenos focos de células tumorais resistentes à quimioterapia, minimizando 0 dano aos tecidos normais circundantes na determinação de doenças residuais mínimas [PARK et al, 2010, DADACHOVA, 2010].

Além da RIT, estudos indicam um tipo de tratamento com pré-alvos (PRIT) para radionuclídeos emissores $\alpha$ de meia-vida curta, sendo particularmente atrativa por permitir a distribuição da radiação para sítios tumorais antes da diminuição da atividade. Isso é importante para ${ }^{213} \mathrm{Bi}\left(t_{1 / 2}=45,6 \mathrm{~min}\right)$ e ${ }^{211} \mathrm{At}\left(t_{1 / 2}=7,21 \mathrm{~h}\right)$ por exemplo, possuidores de meias vidas curtas [PARK et al., 2010]. A PRIT consiste na injeção prévia de um AcM dirigido contra uma molécula-alvo no sítio tumoral, de maneira separada da injeção de uma segunda molécula de peso molecular pequeno, ligada a um radioisótopo, capaz de se ligar com grande afinidade ao AcM previamente injetado, com meia-vida física curta. A vantagem deste tipo de terapia 
é a rápida excreção pelos rins e redução da toxicidade à medula óssea [SHARKEY \& GOLDENBERG, 2006].

\subsection{ANTICORPOS MONOCLONAIS}

Os AcM foram originalmente desenvolvidos por Kohlen e Milstein em 1975, quando uniram com sucesso um anticorpo produtor de células B com uma linhagem de células de mieloma, resultando em um hibridoma. Estas células de hibridoma puderam ser clonadas e selecionadas para produção de AcM em larga escala [KOHLEN \& MILSTEIN, 1975].

Anticorpos são moléculas relativamente grandes, com tempos longos de circulação, necessitando de um período extenso para se acumular no tumor [DEARLING \& PEDLEY, 2007].

Em RIT, o agente-alvo é um anticorpo específico ao antígeno na membrana da célula do tumor. Selecionar o radionuclídeo mais adequado para o tratamento envolve a sua disponibilidade, tipo de ligação, estabilidade, biocinética, meia-vida física e alcance da radiação nos tecidos [PALM et al, 2007].

Segundo o US Food and Drug Administration (FDA), de um ponto de vista regulatório, um radiofármaco deve também ser estéril, livre de pirogênio, seguro para uso humano e eficaz para uma indicação específica. Na marcação de AcM, diversos fatores influenciam na escolha do radionuclídeo: meia-vida física e biológica; natureza da radiação emitida; atividade específica; facilidade de introdução na proteína; estabilidade do produto marcado; caminho metabólico do radionuclídeo no organismo; facilidade de detecção; disponibilidade comercial e preço [VALLABHAJOSULA et al, 2010].

O antígeno é uma molécula expressa na superfície das células cancerígenas o qual o anticorpo liga-se e é subsequentemente retido no tumor. Para obter a seletividade de captação no tumor, o antígeno deve ser expresso unicamente, ou quase predominantemente, nas células cancerígenas. A expressão do antígeno no tumor pode ser heterogênea, levando a uma distribuição não uniforme do radionuclídeo e dose absorvida através do tumor, reduzindo o sucesso terapêutico [DEARLING \& PEDLEY, 2007].

Idealmente, um AcM deve atender diversos critérios para sua marcação: ser altamente expresso pelas células tumorais e não pelas células normais; deve 
estar apresentado de forma estável na superfície da célula do tumor para sua identificação pelo anticorpo, ser expresso por todas, ou quase todas células tumorais e funcionalmente envolvido em processos tumorigênicos em um amplo espectro de diferentes tipos de tumor [BINYAMIN et al, 2006].

O primeiro uso dos AcM para tratamentos de linfomas ocorreu em 1980, quando um anticorpo contra um antígeno de um linfoma foi administrado em um paciente com linfoma reincidente. Embora tenha se mostrado ineficaz devido ao bloqueio do antígeno circulante no sítio ativo do anticorpo, era seguro e bem tolerado [NADLER et al, 1980].

\subsection{LINFOMAS NÃO-HODGKIN'S}

O Linfoma Não-Hodgkin de células do tipo B (LNH) é uma doença hematológica, baseada nas células $B$, sendo o sexto tipo de câncer mais comum (mais de 70.800 novos casos registrados somente em 2014 nos Estados Unidos [NCl, 2015]). No Brasil, o número de novos casos duplicou nos últimos 25 anos, por razões ainda desconhecidas, principalmente entre pessoas com mais de 60 anos, sendo que em 2014 foram registrados cerca de 9.760 novos casos da doença. Seguindo tratamento convencional com quimioterapia ou radioterapia, pacientes em estágio avançado de LNH, apresentam óbito em uma média de 5 anos após o reaparecimento [INCA, 2015].

O LNH de células do tipo B por reincidiva é refratário, apresentam um prognóstico ruim quando utilizado apenas quimioterapia [KRUGER et al, 2012]. A introdução do rituximabe (MabThera ${ }^{\circledR}$ ou Rituxan), um AcM ligado à molécula CD20, tem conduzido a uma melhora no tratamento de pacientes com LNH [KRUGER et al, 2012].

\subsection{ANTI-CD20}

O Anti-CD20 ou rituximabe é um AcM quimérico direcionado à superfície do antígeno CD20, utilizado no tratamento de LNH. Terapias-alvo com anti-CD20, consistem na destruição dos linfócitos B através de AcM associados à molécula CD20 humana, específica das células do tipo B. O uso do rituximabe como um único 
agente ou em complemento à quimioterapia com pacientes com LNH é considerada uma das mais bem sucedidas formas de RIT [MEERTEN \& HAGENBEEK, 2010].

A composição do rituximabe consiste de: uma região humana kappa constante, uma região de fragmento cristalizável $(\mathrm{Fc})$ imunoglobulina (IgG1) humana, e uma região murina variável que identifica o CD20 humano. A molécula humana CD20 é uma fosfoproteína não-glicolisada, com peso molecular cerca de 33-37 kDa, contendo um limitado ciclo celular de 44 aminoácidos (o sítio de ligação para o Anti-CD20 presumivelmente reside neste ciclo) [EISENBERG \& LOONEY, 2005].

O Anti-CD20 fornece um alvo específico às células $B$ específicas que compõem tanto células-tronco hematopoiéticas como células do plasma produtora de anticorpos. Essa distribuição antigênica faz do CD20 um alvo atraente para anticorpos terápicos em LNH. Além disso, o CD20 é altamente expresso na superfície da célula e não é internalizado rapidamente após ligação ao anticorpo. [REZVANI \& MALONEY, 2011, MEERTEN \& HAGENBEEK, 2010].

Rituximabe é o único AcM (Anti-CD20) aprovado pelo US Food and Drug Administration (FDA) desde 1997, para uso em humanos, específico para o tratamento de linfoma de células-B recorrentes de baixo grau [HARRIS, 2004].

Recentemente, a RIT tem emergido como uma opção promissora para o tratamento de linfoma, tornando a resposta mais expressiva quando esta é usada como uma linha de frente de tratamento [PARK et al, 2010].

De acordo com a FIG. 1, o CD20 é expresso em estágios chaves de desenvolvimento de células $B$, que dão origem ao $L N H$ da célula $B$ e Leucemia Linfocítica Crônica (LLC). O CD20 não é expresso nas células-tronco hematopoiéticas ou nas células do plasma [MEERTEN \& HAGENBEEK, 2010]. 


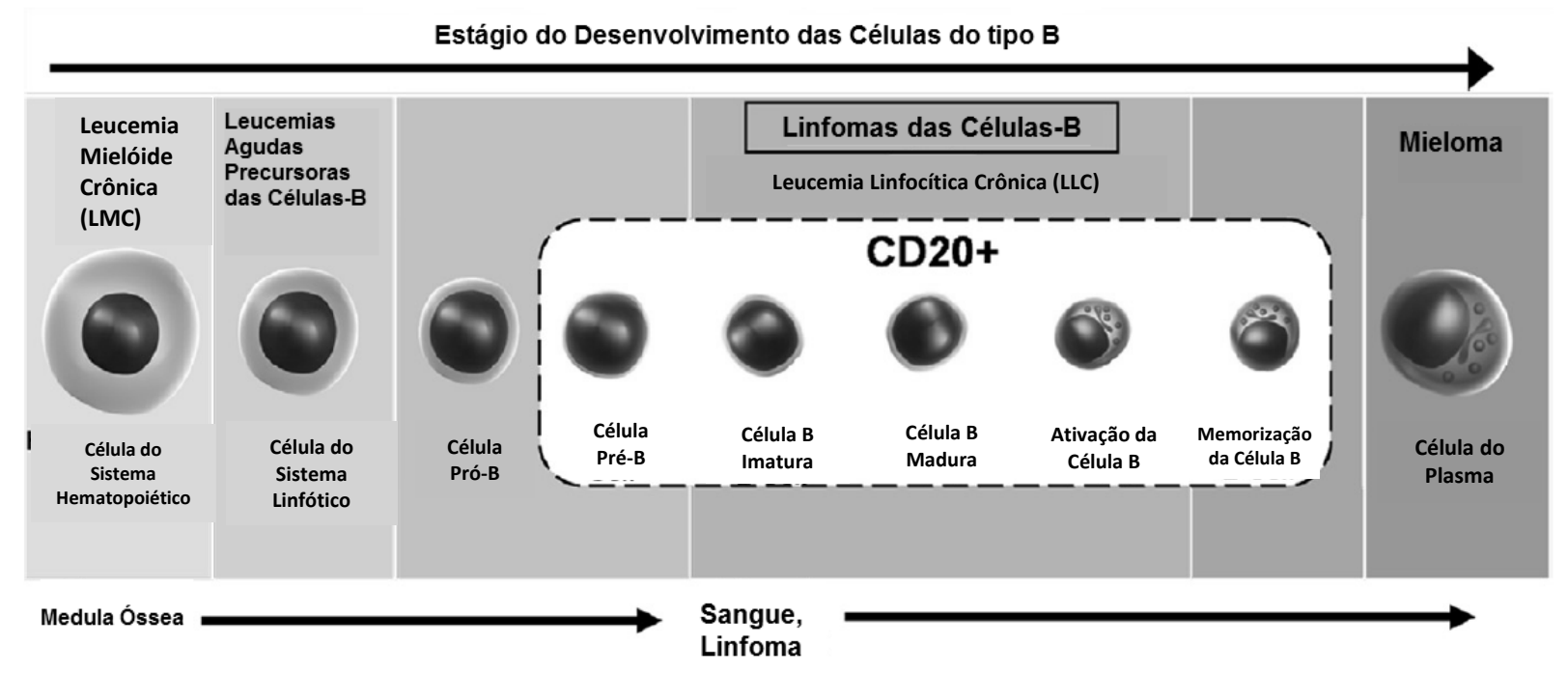

FIGURA 1 - Expressão do CD20 no desenvolvimento das células-B. O antígeno CD20 é expresso primeiro durante o desenvolvimento inicial da pré-célula-B sendo perdido durante diferenciação terminal das células do plasma [MEERTEN \& HAGENBEEK, 2010].

De acordo com a FIG. 2, a molécula CD20 cruza a membrana plasmática das células $B$ cerca de quatro vezes, formando dois fragmentos extracelulares. Estes fragmentos são alvos de ligação ideais para terapia baseada em AcM Anti-CD20 para vantagens do CD20 são que ele não circula no plasma, não desprende da superfície das células e não é internalizado após a ligação com o anticorpo [MEERTEN \& HAGENBEEK, 2010].

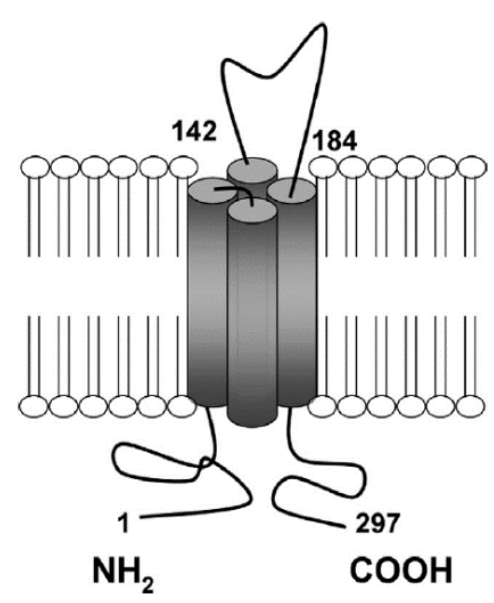

FIGURA 2 - A molécula humana CD20 [MEERTEN \& HAGENBEEK, 2010]. 
O CD20 é selecionado como um marcador, graças à sua ligação não alterar sua expressão, e a apoptose que ele induz, ocorre através da interação com o anticorpo [MEERTEN \& HAGENBEEK, 2010].

Estudos mostram três mecanismos envolvidos na eficácia terapêutica do Anti-CD20. Estes incluem a citoxicidade celular dependente do anticorpo (CCDA), a citoxicidade dependente-complementar (CDC), e a indução a apoptose. A primeira ação (CCDA), ocorre através da ligação dos receptores Fc nas células letais naturais, monócitos e macrófagos, para as células tumorais opsonizadas (ou seja, permite a fagocitose). A segunda ação (CDC) ocorre através da ligação e ativação do lgG1 na região $\mathrm{Fc}$ do rituximabe, levando a formação de uma membrana de ataque às células do linfoma, ocasionando maior opsonização da célula do linfoma, aumentando sua CCDA. Quanto a terceira ação, o rituximabe tem a capacidade de bloquear a proliferação e promover a apoptose nas células do linfoma através de caminhos de mensagens secundárias intracelulares, iniciados pela sua ligação a superfície do CD20 [CAMPBEL \& MARCUS, 2003; CARTRON et al., 2004; GLENNIE et al., 2007].

Atualmente, existem mais de dez agentes alvos CD20, os quais estão clinicamente aprovados ou em testes iniciais. Estes estão listados na TAB. 7 [OKROJ et al, 2013]. 
TABELA 7 - Anticorpos Anti-CD20 em ensaios clínicos e clinicamente aprovados [OKROJ et al, 2013].

\begin{tabular}{|c|c|c|c|c|}
\hline Anticorpo & Status clínico & Formato & Tipo & $\begin{array}{l}\text { Propriedades comparadas } \\
\text { ao Rituximabe }\end{array}$ \\
\hline Rituximabe & Aprovado & IgG1 quimérico & $\mathrm{I}$ & - \\
\hline Tositumomabe & $\begin{array}{l}\text { Aprovado } \\
\text { (somente EUA) }\end{array}$ & $\operatorname{lgG} 2 a$ murino & II & $\begin{array}{l}\text { CDC reduzido, indutor à } \\
\text { apoptose efetiva }\end{array}$ \\
\hline Ibritumomabe & Aprovado & IgG1 murino & $\mathrm{I}$ & Não específico \\
\hline Ofatumomabe & Aprovado & IgG1 humano & I & $\begin{array}{l}\text { CDC reduzido em CD20 de } \\
\text { baixa expressão, taxa de } \\
\text { eliminação mais lento }\end{array}$ \\
\hline Ocrelizumabe & Fase 3 & $\begin{array}{l}\text { IgG1 humanizado } \\
\text { com Fc modificada }\end{array}$ & I & $\begin{array}{l}\text { CDC reduzida, CCDA } \\
\text { reduzida }\end{array}$ \\
\hline Retuxira & Fase 3 & Quimérico & $\begin{array}{l}\text { Não } \\
\text { específico }\end{array}$ & Não específico \\
\hline Veltuzumabe & Fase 2 & IgG1 humanizado & I & $\begin{array}{l}\text { CDC reduzido, taxa de } \\
\text { eliminação mais lento }\end{array}$ \\
\hline $\begin{array}{l}\text { Obinutuzumabe } \\
\text { (GA-101) }\end{array}$ & Fase 2 & $\begin{array}{l}\text { Gliocoengenharia, } \\
\text { lgG1 humanizado }\end{array}$ & II & $\begin{array}{l}\text { CDC reduzido, aumento da } \\
\text { CCDA e apoptose }\end{array}$ \\
\hline PRO131921 & Fase 2 & $\begin{array}{l}\text { IgG1 humanizado } \\
\text { com Fc modificado }\end{array}$ & I & Aumento da CCDA \\
\hline $\begin{array}{l}\text { LY2469298 } \\
\text { (AME-133) }\end{array}$ & Fase 2 & IgG1 humanizado & I & Aumento da CCDA \\
\hline TRU-015 & Fase 2 & $\begin{array}{l}\text { Compostos } \\
\text { baseados em Fv de } \\
\text { cadeia única }\end{array}$ & - & $\begin{array}{l}\text { CCDA reduzida sob baixas } \\
\text { concentrações, diminuição de } \\
\text { CDC, melhor penetração no } \\
\text { tumor pela baixa afinidade }\end{array}$ \\
\hline FBTA05 & Fase $1 / 2$ & $\begin{array}{l}\text { Anti-CD20/CD3 } \\
\text { lgG2a/camundongo, } \\
\text { lgG2b murino } \\
\text { bioespecífico }\end{array}$ & - & $\begin{array}{l}\text { Restabelecimento direto e } \\
\text { ativação das células T do } \\
\text { CD4+/CD8+ para o as células } \\
\text { CD20+ }\end{array}$ \\
\hline LFB-R603 & Fase 1 & IgG1 quimérico & I & Aumento da CCDA \\
\hline
\end{tabular}

Citoxicidade celular dependente do anticorpo (CCDA)

Citoxicidade dependente complementar (CDC) 
Dois agentes radioimunoterápicos possuem aprovação do FDA para utilização: ${ }^{90}$ Y-ibritumomabe tiuxetan (Zevalin ${ }^{\circledR}$ ), em 2002 e ${ }^{131}$ I-tositumomabe (Bexxar $\left.{ }^{\circledR}\right)$, em 2003. Ambos os compostos receberam aprovação para uso comercial no tratamento em $\mathrm{LNH}$ de células-B indolente e em condições relacionadas. Apesar de ambos compostos para RIT marcarem o antígeno da superfície do CD20, seus modelos de uso diferem significamente, em grande parte, devido às diferenças dos dois radioisótopos incorporados junto aos compostos [MACKLIS, 2007].

Em termos de avaliação dosimétrica, a dosimetria do Zevalin é baseada na pré-observação, usando anticorpos marcados com ${ }^{111} \mathrm{In}$, enquanto que para Bexxar, a dosimetria é na massa corpórea do paciente, utilizando a emissão $\gamma$ para imagens [DEARLING \& PEDLEY, 2007].

Além do tratamento de $\mathrm{LNH}$, o rituximabe tem apresentado eficácia nos tratamentos de: artrite reumatóide, lúpus eritematoso sistêmico, dermatomiosite, pênfigo vulgar refratário, diversas anemias hemolíticas, púrpura trombocitopênica imune crônica refratária, hemofilia adquirida, granulomatose de Wegener e crioglobulinemia mista [PEROSA et al., 2005].

Apesar da eficiência do rituximabe frio (sem associação ao material radioativo), $48 \%$ dos pacientes respondem ao tratamento como o imunoterápico, e apenas $10 \%$ conseguem resposta completa ao tratamento [MCLAUGHLIN et al., 1998; EISENBEIS et al., 2003].

\subsection{PROPRIEDADES FÍSICAS E DOSIMÉTRICAS DO ${ }^{188}$ Re-ANTI-CD20}

O uso do ${ }^{188} \mathrm{Re}$, produzido pelo decaimento do ${ }^{188} \mathrm{~W}\left(\mathrm{~T}_{1 / 2}=69 \mathrm{~d}\right)$, a partir de um sistema gerador de ${ }^{188} \mathrm{~W} /{ }^{188} \mathrm{Re}$, tem representado uma alternativa para RIT. Além da emissão $\beta^{-}$para terapia, ${ }^{188}$ Re também decai por fótons emissores $\gamma$ com energia de $155 \mathrm{keV}$, fator importante para avaliação de anticorpos marcados com ${ }^{188} \mathrm{Re}$ em estudos de biodistribuição in vivo através de gama-câmaras [SILVERMAN et al., 2004, MILENIC \& BRECHBIEL, 2004] e dosimetria antes do tratamento.

Em termos de propriedades químicas, rênio está situado abaixo do tecnécio na tabela periódica, apresentando uma química similar. Deste modo, ambos podem ser conjugados a anticorpos usando métodos químicos similares [IZNAGAESCOBAR, 1998, LIU et. al., 2003; TORRES-GARCIA et. al., 2008; FERROFLORES \& MURPHY, 2008]. 
O objetivo da RIT com ${ }^{188}$ Re é direcionar as doses terapêuticas para um tumor, sem afetar gravemente as funções de órgãos críticos. A eficácia de sua terapia depende primeiramente da taxa de dose absorvida e a dose total direcionada para o tumor e tecidos normais. A dose e a taxa de dose dependem das propriedades físicas do radionuclídeo, a atividade injetada em relação à cinética de captação e liberação da radiação junto ao tumor e tecidos/células normais [KASSIS \& ADELSTEIN, 2003].

Atualmente, os radionuclídeos com propriedades mais adequadas para RIT são ${ }^{188} \mathrm{Re},{ }^{90} \mathrm{Y}$ e ${ }^{131} \mathrm{I}$, enquanto que ${ }^{177} \mathrm{Lu}$ e ${ }^{90} \mathrm{Y}$ são usados em Terapia com Radionuclídeos em Receptores de Peptídeos (TRRP). As principais características físicas desses emissores $\beta^{-}$estão listadas na TAB. 8 [FERRO-FLORES \& MURPHY, 2008].

TABELA 8 - Características terapêuticas dos principais radionuclídeos $\beta^{-}$utilizados para terapia [FERRO-FLORES \& MURPHY, 2008].

\begin{tabular}{|c|c|c|c|c|c|c|}
\hline Radionuclídeo & $t_{1 / 2}(h)$ & $\begin{array}{l}\text { Energia de } \\
\text { emissão } \gamma \\
\text { (MeV) } \\
\text { [abundância (\%)] }\end{array}$ & $\begin{array}{l}\text { Energia média } \\
\text { de emissão de } \\
\text { partículas } \beta^{-} \text {por } \\
\text { desintegração } \\
(\mathrm{MeV})\end{array}$ & $\begin{array}{l}\text { Energia máxima } \\
\text { de emissão de } \\
\text { partículas } \beta^{-} \text {por } \\
\text { desintegração } \\
(\mathrm{MeV})\end{array}$ & $\begin{array}{l}\text { Alcance médio } \\
\text { das partículas } \\
\beta^{-} \text {nos tecidos } \\
(\mathrm{mm})\end{array}$ & $\begin{array}{l}\text { Alcance máximo } \\
\text { das partículas } \\
\beta^{-} \text {nos tecidos } \\
(\mathrm{mm})\end{array}$ \\
\hline $90 Y$ & 64,1 & - & 0,935 & 2,28 & 4,0 & 11,3 \\
\hline 131 & 192 & $0,364[82]$ & 0,182 & 0,610 & 0,39 & 2,3 \\
\hline${ }^{177} \mathrm{Lu}$ & 161 & $0,208[6,1]$ & 0,133 & 0,497 & 0,23 & 1,8 \\
\hline${ }^{188} \mathrm{Re}$ & 16,9 & $0,155[15]$ & 0,764 & 2,12 & 3,1 & 10,4 \\
\hline
\end{tabular}

Em relação aos radionuclídeos utilizados em RIT, ítrio-90 ( ${ }^{90} \mathrm{Y}$ ) é um emissor $\beta^{-}$de alta energia, produzido a partir do decaimento do ${ }^{90} \mathrm{Sr}$ ( $\mathrm{t}_{1 / 2}=28$ anos) por meio de um sistema de geradores de ${ }^{90} \mathrm{Sr} / 90 \mathrm{Y}$ [BARRIO, 2010].

A meia-vida física do ${ }^{90}$ Y é compatível com a farmacocinética das biomoléculas, possuindo uma penetração de longo alcance nos tecidos. Uma desvantagem do ${ }^{90}$ Y está no fato de não fornecer imagens diretamente, devido à ausência de emissão $\gamma$. Métodos alternativos têm sido utilizados, através de imagens obtidas com análogos marcados com ${ }^{111}$ In ou com o uso de emissores $\beta^{+}$como ${ }^{86} \mathrm{Y}$ e através da radiação de Bremsstrahlung para estimar a dose da radiação absorvida, 
devido à alta energia $\beta$ do ${ }^{90} Y$, [STABIN et. al., 1994, CREMONESI et. al., 1999; FORSTER et. al., 2001; HELISCH et. al., 2004; PAUWELS et. al., 2005, GAD, 2007].

Além da ausência de emissão $\gamma$, uma questão importante refere-se à sua dosimetria, pois ${ }^{90} \mathrm{Sr}$ é um radioisótopo que tende a se acumular nos ossos dado o seu comportamento químico similar ao cálcio, possuindo significativo potencial para toxicidade e causar supressões na medula óssea. Portanto, o limite aceitável de ${ }^{90} \mathrm{Sr}$ nos radiofármacos de ${ }^{90} \mathrm{Y}$ deve ser muito baixo $\left(74 \mathrm{kBq}\right.$ de ${ }^{90} \mathrm{Sr} / \mathrm{mL}$ de $\left.{ }^{90} \mathrm{Y}\right)$ assim como o limite em relação à atividade do ${ }^{90} Y$ [DIETZ \& HOROWITZ, 1992].

Lutécio-177 ( $\left.{ }^{177} \mathrm{Lu}\right)$ é um radionuclídeo emissor $\beta^{-}$e $\gamma$, sua emissão $\gamma$ é usada para obtenção de imagens de biodistribuição e estudos dosimétricos, enquanto a emissão $\beta$ - produz o efeito terapêutico desejado. Esta combinação das modalidades terapêutica e diagnóstica, conhecida como teranóstica, direciona o radiofármaco para estas duas modalidades ao mesmo tempo, com uma única dose no paciente. $O$ objetivo do conceito teranóstico é ganhar a capacidade de imagem e monitorar o tecido doente, com uma eficácia do radiofármaco, monitorando a terapia e dosando com controle até então inatingível [KELKAR \& REINEKE, 2011]. ${ }^{177} \mathrm{Lu}$ possui várias vantagens como radionuclídeo para terapia: baixa penetração nos tecidos, danos insuficientes ao tecido normal circundante, baixa radiação de energia gama, uma baixa abundância e meia vida física adequada [MILENIC \& BRECHBIEL, 2004].

lodo-131 $\left({ }^{131} I\right)$ é um radionuclídeo terápico cujas principais vantagens são o baixo custo de produção, a fácil química de marcação e a emissão $\gamma$ para aquisição de imagens. No entanto, as desvantagens para este radionuclídeo são a dehalogenação in vivo e exposição à radiação para pacientes e profissionais (requerendo cuidados especiais na sua administração com doses elevadas) [AKANJI, 2006].

A FIG. 3 mostra o poder de penetração dos principais radionuclídeos usados em terapia de acordo com a sua energia máxima de emissão [KNAPP, 2006]. 


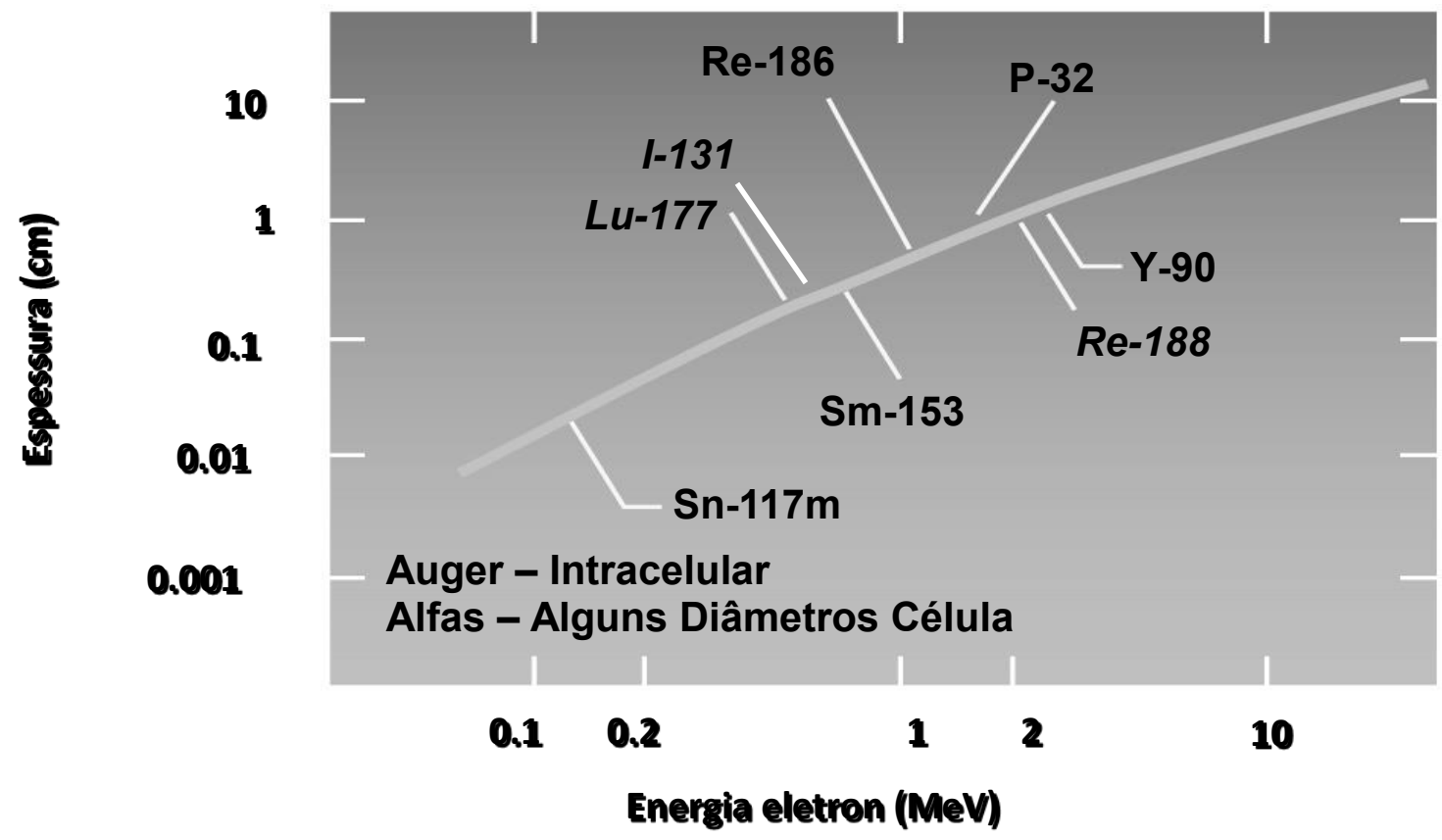

FIGURA 3 - Poder de penetração dos radionuclídeos emissores de partículas $\beta$ usados em terapia em função da energia $(\mathrm{MeV})$ para diferentes espessuras teciduais [KNAPP, 2006].

O uso de AcM radiomarcados diretamente com ${ }^{188}$ Re como potencial agente para RIT oferece diversas vantagens: ${ }^{188} \mathrm{Re}$ disponível na sua forma livre de carregador, permite o preparo de AcM radiomarcados com alta atividade específica; uma radiomarcação direta com alta pureza radioquímica, formulação de alta atividade específica, baixa formação radiocoloidal e boa estabilidade in vitro acima de $96 \mathrm{~h}$ do anticorpo radiomarcado com rênio, sem a necessidade de purificação pósradiomarcação, para eliminar o radionuclídeo livre. A disponibilidade de um gerador de ${ }^{188} \mathrm{~W} /{ }^{188} \mathrm{Re}$ que permite a eluição local do ${ }^{188} \mathrm{Re}$, similar ao procedimento em que o ${ }^{99 m}$ Tc é obtido atualmente; um kit que pode ser desenvolvido, que apenas exigiria a mistura do perrenato com outros reagentes em um único frasco; o processo integral que pode permitir de forma simples e rápida, o mínimo de manipulação [IZNAGAESCOBAR, 2001]. 


\subsection{ESTUDOS DE BIODISTRIBUIÇÃO, FARMACOCINÉTICA E DOSIMETRIA COMO FERRAMENTAS ALIADAS À TERAPIA}

Radiofármacos exibem um grande número de propriedades fisicas e químicas. Um fator importante é que a biodistribuição de um radiofármaco não pode ser explicada em termos de mecanismos únicos, mas como resultados de interações entre diferentes mecanismos, envolvendo diluições iniciais junto ao sistema circulatório, promovendo possível ligação de proteínas ao plasma, transporte transmembrana passivo ou ativo, incorporação metabólica ou catabolismo, eliminação e excreção. A farmacocinética compreende o processo de absorção, distribuição, metabolismo e excreção (ou eliminação) pode ser descrito quantitativamente pela análise da concentração de um radiofármaco dentro do corpo. Este conhecimento é importante para determinação das doses adequadas a serem administradas e a frequência de dosagem necessária para obter uma concentração adequada no local desejado [PICKETT, 2011].

Pelo uso de modelos matemáticos é possível mostrar a interpretação dos dados de entrada observados e a predição dos efeitos de perturbação num sistema. Análises Bayesianas de modelos não-lineares tem sido adicionadas pelo avanço das técnicas computacionais, aumentando a classe de modelos que podem ser analisados por este método [PICKETT, 2011].

\subsubsection{PROGRAMAS COMPUTACIONAIS DE MODELOS COMPARTIMENTAIS PARA ESTUDOS FARMACOCINÉTICOS COM RADIOFÁRMACOS}

Um estudo da farmacocinética em animais antes da sua administração em humanos é necessário para auxiliar nos cálculos de dose e escalonamento de dose, avaliar a exposição do animal ao produto através do cálculo da área sob a curva (ASC) e sua máxima concentração ( $\mathrm{C}_{\text {máx }}$ ). A extrapolação para o uso em humanos requer uma avaliação cuidadosa, que leva em conta a imunogenicidade do anticorpo no animal e a necessidade de alvos solúveis, que possam ser encobertos por tumores humanos. Além dessas dificuldades, as medidas de $\mathrm{C}_{\text {máx }}$ e $\mathrm{AUC}$ nos animais e em humanos são essenciais para uma melhor extrapolação dos resultados obtidos (sejam experimentais ou teóricos) dos animais para os humanos [LOISEL et al., 2007]. 
Os métodos para análise de dados biocinéticos de radiofármacos são diversos e variam desde métodos computacionais muito simples até com grande complexidade. $\mathrm{O}$ uso de métodos mais simples consistem na integração direta dos dados observados [VICINI et al., 2008; HOFF, 2011].

Sistemas mais complexos, fazem uso de modelos compartimentais para representar a fisiologia do sistema e a biodistribuição dos traçadores. Nesse caso, os dados são modelados através de uma solução ou um sistema de equações diferenciais [VICINI et al. 2008; HOFF, 2011].

A primeira aplicação dos modelos compartimentais foi na física, especificamente para descrever o processo do decaimento radioativo (EQ. 1) e foi formalizada após as descobertas e experimentos realizados por Becquerel, Rutherford e Soddy [VICINI et al., 2008].

$$
\frac{d x}{d t}=-k \cdot X(t)
$$

onde $X(t)$ é a quantidade de substância radioativa presente no tempo $t$.

A integral da EQ. 1 resulta na EQ. 2, que permite tratar o decaimento radioativo como um processo de primeira ordem [VICINI et al. 2008].

$$
X(t)=X\left(t_{0}\right) e^{-k \cdot X\left(t-t_{0}\right)}
$$

onde $X\left(t_{0}\right)$ é o valor inicial de $X(t)$ no tempo to.

Deste modo, o processo de decaimento radioativo é modelado como um processo de primeira ordem, sendo este verificado independentemente por diversas observações experimentais [VICINI et al. 2008].

Modelos compartimentais são uma das formas mais usadas para formulação e análise de dados obtidos a partir de estudos de medicina nuclear. Um compartimento pode representar uma localização física de onde a substância reside ou um estado químico da substância em estudo [VICINI et al. 2008].

Seja um sistema, conhecido como compartimento, e nesse sistema uma variável $\mathrm{x}(\mathrm{t})$ governada por uma equação diferencial do tipo:

$$
\frac{d x}{d t}=-k \cdot X(t)+r(t)
$$


onde k é uma constante. Essa constante foi considerada como a taxa de desintegração, ou a taxa de eliminação de uma substância, ou a probabilidade de uma partícula passar do estado atual para outro estado possível, k é sempre constante num sistema de compartimentos de um estado estacionário [VICINI et al. 2008].

Quando um AcM imunoconjugado, marcado no caso com ${ }^{188} \mathrm{Re}$, seja para estudos em animais ou avaliação em humanos por exemplo é injetado intravenosamente, passa por compartimentos, que incluem os espaços vasculares e extravasculares (órgãos, tecidos e fluidos do corpo), onde posteriormente é metabolizado e excretado. [IZNAGA-ESCOBAR, 1998].

\subsubsection{PROGRAMAS COMPUTACIONAIS PARA ESTUDOS DE DOSIMETRIA INTERNA DE RADIOFÁRMACOS EM MODELO ANIMAL}

O estudo quantitativo da dosimetria interna é tão importante para tratamentos humanos quanto para estudos em animais. A dosimetria em animais estabelece a relação entre a dose absorvida e o efeito biológico (toxicidade ou eficácia) durante a avaliação pré-clínica do radiofármaco terápico. O uso de modelos para estudos de dosimetria consiste em obter estatisticamente, um acordo entre os dados experimentais observados e os resultados previstos pelo modelo, com o resultado final a ser útil no cálculo da estimativa da dose de radiação nos órgãos do organismo. Com isso, o principal objetivo da modelagem biocinética para a dosimetria é, obter a área sob a curva da atividade-tempo para todos os órgãos com medidas, e captação significativa do traçador [VICINI et al. 2008].

Para a curva de decaimento, espera-se que seja diferente para os diferentes órgãos e os diferentes indivíduos, devido a meia vida biológica, sendo esta a primeira fonte de informação sobre a radiação absorvida em órgãos individuais. $A$ área sobre a curva atividade-tempo, é definida como a integral da curva da atividadetempo sobre um tempo fixo (zero até $\infty$ ), fornecendo o número de desintegrações que ocorreram na região medida sobre o intervalo da integração, sendo diretamente proporcional a dose acumulada recebida naquele local [VICINI et al. 2008].

A dose total da radiação $\beta^{-}$para um órgão depende: a) o tamanho e a forma do órgão; b) a densidade e a composição anatômica do meio do órgão; c) a biodistribuição (em termos de atividade específica aqui representando atividade por 
grama de órgão, tecido ou sistema) do anticorpo. Em outras palavras, a atividade específica somente não é o suficiente para definir a dosimetria [BOUTALEB et al. 2010].

Cerca de $90 \%$ dos mamíferos utilizados em pesquisas biomédicas são camundongos. Eles ganharam popularidade não somente pelas excelentes propriedades como animais de laboratório (tamanho físico pequeno acoplado com um rápido ciclo de reprodução, cuidado fácil e custo relativamente baixo), mas também pelo fato de apresentarem uma grande similaridade de genes em relação ao genoma humano, permitindo assim, realizar extrapolações dos seus dados para seres humanos [LIANG et al. 2007].

O ADN codificador do camundongo possui uma homologia em relação ao do humano que pode variar de 70 a $90 \%$, isso aumenta as possibilidades de se encontrarem genes ortólogos (ou seja, mesmo gene em diferentes espécies) nas duas espécies estudadas. O camundongo é o mamífero que possui o genoma mais bem estudado e conhecido depois do homem, devido à grande quantidade de marcadores genéticos e de mutações já isoladas, além da possibilidade de se obter proles viáveis e férteis a partir de cruzamentos interespecíficos, permitindo a observação da segregação de polimorfismos de várias classes [STRACHAN \& REED, 2002].

Quando é considerado um modelo dosimétrico para estudos biológicos de tumores, a principal diferença entre o camundongo e o ser humano inclui o tamanho do órgão, geometria e relação física do tumor com tecidos circundantes e outros órgãos normais. Os órgãos dos camundongos são relativamente pequenos se comparados ao alcance das partículas $\beta$ - de altas energias. Dependendo do espectro de energia do radionuclídeo, este pode resultar numa quantidade significante de energia de radiação $\beta^{-}$originada no tecido sendo transmitida para órgãos ou tecidos adjacentes. Com isso, frações de absorção e fatores " $S$ " associados (que corresponde à dose absorvida por unidade de atividade acumulada) para radionuclídeos selecionados nos órgãos humanos não podem ser aplicados diretamente para os órgãos dos camundongos de laboratório [HUI et al. 1994]. 


\subsubsection{MODELOS ANTROPOMÓRFICOS}

Os modelos antropomórficos descrevem a anatomia do corpo, seja ele humano ou animal, desde o seu contorno à maioria ou todos os órgãos e tecidos, com informações sobre a densidade, composição química, forma, tamanho e localização. Reproduzem as características de absorção e espalhamento no corpo, quando expostos ao campo de radiação, viabilizando a avaliação da dose. Muitos modelos antropomórficos são descritos na ICRU (International Commission on Radiation Units and Measurements) [ICRU, 1992]; desde modelos relativamente simples até modelos mais complexos. Os modelos antropomórficos atualmente mais utilizados são os modelos matemáticos ou estilizados, os modelos tomográficos e recentemente os modelos baseados em superfícies 3D.

Os modelos matemáticos, também conhecidos como objeto simulador ou fantom de Voxel (VOlume piXEL) são desenvolvidos a partir de equações matemáticas, onde, por meio de parâmetros definidos na própria equação, podem ser visualizadas áreas de seção, vistas de topo, ao longo do corpo do animal ou indivíduo. Os modelos são constituídos de cubos, conhecidos como voxels; onde um "voxel" é o elemento de unidade de volume. No modelo matemático, cada voxel teria uma composição elementar e densidade definida, de acordo com o órgão ou tecido a que este corresponderia [VEIT, 1989].

Os modelos antropomórficos em voxels são representações reais do corpo animal/humano e sua estrutura permite determinar a energia depositada, através da equação de transporte em nível de órgão ou tecido. As imagens fornecem informações detalhadas da anatomia do corpo. Uma fatia de imagem, representa uma matriz de pixels em uma geometria de duas dimensões. Por multiplicação do tamanho do pixel pela fatia da espessura de uma imagem, obtém-se o elemento tridimensional, o voxel (FIG. 4). A dimensão de pixels de cada imagem bidimensional depende da resolução escolhida durante a opção de varredura para a obtenção do conjunto original de imagens [BUSHBERG et. al, 2002]. 


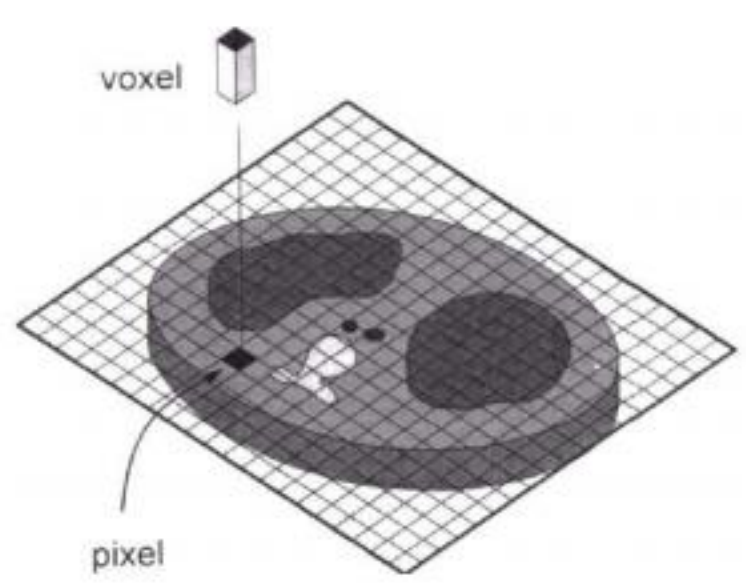

FIGURA 4 - Exemplo de uma Imagem bidimensional de uma Tomografia Computadorizada (TC) que corresponde a uma fatia tridimensional de um corpo humano. Cada pixel na imagem corresponde a um voxel. $O$ voxel tem as duas dimensões do pixel no plano da imagem e a terceira dimensão representa a espessura da fatia da varredura TC [BUSHBERG et. al, 2002].

\subsubsection{O MÉTODO DE MONTE CARLO}

O Método de Monte Carlo é um método estatístico de simulação, onde cada partícula é acompanhada desde o seu "nascimento" até a sua "morte" (ou história da partícula). Este método faz uso de uma sequência de números aleatórios. O gerador de números aleatórios é um algoritmo computacional que gera números aleatórios toda vez que solicitado durante o processo de simulação. A interação da radiação com a matéria é representada por funções de probabilidade conhecidas como Funções de Densidade de Probabilidade (FDP). As FDP's caracterizam matematicamente, o processo físico que está sendo simulado, como por exemplo o tipo de interação, energia, etc [ROBERT \& CASELLA, 2004].

Para o transporte de partículas são usados diversos códigos que utilizam o método Monte Carlo, destacando-se o MCNP (Monte Carlo N-Particle), o EGS (Electron Gamma Shower), GEANT (GEometry ANd Tracking), GATE (GEANT application for tomographic emission), PENELOPE (PENetration and Energy LOss of Positrons and Electrons), ALGAM (Monte Carlo Estimation of Internal Dose from Gamma-Ray Sources in a Phantom Man) e ETRAN (Electron TRANsport) [ROGERS, 2006]. 
Para fins de avaliação dosimétrica, o cálculo da dose pelo método de Monte Carlo requer a utilização de um modelo geométrico ou fantom do paciente ou do órgão a ser estudado. Essa metodologia pode ser usada para cálculos de dose de corpo inteiro ou de um órgão específico (macrodosimetria), como também para avaliação da dose absorvida por tecidos e células (dosimetria de pequena escala ou microdosimetria). Os fantoms matemáticos constituíram um avanço significativo em dosimetria numérica, usando superfícies como planos, cilindros, esferas, elipsóides, cones, suas intersecções e adições [FISHER, 1994].

O MCNP e o EGS são códigos já bem estabelecidos e usados no mundo inteiro para diferentes finalidades, como, por exemplo, na área de neutrônica, física nuclear, radioproteção, dosimetria, entre outras, permitindo simular o transporte de elétrons, fótons e nêutrons, com capacidade para definir uma geometria complexa para diversos tipos de fontes [FISHER, 1994].

O MCNP é um código que realiza o transporte de partículas utilizando o método de Monte Carlo, com capacidade para simular nêutrons com energias entre 10 a $20 \mathrm{MeV}$, enquanto que a faixa de energia para os fótons e elétrons varia de 1 $\mathrm{keV}$ a $1000 \mathrm{MeV}$. [BRIESMEISTER, 2000].

O código MCNP tem a capacidade de simular sistemas com geometrias que vão de superfícies pré-determinadas como esferas, planos, parabolóides de revolução, cilindros, elipsóides, até superfícies bem elaboradas utilizando conjunto de pontos no espaço. O pesquisador ao utilizar o MCNP constrói um arquivo de entrada no código que pode ser organizado em blocos descrevendo regiões envolvidas no modelo; especificação da geometria por meio de superfícies geométricas e suas intersecções; posição e distribuição energética da fonte, descrição dos materiais e todos os parâmetros físicos agregados juntamente com algumas técnicas de redução de variância para melhorar a eficiência e obter melhores resultados [BRIESMEISTER, 2000].

A versatilidade juntamente com o aspecto funcional do código MCNP para diferentes tipos de problemas faz com que este seja bem aceito na comunidade científica que trabalha com transporte de radiação e cálculo de dose [BRIESMEISTER, 2000]. 


\subsubsection{DOSIMETRIA POR FONTE PONTUAL PARA EMISSORES $\beta^{-}$}

Existem diversas metodologias para se determinar a dosimetria com emissores $\beta$, de acordo com as diferentes formas geométricas. A taxa de dose $(\dot{D})$ de uma fonte pontual pode ser calculada através da Fórmula de Loevinger [GAD, 2000] dada por:

$$
\dot{D} \cdot[G y / h]=\frac{k A_{\text {int }}}{(\mu r)^{2}}\left\{c\left[1-\left(\frac{\mu r}{c}\right)^{(1-\mu r / c)}\right]+\mu r e^{(1-\mu r)}\right\}
$$

onde:

$r \rightarrow$ distância do alvo a fonte pontual, em g.cm-2;

$\mathrm{A}_{\text {int }} \rightarrow$ atividade acumulada da fonte em $\mathrm{Ci}$;

$c \rightarrow$ parâmetro dependente da energia $\beta^{-}$máxima (dimensionada);

$\mu \rightarrow$ coeficiente de absorção de energia em $\mathrm{cm}^{2} \cdot \mathrm{g}^{-1}$;

$\mathrm{k} \rightarrow$ constante de normalização

A constante de normalização, por sua vez, é dada por:

$$
k\left[\frac{G y / h}{\text { Curie }}\right]=\frac{1,7 \times 10^{3} \rho^{2} \mu^{3} E_{a v}}{\left[3 c^{2}-e\left(c^{2}-1\right)\right]}
$$

onde:

$\rho \rightarrow$ densidade do absorvedor, em g.cm ${ }^{-3}$;

$e \rightarrow$ número matemático neperiano;

$E_{a v} \rightarrow$ energia $\beta$ - média, em MeV.

O valor de c no ar é $3,11 e^{-0,55 E_{\text {max }}}$ e no tecido: 
$\mathrm{C}=2 \rightarrow$ para $0,17 \leq \mathrm{E}_{\text {máx }}<0,5 \mathrm{MeV}$

$\mathrm{C}=1,5 \rightarrow$ para $0,5 \leq \mathrm{E}_{\text {máx }}<1,5 \mathrm{MeV}$

$\mathrm{C}=1 \rightarrow$ para $1,5 \leq \mathrm{E}_{\text {máx }}<3,0 \mathrm{MeV}$

O valor de $\mu$ no ar é dado por:

$$
\mu\left[\frac{c m^{2}}{g}\right]=\frac{16\left(2-E_{a v} / E_{a v}^{*}\right)}{\left.\left[E_{\text {máx }}-0,036\right)^{1,4}\right]}
$$

$E_{a v}^{*}$ é definida como a energia $\beta^{-}$média, para uma desintegração hipotética, tendo a mesma $E_{\text {máx }}$ como uma transição de um decaimento $\beta^{-}$permitido num mesmo elemento Z. Para espectros permitidos, $E_{a v} / E_{a v}^{*}=1$.

Uma expressão mais simples para a determinação da taxa de dose para fonte pontual com emissores $\beta^{-}$é análoga à determinação da dosimetria para fonte pontual com emissores $\gamma$, sendo representada por:

$$
\dot{D}_{\beta}[G y]=2,14 \times 10^{4} \cdot \rho^{2} \cdot\left(\frac{\mu}{\rho}\right) \cdot A_{\mathrm{int}} E_{m e ́ d} \cdot \frac{e^{-\left(\frac{\mu}{\rho}\right) \cdot d \cdot \rho}}{4 \cdot \pi \cdot(d \cdot \rho)^{2}}
$$

onde:

$\rho \rightarrow$ densidade do material absorvedor em g.cm ${ }^{-3}$;

$A_{\text {int }} \rightarrow$ atividade integrada durante tempo de validade do produto, dentro do organismo em Ci;

$E_{\text {méd }} \rightarrow$ energia média da emissão $\beta^{-}$em MeV;

$d \rightarrow$ distância entre fonte/material em $\mathrm{cm}$;

$\mu / \rho \rightarrow$ probabilidade de interação, em cm².g.

A probabilidade de interação é dada por:

$$
\left(\frac{\mu}{\rho}\right)\left[\frac{c m^{2}}{g}\right]=17\left(E_{\text {máx }}\right)^{-1,14}
$$




\subsubsection{EXTRAPOLAÇÃO DE DADOS DE ESTUdOS EM ANIMAIS PARA HUMANOS}

No estudo in vivo em animais, a determinação da sua dosimetria, normalmente é realizada com um certo número de animais, que são sacrificados em diferentes intervalos de tempo, seus órgãos, tecidos ou sistemas são separados. A atividade em cada um é avaliada, através da sua contagem em contadores ou por técnicas de autoradiografia em amostras de tecidos excisados, ou pela avaliação não invasiva, pela formação de imagens através de equipamentos microPET ou microSPECT. Esses dados recebidos podem ser usados para predizer captações em humanos, a partir das concentrações observadas nos tecidos animais (extrapolação) [STABIN, 2008].

Um dos métodos de extrapolação animal mais usado é o método que relaciona o percentual de massa corpórea (equação 9). Neste método, os dados referentes aos órgãos do animal são necessários, para informar o percentual de atividade injetada por grama de tecido, informação adicionada ao peso do corpo inteiro do animal conhecido, fornecendo a seguinte extrapolação [STABIN, 2008]:

$$
\left(\frac{\%}{\text { órgão }}\right)_{\text {humano }}=\left[\left(\frac{\%}{g_{\text {orgão }}}\right)_{\text {animal }} \times\left(k g_{\text {corpototal }}\right)_{\text {animal }}\right] \times\left(\frac{g_{\text {órgão }}}{k g_{\text {corpototal }}}\right)_{\text {humano }}
$$




\section{OBJETIVOS}

O presente trabalho teve como Objetivo Principal:

> Comparar aspectos da marcação do AcM anti-CD20 com radionuclídeos emissores $\beta^{-} \mathrm{e} \alpha$, incluindo estudos de farmacocinética e dosimetria.

E como Objetivos Específicos:

> Comparar as propriedades físicas e as características da marcação do AcM Anti-CD20 com radionuclídeos emissores $\beta$, a saber: ${ }^{188} \mathrm{Re},{ }^{90} \mathrm{Y},{ }^{131} \mathrm{I},{ }^{177} \mathrm{Lu}$, e também ${ }^{99 \mathrm{~m} T \mathrm{~T} \text {. }}$

$>$ Comparar a similaridade do ${ }^{188} \mathrm{Re}$-Anti-CD20 com ${ }^{99 \mathrm{~m} T c-A n t i-C D 20}$ através da análise compartimental;

$>$ Apresentar as características da marcação do Anti-CD20 com radionuclídeos $\alpha$ : ${ }^{211} \mathrm{At},{ }^{213} \mathrm{Bi},{ }^{223} \mathrm{Ra}$ e ${ }^{225} \mathrm{Ac}$, com potencial para terapia de tumores;

> Estabelecer modelos matemáticos que simulem a geometria dos principais órgãos do corpo de um camundongo. Determinar modelos compartimentais para o desenvolvimento das rotinas de cálculo de dosimetria e farmacocinética, em estudos com fonte contendo emissores de radiação $\beta$. 


\section{MATERIAIS E MÉTODOS}

\subsection{MATERIAIS}

\subsubsection{INFRAESTRUTURA E EQUIPAMENTOS}

Todo o trabalho foi realizado no Centro de Radiofarmácia (CR) do Instituto de Pesquisas Energéticas e Nucleares (IPEN-CNEN/SP).

\subsection{MÉTODOS}

\subsubsection{ESTUDO DAS PROPRIEDADES FÍSICAS DOS RADIONUCLÍDEOS}

Foi realizado um levantamento bibliográfico das propriedades físicas dos radionuclídeos emissores $\beta^{-188} \mathrm{Re},{ }^{90} \mathrm{Y},{ }^{131} \mathrm{I},{ }^{177} \mathrm{Lu}$ e emissores $\alpha{ }^{211} \mathrm{At},{ }^{213} \mathrm{Bi},{ }^{223} \mathrm{Ra}$ e ${ }^{225} \mathrm{Ac}$, levando em consideração as reações nucleares de produção dos radionuclídeos e dos produtos de decaimento, quando radioativos, meia-vida física e energias principais de decaimento. Foram obtidas as curvas de decaimento de cada um dos radionuclídeos.

\subsubsection{ESTUDO DA PUREZA RADIOQUÍMICA DOS RADIOFÁRMACOS}

Foi realizado um levantamento bibliográfico das possíveis impurezas radioquímicas dos radiofármacos ${ }^{188} \mathrm{Re}$-Anti-CD20, ${ }^{90}$ Y-Anti-CD20, ${ }^{131}$ I-Anti-CD20 e ${ }^{177} \mathrm{Lu}$-Anti-CD20, advindas dos processos de marcação in vivo, assim como informações de farmacopéias e de referências obtidas de grupos de pesquisa do CRIPEN. 


\subsubsection{AVALIAÇÃO DA FARMACOCINÉTICA DO ANTI-CD2O MARCADO COM OS PRINCIPAIS RADIONUCLÍDEOS EMISSORES $\alpha$ E $\beta$-PARA RIT}

O estudo de farmacocinética foi realizado com a definição de um modelo compartimental [KEITH et al, 2000] para o radiofármaco ${ }^{188}$ Re-Anti-CD20 e outros radiofármacos emissores $\beta:{ }^{131}$ I-Anti-CD20 e ${ }^{177}$ Lu-Anti-CD20 e o emissor $\gamma{ }^{99 m T C-}$ Anti-CD20. Foi realizado um estudo com o radiofármaco emissor $\alpha{ }^{211}$ At-Anti-CD20, onde, segundo dados de literatura, tem apresentado resultados satisfatórios quanto à marcação com Anti-CD20 e potencial para a RIT [AUDICIO et al.,2011, AKANJI, 2006; DIAS, 2010; AURLIEN et al, 2000].

\subsubsection{MODELO COMPARTIMENTAL PARA ESTUDOS CINÉTICOS}

A cinética do Anti-CD20 foi avaliada usando um modelo multicompartimental em uma configuração mamilar, que consiste de um modelo compartimental central, ligado a um ou mais compartimentos periféricos. Este compartimento central representa o plasma ou sangue, que junto com os órgãos, entra em equilíbrio rapidamente, após uma administração intravenosa do radiofármaco [KEITH et al, 2000].

O modelo compartimental utilizado para descrever o metabolismo dos radiofármacos dentro do organismo está representado pela FIG. 5 , modificado de acordo com Keith colaboradores [KEITH et al, 2000]. 


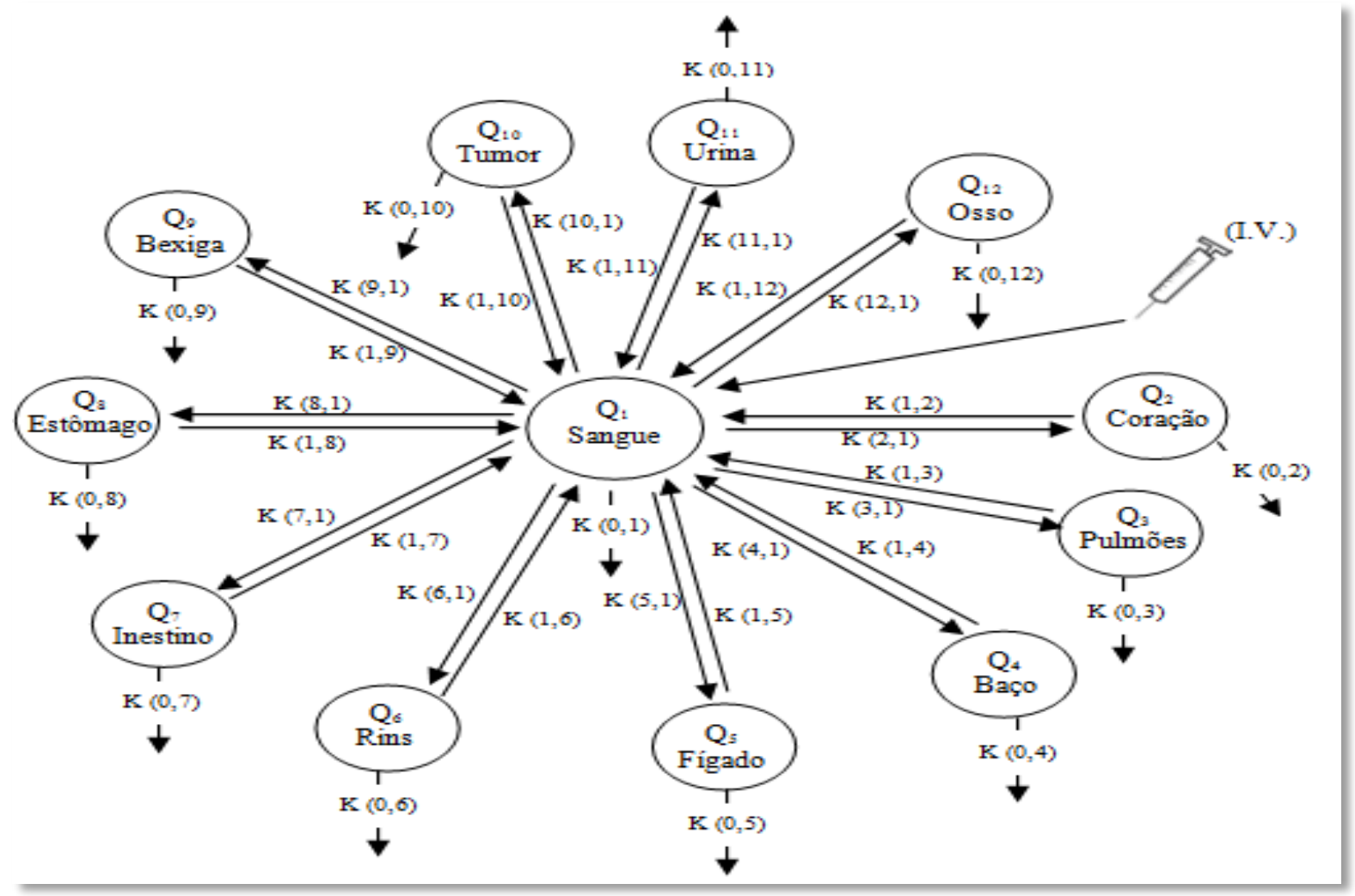

FIGURA 5 - Modelo mamilar utilizado para estudos farmacocinéticos com AntiCD20. O modelo descreve a interação do radiofármaco entre o sangue e cada um demais compartimentos, correspondendo aos órgãos e tumor. A perda de material pela urina foi considerada irreversível de material [KEITH et al, 2000 - Adaptado].

O modelo mamilar apresentado foi composto por um compartimento central, que está representado pelo sangue e onze compartimentos periféricos, cuja troca de material foi feita exclusivamente com o compartimento central. Os doze compartimentos no total representaram os órgãos, o osso, o tumor, a urina acumulada estimada e as demais partes do corpo [KEITH et al, 2000].

Para cada um dos 11 compartimentos foi descrita uma equação diferencial. Considerou-se $Q_{P}(t)$ a atividade injetada do radiofármaco no plasma em um tempo t, $Q_{C}(t)$ a atividade no coração, $Q_{F}(t)$ a atividade no fígado, etc. As constantes foram designadas por $k_{c}$ e dimensionadas por $\mathrm{t}^{-1}$, sendo que $k_{p c}$ regulou a transferência do Anti-CD20 do coração $C$ para o plasma $P$, etc. As 11 equações diferenciais encontram-se relacionadas na Eq (10): 


$$
\begin{aligned}
\frac{d Q_{C}}{d t}=-\left(K_{C P}\right. & \left.+K_{L P}+K_{F P}+K_{I P}+K_{E P}+K_{B P}+K_{A P}+K_{T P}+K_{O P}\right) Q_{P}+K_{C P} Q_{P}+K_{L P} Q_{L} \\
& +K_{F P} Q_{F}+K_{I P} Q_{I}+K_{E P} Q_{E}+K_{B P} Q_{B}+K_{A P} Q_{A}+K_{T P} Q_{T}+K_{O P} Q_{O}
\end{aligned}
$$

Na TAB. 9, encontra-se a descrição matemática de cada uma delas.

TABELA 9 - Equações diferenciais dos onze compartimentos no modelo compartimental mamilar para o Anti-CD20 [KEITH et al, 2000].

\begin{tabular}{lll}
\hline Compartimento & Interação & Equação \\
\hline Coração & Plasma(1) $\rightarrow$ Coração(2) & $\frac{d Q_{1}}{d t}=k_{2,1} Q_{1}-k_{1,2} Q_{2}$ \\
Pulmões & Plasma(1) $\rightarrow$ Pulmões(3) & $\frac{d Q_{3}}{d t}=k_{3,1} Q_{1}-k_{1,3} Q_{3}$ \\
Baço & Plasma(1) $\rightarrow$ Baço(4) & $\frac{d Q_{4}}{d t}=k_{4,1} Q_{1}-k_{1,4} Q_{4}$ \\
Fígado & Plasma(1) $\rightarrow$ Fígado(5) & $\frac{d Q_{5}}{d t}=k_{5,1} Q_{1}-k_{1,5} Q_{5}$ \\
Rins & Plasma(1) $\rightarrow$ Rins(6) $\rightarrow$ Urina(11) & $\frac{d Q_{6}}{d t}=k_{6,1} Q_{1}-k_{1,6} Q_{6}-k_{1,11} Q_{11}$ \\
Intestino & Plasma(1) $\rightarrow$ Intestino(7) & $\frac{d Q_{7}}{d t}=k_{7,1} Q_{1}-k_{1,7} Q_{7}$ \\
Estômago & Plasma(1) $\rightarrow$ Estômago(8) & $\frac{d Q_{8}}{d t}=k_{8,1} Q_{1}-k_{1,8} Q_{8}$ \\
Bexiga & Plasma(1) $\rightarrow$ Bexiga(9) & $\frac{d Q_{9}}{d t}=k_{9,1} Q_{1}-k_{1,9} Q_{9}$
\end{tabular}




\subsubsection{INTERPRETAÇÃO DA CONSTANTE $K$}

As constantes $k$ das equações foram determinadas através dos dados experimentais obtidos na literatura. Seja $\mathbf{X}$ um compartimento periférico geral, ou um órgão:

$$
\frac{d Q_{X}}{d t}=k_{X, 1} Q_{1}-k_{1, X} Q_{X}
$$

foi aplicado para representar a derivada $\frac{d Q_{X}}{d t}$ como sendo a soma de duas derivadas constituintes, cada uma maior que zero:

$$
\frac{d Q_{X}}{d t}=\left|\frac{d Q_{1}}{d t}\right|_{1 \rightarrow X}-\left|\frac{d Q_{X}}{d t}\right|_{X \rightarrow 1}
$$

A $1^{\underline{a}}$ derivada do lado direito da Eq (12) governa a transferência do "anticorpo/radionuclídeo" do plasma para o compartimento e a $2^{\text {a }}$ derivada do compartimento $X$ para o plasma. Assim, pode-se escrever:

$$
\begin{aligned}
& \left|\frac{d Q_{1}}{d t}\right|_{1 \rightarrow X}=K_{1, X} Q_{1} \\
& \left|\frac{d Q_{X}}{d t}\right|_{X \rightarrow 1}=K_{X, 1} Q_{X}
\end{aligned}
$$

Aproximando as derivadas por diferença finita, temos:

$$
\begin{aligned}
& \left|\frac{d Q_{1} / Q_{1}}{d t}\right|_{1 \rightarrow X}=K_{X, 1} \\
& \left|\frac{d Q_{X} / Q_{X}}{d t}\right|_{X \rightarrow 1}=K_{1, X}
\end{aligned}
$$

A equação 16 permitiu interpretar a constante $K_{1, X}$ como a perda de fração na atividade do radiofármaco do órgão $\mathbf{X}$, por unidade de tempo. Similarmente, a equação 15 permitiu interpretar a constante $K_{X, 1}$ como a perda fracional da atividade do radiofármaco do plasma por unidade de tempo, que foi determinada para órgãos ou tecidos $\mathbf{X}$. 


\subsubsection{SIMULAÇÃO DOS DADOS A PARTIR DO MONOLIX}

Para a simulação dos dados obtidos a partir dos estudos de biodistribuição por revisão de literatura, foi utilizado o software MONOLIX (Non Linéaires à effects miXtes), versão 4.3.3s, que consiste no uso de modelos não lineares por efeitos mistos, através do uso de uma plataforma de referência para modelagem de novas drogas. O software permitiu a realização de simulações para avaliar o comportamento farmacocinético dentro do organismo para o ${ }^{188} \mathrm{Re}-\mathrm{Anti}$-CD20 [DIAS, 2010], 99mTc-Anti-CD20 [DIAS, 2010], ${ }^{131}$ I-Anti-CD20 [AKANJI, 2006], ${ }^{177}$ Lu-AntiCD20 [AUDICIO et al, 2011] e 211 At-Anti-CD20 [AURLIEN et al., 2000], baseados em estudos de biodistribuição extraídos de dados de literatura.

MONOLIX implementa uma aproximação estocástica (stochastic approximation - SA) da maximização da expectativa padrão (standard expectation maximization - EM) (=SAEM) do algoritmo para modelos não lineares de efeitos mistos, sem aproximações. O algoritmo SAEM substitui a estimativa usual EM por um processo estocástico eficaz com maior convergência para estimativas de probabilidade máxima (maximum likelihood - ML). SAEM executa estimativas EM sem qualquer aproximação do modelo estatístico. Com isso, as propriedades estatísticas "ótimas" (consistência e variância mínima da estimativa) são esperados com o SAEM. A implementação do SAEM no MONOLIX é otimizado e configurações da cadeia de Markov Monte Carlo (MCMC) são usados para definição das etapas das simulações [MONOLIX, 2013].

\subsubsection{AVALIAÇÃO DA DOSIMETRIA NO TUMOR E EM TECIDOS NORMAIS EM RIT COM ANTI-CD2O MARCADO COM EMISSORES $\beta$ -}

Os cálculos da dose absorvida nos órgãos e no tumor em camundongos a partir dados obtidos na literatura, foram realizados usando duas metodologias: 0 Método de Monte Carlo e o pelo do uso de uma Fonte Pontual, para avaliar a eficácia da RIT com radionuclídeos emissores $\beta^{-}$, de maior potencial para esse tipo de terapia. Os radionuclídeos avaliados nessas duas metodologias foram: ${ }^{90} \mathrm{Y},{ }^{131}{ }^{1},{ }^{177} \mathrm{Lu}$ $\mathrm{e}^{188} \mathrm{Re}$. 


\subsubsection{USO DE MODELOS MATEMÁTICOS}

Nas duas metodologias propostas para o cálculo da dose absorvida nos órgãos e no corpo do animal, foi inicialmente estabelecidos a geometria dos órgãos e do tumor. Foi proposto o uso de equações matemáticas (TAB. 10) para a definição da geometria de cada órgão do animal para uso nos cálculos necessários. As equações matemáticas para cada órgão foram baseadas nas dimensões específicas de um camundongo de aproximadamente $m=25,0 \mathrm{~g}$, da linhagem nude, com valores definidos de massas e densidades dos principais órgãos. A superfície de cada órgão foi construída utilizando equações elípticas, de diferentes dimensões, e para o tumor foi utilizada uma equação da esfera [HINDORF et. al, 2004]. 
TABELA 10 - Relação das equações utilizadas para definição do modelo matemático dos órgãos do camundongo, usados como dados de entrada para calcular a dose absorvida nos órgãos normais e no tumor, no estudo da dosimetria com emissores $\beta$ - em RIT.

\begin{tabular}{|c|c|c|}
\hline Região/Órgão & Equação & Condição \\
\hline Tronco & $\left(\frac{x}{1,1}\right)^{2}+\left(\frac{y}{1,2}\right)^{2} \leq 1$ & Para $0 \leq z \leq 4,7$ \\
\hline Cabeça & $\left(\frac{x}{1,1}\right)^{2}+\left(\frac{y}{1,2}\right)^{2}+\left(\frac{z-4,7}{1,6}\right)^{2} \leq 1$ & Para $z>4,7$ \\
\hline Glândula Tireóide & $\begin{array}{l}\left(\frac{x+0,1}{0,05}\right)^{2}+\left(\frac{y+1}{0,05}\right)^{2}+\left(\frac{z-4,9}{0,11}\right)^{2} \leq 1 \\
\left(\frac{x-0,1}{0,05}\right)^{2}+\left(\frac{y+1}{0,05}\right)^{2}+\left(\frac{z-4,9}{0,11}\right)^{2} \leq 1\end{array}$ & - \\
\hline Coração & $\left(\frac{x}{0,29}\right)^{2}+\left(\frac{y+0,55}{0,32}\right)^{2}+\left(\frac{z-4,2}{0,32}\right)^{2} \leq 1$ & - \\
\hline Pulmões & $\begin{array}{l}\left(\frac{x+0,32}{0,32}\right)^{2}+\left(\frac{y}{0,32}\right)^{2}+\left(\frac{z-3,3}{1,2}\right)^{2} \leq 1 \\
\left(\frac{x-0,32}{0,32}\right)^{2}+\left(\frac{y}{0,32}\right)^{2}+\left(\frac{z-3,3}{1,2}\right)^{2} \leq 1\end{array}$ & Para $z \geq 3,3$ \\
\hline Rins & $\begin{array}{l}\left(\frac{x+0,4}{0,27}\right)^{2}+\left(\frac{y+0,7}{0,27}\right)^{2}+\left(\frac{z-2,2}{0,46}\right)^{2} \leq 1 \\
\left(\frac{x-0,4}{0,27}\right)^{2}+\left(\frac{y+0,7}{0,27}\right)^{2}+\left(\frac{z-2,2}{0,46}\right)^{2} \leq 1\end{array}$ & - \\
\hline Fígado & $\left(\frac{x+0,2}{0,8}\right)^{2}+\left(\frac{y+0,15}{0,85}\right)^{2}+\left(\frac{z-2,7}{0,6}\right)^{2} \leq 1$ & Para $z \geq 2,7$ \\
\hline Baço & $\left(\frac{x-0,8}{0,15}\right)^{2}+\left(\frac{y+0,5}{0,25}\right)^{2}+\left(\frac{z-2,1}{0,57}\right)^{2} \leq 1$ & - \\
\hline Testículos & $\begin{array}{l}\left(\frac{x+0,3}{0,26}\right)^{2}+\left(\frac{y+0,8}{0,26}\right)^{2}+\left(\frac{z-0,5}{0,44}\right)^{2} \leq 1 \\
\left(\frac{x-0,3}{0,26}\right)^{2}+\left(\frac{y+0,8}{0,26}\right)^{2}+\left(\frac{z-0,5}{0,44}\right)^{2} \leq 1\end{array}$ & - \\
\hline Bexiga & $\left(\frac{x}{0,25}\right)^{2}+\left(\frac{y+0,3}{0,25}\right)^{2}+\left(\frac{z-1,6}{0,25}\right)^{2} \leq 1$ & - \\
\hline Coluna & $\left(\frac{x}{0,1}\right)^{2}+\left(\frac{y-1}{0,1}\right)^{2} \leq 1$ & Para $z \leq 4,7$ \\
\hline Tumor & $(x+0,5)^{2}+(y-0,7)^{2}+(z-4,5)^{2} \leq 1$ & - \\
\hline
\end{tabular}


$\mathrm{Na}$ tabela 10, cada semi-eixo e centros da elipse nas equações elípticas e cada coordenada no centro da esfera e seus semi-eixos na equação da esfera, determinaram a posição de cada órgão e do tumor dentro do tronco do animal.

O material considerado nos cálculos para as duas metodologias foi a água (densidade págua $=1,0 \mathrm{~g} \cdot \mathrm{cm}^{-3}$ ), que também tem sido utilizada como referência para simulações realizadas com fantoms simuladores na área da radioterapia e para calibração de equipamentos. A água foi utilizada para a composição do corpo, órgãos e tumor no camundongo.

Para alguns órgãos, como pulmões e coluna (que corresponde a medula óssea), suas densidades foram definidas de acordo com a literatura, e estão descritas na TAB. 11 [HINDORF et. al, 2004].

TABELA 11 - Densidades dos pulmões, coluna (medula óssea), além dos demais órgãos e tumor, usadas como dados de entrada na determinação da dose absorvida em estudos com radionuclídeos emissores $\beta$.

\begin{tabular}{|c|c|}
\hline Órgão & Densidade $\left(\mathrm{g} \mathrm{cm}^{-3}\right)$ \\
\hline Pulmões & 0,3 \\
\hline Coluna & 1,4 \\
\hline Tecidos moles & 1,0 \\
\hline
\end{tabular}

As massas de cada órgão e do tumor do camundongo nude utilizados para o cálculo da dose absorvida, estão descritos na TAB. 12 [HINDORF et. al, 2004]. 
TABELA 12 - Massa dos órgãos do camundongo e massa do tumor utilizados como dados de entrada na determinação da dose absorvida em estudos com radionuclídeos emissores $\beta$.

\begin{tabular}{cc}
\hline Órgão & Massa do órgão $(\mathbf{g})$ \\
\hline Coração & 0,12 \\
Rins & 0,28 \\
Pulmões & 0,15 \\
Fígado & 0,89 \\
Glândula tireóide & 0,02 \\
Baço & 0,09 \\
Bexiga & 0,03 \\
Testículos & 0,25 \\
Coluna & 0,19 \\
Tumor & 0,05 \\
\hline
\end{tabular}

\subsubsection{MÉTODO POR MONTE CARLO PARA ESTUDOS DE DOSIMETRIA}

Neste trabalho, foi usado o método de Monte Carlo MCNP versão 4C (Oak Ridge National Laboratory) para simular o transporte das partículas $\beta^{-}$do radionuclídeo ${ }^{188} \mathrm{Re}$, e dos demais radionuclídeos de mesma emissão $\left({ }^{90} \mathrm{Y},{ }^{131} \mathrm{I}\right.$ e ${ }^{177} \mathrm{Lu}$ ). Este programa permitiu o uso das equações matemáticas para a construção do corpo do camundongo, para o dimensionamento e posicionamento dos órgãos e do tumor, composição desses órgãos e do tumor pelas suas respectivas massas e densidades. A partir disso, o modelo para o corpo do animal pôde ser definido pelo MCNP, conforme perspectiva representada pela FIG. 6 . 


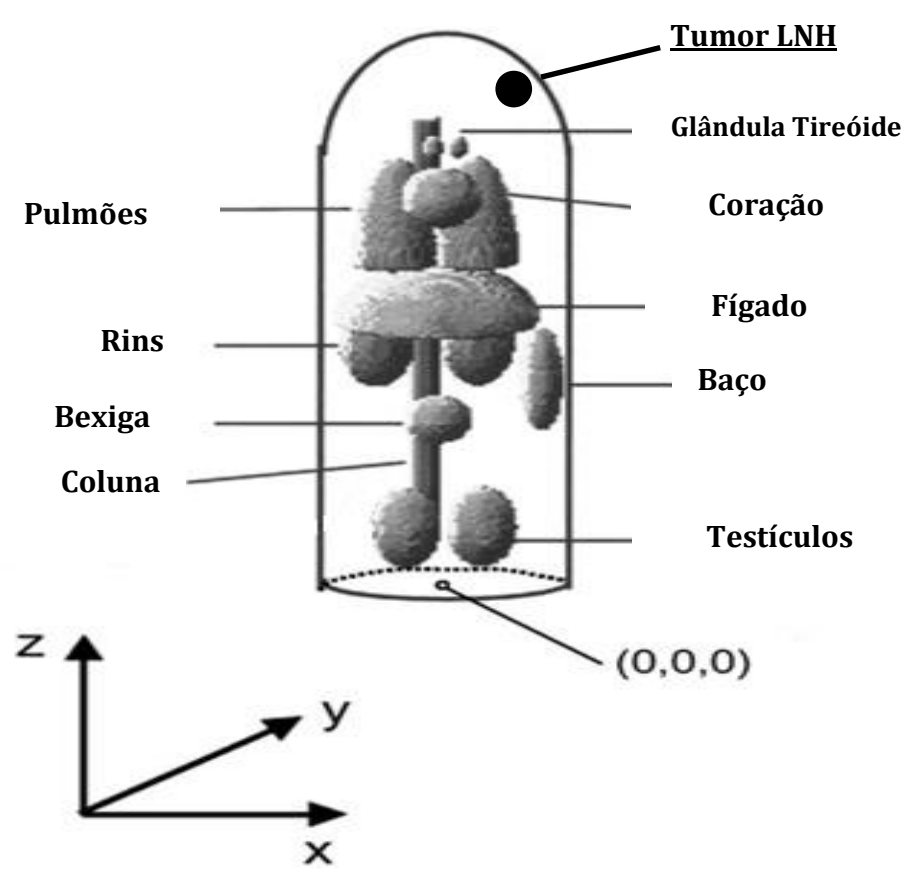

FIGURA 6 - Modelo matemático do corpo de um camundongo, proposto pelo código de Monte Carlo MCNP-4C. Este modelo foi utilizado para estabelecer a geometria dos órgãos e do tumor, dentro de um corpo simulado de um camundongo, na determinação da dose absorvida [HINDORF et. al, 2004, THOMPSON et al, 2014].

Foram considerados dados de entrada do MCNP, as equações matemáticas para estabelecer a geometria dos órgãos, características da massa e densidade para definir os materiais envolvidos na modelagem, parâmetros físicos para definir o tipo de interação envolvida no processo da simulação, além da posição e distribuição da fonte utilizada (especificações quanto às características físicas do radionuclídeo desejado, não necessitando de informações quanto ao anticorpo ligado a ele).

Nas simulações foram consideradas somente as interações com as partículas $\beta$, pois a emissão $\gamma$ não contribui para a deposição de energia no local desejado.

A fonte utilizada nas simulações apresentou formato esférico (no caso, utilizou-se a equação correspondente ao tumor), cujo dado de entrada utilizado foi a energia de emissão $\beta$ - máxima dos radionuclídeos propostos neste trabalho, listados na TAB. 13 [FERRO-FLORES \& MURPHY, 2008]. 
TABELA 13 - Energias máximas de emissão dos radionuclídeos emissores $\beta$ usados nas simulações com MCNP para determinação da dose absorvida nos tecidos [FERRO-FLORES \& MURPHY, 2008].

\begin{tabular}{cc}
\hline Radionuclídeo & $\begin{array}{c}\text { Emáx de emissão de partículas } \boldsymbol{\beta}^{-} \text {por } \\
\text { desintegração }(\mathrm{MeV})\end{array}$ \\
\hline${ }^{90} \mathrm{Y}$ & 2,280 \\
${ }^{131} \mathrm{I}$ & 0,610 \\
${ }^{177} \mathrm{Lu}$ & 0,497 \\
${ }^{188} \mathrm{Re}$ & 2,120 \\
\hline
\end{tabular}

No processo de distribuição da fonte dentro do corpo do animal nas simulações foram considerados dois casos para o estudo da sua dosimetria:

- Caso 1: Distribução da fonte totalmente no tumor, ou seja, captação de $100 \%$ (no caso foi considerado que o anticorpo ligado ao radionuclídeo foi $100 \%$ captado pelo tumor) - máxima eficácia no tratamento;

- Caso 2: Distribuição entre o tumor e todos órgãos dentro do corpo do animal (considerando que após a injeção do radiofármaco no animal, não houve 100\% de captação do anticorpo no tumor e sim uma distribuição dentro do corpo do animal).

Para ambos os casos descritos, foram realizadas simulações onde a dimensão da fonte (ou do tumor) foi variada. Como a fonte é uma esfera, seu raio foi variado e os valores avaliados estão descritos pela TAB. 14 . 
TABELA 14 - Tamanho de tumor (raio) usado nas simulações para avaliar a variação tumoral em relação à sua dosimetria.

\begin{tabular}{ccc}
\hline Radionuclídeos avaliados & No. do tumor & Raio do tumor (cm) \\
\hline 1 & 0,01 \\
2 & 0,02 \\
3 & 0,03 \\
4 & 0,04 \\
${ }^{90} \mathrm{Y},{ }^{131} \mathrm{I},{ }^{177} \mathrm{Lu}$ e ${ }^{188} \mathrm{Re}$ & 5 & 0,05 \\
& 6 & 0,06 \\
& 7 & 0,07 \\
& 8 & 0,08 \\
& 9 & 0,09 \\
& 10 & 0,10 \\
& 11 & 0,20 \\
& 12 & 0,30 \\
& 13 & 0,40 \\
\hline
\end{tabular}

O processo de cada simulação ocorreu durante 300 minutos, registrados pelo computador.

Como resposta ao processo de simulação, o MCNP gerou dados de saída, em unidade de energia por desintegração $[\mathrm{MeV} / \mathrm{des}]$, sendo necessário uma transformação de unidades para a obtenção da dose absorvida em Gray por desintegração [Gy/des].

A dose absorvida em um determinado órgão ou no corpo inteiro foi determinada por :

$$
\text { Dose }\left[\frac{G y}{d e s}\right]=\frac{E\left[\frac{\mathrm{MeV}}{\mathrm{des}}\right] \times 1,6 \times 10^{-19}\left[\frac{\mathrm{J}}{\mathrm{MeV}}\right] \times 1\left[\mathrm{~Gy} \cdot \frac{\mathrm{Kg}}{\mathrm{J}}\right]}{\rho\left[\frac{\mathrm{g}}{\mathrm{cm}^{3}}\right] x\left\{\frac{4}{3} \times \pi x\left(r^{3}\right)\left[\mathrm{cm}^{3}\right]\right\} \times 0,001\left[\frac{\mathrm{kg}}{\mathrm{g}}\right]}
$$

onde:

- $\quad E[\mathrm{MeV} / \mathrm{des}] \rightarrow$ Energia depositada por desintegração; 
- $1,6 \times 10^{-13}[\mathrm{~J} / \mathrm{MeV}] \times 1$ [Gy.kg/J] $\rightarrow$ Constante resultante da transformação de $\mathrm{MeV} / \mathrm{kg}$ para Gy;

- $\quad \rho\left[\mathrm{g} / \mathrm{cm}^{3}\right] \rightarrow$ Densidade usada para modelar o tumor (água);

- $\quad r[\mathrm{~cm}] \rightarrow$ Raio da esfera, correspondendo ao tumor;

- $\quad 0,001[\mathrm{~kg} / \mathrm{g}] \rightarrow$ Conversão de [g] para $[\mathrm{kg}]$.

\subsubsection{MÉTODO POR USO DE UMA FONTE PONTUAL PARA ESTUDOS DE DOSIMETRIA}

O método de uso de uma fonte pontual emissora $\beta^{-}$foi totalmente desenvolvido dentro do programa Excel (versão 2010), pela construção de diversas planilhas. Cada órgão (ou modelo) foi representado por uma planilha do programa. Esses modelos foram constituídos de cubos (ou elementos de unidade de volume). Cada cubo foi representado por uma célula, correspondendo a 1 voxel. Cada voxel foi determinado pelas coordenadas: $x$, y e $z$, para a modelagem desse órgão. Essas coordenadas, foram extraídas a partir do conjunto de equações mostradas na TAB. 10.

Após a construção do corpo do animal no programa, a determinação da dose absorvida foi realizada através de uma fonte pontual, representada pelo tumor, dentro do corpo do camundongo.

A dose absorvida para emissores $\beta^{-}$, foi determinada a partir da seguinte equação:

$$
D_{\beta}[G y]=2,14 \times 10^{4} \cdot \rho^{2} \cdot\left(\frac{\mu}{\rho}\right) \cdot E_{m e d} \cdot \frac{e^{-\left(\frac{\mu}{\rho}\right) \cdot d \cdot \rho}}{4 \cdot \pi \cdot(d \cdot \rho)^{2}}
$$

onde:

- $\quad \rho\left[\mathrm{g}_{\mathrm{cm}} \mathrm{cm}^{-3} \rightarrow\right.$ Densidade do material absorvedor;

- $\quad E_{\text {méd }}[\mathrm{MeV}] \rightarrow$ Energia média da emissão $\beta$;

- $\quad d[\mathrm{~cm}] \rightarrow$ Distância entre fonte/material;

- $\quad(\mu / \rho)\left[\mathrm{cm}^{2} \cdot \mathrm{g}^{-1}\right] \rightarrow$ Probabilidade de interação. 
a probablidade de interação foi determinada por:

$$
\left(\frac{\mu}{\rho}\right)\left[\frac{\mathrm{cm}^{2}}{g}\right]=17\left(E_{\text {máx }}\right)^{-1,14}
$$

a taxa de dose por:

$$
D_{\beta}[G y]=2,14 \times 10^{4} \cdot \rho^{2} \cdot\left(\frac{\mu}{\rho}\right) \cdot A_{\mathrm{int}} E_{m e ́ d} \cdot \frac{e^{-\left(\frac{\mu}{\rho}\right) \cdot d \cdot \rho}}{4 \cdot \pi \cdot(d \cdot \rho)^{2}}
$$

e a atividade acumulada é dada por:

$$
\tilde{A}=A_{0} \cdot\left[\left(\frac{e^{-\lambda \cdot t_{0}}}{\lambda}\right)-\left(\frac{e^{-\lambda \cdot t}}{\lambda}\right)\right]
$$

onde:

- $\tilde{\mathrm{A}}$ [Ci.h] $\rightarrow$ Atividade acumulada em um intervalo de tempo $\Delta \mathrm{t}$;

- $\mathrm{A}_{0}[\mathrm{Ci}] \rightarrow$ Atividade inicial;

- $\lambda\left[\mathrm{h}^{-1}\right] \rightarrow$ Constante de decaimento físico;

- $\Delta \mathrm{t}[\mathrm{h}] \rightarrow$ Tempo decorrido (t-to).

\subsubsection{EXTRAPOLAÇÃO DE DADOS EM ANIMAIS PARA HUMANOS}

Após a determinação das doses absorvidas nos órgãos por meio das duas metodologias apresentadas neste trabalho (Monte Carlo e Fonte Pontual), foi realizada uma extrapolação desses dados, para determinar a possível dose absorvida nas mesmas condições em humanos. A equação que descreveu esta relação está representada pela seguinte equação [STABIN, 2008]:

$$
\left(\frac{\%}{\text { órgão }}\right)_{\text {humano }}=\left[\left(\frac{\%}{g_{\text {órgão }}}\right)_{\text {animal }} \times\left(k g_{\text {corpototal }}\right)_{\text {animal }}\right] \times\left(\frac{g_{\text {órgão }}}{k g_{\text {corpototal }}}\right)_{\text {humano }}
$$


Os dados de referência para as massas dos órgãos de um ser humano de 70 kg, utilizados para os cálculos de extrapolação estão descritos na TAB. 15 [ICRP, 2002].

TABELA 15 - Valores de referência para massa de órgãos, considerando um ser humano pesando $70 \mathrm{~kg}$.

\begin{tabular}{cc}
\hline Órgão & Massa do órgão (g) \\
\hline Glândula Tireóide & 20 \\
Coração & 840 \\
Pulmões & 1200 \\
Rins & 310 \\
Fígado & 1800 \\
Baço & 150 \\
Testículos & 35 \\
Bexiga & 50 \\
Coluna & 1170 \\
\hline
\end{tabular}




\section{RESULTADOS E DISCUSSÃO}

\subsection{PROPRIEDADES FíSICAS DOS RADIONUCLÍDEOS PARA APLICAÇÃO EM} RIT

A FIG. 7 apresenta as curvas de decaimento radioativo dos principais radionuclídeos emissores $\beta^{-}\left({ }^{188} \mathrm{Re},{ }^{90} \mathrm{Y},{ }^{131} \mathrm{I},{ }^{177} \mathrm{Lu}\right)$ e $\alpha\left({ }^{211} \mathrm{At},{ }^{213} \mathrm{Bi},{ }^{223} \mathrm{Ra}\right.$ e $\left.{ }^{225} \mathrm{Ac}\right)$, usados em RIT in vivo, normalizando-se a atividade inicial e o tempo.
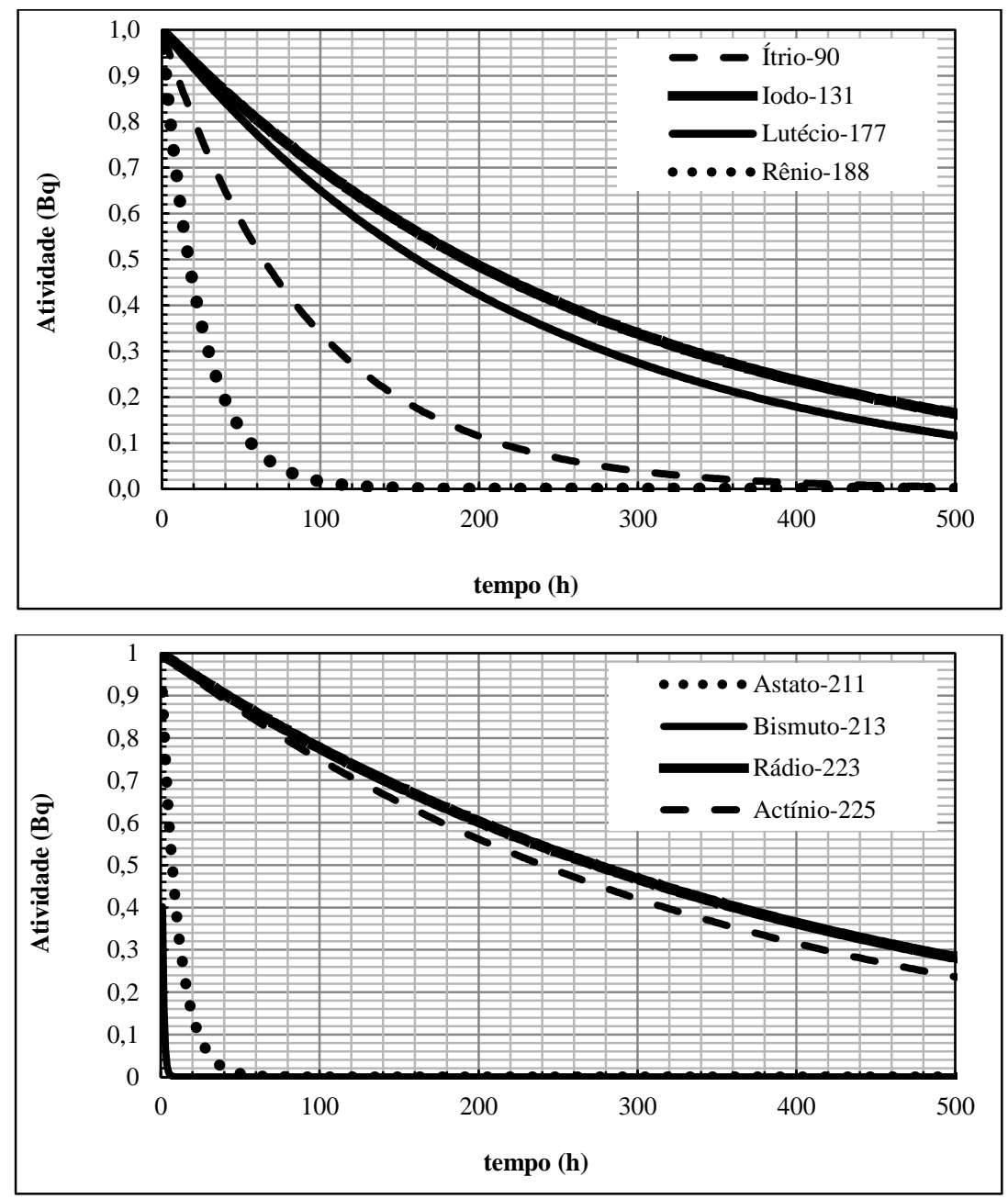

FIGURA 7 - Curvas de decaimento radioativo dos principais radionuclídeos emissores $\beta^{-}$e $\alpha$ usados em RIT, obtidas teoricamente. 
A TAB. 16 mostra os valores obtidos para cada radionuclídeo em relação à sua meia-vida.

TABELA 16 - Radionuclídeos emissores $\beta^{-}$e $\alpha$ e suas respectivas meias-vidas.

\begin{tabular}{cc}
\hline Radionuclídeo & Meia-vida (h) \\
\hline${ }^{90} \mathrm{Y}$ & 64,1 \\
${ }^{131} \mathrm{I}$ & 192,0 \\
${ }^{177} \mathrm{Lu}$ & 161,0 \\
${ }^{188} \mathrm{Re}$ & 16,9 \\
${ }^{211} \mathrm{At}$ & 7,2 \\
${ }^{213} \mathrm{Bi}$ & 0,7 \\
${ }^{223} \mathrm{Ra}$ & 273,6 \\
${ }^{225} \mathrm{Ac}$ & 240,0 \\
\hline
\end{tabular}

Do ponto de vista cinético, dentre os emissores $\beta,{ }^{188} \mathrm{Re}$ apresenta melhores características, visto que a meia-vida biológica proporciona um menor tempo de eliminação do organismo em comparação aos demais radionuclídeos. $\mathrm{O}$ mesmo raciocínio é aplicável para os emissores $\alpha\left({ }^{211} \mathrm{At}\right.$ e $\left.{ }^{213} \mathrm{Bi}\right)$, que apresentam vantagens pela rápida cinética de decaimento radioativo, proporcionando aplicação de doses adequadas aos tecidos. É importante ressaltar que a farmacocinética dos AcM é lenta no corpo humano, portanto um compromisso entre a $t_{1 / 2}$ do radioisótopo e o tempo de máxima captação no tumor é importante.

\subsection{1 ÍTRIO-90}

$\mathrm{O}^{90} \mathrm{Y}\left(\mathrm{E}_{\beta^{-}}=2,28 \mathrm{MeV}, 100 \%, \mathrm{t}_{1 / 2}=64,1 \mathrm{~h}\right)$ é um emissor $\beta^{-}$puro. A alta energia das partículas $\beta$ - do ${ }^{90} Y$ é adequada para o tratamento de tumores volumosos e realização da radiosinovectomia em articulações. Embora a meia-vida física do ${ }^{90} Y$ seja relativamente curta, este problema pode ser resolvido a partir do uso de um gerador de ${ }^{90} \mathrm{Sr} /{ }^{90} \mathrm{Y}$ com produção de ${ }^{90} \mathrm{Y}$ livre de carregador. Existem diversos peptídeos, AcM e particulados marcados com ${ }^{90} \mathrm{Y}$ os quais encontram uso no tratamento de algumas formas de cânceres primários e artrites reumatóides. A 
obtenção do ${ }^{90} Y$ a partir da irradiação neutrônica direta dos alvos de ítrio natural (FIG. 8), apresenta baixa atividade específica, tornando seu interesse limitado ao preparo de radiofármacos particulados para 0 tratamento de carcinomas hepáticos (microesferas) e artrites reumatóides (colóides) [PILLAI \& DAS, 2013].

$$
{ }^{89} Y \stackrel{n, \gamma}{\rightarrow}{ }^{90} Y
$$

FIGURA 8 - Produção alternativa do ${ }^{90} Y$ a partir da irradiação de alvos naturais de ${ }^{89}$ Y.

Uma rota favorável para obtenção de grandes quantidades de ${ }^{90} Y$ é o emprego de um gerador de ${ }^{90} \mathrm{Sr} /{ }^{90} \mathrm{Y}$. Este par de radionuclídeos representa um exemplo típico de equilíbrio secular com um radionuclídeo pai de longa meia-vida física $\left({ }^{90} \mathrm{Sr} ; \mathrm{t}_{1 / 2}=28,78\right.$ anos) e um radionuclídeo filho de meia-vida física relativamente curta $\left({ }^{90} \mathrm{Y} ; \mathrm{t}_{1 / 2}=64,1 \mathrm{~h}\right)$ (FIG. 9). A disponibilidade de um gerador de ${ }^{90} \mathrm{Sr} /{ }^{90} \mathrm{Y}$, capaz de produzir ${ }^{90} \mathrm{Y}$ em grau farmacêutico, em uma radiofarmácia centralizada é suficiente para atender a demanda deste radionuclídeo ao longo dos anos e assim, atender as necessidades dos pacientes que precisam de tratamento com radiofármacos terapêuticos baseados em ${ }^{90}$ Y [PILLAI \& DAS, 2013].

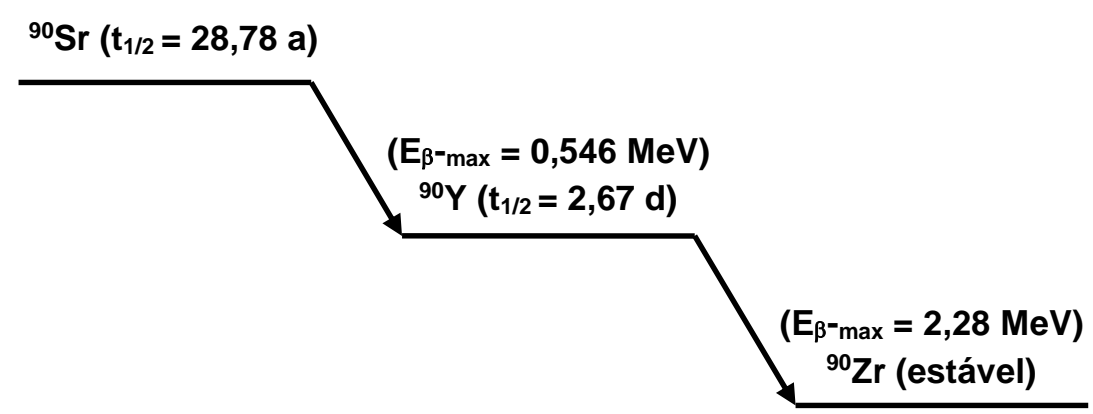

FIGURA 9 - Esquema de produção do ${ }^{90} Y$ a partir do processo de decaimento do ${ }^{90} \mathrm{Sr}$ produzido via reator e seu decaimento para o ${ }^{90} \mathrm{Zr}$ (estável).

\subsubsection{IODO-131}

$\left.\mathrm{O}{ }^{131}\right]\left[\mathrm{t}_{1 / 2}=8,02\right.$ dias; $\mathrm{E}_{\beta \text { máx }}=0,606(90 \%) \mathrm{MeV}, \mathrm{E}_{\gamma}=284 \mathrm{keV}(6,1 \%), 364$ $\mathrm{keV}(81,2 \%)$ e $637 \mathrm{keV}(7,3 \%)]$ é produzido em grandes quantidades como produto de fissão do ${ }^{235} \mathrm{U}$ ou pela ativação de alvos de telúrio natural (FIG. 10). 


$$
\begin{gathered}
{ }^{235} U(n, f){ }^{131} I \\
{ }^{130} \mathrm{Te}(n, \gamma){ }^{131} \mathrm{Te} \stackrel{\beta^{-}}{\rightarrow}{ }^{131} I
\end{gathered}
$$

FIGURA 10 - Produção do ${ }^{131}$ I a partir de dois métodos: como produto de fissão do ${ }^{235} \mathrm{U}$ ou pela ativação de alvos de telúrio natural.

A meia-vida física longa do ${ }^{131}$ I fornece tempo suficiente para produzir os radiofármacos e distribuí-los com perda pequena devido ao decaimento (FIG. 11). É atualmente o radionuclídeo terapêutico mais utilizado e seu uso não é limitado somente às doenças relacionadas à tireóide, extendendo-se para tratamentos de doenças hematológicas como o LNH [PILLAI \& DAS, 2013].

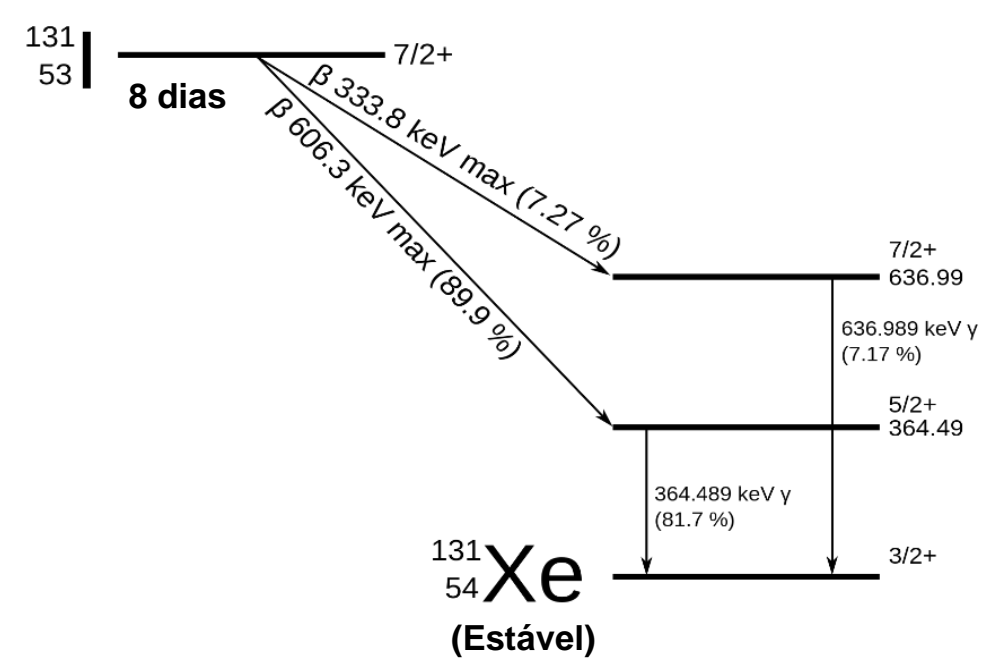

FIGURA 11 - Esquema de decaimento do ${ }^{131}$.

\subsubsection{LUTÉCIO-177}

${ }^{177} \mathrm{Lu}\left[\mathrm{t}_{1 / 2}=6,71\right.$ d; $\mathrm{E}_{\beta \operatorname{máx}}=176 \mathrm{keV}(12 \%), 384 \mathrm{keV}(9 \%)$ e $497 \mathrm{keV}(79 \%) ;$ $\left.E_{\gamma}=113 \mathrm{keV}(6,4 \%), 208 \mathrm{keV}(11 \%)\right]$ pode ser produzido empregando tanto 0 'método direto' (envolvendo ativação neutrônica do $\mathrm{Lu}_{2} \mathrm{O}_{3}$ natural/enriquecido) ou o 'método indireto' (usando $\mathrm{Yb}_{2} \mathrm{O}_{3}$ como o material alvo) (FIG. 12). Embora as atividades específicas obtidas via reações de ativação $(n, \gamma)$ sejam normalmente baixas, a alta seção de choque de captura dos nêutrons térmicos do ${ }^{176} \mathrm{Lu}(\mathrm{n}, \gamma){ }^{177} \mathrm{Lu}$ 
( $\sigma=2065 b)$, garante que ${ }^{177} \mathrm{Lu}$ seja obtido pela irradiação de alvos enriquecidos em reatores de fluxo médio a alto, alcançando atividades específicas adequadas para uso [PILLAI \& DAS, 2013, PILLAI \& KNAPP JR, 2015].

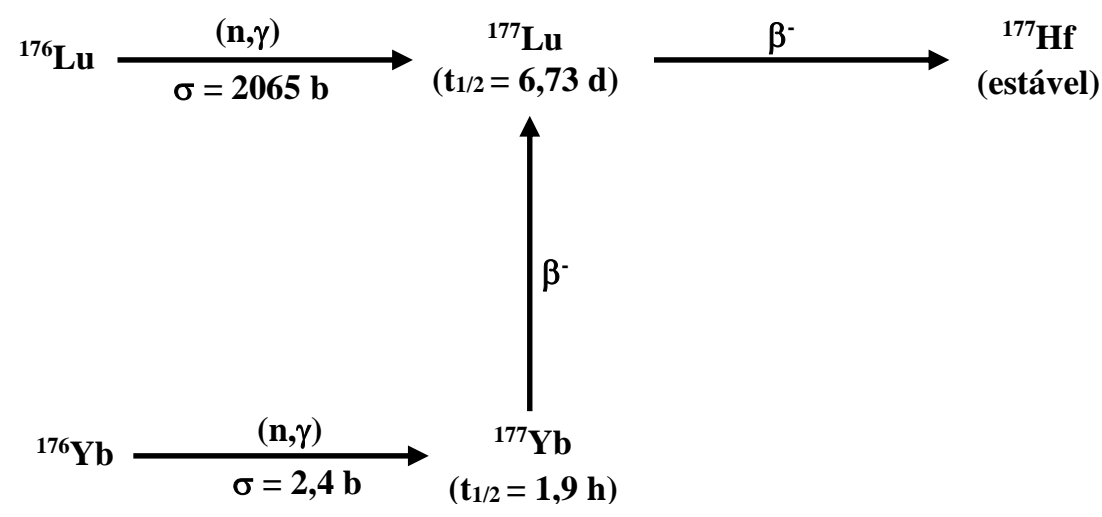

FIGURA 12 - Representação esquemática da produção do ${ }^{177}$ Lu pelo método 'direto' através da irradiação do alvo de ${ }^{176} \mathrm{Lu}$ enriquecido e o método 'indireto' pela irradiação dos alvos de ${ }^{176} \mathrm{Yb}$.

${ }^{177} \mathrm{Lu}$ na sua forma livre de carregador pode ser obtido pela irradiação neutrônica do alvo de ${ }^{176} \mathrm{Yb}$ enriquecido pelo 'método indireto' $(\sigma=2,4 \mathrm{~b})$, importante para a produção do ${ }^{177} \mathrm{Yb}$, o qual sofre emissão de partículas $\beta^{-}\left(\mathrm{t}_{1 / 2}=1,9 \mathrm{~h}\right)$ para produzir ${ }^{177} \mathrm{Lu}$. Umas das vantagens deste tipo de rota de produção, além da obtenção de ${ }^{177} \mathrm{Lu}$ livre de carregador, é a produção do radionuclídeo livre de impurezas radionuclídicas do ${ }^{177 m} \mathrm{Lu}$, cuja presença é inevitável quando ${ }^{177} \mathrm{Lu}$ é produzido via 'método direto'. Quanto ao seu processo de decaimento, ${ }^{177} \mathrm{Lu}$ decai por emissão $\beta^{-}$para o ${ }^{177} \mathrm{Hf}$ (FIG. 13) [PILLAI \& DAS, 2013, PILLAI \& KNAPP JR, 2015].

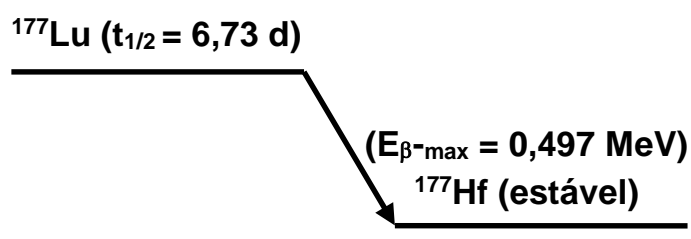

FIGURA 13 - Esquema de decaimento do ${ }^{177} \mathrm{Lu}$. 


\subsubsection{RÊNIO-188}

O uso do ${ }^{188} \operatorname{Re}\left[\mathrm{t}_{1 / 2}=17 \mathrm{~h} ; \mathrm{E}_{\beta \operatorname{máx}}=2,12 \mathrm{MeV}(85 \%) ; \mathrm{E}_{\gamma}=155 \mathrm{keV}(15 \%)\right]$ a partir de um sistema gerador, representa um radionuclídeo alternativo atraente para terapia. ${ }^{188} \mathrm{Re}$ é produzido a partir do decaimento $\beta^{-}$do pai ${ }^{188} \mathrm{~W}$ ( $\mathrm{t}_{1 / 2}=69$ dias). Além da emissão de elétrons de alta energia, ${ }^{188}$ Re também decai por emissão de um fóton gama [IZNAGA-ESCOBAR, 1998; LIU et al, 2003; TORRES-GARCIA et al, 2008; FERRO-FLORES \& MURPHY, 2008].

A produção do ${ }^{188} \mathrm{~W}$ consiste na dupla captura neutrônica de alvos de tungstênio-186 ( $\left.{ }^{186} \mathrm{~W}\right)$. As FIGs. 14 e 15 mostram os esquemas de produção e decaimento do par ${ }^{188} \mathrm{~W} /{ }^{188} \mathrm{Re}$, respectivamente.

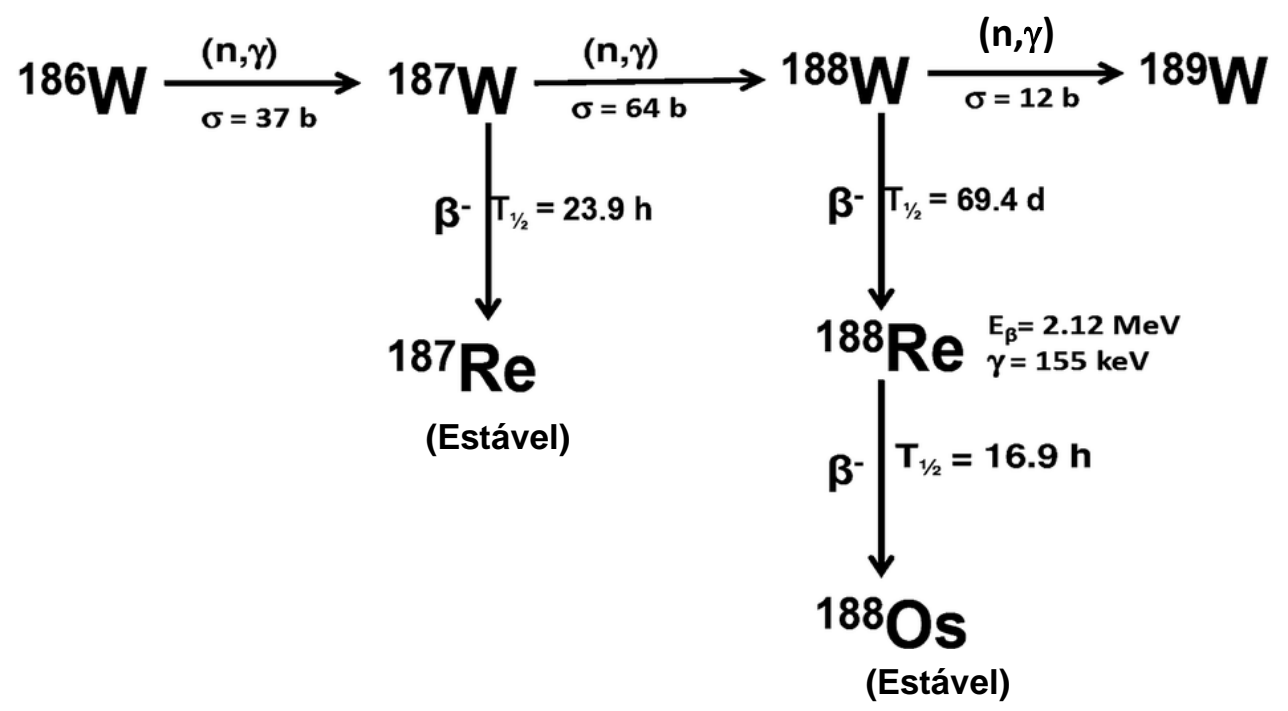

FIGURA 14 - Esquema de produção para o ${ }^{188}$ Re a partir da irradiação do alvo de ${ }^{186} \mathrm{~W}$ enriquecido com nêutrons [DASH \& KNAPP, 2015].

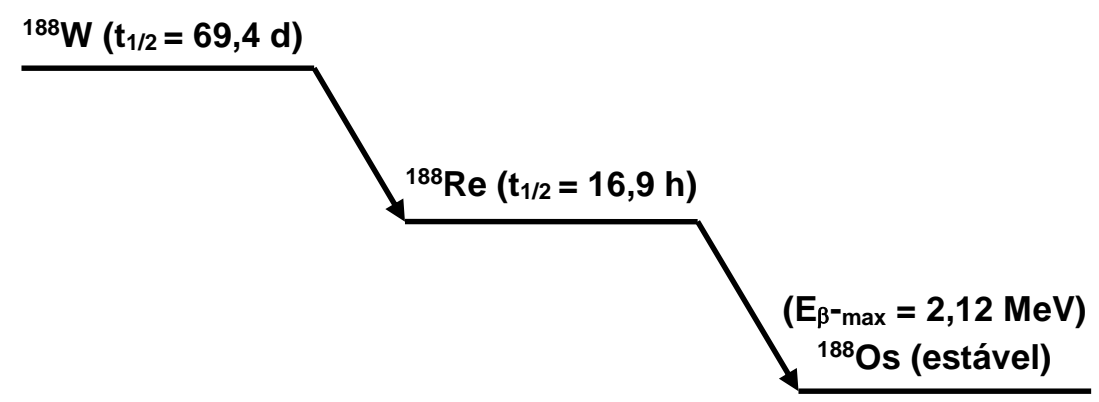

FIGURA 15 - Esquema de produção do ${ }^{188}$ Re a partir do processo de decaimento do ${ }^{188} \mathrm{~W}$ e seu decaimento para o ${ }^{188}$ Os (estável). 
$\mathrm{O}{ }^{188} \mathrm{~W}$ é produzido pela captura inicial de nêutrons do ${ }^{186} \mathrm{~W}$ enriquecido, para a formação de ${ }^{187} \mathrm{~W}$ intermediário, o qual se torna disponível para uma segunda captura de nêutrons formando ${ }^{188} \mathrm{~W}$, que decai com uma meia-vida de 69 dias para o ${ }^{188} \mathrm{Re}$, que por sua vez decai para o ôsmio-188 ( $\left.{ }^{188} \mathrm{Os}\right)$. Devido ao ${ }^{188} \mathrm{~W}$ ser formado pelo processo da dupla captura neutrônica, o fluxo neutrônico térmico deve ser relativamente alto, tornando o rendimento de ${ }^{188} \mathrm{~W}$ proporcional ao quadrado do fluxo de nêutrons. Atualmente, há poucos reatores capazes de produzir ${ }^{188} \mathrm{~W}$ de atividade específica suficientemente alta, necessária para o preparo de geradores comerciais de ${ }^{188} \mathrm{~W} /{ }^{188} \mathrm{Re}$ com base de alumina [PILLAI \& DAS, 2013].

$\mathrm{O}$ método alternativo da produção de ${ }^{188} \mathrm{Re}$ pelo bombardeamento com nêutrons térmicos de alvos de ${ }^{187} \mathrm{Re}$ enriquecidos traz a necessidade de alvos de ${ }^{187} \mathrm{Re}$ altamente enriquecidos e leva à baixa atividade específica do produto resultante, a qual não é suficiente para o desenvolvimento de agentes terapêuticos usando peptídeos e anticorpos. Além disso, a meia-vida física curta torna difícil o transporte para locais mais distantes [PILLAI \& DAS, 2013].

\subsubsection{ASTATO-211}

${ }^{211} \mathrm{At}\left(t_{1 / 2}=7,2\right.$ horas $)$ decai por emissão de partículas $\alpha$ e por uma cascata atinge, no final, o ${ }^{207} \mathrm{~Pb}$ estável (FIG. 16) [ZALUTSKY et al, 2007]. A partícula $\alpha$ produzida pelo decaimento do ${ }^{211}$ At possui uma energia média de $6,7 \mathrm{MeV}(41,8 \%)$ e um LET médio de 97-99 keV/ $\mu \mathrm{m}$. Além disso, o alto LET do ${ }^{211}$ At está próximo ao valor ideal para uma alta EBR. O decaimento por captura eletrônica de um dos filhos intermediários, Polônio-211, é acompanhado pela emissão de raios- $X$, com energias de 77-92 keV. Devido a sua curta meia vida física, radiofármacos com ${ }^{211} \mathrm{At}$ podem ser usados mesmo quando a molécula-alvo não obtém acesso imediato às células do tumor. ${ }^{211} \mathrm{At}$ é produzido pelo bombardeamento do ${ }^{209} \mathrm{Bi}$ com partículas $\alpha$ via cíclotron (FIG. 17), onde o produto é isolado por meio de processos de destilação a seco. Além disso, é menos retido do que os outros radiometais emissores $\alpha$ após internalização do complexo antígeno-anticorpo. ${ }^{211} \mathrm{At}$ é um halogêneo, como ${ }^{131}$, sendo incorporado diretamente ao anticorpo pela ligação conhecida como carbonoastato-arila, dentro do próprio anticorpo [DADACHOVA, 2010; MULDORF et al, 2005, AURLIEN et al, 2000]. 


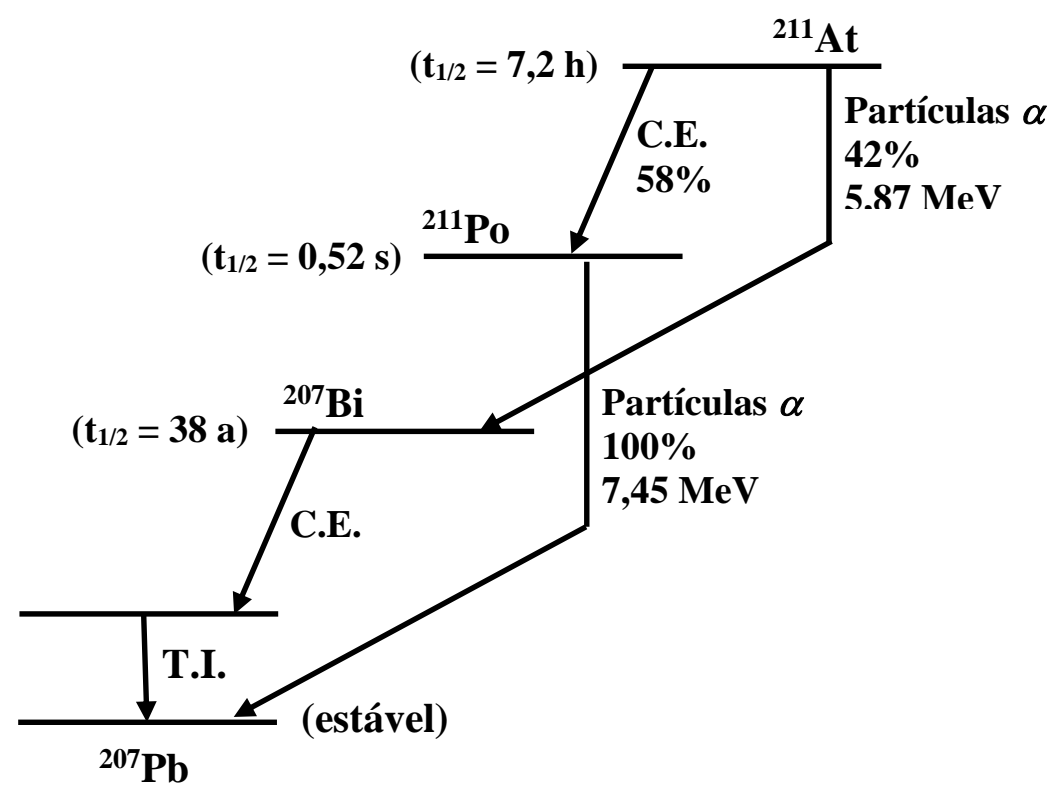

FIGURA 16 - Cascata de decaimento do ${ }^{211} \mathrm{At}$, com decaimento de partículas associadas e meias-vidas.

$$
{ }^{209} \mathrm{Bi} \stackrel{\propto, 2 n}{\longrightarrow}{ }^{211} \mathrm{At}
$$

FIGURA 17 - Produção do ${ }^{211}$ At via cíclotron.

\subsubsection{BISMUTO-213}

$\mathrm{O}{ }^{213} \mathrm{Bi}\left({ }^{213} \mathrm{Bi}, \mathrm{t}_{1 / 2}=45,6\right.$ minutos) é um radiometal que emite partículas $\alpha$ de $8 \mathrm{MeV}$ com uma abundância de $97,9 \%$, sendo obtido para uso clínico a partir da tecnologia de um gerador de ${ }^{225} \mathrm{Ac} /{ }^{213} \mathrm{Bi}$. [ROSENBLAT et al, 2010]. O ${ }^{213} \mathrm{Bi}$ decai para ${ }^{209} \mathrm{Bi}$ estável através da emissão de uma partícula $\alpha$ e duas partículas $\beta^{-}$. Além disso, a emissão de fótons de $440 \mathrm{keV}$ permite estudos de biodistribuição, farmacocinética e de dosimetria [DADACHOVA, 2010, MULDORF et al, 2005].

O potencial terapêutico do ${ }^{213} \mathrm{Bi}$, no tratamento de síndromes neoplásticas de células únicas como leucemia, linfomas e neoplasmas micrometásticos assim como de outros cânceres e síndromes, tornou o desenvolvimento do gerador uma grande prioridade. A FIG. 18 mostra a cascata de decaimento do ${ }^{225} \mathrm{Ac}$ e seus filhos gerados [SGOUROS, 2008; MA et al, 2001]. 


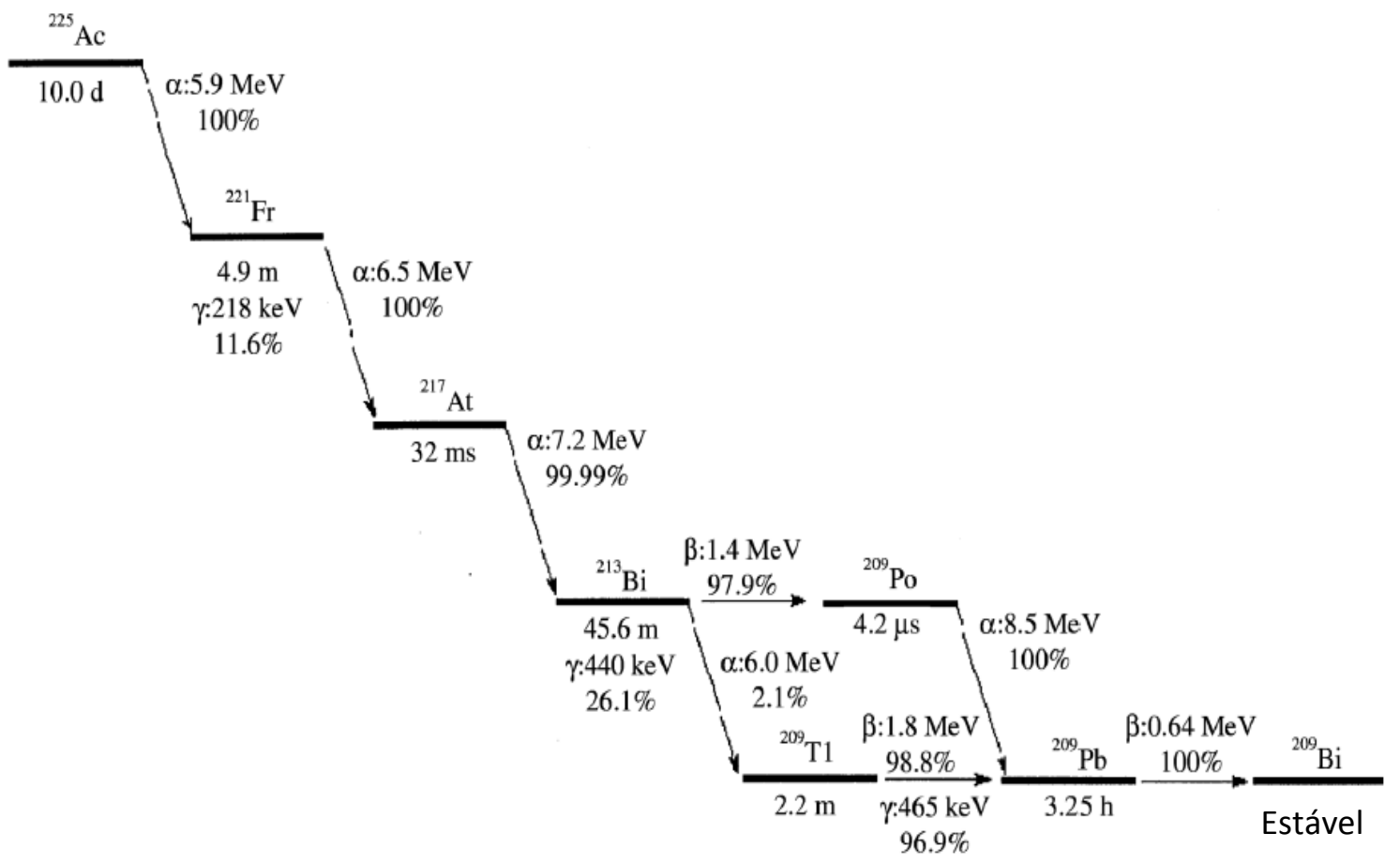

FIGURA 18 - Cascata de decaimento do ${ }^{213} \mathrm{Bi}$ com decaimento de partículas associadas e meias-vidas.

\subsubsection{RÁDIO-223}

O ${ }^{223} \mathrm{Ra}$ ( $\mathrm{t}_{1 / 2}=11,4$ dias), decai por uma cascata de emissores de partículas $\alpha$ e $\beta$ - de meia-vida física curta para o ${ }^{207} \mathrm{~Pb}$ estável, liberando uma energia total de aproximadamente $28 \mathrm{MeV}$ (FIG. 19). A fração de energia emitida de partículas $\alpha$ no decaimento do ${ }^{223} \mathrm{Ra}$ é de $\sim 96 \%$. A longa meia-vida física do ${ }^{223} \mathrm{Ra}$ faz deste emissor o mais adequado para algumas aplicações de RIT, considerando a farmacocinética dos AcM administrados sistemicamente. A vantagem da meia-vida física longa permite um tempo maior para a administração, preparo e envio do conjugado para locais mais distantes [HENRIKSEN et al, 2002]. Similar ao ${ }^{225} \mathrm{Ac}$, o fornecimento de ${ }^{223} \mathrm{Ra}$ é limitado pelo seu método de produção, a partir do decaimento do ${ }^{227}$ Th que é obtido pelo decaimento do isótopo de longa meia-vida física ${ }^{227} \mathrm{Ac}$, produzido pela reação ${ }^{226} \mathrm{Ra}(\mathrm{n}, \gamma){ }^{227} \mathrm{Ac}$. Além disso, o cloreto de ${ }^{223} \mathrm{Ra}$ foi o primeiro radiofármaco emissor $\alpha$ aprovado pelo FDA para terapia de câncer de próstada. Sua distribuição foi interrompida temporariamente pela falta de ${ }^{223} \mathrm{Ra}$ no mercado [MIEDERER et. al, 2008] e restabelecida rapidamente. O seu uso, com o 
nome comercial de $\mathrm{Xofigo}^{\circledR}$, foi autorizado pela ANVISA no Brasil em 2015 de acordo com a RDC 64/2009 [ANVISA, 2015].

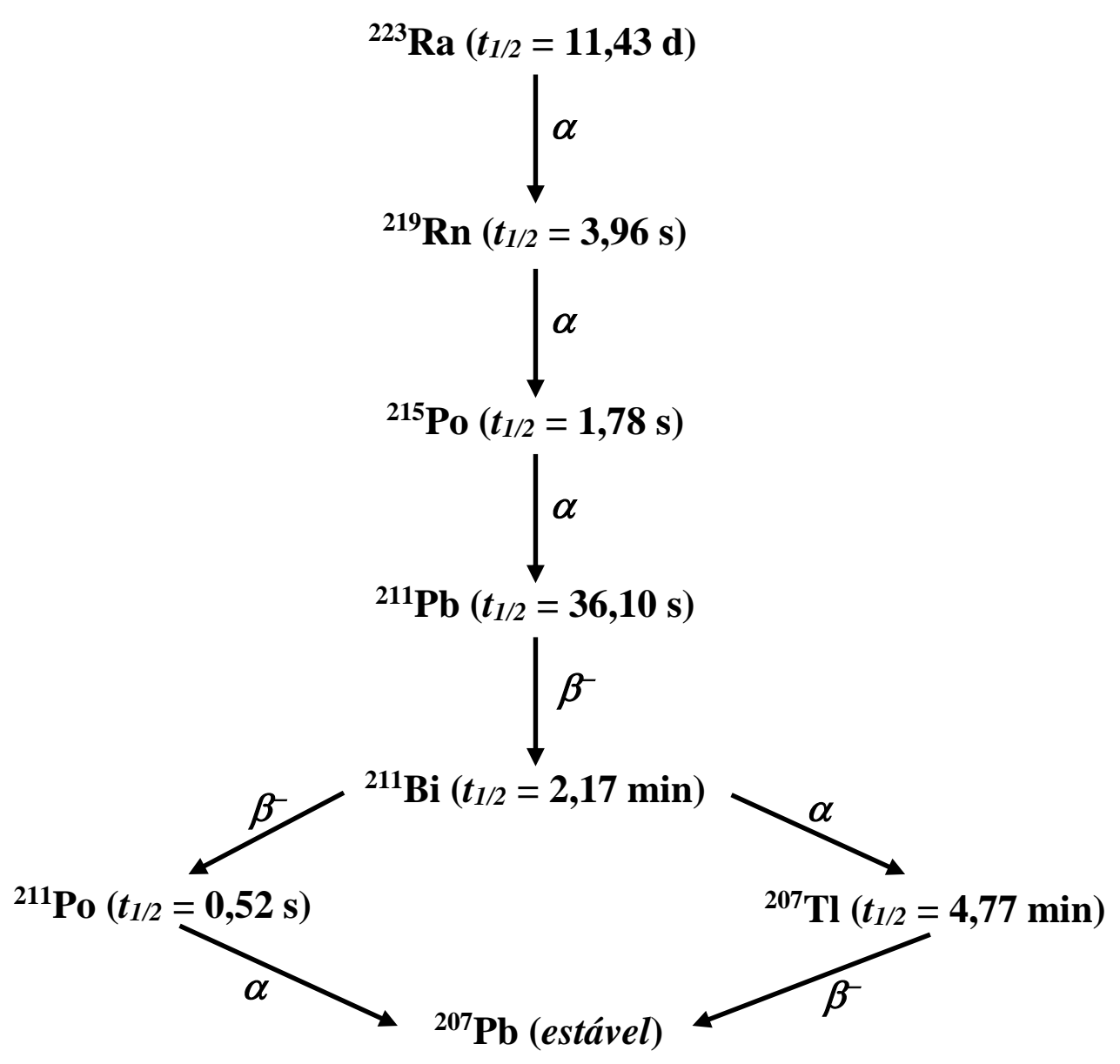

FIGURA 19 - Cascata de decaimento do ${ }^{223}$ Ra com decaimento de partículas associadas e meias-vidas.

\subsubsection{ACTÍNIO-225}

O ${ }^{225} \mathrm{Ac}\left[t_{1 / 2}=10\right.$ dias, $\left.\mathrm{E}_{\alpha}=6,83 \mathrm{MeV}(50,7 \%)\right]$ decai por emissão $\alpha$ gerando os filhos: ${ }^{221} \mathrm{Fr}$ ( $\mathrm{t}_{1 / 2}=4,8 \mathrm{~min}$, partícula $\alpha$ de $6 \mathrm{MeV}$ e emissão $\gamma$ de 218 $\mathrm{keV}),{ }^{217} \mathrm{At}\left(\mathrm{t}_{1 / 2}=32,3 \mathrm{~min}\right.$, partícula $\alpha$ de $\left.7 \mathrm{MeV}\right),{ }^{213} \mathrm{Bi},{ }^{213} \mathrm{Po}\left(\mathrm{t}_{1 / 2}=4,2 \mu \mathrm{s}\right.$, partícula $\alpha$ de $8 \mathrm{MeV}),{ }^{209} \mathrm{TI}\left(\mathrm{t}_{1 / 2}=2,2 \mathrm{~min}\right.$, partícula $\beta$ - de $\left.659 \mathrm{keV}\right),{ }^{209} \mathrm{~Pb}\left(\mathrm{t}_{1 / 2}=3,25 \mathrm{~h}\right.$, partícula $\beta^{-}$de $198 \mathrm{keV}$ ) e ${ }^{209} \mathrm{Bi}$ (estável). Dada a sua meia-vida física de 10 dias, sua emissão de partículas de altas energias e favorável rápido decaimento para o ${ }^{209} \mathrm{Bi}$ estável, fazem deste radionuclídeo um potencial candidato para uso em terapias-alvo. Este radionuclídeo pode ser produzido pelo decaimento natural do ${ }^{235} \mathrm{U}$, pelo decaimento 
$\alpha$ do ${ }^{229}$ Th ou pela reação ${ }^{226} \mathrm{Ra}(\mathrm{p}, 2 \mathrm{n}){ }^{225} \mathrm{Ac}$. [MCDEVITT et. al, 1999, MCDEVITT et. al, 2002]. Sua cascata de decaimento pode ser visualizada através da FIG. 20 [MCDEVITT et. al, 1999].

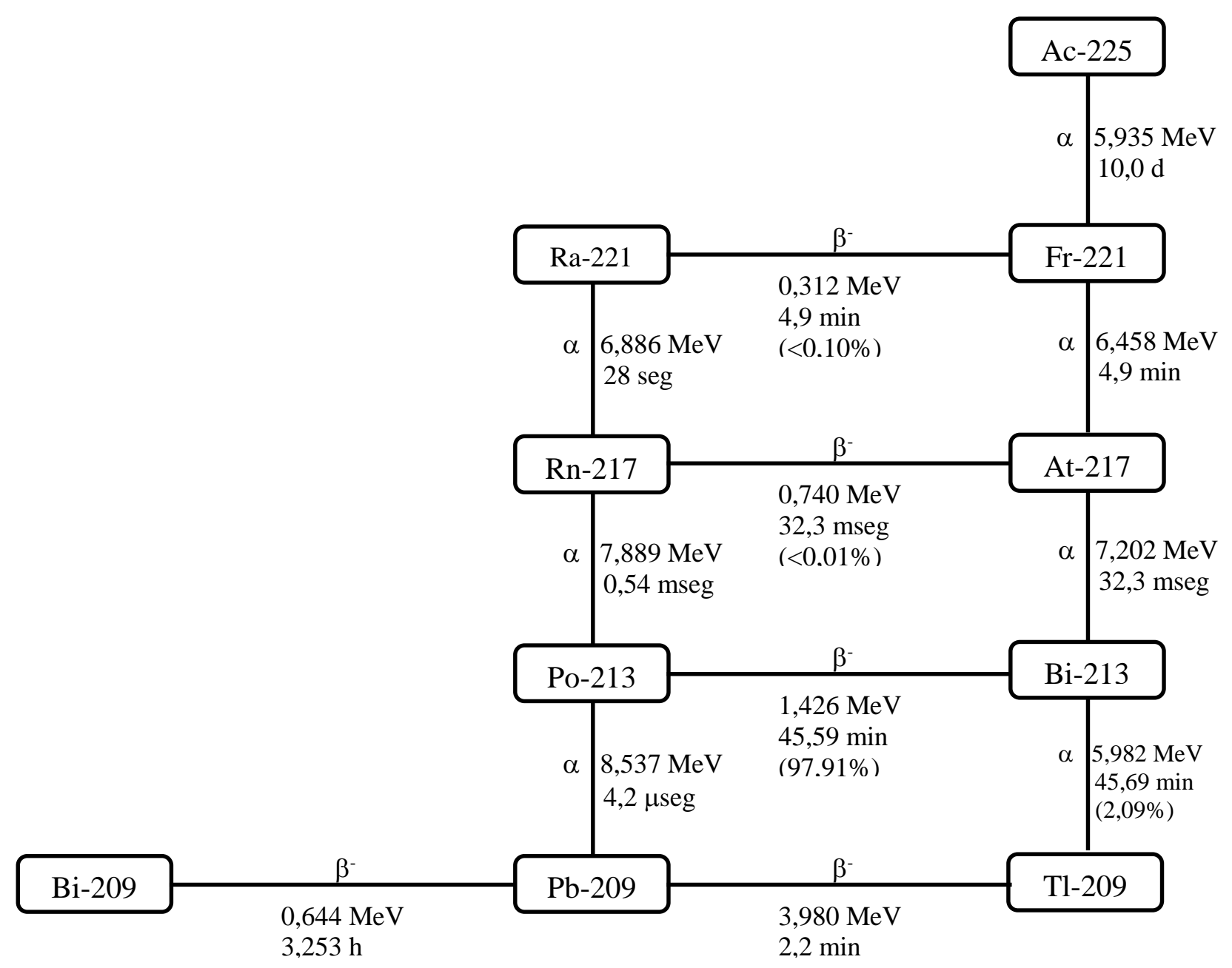

FIGURA 20 - Cascata de decaimento do ${ }^{225} \mathrm{Ac}$ incluindo as partículas associadas e meias-vidas [MCDEVITT et. al, 1999].

\subsubsection{CONSIDERAÇÕES SOBRE AS CARACTERÍSTICAS FÍSICAS DOS RADIONUCLÍDEOS PARA APLICAÇÃO EM RIT}

O ${ }^{90} \mathrm{Y}$ oferece a vantagem da alta energia de partículas, alcance relativamente longo nos tecidos e uma meia-vida física apropriada [IZNAGAESCOBAR, 1998]. Em decorrência da não emissão de raios $\gamma$ no decaimento deste isótopo, a visualização da captação do radiofármaco é muito ruim nas gama câmaras utilizadas em rotina clínica. Por esta razão, um isotopo alternativo $\left({ }^{111} \mathrm{In}\right)$ com uma 
emissão $\gamma$ apropriada e química similar ao radiometal, é usado para permitir a formação de imagens e estudos de biodistribuição para o radiofármaco emissor $\beta^{-}$[MACKLIS, 2007; LIU et. al, 2003; MARCUS, 2006; STANLEY \& GOLDSMITH, 2010]. Suas desvantagens associadas ao uso de AcM são: instabilidade in vivo do quelante levando a liberação de ítrio, com distribuição similar ao íon férrico pós metabolismo, localizando-se no espaço radiosensível da medula e a dificuldade de desenvolvimento de estimativas dosimétricas pela ausência de raios $\gamma$. Baseado nas características físicas de decaimento, ${ }^{90} \mathrm{Y}$ se liga ao Zevalin através de um grupo ligante acoplado ao AcM, formando ligações não covalentes com o radiometal. [IZNAGA-ESCOBAR, 2001].

Embora o ${ }^{131}$ I tenha um alcance adequado para o tratamento de tumores pouco volumosos, a emissão $\gamma$ de $364 \mathrm{keV}$ acompanhada de alta abundância (81\%) é sua principal desvantagem na formação de imagens de excelente qualidade [PILLAI \& DAS, 2013]. Anticorpos marcados com ${ }^{131}$ | tem sido relativamente ineficientes, porque após captação de um AcM radioiodado junto às células do tumor, há uma degradação do anticorpo, com liberação de radioiodo das células do tumor junto ao organismo, resultando na perda da sua ação nas células tumorais e espalhando a radiação aos tecidos normais, com consequente desenvolvimento de mielossupressores. [IZNAGA-ESCOBAR, 1998].

Pelas suas características físicas de emissão, o isótopo apresenta razoável estabilidade de ligação com anticorpo, envolvendo uma ligação covalente. O ${ }^{131}$ I Bexxar, composto pelo anticorpo murino tositumomabe é usado para o mesmo propósito que o ${ }^{90} \mathrm{Y}$-Zevalin. Embora alguns estudos in vitro mostrem aumento da atividade citotóxica para toxitumomabe, o anticorpo quimérico rituximabe sobrevive aparentemente mais na corrente sanguínea e, além disso, é capaz de ativar outros componentes do sistema imunológico [MACKLIS, 2007].

O ${ }^{177} \mathrm{Lu}$ é um radiolantanídeo com uma emissão $\beta^{-}$similar ao ${ }^{131} \mathrm{I}$. Os principais fótons $\gamma$ do ${ }^{177} \mathrm{Lu}$ são mais adequados para formação de imagens do que ${ }^{131}$ [ [RASANEH et. al, 2009]. Sua emissão $\gamma$ é usada para aquisição de imagens in vivo para estudos de biodistribuição e dosimétricos, enquanto que a emissão $\beta$ produz o efeito terapêutico desejado. ${ }^{177} \mathrm{Lu}$ possui diversas vantagens para terapia de radionuclídeos: baixa penetração nos tecidos, danos mínimos aos tecidos circundantes, radiação $\gamma$ de baixa energia e baixa abundância e meia-vida física 
adequada [AUDICIO et al, 2011, LASSMANN \& EBERLEIN, 2015]. Além disso, estudos mostram sua eficácia para uso em terapia teranóstica [DAS \& BANERJEE, 2016].

A energia liberada por unidade de atividade de ${ }^{188} \mathrm{Re}$ é cerca de quatro vezes maior do que a energia liberada do ${ }^{131} \mathrm{l}$, produzindo uma dose de radiação significamente maior direcionada ao tumor. A alta emissão de energia $\beta^{-}$do ${ }^{188} \mathrm{Re}$ é considerada adequada para tumores volumosos por apresentar uma penetração satisfatória nos tecidos, em relação à baixa energia $\beta^{-}$emitida pelo ${ }^{131}$ | [IZNAGAESCOBAR, 1998].

Em virtude da partícula $\alpha$ produzida pelo decaimento do ${ }^{211} \mathrm{At}$ possuir uma energia suficiente e alcance nos tecidos capaz de atingir células de diâmetros curtos, existe uma necessidade mínima de blindagem para pacientes, permitindo a $\alpha$-RIT ser aplicada em bases ambulatoriais. O alto LET de $97 \mathrm{keV} . \mu \mathrm{m}^{-1}$, está próximo ao valor ideal para uma alta eficiência biológica relativa (EBR). Estas características, em conjunto com a capacidade de marcação aos AcM, faz esse imunoconjugado de interesse para a RIT contra células dispersas e micrometástases, decaindo por emissão de partículas $\alpha$, em cascata, atingindo, no final, ${ }^{207} \mathrm{~Pb}$ estável [AURLIEN et al, 2000].

$\mathrm{Na}$ RIT, o ${ }^{213} \mathrm{Bi}$ distribui uma dose de radiação citotóxica ao tumor, destruindo células únicas e micrometástases com toxicidade limitada aos tecidos normais adjacentes. A meia-vida física curta do ${ }^{213} \mathrm{Bi}$ é adequada para alvos de malignidades hematológicas e micrometástases pré-vascularizadas. Devido a sua meia-vida física curta, o radionuclídeo somente é utilizado quando do uso da PRIT, marcando o complexo biotin-AcM. A eficácia da ação destrutiva do ${ }^{213} \mathrm{Bi}$ tem sido relatada em tumores de próstata in vitro e tumores intramusculares in vivo. Em três modelos de camundongos com metástases de câncer de cólon intraperitoneal, pancreático e estômago, anticorpos marcados com ${ }^{213} \mathrm{Bi}$ foram capazes de melhorar as suas taxas de sobrevivência nesses camundongos. A eficácia dos anticorpos marcados com ${ }^{213} \mathrm{Bi}$ para alvo de metástases de pulmão e melanoma foi também relatada por ensaios clínicos mostrando viabilidade e imagem dos anticorpos antiCD33 marcados com ${ }^{213} \mathrm{Bi}$ em terapias-alvo de leucemia mielóide [SONG et al, 2008]. 
O uso de AcM marcados com ${ }^{223} \mathrm{Ra}$, pode levar a uma redistribuição dos nuclídeos filhos em decorrência da difusão do gás nobre ${ }^{219} \mathrm{Rn}$ e dos efeitos de recuo durante o decaimento. Com isso, as partículas $\alpha$ dos três primeiros nuclídeos na cadeia de decaimento são emitidas quase que instantaneamente, contribuindo para a dose de radiação nas proximidades do sítio de decaimento do ${ }^{223} \mathrm{Ra}$. Por isso, ${ }^{223} \mathrm{Ra}$ possui o potencial de direcionar uma dose terapeuticamente relevante ao tumor a partir de uma pequena quantidade de atividade administrada sem causar doses indesejáveis aos tecidos sadios adjacentes [HENRIKSEN et al, 2002]. Similar ao ${ }^{225} \mathrm{Ac}$, o fornecimento de ${ }^{223} \mathrm{Ra}$ é limitado pelo seu método de produção.

Devido à cascata de decaimento $\alpha$ do ${ }^{225} \mathrm{Ac}$, os anticorpos marcados com este radioisótopo são 1000 vezes mais potentes que análogos contendo ${ }^{213} \mathrm{Bi}$. Apesar disso, a possibilidade de radioisótopos filhos livres em circulação após o decaimento do ${ }^{225} \mathrm{Ac}$ levanta interesse na sua potencial toxicidade [MIEDERER et. al, 2008, MCDEVITT et. al, 2002, MULDORF et al, 2005].

\subsection{MARCAÇÃO DO ANTI-CD20 COM RADIONUCLÍDEOS $\alpha$ E $\beta$ -}

Rituximabe (MabThera ${ }^{\circledR}$ ou Rituxan) é um AcM usado em rotina clínica para o tratamento de linfomas (TAB. 17). É humanizado e pode ser detectado no sangue em até 3 meses após sua administração [CAMPBELL \& MARCUS, 2003]. 
TABELA 17 - Comparação da farmacologia dos radiofármacos comerciais preparados com o AcM Anti-CD20, e o próprio imunoterápico Anti-C20 [CAMPBELL \& MARCUS, 2003].

\begin{tabular}{|c|c|c|c|}
\hline & ${ }^{131}$ I tositumomabe & $\begin{array}{l}{ }^{90} \mathrm{Y} \text { ibritumomabe } \\
\text { tiuxetan }\end{array}$ & Rituximabe \\
\hline Antígeno alvo & CD20 & CD20 & CD20 \\
\hline $\begin{array}{l}\text { Tipo de } \\
\text { anticorpo }\end{array}$ & Murino & Murino & $\begin{array}{l}\text { Quimérico } \\
\text { camundongo/humano }\end{array}$ \\
\hline Meia-vida & $8 \operatorname{dias}^{*}\left({ }^{131} I\right)$ & $2,6 \operatorname{dias}^{*}\left({ }^{90} \mathrm{Y}\right)$ & 8 dias $^{\star \star}$ \\
\hline $\begin{array}{l}\text { Eventos } \\
\text { adversos }\end{array}$ & $\begin{array}{l}\text { - Toxicidade devida à } \\
\text { mielosupressão } \\
\text { infusional } \\
\text { - Hipotiroidismo }\end{array}$ & $\begin{array}{l}\text { Toxicidade devido à } \\
\text { mielossupressão } \\
\text { infusional }\end{array}$ & Toxicidade infusional \\
\hline $\begin{array}{l}\text { Modo de } \\
\text { Aplicação }\end{array}$ & $\begin{array}{l}\text { Dosimetria: dose } \\
\text { pequena da droga } \\
\text { uma semana antes da } \\
\text { dose principal }\end{array}$ & $\begin{array}{l}\text { Dosimetria: }{ }^{111} \text { In } \\
\text { ibritumomab tiuxetan } \\
\text { uma semana antes da } \\
\text { dose principal }\end{array}$ & $\begin{array}{l}375 \mathrm{mg} / \mathrm{m}^{2} \text { semana } \\
\text { por } 4 \text { semanas }\end{array}$ \\
\hline Cuidados & $\begin{array}{l}\text { Implicações na } \\
\text { medula óssea }\end{array}$ & $\begin{array}{l}\text { Implicações na } \\
\text { medula óssea }\end{array}$ & $\begin{array}{l}\text { Células tumorais } \\
\text { circulantes }\end{array}$ \\
\hline
\end{tabular}

A conjugação de radioisótopos emissores $\beta^{-}$a um AcM (radioimunoconjugado), Ihe confere a capacidade de distribuir a radiação, não somente para áreas compostas exclusivamente de células do linfoma CD20-positivo, mas também para infiltração em células linfomatosas vizinhas, onde o anticorpo não encontra acesso ou não é ligado ao antígeno. O conhecimento sobre os mecanismos de resistência do rituximabe tem auxiliado no desenvolvimento de novos anticorpos, alguns dos quais tem entrado em ensaios clínicos em fase avançada em humanos. Anticorpos Anti-CD20 podem ser divididos em Tipo I e Tipo II, baseados nos efeitos epítopos e de ligação. A maioria das moléculas de Anti-CD20 descritas na literatura são anticorpos do Tipo I, que estabiliza o CD20 em grandes quantidades de lipídeos, induzindo a CDC com diminuta à apoptose in vitro. Dentre os exemplos estão o próprio rituximabe, ofatumomabe, veltuzumabe e ocrelizumabe. Em contraste, os anticorpos Tipo II não localizam o CD20 dentro das grandes quantidades de lipídeos e somente induzem fracamente a CDC, com elevados níveis de apoptose. Os 
anticorpos Anti-CD20 de Tipo II mais amplamente estudados são tositumomabe e o anticorpo GA-101 [REZVANI et al, 2011]. As TABs. 18 e 19 resumem as principais metodologias de marcação com AcM com radionuclídeos emissores $\beta^{-}$e $\alpha$ promissores para RIT.

TABELA 18 - Metodologias de marcação com AcM com radionuclídeos emissores $\beta^{-}$promissores para RIT.

\begin{tabular}{|c|c|c|c|c|}
\hline Radionuclídeo & Metodologia de Marcação & Aplicação & $\begin{array}{l}\text { Rendimento de } \\
\text { Marcação }\end{array}$ & Referência \\
\hline${ }^{177} \mathrm{Lu}$ & 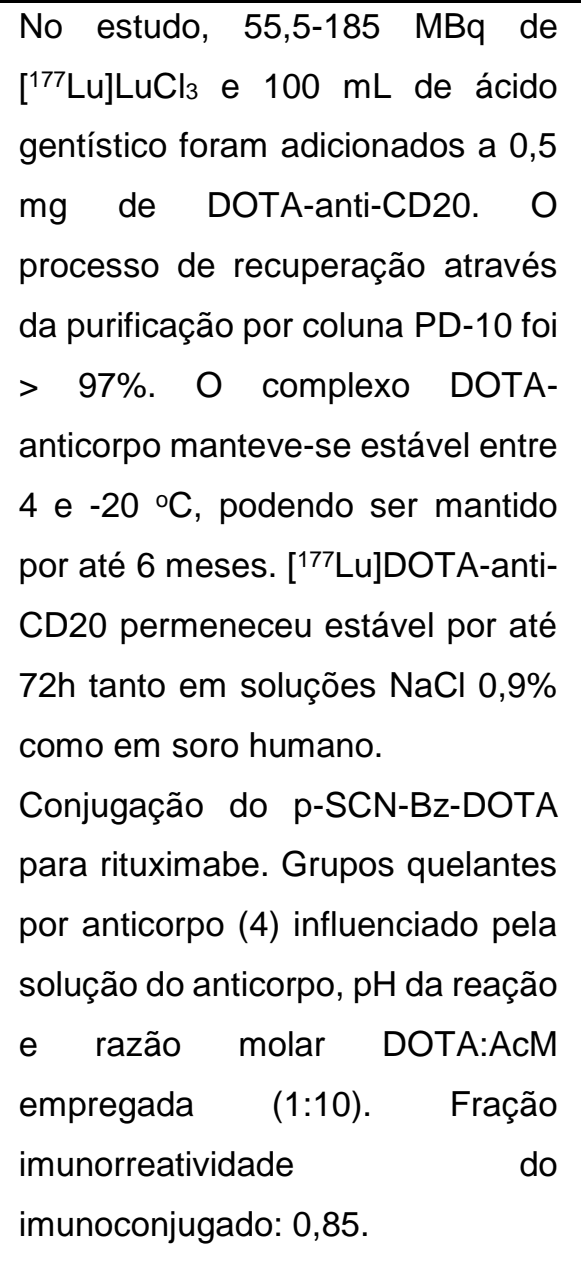 & LNH & $\begin{array}{c}75 \%-79 \% \\
>95 \%\end{array}$ & $\begin{array}{l}\text { AUDICIO et. al, } \\
2011 . \\
\text { FORRER et al, } \\
2009 .\end{array}$ \\
\hline${ }^{188} \mathrm{Re}$ & $\begin{array}{l}\text { Núcleo de tricarbonila; método } \\
\text { direto de marcação - tecnologia } \\
\text { IsoLink } \\
{\left[{ }^{99 m} \mathrm{Tc}(\mathrm{CO})_{3}\right]^{+} \text {e }\left[{ }^{188} \operatorname{Re}(\mathrm{CO})_{3}\right]^{++} \text {anti- }} \\
\mathrm{CD} 20 \\
{ }^{188} \mathrm{Re}(\mathrm{CO})_{3}-\mathrm{RTX} \mathrm{X}_{\text {red } \quad \text { purificado: }} \\
\text { estudos in vitro e in vivo } \\
{ }^{188} \mathrm{Re}(\mathrm{CO})_{3}-\mathrm{RTX} \text { red não purificado: } \\
\text { estudos in vitro e in vivo }\end{array}$ & LNH & $\begin{array}{c}\text { RTX } \mathrm{X}_{\text {red: }}: 98 \% \\
\left({ }^{99 m T c)}\right. \\
\text { após 3h } \\
\text { RTX } \text { red: }^{83} \% \\
\left({ }^{188} \mathrm{Re}\right) \\
\text { após } 48 \mathrm{~h}\end{array}$ & $\begin{array}{c}\text { DIAS, 2010; } \\
\text { DIAS et al, } \\
2011 .\end{array}$ \\
\hline
\end{tabular}


TABELA 19 - Metodologias de marcação com AcM com radionuclídeos emissores $\alpha$ promissores para RIT.

\begin{tabular}{|c|c|c|c|c|}
\hline Radionuclídeo & Metodologia de Marcação & Aplicação & $\begin{array}{l}\text { Rendimento de } \\
\text { Marcação }\end{array}$ & Referência \\
\hline${ }^{211} \mathrm{At}$ & $\begin{array}{l}\text { Estudos in vivo com células RAEL } \\
\text { e K422, incubadas com }{ }^{211} \text { At- } \\
\text { rituximabe, passando por ensaio } \\
\text { clonogênico para análise de } \\
\text { sobrevivência. A incubação foi de } 1 \\
\mathrm{~h} \text {, em concentrações de } 50 \\
\mathrm{kBq} / \mathrm{mL} \text {. Estudos de biodistribuição } \\
\text { do }{ }^{211} \text { At-rituximabe } \\
\text { camundongos (linhagem Balb/c) } \\
\text { mostrou similaridade com o } \\
\text { rituximabe. }\end{array}$ & LNH & $36 \%$ & $\begin{array}{c}\text { AURLIEN et al, } \\
2000 .\end{array}$ \\
\hline${ }^{213} \mathrm{Bi}$ & $\begin{array}{l}\text { 2-10 } \mathrm{mL} \text { de } 3 \mathrm{mg} / \mathrm{mL} \text { de DOTA- } \\
\text { biotin foi adicionado ao }{ }^{213} \mathrm{Bi} \text { eluído } \\
\text { e reagido por } 5 \text { min. à } 80^{\circ} \mathrm{C} \text {. A } \\
\text { mistura foi resfriada em } \\
\text { temperatura ambiente em } 10 \mathrm{~mL} \\
\text { de DTPA } 100 \mathrm{mM} \text {. Após } 2 \text { min, } 100 \\
\mathrm{~mL} \text { de } \mathrm{NaOH} 1 \mathrm{M} \text { foi adicionado } \\
\text { para neutralizar o } \mathrm{pH} \text {. Para o } \\
\text { anticorpo marcado diretamente, } \\
200-500 \mathrm{~mL} \text { de } 1 \mathrm{~F} 5-\mathrm{CHX}-\mathrm{A} "(3,7 \\
\mathrm{mg} / \mathrm{mL}) \text { ou HB8181-CHX-A" (5,9 } \\
\mathrm{mg} / \mathrm{mL} \text { ) foi adicionado ao }{ }^{213} \mathrm{Bi} \\
\text { eluído, reagindo durante } 5 \text { min em } \\
\text { temperatura ambiente. A mistura } \\
\text { passou para uma coluna PB-10 } \\
\text { equilibrada em PBS. A proteína } \\
\text { contendo frações foi combinada e } \\
\text { diluída para o volume final de } \\
\text { injeção em PBS. }\end{array}$ & LNH & $\begin{array}{c}\text { [213Bi]DOTA-biotin: } \\
\text { 82\%-98\% } \\
\text { [133i]-CHX-A": } \\
94 \%-97 \%\end{array}$ & $\begin{array}{l}\text { PARK et al, } \\
2010 .\end{array}$ \\
\hline${ }^{225} \mathrm{Ac}$ & $\begin{array}{l}\text { Radiomarcação do }{ }^{225} \mathrm{Ac} \text { para RIT } \\
\text { conjugando o } \quad \text { anticorpo } \\
\text { representativo com } 2 \text { formas de } \\
\text { DOTA }\end{array}$ & $\begin{array}{c}\text { Vários } \\
\text { tipos } \\
\text { de câncer }\end{array}$ & $>80 \%$ & $\begin{array}{c}\text { MAGUIRE et al, } \\
2014 .\end{array}$ \\
\hline
\end{tabular}




\subsection{1 ${ }^{177}$ Lu-ANTI-CD20}

Audicio e colaboradores [2011] descreveram a radiomarcação do AntiCD20 com ${ }^{177} \mathrm{Lu}$ por meio da conjugação com DOTA (ácido tetraacético- N"', N', N, ciclododecano-N 1, 4, 7, 10-tetraaza) para tratamento de LNH. Comparado com outros agentes bifuncionais como o DTPA, o DOTA forma complexos mais estáveis tanto in vivo como in vitro. O processo de recuperação através da purificação por uma coluna do tipo PD-10 foi maior que $97 \%$. O complexo DOTA-anticorpo mantevese estável entre 4 e $-20^{\circ} \mathrm{C}$, podendo ser mantido por até 6 meses. $O$ rendimento de marcação permaneceu entre $75 \%$ e $79 \%$ e sua pureza radioquímica foi superior a $97 \%$. A maior atividade específica obtida para uso clínico foi de $300 \mathrm{MBq} / \mathrm{mg}$. Pelos estudos de biodistribuição realizados em camundongos CD-1, as principais rotas de eliminação foram o sistema urinário e hepato-biliar.

Forrer e colaboradores [2009], descreveram em detalhes a metodologia para a conjugação do $p$-SCN-Bz-DOTA para rituximabe. Os resultados mostraram que o número de grupos quelantes por anticorpo foi influenciado pela concentração da solução do anticorpo, $\mathrm{pH}$ da reação e a razão molar DOTA:AcM empregada. ${ }^{177}$ Lu-DOTA-Rituximabe foi obtido em alto rendimento radioquímico (> 95\%) quando o anticorpo foi conjugado para DOTA usando $100 \mathrm{mg} / \mathrm{mL}$ como concentração final de anticorpo e razão molar AcM:DOTA de 1:10. Nesta condição de reação, o número de grupos quelantes por anticorpo foi 4 e a fração de imunorreatividade do imunoconjugado marcado foi 0,85 .

\subsection{2 ${ }^{188}$ Re-ANTI-CD20}

A alta estabilidade química relativa dos precursores permite a radiomarcação sob condições moderadas e fisiológicas, adequadas para a marcação de moléculas sensíveis a temperatura tais como as proteínas. A localização do rênio no Grupo VIla, diretamente abaixo do tecnécio na tabela periódica, resulta no potencial para ${ }^{188} \mathrm{Re}$ ser usado como um "parceiro" terapêutico ao ${ }^{99 \mathrm{~m}} \mathrm{Tc}$, usado para diagnóstico. A "similaridade" das propriedades químicas do perrenato e do pertecnetato sugere que, métodos químicos para a radiomarcação do 99mTc às proteínas, como o método de radiomarcação direta, pode ser usada também para ligar o ${ }^{188}$ Re a AcM [IZNAGA-ESCOBAR, 2001]. 
Embora as propriedades químicas do rênio e tecnécio sejam similares, elas não são idênticas. Por exemplo, especificando o potencial de redox do rênio é menor que do tecnécio (Eq. 23):

$$
\begin{gathered}
\mathrm{TcO}_{4}^{-}+4 \mathrm{H}^{+}+3 e^{-} \rightarrow \mathrm{TcO}_{2}+2 \mathrm{H}_{2} \mathrm{OU}=0,738 \mathrm{~V} \\
\mathrm{ReO}_{4}^{-}+4 \mathrm{H}^{+}+3 e^{-} \rightarrow \mathrm{ReO}_{2}+2 \mathrm{H}_{2} \mathrm{OU}=0,510 \mathrm{~V}
\end{gathered}
$$

A diferença de $228 \mathrm{mV}$ no potencial de redox mostra que, complexos de Re são termodinamicamente mais estáveis nos seus altos níveis de oxidação, do que os análogos de Tc correspondentes. Rênio também forma espécies aniônicas estáveis de $\mathrm{ReO}_{4}^{-}$(perrenato) e não se liga a ligantes orgânicos, sem redução a baixos níveis de oxidação. Para o mesmo perrenato, é mais difícil reduzir que o pertecnetato, sendo este re-oxidado mais facilmente [IZNAGA-ESCOBAR, 2001].

$O$ baixo poder de oxidação do perrenato se comparado ao pertecnetato, pode fazer com que o rênio tenha dificuldades para ser reduzido a baixos níveis de oxidação $\operatorname{Re}\left(4^{+}\right)$e $\operatorname{Re}\left(5^{+}\right)$. Foi teorizado que é necessário um agente redutor para produzir uma espécie de rênio catiônica que é então quelado com ligantes. A redução do ${ }^{188} \mathrm{ReO}_{4}^{-}$geralmente é realizada pela adição do $\mathrm{SnCl}_{2}$ em solução ácida. Entretanto, devido a rápida reação reversível de redox do $\mathrm{Re}^{7+}, \mathrm{Re}^{5+}$ e $\mathrm{Re}^{4+}$ (em comparação a reação de redox de análogos de Tc), uma concentração consideravelmente alta de $\mathrm{SnCl}_{2}$ é necessária para a radiomarcação com ${ }^{188} \mathrm{Re}$ [IZNAGA-ESCOBAR, 2001].

Métodos de marcação têm sido reportados mostrando a vantagem que ${ }^{99 m \mathrm{Tc}}\left(t_{1 / 2}=6 \mathrm{~h} ; \mathrm{E}_{\gamma}=140 \mathrm{keV}\right) \mathrm{e}^{188} \mathrm{Re}$ representam como um par de radionuclídeos atrativos para uso médico, em virtude de suas propriedades favoráveis de decaimento para diagnóstico e terapia, além da sua disponibilidade local, graças aos sistemas geradores de ${ }^{99} \mathrm{Mo} /{ }^{99 m} \mathrm{Tc}$ e ${ }^{188} \mathrm{~W} / 188 \mathrm{Re}$ correspondentes. [IZNAGAESCOBAR, 2001, MÜLLER et al, 2007, THIEME et. al, 2011].

Um estudo mostrou que o uso do núcleo de tricarbonila pode ser uma estratégia promissora e adequada para a radiomarcação de anticorpos com ${ }^{188} \mathrm{Re}$. Nosso grupo de pesquisa do IPEN-CNEN/SP mostrou um procedimento de radiomarcação do anticorpo comercial rituximabe Anti-CD20 com [ $\left.{ }^{99 \mathrm{~m}} \mathrm{Tc}(\mathrm{CO})_{3}\right]^{+} \mathrm{e}$ $\left[{ }^{188} \mathrm{Re}(\mathrm{CO})_{3}\right]^{+}$como sendo uma alternativa potencial para o sistema ${ }^{111} \mathrm{In} /{ }^{90} \mathrm{Y}$-Zevalin, 
usado para diagnóstico e terapia de tumores de LNH. Os resultados obtidos mostraram que rituximabe pode ser marcado diretamente e estavelmente com o par combinado ${ }^{99 \mathrm{~m}} \mathrm{Tc} /{ }^{188} \mathrm{Re}$ usando a tecnologia IsoLink usando núcleos de carbonila com retenção da atividade biológica. A eficiência de radiomarcação do $\mathrm{RTX}$ red foi de $98 \%\left({ }^{99 m} \mathrm{Tc}\right)$ após um período de $3 \mathrm{~h}$ e $83 \%\left({ }^{188} \mathrm{Re}\right)$ após um período de $48 \mathrm{~h}$.

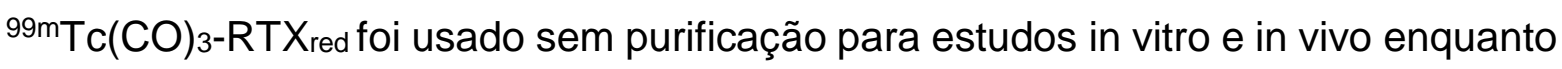
que ${ }^{188} \mathrm{Re}(\mathrm{CO}){ }^{3-} \mathrm{RTX}$ red foi purificado para eliminar ${ }^{188} \mathrm{Re}$ livre. A captação tumoral do ${ }^{188} \mathrm{Re}(\mathrm{CO}){ }^{3-} \mathrm{RTX}$ red foi de $2,5 \% \mathrm{DI} / \mathrm{g}$ e 0,8\% DI/g para ${ }^{99 \mathrm{~m} T c(C O)}{ }_{3}-\mathrm{RTX}$ red $48 \mathrm{~h}$ após injeção. Os valores para outros órgãos e tecidos foram similares para ambos os compostos [DIAS, 2010; DIAS et. al, 2011].

\subsection{3 ${ }^{211}$ At-ANTI-CD20}

Aurlien e colaboradores [2000] mostraram um estudo in vitro com ${ }^{211} \mathrm{At}-$ rituximabe, com duas linhagens de células de linfoma-B, RAEL e K422, e células normais progenitoras hematopoiéticas de aspirados da medula óssea humana. As células foram incubadas com ${ }^{211}$ At-rituximabe, passando por ensaio clonogênico para análise de sobrevivência. O radioimunoconjugado foi incubado em temperatura ambiente durante 1-2 h, com cerca de $10^{7}$ células em $0,3 \mathrm{~mL}$ de meio. Uma média de $36,4 \%$ do anticorpo marcado ligou-se às células RAEL antígeno-positivas, correspondendo a uma fração de imunorreatividade de 50-60\%. Estudos de biodistribuição do ${ }^{211} \mathrm{At}$-rituximabe em camundongos mostrou similaridade com o ${ }^{125}$ rituximabe, com altos níveis de atividade inicial no sangue e em tecidos de alta irrigação sanguínea.

\section{$5.2 .4{ }^{213} \mathrm{Bi}-\mathrm{ANTI}-\mathrm{CD} 20$}

Park e colaboradores [2010] demonstraram para RIT de pré-alvos (PRIT) o uso do ${ }^{213} \mathrm{Bi}$ conjugado ao anticorpo estreptadivina para o tratamento de $\mathrm{LNH}$, permitindo rápida radiomarcação e localização específica no local do tumor. Camundongos tratados para PRIT com Anti-CD20 e $600 \mu \mathrm{Ci}(2,22 \mathrm{MBq})$ de [ $\left.{ }^{213} \mathrm{Bi}\right]$ DOTA-biotina exibiram uma captação tumoral crescente, mostrando favorável perfil de biodistribuição e excelente eficácia terapêutica. 


\subsection{5 ${ }^{225}$ AC-ANTI-CD20}

Maguire e colaboradores [2014], estudaram o processo de radiomarcação do ${ }^{225} \mathrm{Ac}$ para RIT conjugando o anticorpo representativo com 2 formas de DOTA, bem como demais agentes quelantes como controle, devido a dificuldades encontradas em busca de quelantes adequados para ligá-lo de forma estável. Foram desenvolvidas condições para radiomarcar em 1 procedimento químico, caracterizar sua estabilidade, imunorreatividade, biodistribuição e eficácia terapêutica em camundongos saudáveis e portadores de tumores. O anticorpo acoplado ao DOTA, foi radiomarcado em uma ampla faixa de atividades a $37^{\circ} \mathrm{C}$. Os produtos mantiveram imunorreatividade e foram estáveis ao soro em estudos in vitro em camundongos. A cinética de marcação do anticorpo-DOTA construído ligado ao grupo quelante benzil isotiocianato foi mais favorável que ligado a grupos $\mathrm{N}$-hidroxisucinimidas [MAGUIRE et al, 2014].

\subsection{AVALIAÇÃO DA FARMACOCINÉTICA DO ANTI-CD20}

A FIG. 21 mostra ajustes individuais para o sangue obtidos após determinação das constantes $\mathrm{k}$ de eliminação, para cada produto avaliado, através do MONOLIX (considerando $\mathrm{n}=5$ simulações), realizados a partir de estudos de biodistribuição do AcM Anti-CD20 marcado com diferentes radionuclídeos, por diferentes métodos de marcação extraídos de literatura: Emissores $\beta:{ }^{188} \mathrm{Re},{ }^{177} \mathrm{Lu}$,

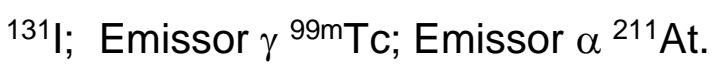



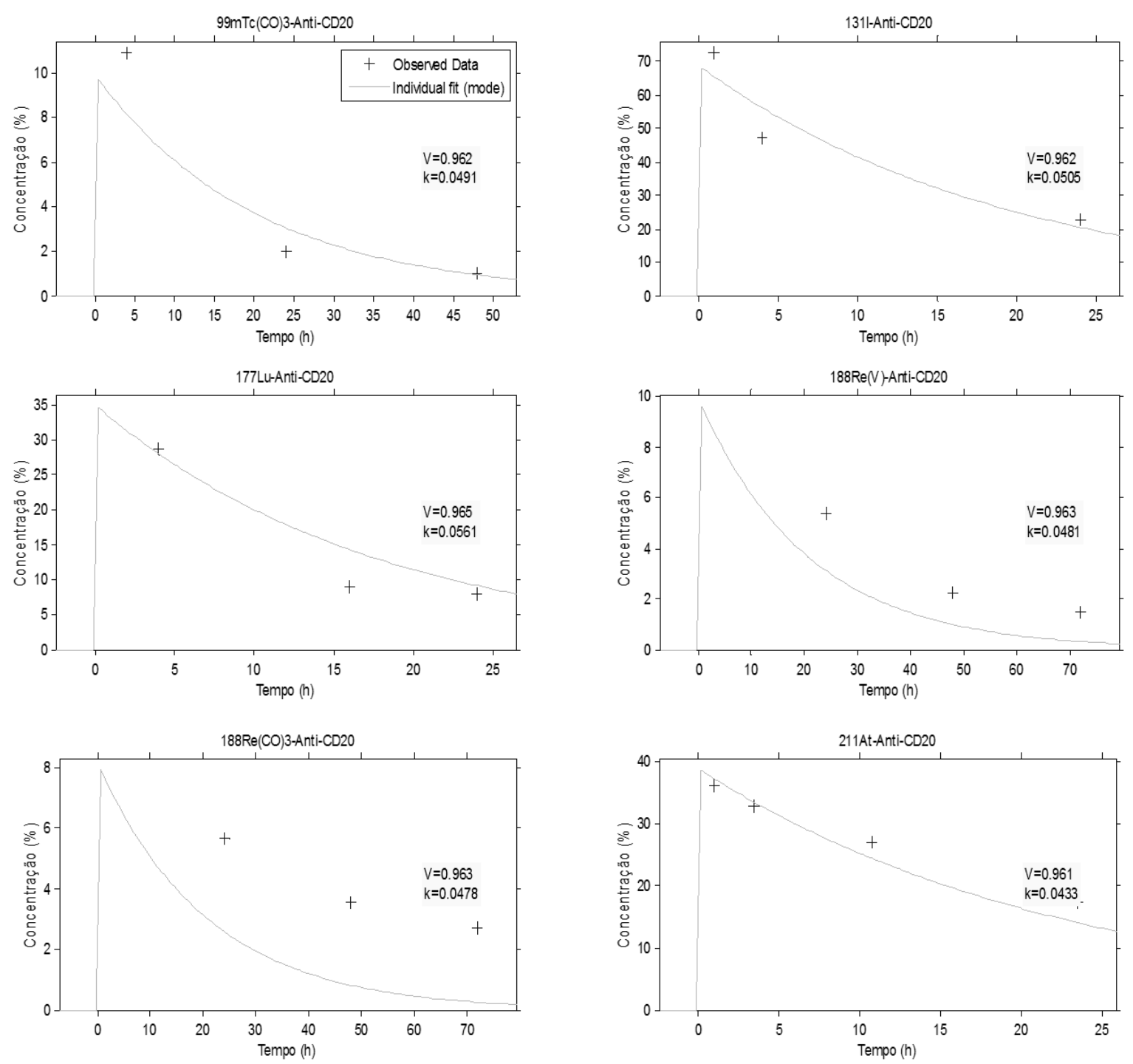

V - Volume de distribuição $\mathrm{K}$ - Constante de eliminação

FIGURA 21 - Ajustes das curvas de concentração do AcM Anti-CD20 marcado com os radionuclídeos, no sangue de animais, em função do tempo: ${ }^{188} \mathrm{Re}$ (com dois métodos de marcação) [DIAS, 2010]; ${ }^{177} \mathrm{Lu}$ [AUDICIO et al, 2011]; ${ }^{131}$ I [AKANJI, 2006], ${ }^{99 m}$ Tc [DIAS, 2010] e e11 At [AURLIEN et al, 2000].

De acordo com os resultados, a constante $\mathrm{k}$ média, de eliminação dos radiofármacos com Anti-CD20 para o sangue foi de aproximadamente $0,05 \mathrm{~h}^{-1}$, o que corresponde a um tempo de meia-vida de 14 horas em camundongos. O volume de distribuição $(K)$ para todos os produtos foram similares, com um valor médio de 0,963 . O valor de $k$ para ${ }^{188} \mathrm{Re}-A n t i-C D 20$ foi satisfatório, indicando eficácia no processo de marcação apresentado em literatura. Esses resultados mostram que os produtos apresentados pelo FDA que apresentam farmacocinética já conhecida e, 
outros radionuclídeos, indicam valores próximos, confirmando que não gouve problemas no processo de marcação.

Os valores satisfatórios de $\mathrm{k}$ encontrados para todos os produtos marcados é justificado pela FIG. 22, onde mostra os coeficientes de correlação calculados, relacionados com os valores da concentração da dose injetada do anticorpo marcado com os radionuclídeos no animal, através dos dados de biodistribuição extraídos de estudos de literatura e previstos por processos de simulação. 

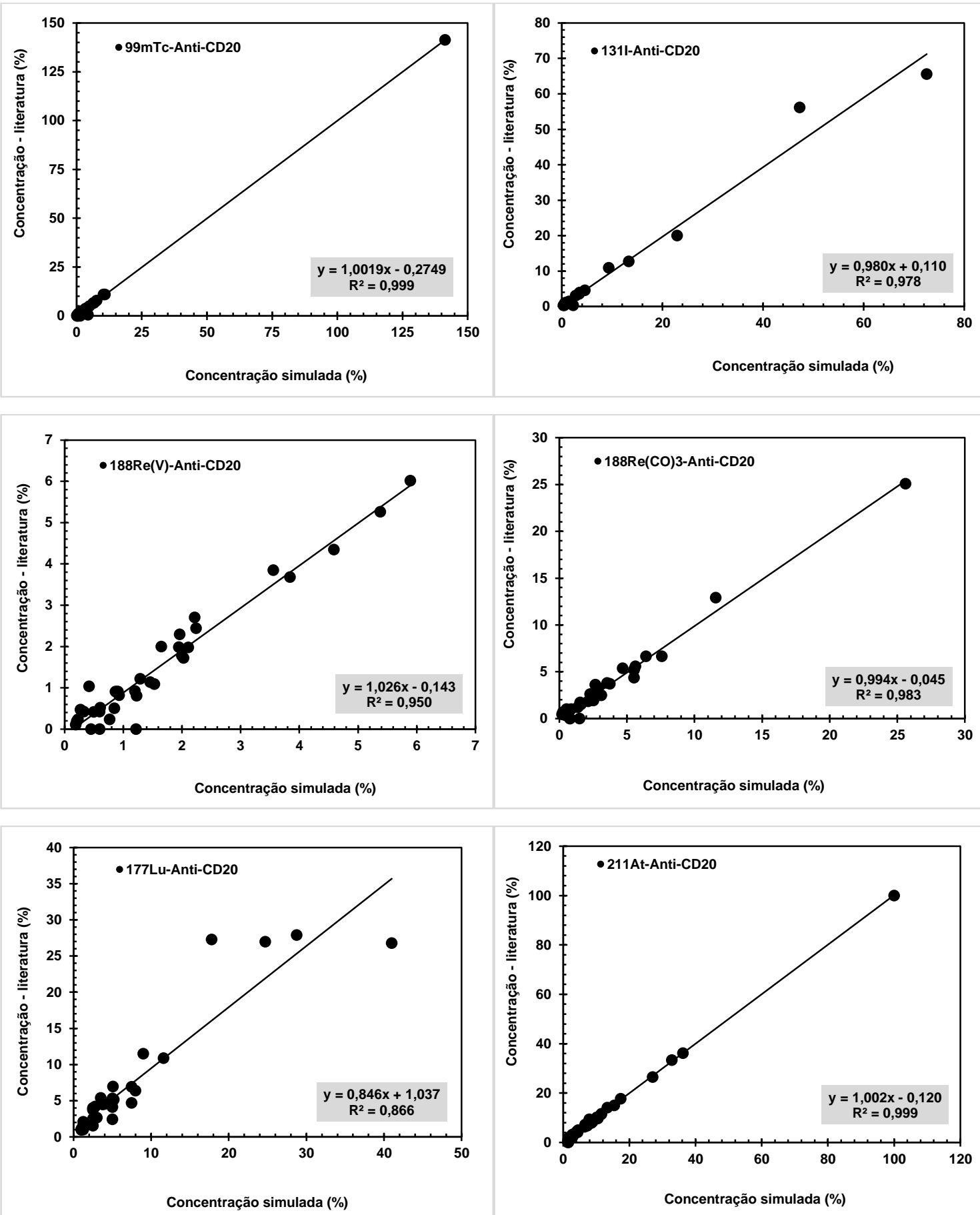

FIGURA 22 - Correlação entre as concentrações das atividades de todos os produtos Anti-CD20 marcado com os radionuclídeos ${ }^{188} \mathrm{Re}$ (com dois métodos de marcação) [DIAS, 2010]; ${ }^{177} \mathrm{Lu}$ [AUDICIO et al, 2011]; ${ }^{131}$ I [AKANJI, 2006], ${ }^{99 \mathrm{mTC}}$ [DIAS, 2010] e 211 At [AURLIEN et al, 2000], injetados no animal, obtidos por literatura e previstos por simulação. 
A partir dos resultados, pode-se observar uma boa correlação encontrada para os dados das concentrações obtidas em literatura e por simulação para todos os produtos estudados, com valores superiores a 0,95. Entretanto, a baixa correlação encontrada para $0{ }^{177}$ Lu-Anti-CD20 se deve aos dados utilizados, extraídos de literatura terem sido escassos, justificando sua menor correlação frente aos demais produtos, porém o valor encontrado ainda é satisfatório, $>0,87$. Alem disso, a correlação nos resultados encontrados mostra uma convergência apropriada do algoritmo utilizado.

Com relação à farmacocinética do Anti-CD20, a biodistribuição normal esperada inclui: (1) atividade concentrada no coração, abdômem, pescoço e extremidades; (2) captação de moderadamente alta para alta no fígado, bexiga e (3) captação de moderadamente baixa para baixa nos rins, tracto urinário e intestino. Os critérios para uma biodistribuição alterada são: (1) intensa captação do radiotraçador no fígado, rins e medula; (2) captação difusa nos pulmões mais intensa do que no fígado, e (3) captação nos rins é maior do que no fígado em uma visão posterior da imagem [VALLABHAJOSULA et al., 2010].

As FIGs. 23 a 27, apresentam o estudo compartimental para o Anti-CD20 marcado com ${ }^{188} \mathrm{Re}$ comparado à mesma marcação com ${ }^{131} \mathrm{I},{ }^{177} \mathrm{Lu},{ }^{99 \mathrm{~m}} \mathrm{Tc}$ e ${ }^{211} \mathrm{At}$, após uma administração intravenosa do radiofármaco no animal, baseados em dados de estudos de biodistribuição extraídos da literatura [DIAS, 2010; AKANJI, 2006; AUDICIO et al, 2011; AURLIEN et al, 2000]. 

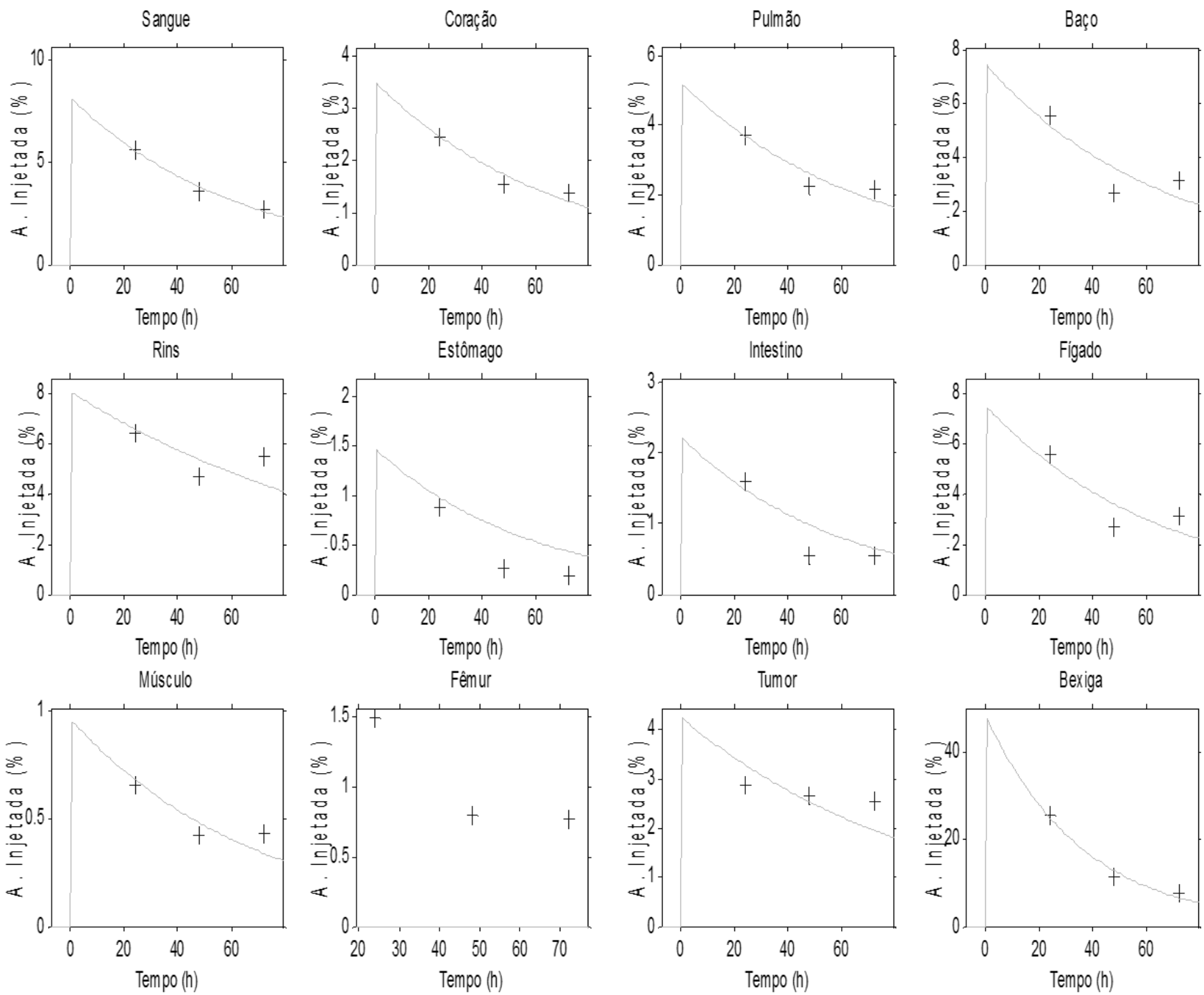

FIGURA 23 - Estudo compartimental para o ${ }^{188}$ Re-Anti-CD20 [DIAS, 2010]. 

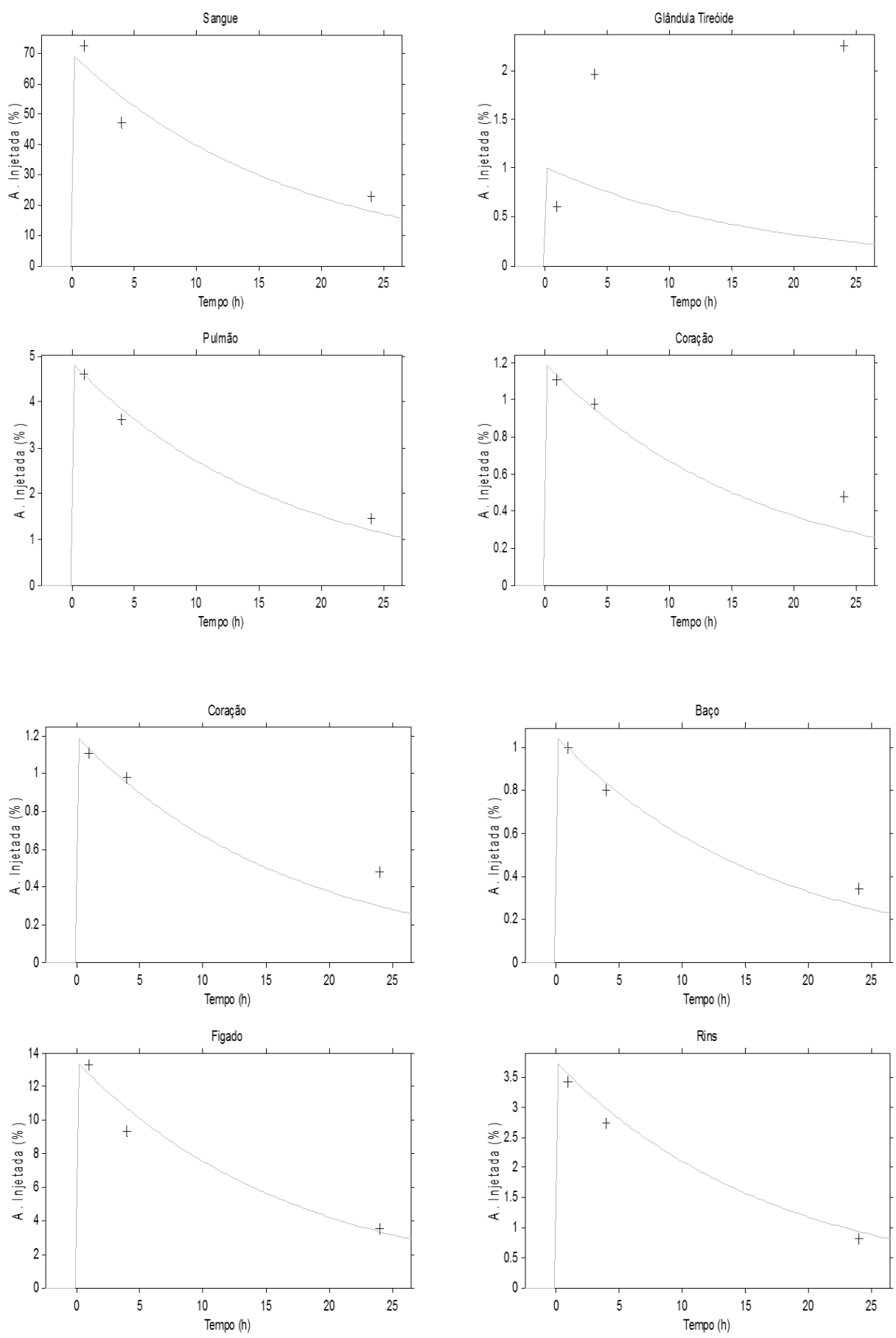

FIGURA 24 - Estudo compartimental para o ${ }^{131} \mid$-Anti-CD20 [AKANJI, 2006]. 

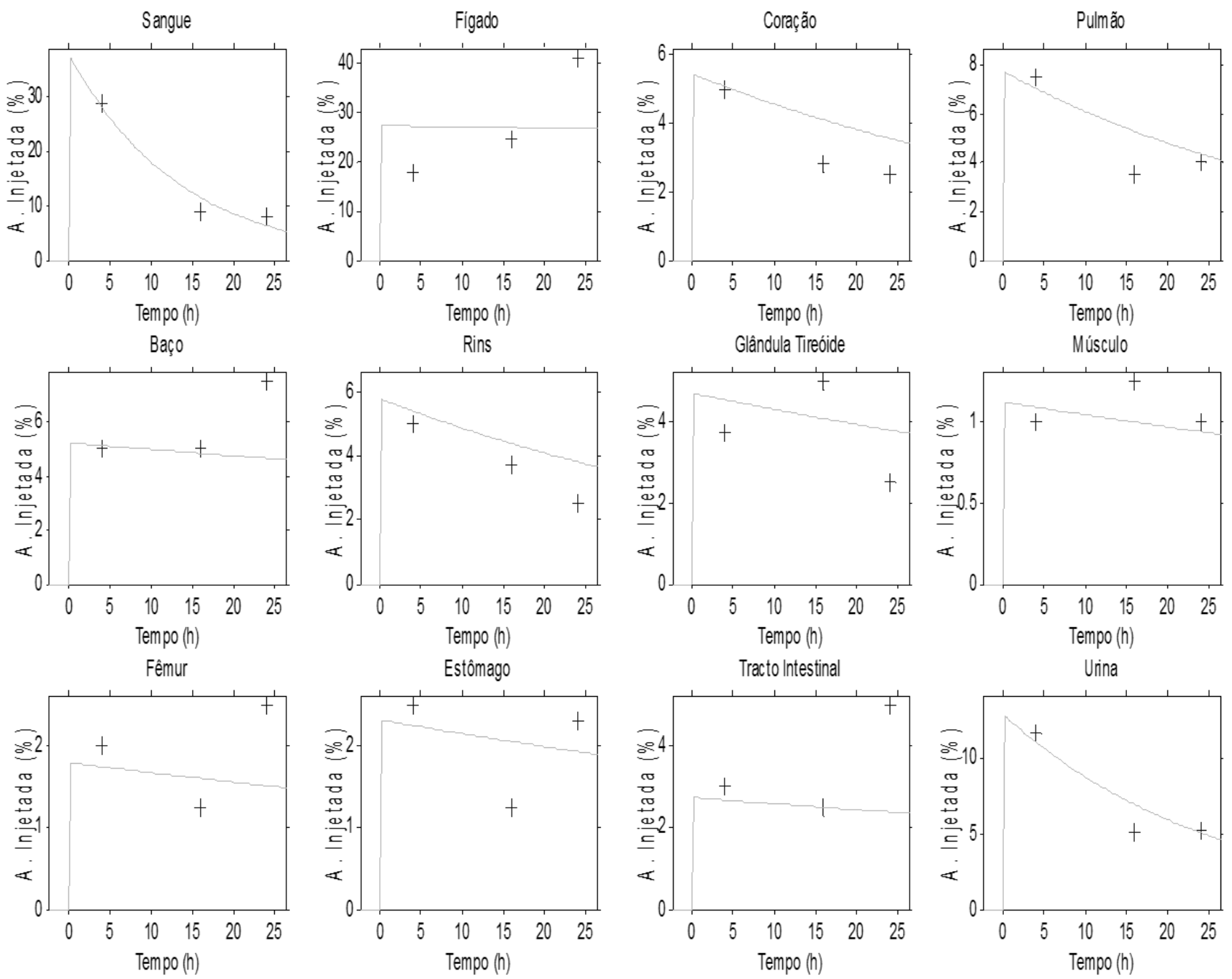

FIGURA 25 - Estudo compartimental para o ${ }^{177}$ Lu-Anti-CD20 [AUDICIO et. al, 2011]. 

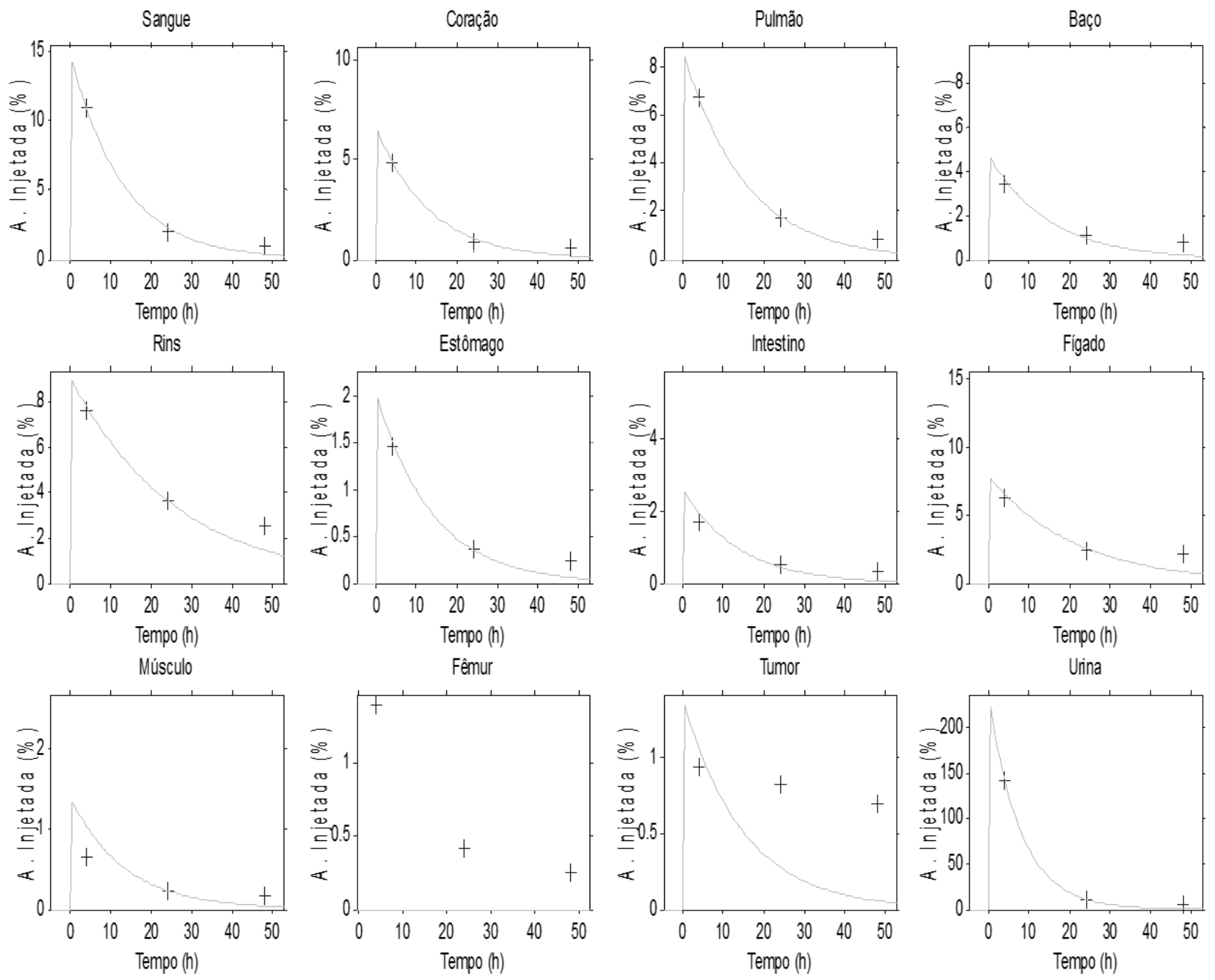

FIGURA 26 - Estudo compartimental obtido para o ${ }^{99 m T C-A n t i-C D 20 ~[D I A S, ~ 2010] . ~}$ 

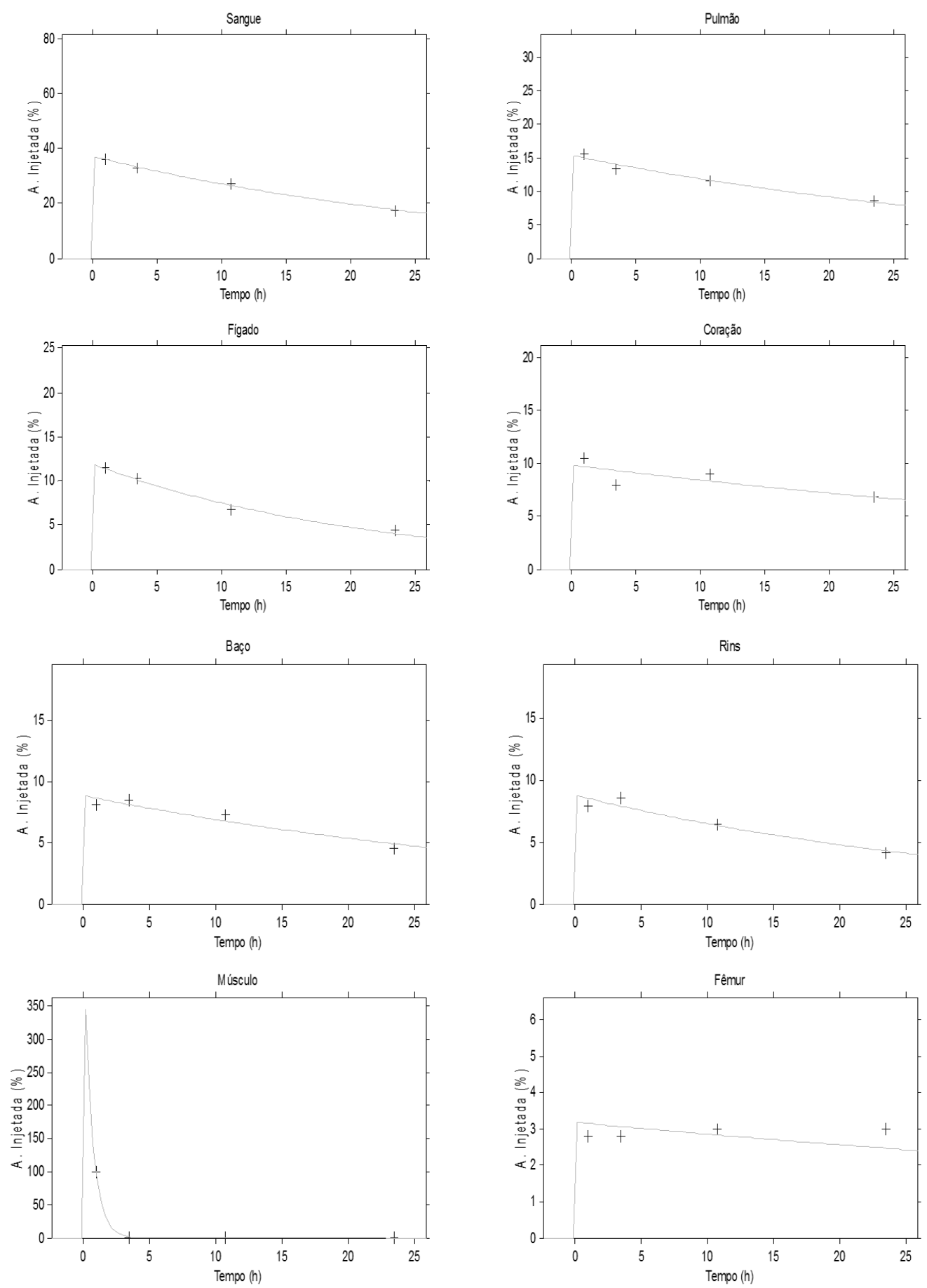

FIGURA 27 - Estudo compartimental obtido para o ${ }^{211}$ At-Anti-CD20 [AURLIEN et al, 2000]. 
A TAB. 20 apresenta taxas de eliminação e meia-vida biológica determinadas para cada órgão a partir de dados extraídos de literatura. Estes resultados foram obtidos através do Monolix. O estudo procurou avaliar o comportamento metabólico do anticorpo marcado com cada radionuclídeo no organismo. Radionuclídeos marcados com Anti-CD20: ${ }^{188}$ Re [DIAS, 2010] em comparação com ${ }^{131}$ I [AKANJI, 2006], ${ }^{177} \mathrm{Lu}$ [AUDICIO et. al, 2011], ${ }^{99 \mathrm{mTC}}$ [DIAS, 2010] e ${ }^{211}$ At [AURLIEN et al, 2000]. 
TABELA 20 - Taxa de eliminação (k) e meia-vida biológica obtidas para o AntiCD20 radiomarcado com ${ }^{188} \mathrm{Re}$ [DIAS, 2010] em comparação com ${ }^{131}$ I [AKANJI, 2006], ${ }^{177} \mathrm{Lu}$ [AUDICIO et. al, 2011], ${ }^{99 \mathrm{~m} T c}$ [DIAS, 2010] e ${ }^{211} \mathrm{At}$ [AURLIEN et al, 2000].

\begin{tabular}{|c|c|c|c|c|c|}
\hline \multirow[b]{2}{*}{ Órgão } & \multicolumn{4}{|c|}{ Taxa de eliminação $\left(h^{-1}\right)$} & \multirow[b]{2}{*}{$\begin{array}{l}{ }^{211} \text { At } \\
\text { Anti-CD20 }\end{array}$} \\
\hline & $\begin{array}{l}131 \mid \\
\text { Anti- } \\
\text { CD20 }\end{array}$ & $\begin{array}{l}{ }^{177} \text { Lu-DOTA } \\
\text { Anti-CD20 }\end{array}$ & $\begin{array}{c}{ }^{188} \operatorname{Re}(\mathrm{CO})_{3} \\
\text { Anti-CD20 }\end{array}$ & $\begin{array}{c}{ }^{99 m} \mathrm{Tc}\left(\mathrm{CO}_{3}\right) \\
\text { Anti-CD20 }\end{array}$ & \\
\hline Sangue & 0,051 & 0,056 & 0,048 & 0,049 & 0,043 \\
\hline Glândula Tireóide & 0,039 & ND & 0,077 & ND & ND \\
\hline Pulmão & 0,049 & 0,034 & 0,074 & 0,048 & 0,025 \\
\hline Coração & 0,036 & 0,036 & 0,074 & 0,047 & 0,014 \\
\hline Baço & 0,045 & 0,019 & 0,078 & 0,024 & 0,027 \\
\hline Fígado & 0,054 & 0,041 & 0,082 & 0,024 & 0,043 \\
\hline Intestino & ND & ND & 0,107 & 0,036 & ND \\
\hline Estômago & ND & ND & 0,084 & 0,040 & ND \\
\hline Rins & 0,062 & 0,034 & 0,086 & 0,034 & 0,032 \\
\hline Bexiga & ND & 0,042 & 0,077 & ND & ND \\
\hline Osso & ND & ND & 0,076 & 0,039 & 0,015 \\
\hline Músculo & ND & ND & 0,077 & 0,031 & 0,010 \\
\hline \multirow[t]{2}{*}{ Tumor } & ND & ND & 0,074 & ND & ND \\
\hline & \multicolumn{4}{|c|}{ Meia-vida biológica (h) } & \\
\hline Órgão & $\begin{array}{l}\text { 131I } \\
\text { Anti-CD20 }\end{array}$ & $\begin{array}{l}\text { 177Lu-DOTA } \\
\text { Anti-CD20 }\end{array}$ & $\begin{array}{c}{ }^{188} \operatorname{Re}(C O)_{3} \\
\text { Anti-CD20 }\end{array}$ & $\begin{array}{l}{ }^{99 m} \mathrm{Tc}\left(\mathrm{CO}_{3}\right) \\
\text { Anti-CD20 }\end{array}$ & $\begin{array}{l}{ }^{211} \mathrm{At} \\
\text { Anti-CD20 }\end{array}$ \\
\hline Sangue & 13,7 & 12,3 & 14,4 & 14,1 & 16,0 \\
\hline Glândula Tireóide & 17,9 & ND & 9,0 & ND & ND \\
\hline Pulmão & 14,1 & 20,4 & 9,4 & 14,7 & 27,7 \\
\hline Coração & 19,3 & 19,3 & 9,4 & 14,4 & 49,5 \\
\hline Baço & 15,4 & 37,1 & 8,9 & 28,9 & 25,7 \\
\hline Fígado & 12,8 & 17,1 & 8,5 & 28,9 & 16,1 \\
\hline Intestino & ND & ND & 6,5 & 19,3 & ND \\
\hline Estômago & ND & ND & 8,3 & 17,3 & ND \\
\hline Rins & 11,2 & 20,4 & 8,1 & 20,4 & 21,7 \\
\hline Bexiga & ND & 16,5 & 9,0 & 22,4 & ND \\
\hline Osso & ND & ND & 9,1 & 17,8 & 46,2 \\
\hline Músculo & ND & ND & 9,0 & 22,4 & 66,6 \\
\hline Tumor & ND & ND & 9,4 & ND & ND \\
\hline
\end{tabular}

ND - Não Definido 
De acordo com a tabela, pode-se observar que ${ }^{188}$ Re-Anti-CD20 apresentou valores de eliminação e meia-vida biológica similares e satisfatórios em relação aos demais radiofármacos, indicando a eficácia da técnica de marcação apresentada pela literatura.

\subsection{AVALIAÇÃO DOS ESTUDOS DE DOSIMETRIA COM RADIOIMUNOTERÁPICOS}

\subsubsection{AVALIAÇÃO DOSIMÉTRICA PELO MÉTODO DE MONTE CARLO}

Um dos principais elementos de saída do MCNP é a geometria do animal, definida pelos dados de entrada inseridos no código para sua execução. Com a definição dos órgãos através da especificação de suas superfíces, foi possível determinar a dose absorvida em cada orgão ou região (determinada pelos dados de entrada inseridos), a partir da energia máxima de emissão das partículas $\beta$ - do radionuclídeo simulado.

A FIG. 28 mostra o corpo do camundongo construído pelo MCNP, por meio de equações matemáticas, dentro de uma superfície esférica, de composição vazia, para que durante os processos de simulação dos elétrons, não houvesse perda de partículas, prejudicando o processo. 


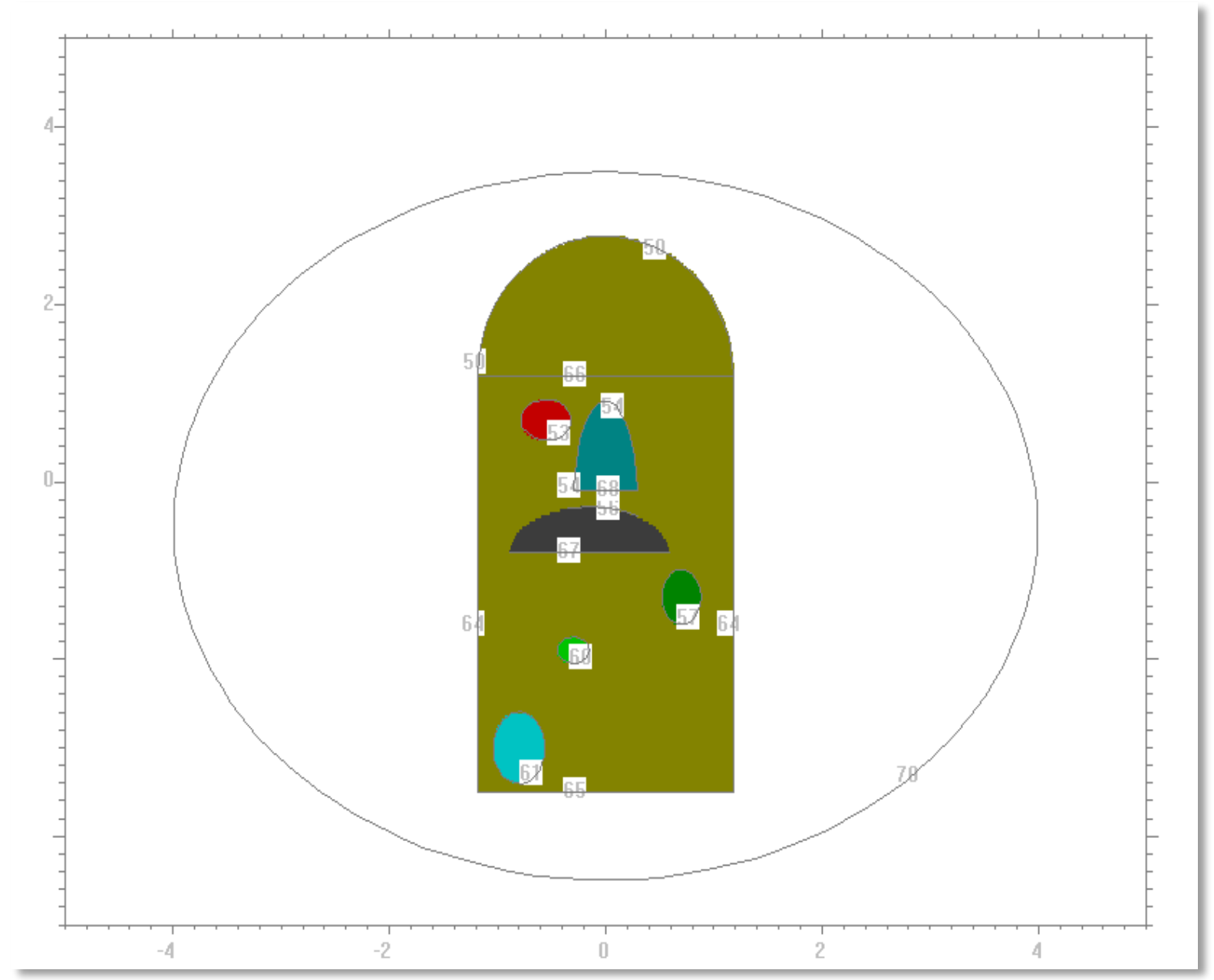

FIGURA 28 - Visão lateral da geometria do corpo do camundongo, envolvida por uma superfície esférica vazia, para que não haja perda de partículas durante o processo de simulação. Órgãos visualizados pelas superfícies de volume: coração (53), pulmão esquerdo (54), fígado (56), rim esquerdo (57), bexiga (60) e testículo esquerdo (61).

A esfera vazia (representada pela superfície de volume 78 ) foi importante nas simulações para que não houvesse escape ou perda de partículas no processo. Não somente neste caso, em que se utilizou um camundongo, é importante para qualquer processo de simulação que faz o uso do MCNP, a presença de uma superfície vazia que envolva todo o objeto.

As FIGs. 29, 30 e 31 mostram em diferentes planos, a distribuição de toda a estrutura simulada: posição de todos os órgãos e do tumor dentro do corpo do animal. 


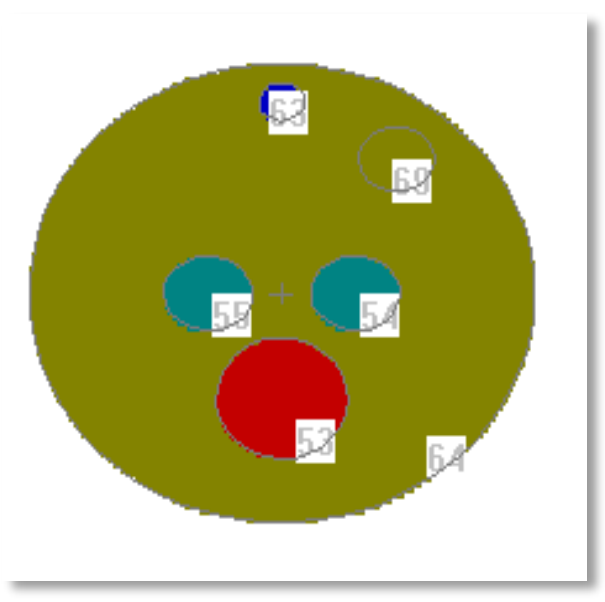

FIGURA 29 - Representação geométrica do corpo do camundongo, no Plano XY, visualizando o tumor pela superfície de volume (69), posicionado entre os pulmões (54 e 55) e coluna (63).

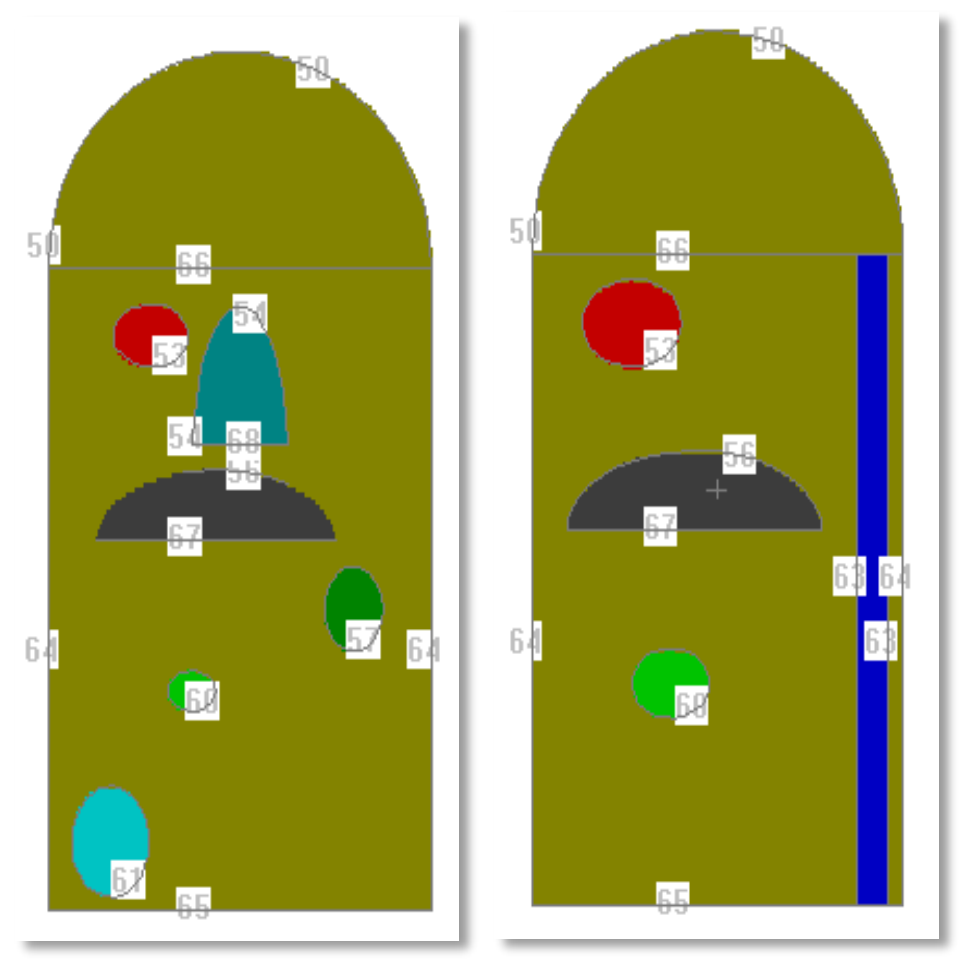

FIGURA 30 - Representação geométrica do corpo do camundongo no plano YZ. Órgãos visualizados pelas superfícies de volume: coração (53), pulmões (54), fígado (56 e 67), rins (57), bexiga (60), testículos (61) e coluna (63). 

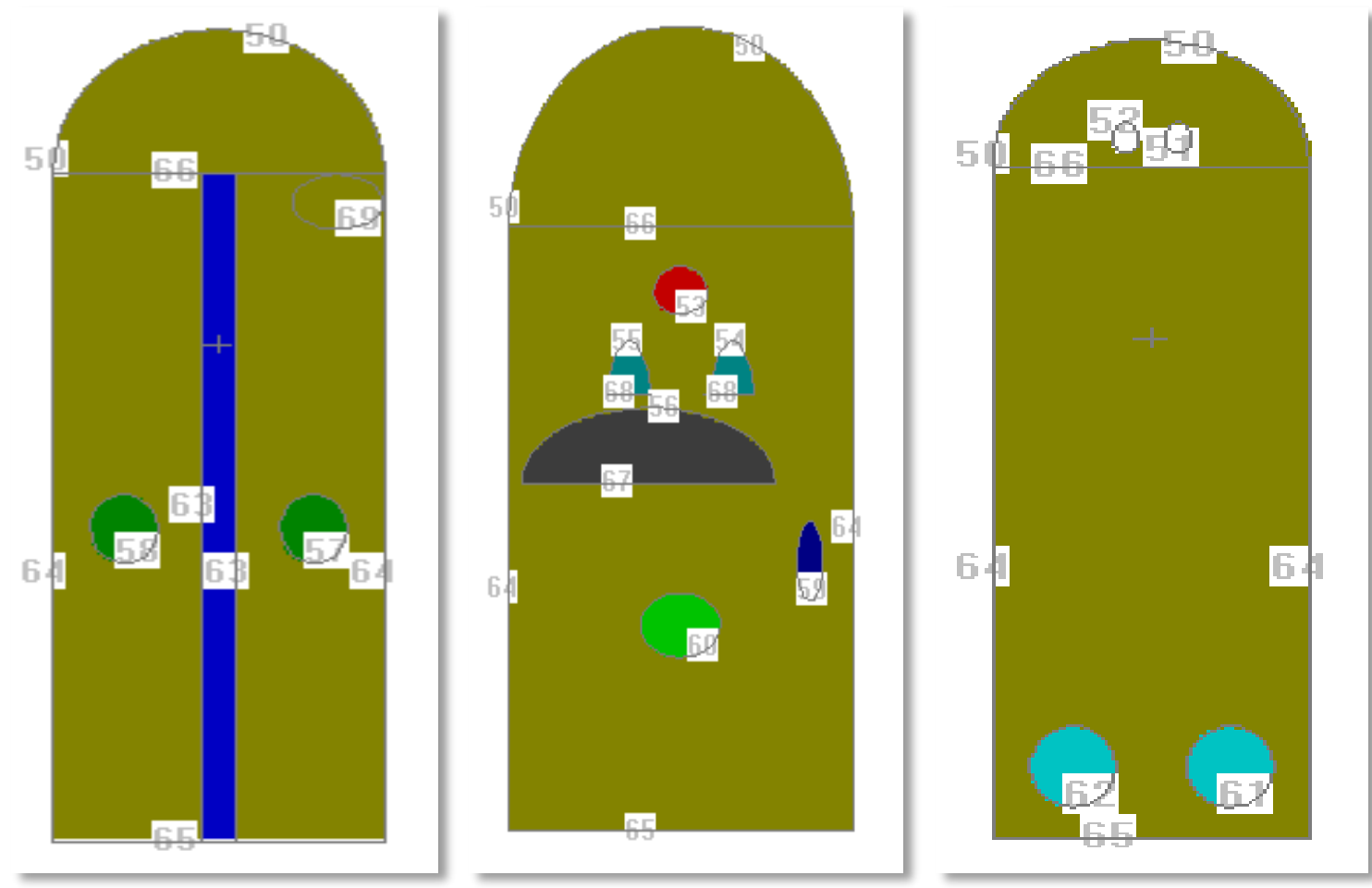

FIGURA 31 - Representação geométrica do corpo do camundongo no plano XZ. Órgãos visualizados pelas superfícies de volume: glândula tireóide (51 e 52), coração (53), pulmões (54 e 55), rins (57 e 58), bexiga (60), testículos (61 e 62), coluna (63) e o tumor (69).

De acordo com a FIG. 29, o tumor foi posicionado dentro do animal próximo à região da coluna, correspondendo à região dos flancos (ou o dorso do animal). O tamanho do tumor dentro do corpo do animal foi variado. O radionuclídeo foi inserido e distribuído homogeneamente no tumor.

A TAB. 21 mostra as massas dos órgãos calculadas pelo MCNP, com a inserção das equações matemáticas para a construção das superfícies de cada órgão e composição de cada um deles pela sua densidade, no corpo do animal. 
TABELA 21 - Massas dos órgãos do camundongo calculadas pelo MCNP, comparadas às massas deles utilizadas em literatura [HINDORF et al, 2004].

\begin{tabular}{cccc}
\hline Órgão & $\begin{array}{c}\text { Massa do órgão (g) } \\
\text { (Literatura) }\end{array}$ & $\begin{array}{c}\text { Massa do órgão (g) } \\
\text { (MCNP) }\end{array}$ & Erro (\%) \\
\hline Coração & 0,12 & 0,12439 & 0,4 \\
Rins & 0,28 & 0,28093 & 0,09 \\
Pulmões & 0,15 & 0,13516 & 1,5 \\
Fígado & 0,89 & 1,05000 & 16 \\
Glândula tireóide & 0,02 & 0,00230 & 1,8 \\
Baço & 0,09 & 0,09012 & 0,01 \\
Bexiga & 0,03 & 0,06545 & 3,5 \\
Testículos & 0,25 & 0,24918 & 0,08 \\
Coluna & 0,19 & 0,20672 & 1,7 \\
\hline
\end{tabular}

As massas de cada um dos órgãos, calculadas pelo MCNP apresentaramse próximas aos valores das massas de referência (literatura), confirmadas pelo pequeno erro percentual obtido entre os valores para cada órgão. Apesar do fígado ter apresentado erro percentual superior a 10\%, este resultado não interferiu significamente nos cálculos de dosimetria.

A TAB. 22 mostra a relação entre a dimensão do tumor simulado dentro do corpo do camundongo e suas respectivas massas, calculadas pelo MCNP. 
TABELA 22 - Relação entre a dimensão do tumor dentro do corpo do camundongo (através do seu raio), e suas respectivas massas tumorais, calculadas pelo MCNP.

\begin{tabular}{cc}
\hline Raio do tumor $(\mathbf{c m})$ & Massa do tumor calculada pelo MCNP $(\mathbf{g})$ \\
\hline 0,01 & $4,18 \cdot 10^{-06}$ \\
0,02 & $3,35 \cdot 10^{-05}$ \\
0,03 & $1,13 \cdot 10^{-04}$ \\
0,04 & $2,68 \cdot 10^{-04}$ \\
0,05 & $5,23 \cdot 10^{-04}$ \\
0,06 & $9,04 \cdot 10^{-04}$ \\
0,07 & $1,43 \cdot 10^{-03}$ \\
0,08 & $2,14 \cdot 10^{-03}$ \\
0,09 & $3,05 \cdot 10^{-03}$ \\
0,10 & $4,18 \cdot 10^{-03}$ \\
0,20 & $3,35 \cdot 10^{-02}$ \\
0,30 & $1,13 \cdot 10^{-01}$ \\
0,40 & $2,68 \cdot 10^{-01}$ \\
\hline
\end{tabular}

A FIG. 32 mostra a relação entre a energia média do radionuclídeo inserido no tumor localizado no corpo do camundongo e a dimensão do raio do tumor. Para execução da simulação, foram considerados como dados de entrada a energia máxima de emissão de cada radionuclídeo associado ao anticorpo e o radiofármaco $100 \%$ inserido no tumor. 


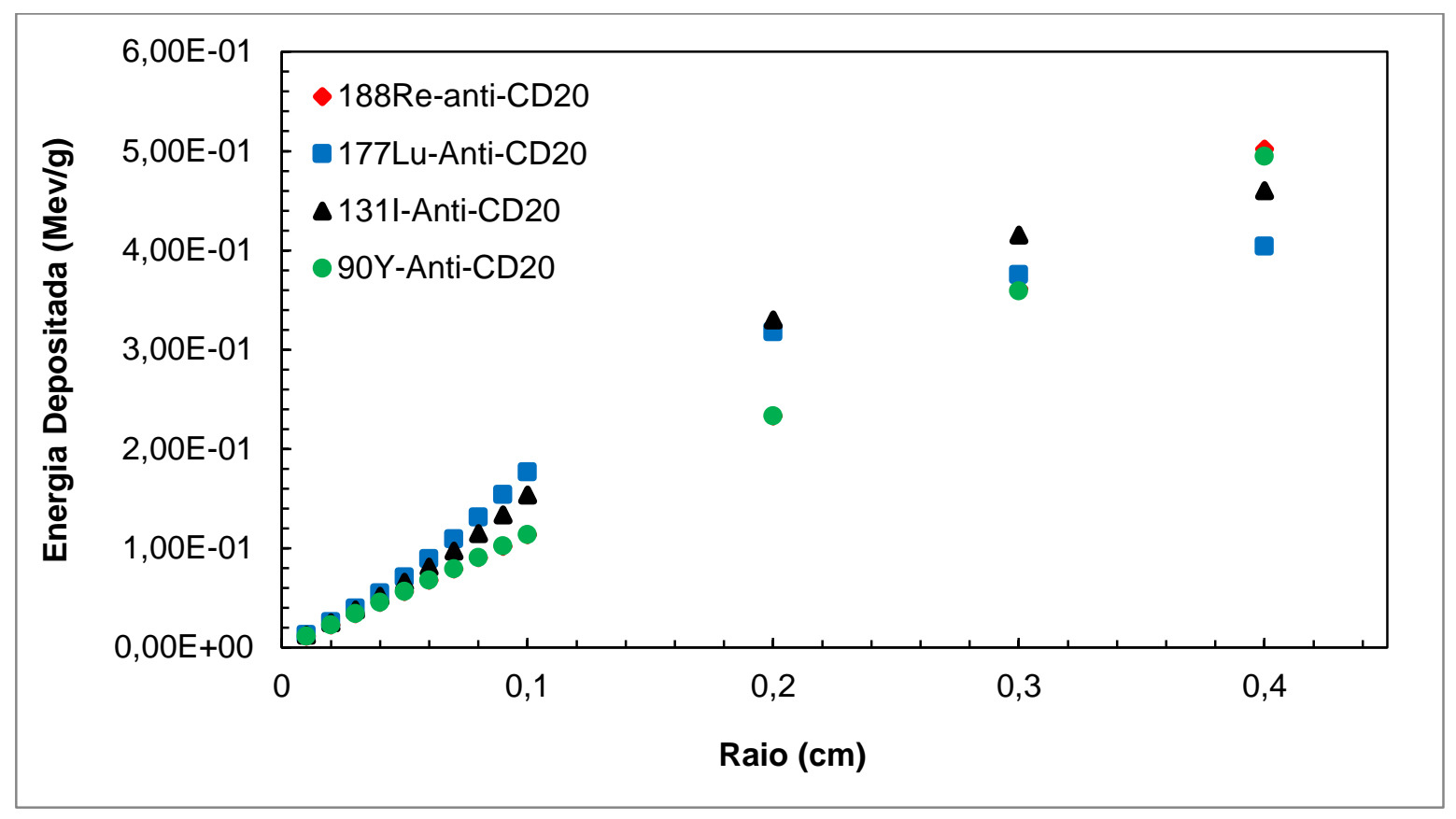

FIGURA 32 - Energia no tumor em função do seu raio, determinados pela simulação por Monte Carlo, utilizando Anti-CD20 marcado com ${ }^{90} \mathrm{Y},{ }^{131} \mathrm{I},{ }^{177} \mathrm{Lu}$ e ${ }^{188} \mathrm{Re}$, considerando o material situado totalmente dentro do tumor. Tempo de cada simulação: 300 minutos.

Os resultados indicam que para os radionuclídeos estudados, a energia máxima no tumor, calculada pelo MCNP, para cada radionuclídeo, ocorreu de maneira uniforme e crescente nos quatro casos avaliados.

Pode-se observar que para tumores de tamanhos pequenos $(R<0,1 \mathrm{~cm})$ ${ }^{177} \mathrm{Lu}$ e ${ }^{131}$ I destacaram-se entre os demais radionuclídeos, mostrando-se mais adequado para tratamento desses tumores pois obtém-se uma dose maior em tumores menores.

Simulações com os mesmos radiofármacos foram realizadas em uma situação em que o produto não é captado $100 \%$ no tumor, numa condição mais próxima do real, considerando uma biodistribuição do produto dentro do organismo. Foi simulado para cada radiofármaco, $45 \%$ de captação dentro do tumor e o restante, distribuído pelo organismo, supondo um procedimento intravenoso. As FIG.s 33 e 34 mostram as doses absorvida no tumor de diferentes dimensões radiais no corpo de um camundongo. 


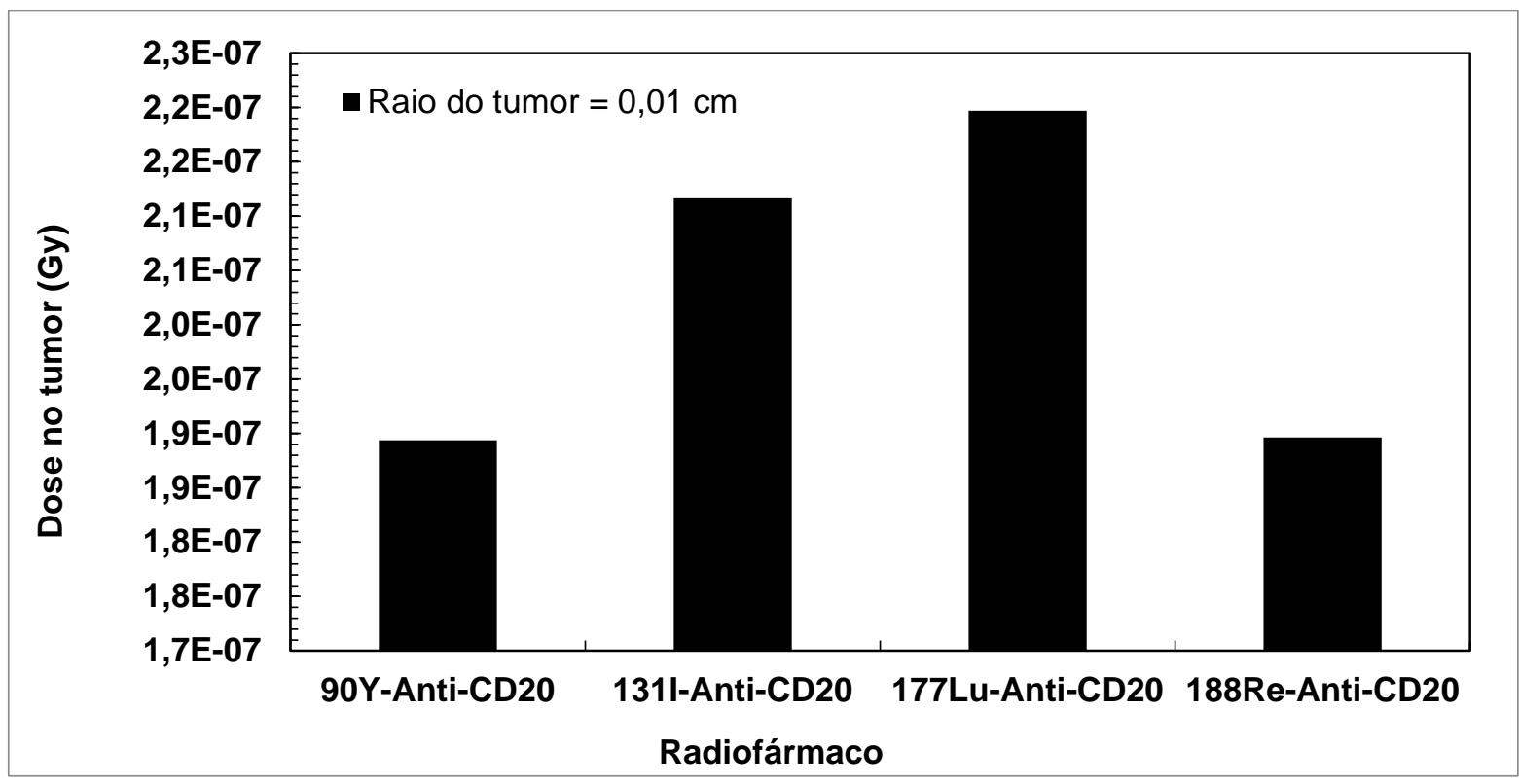

FIGURA 33 - Dose absorvida em tumores de $r=0,01 \mathrm{~cm}$, calculada por método de Monte Carlo para cada radiofármaco. Considerou-se $45 \%$ de captação do produto dentro do tumor e o restante distribuído no organismo do camundongo. Tempo de cada simulação: 300 minutos. Atividade simulada do radiofármaco: $85 \mathrm{~Bq}$.

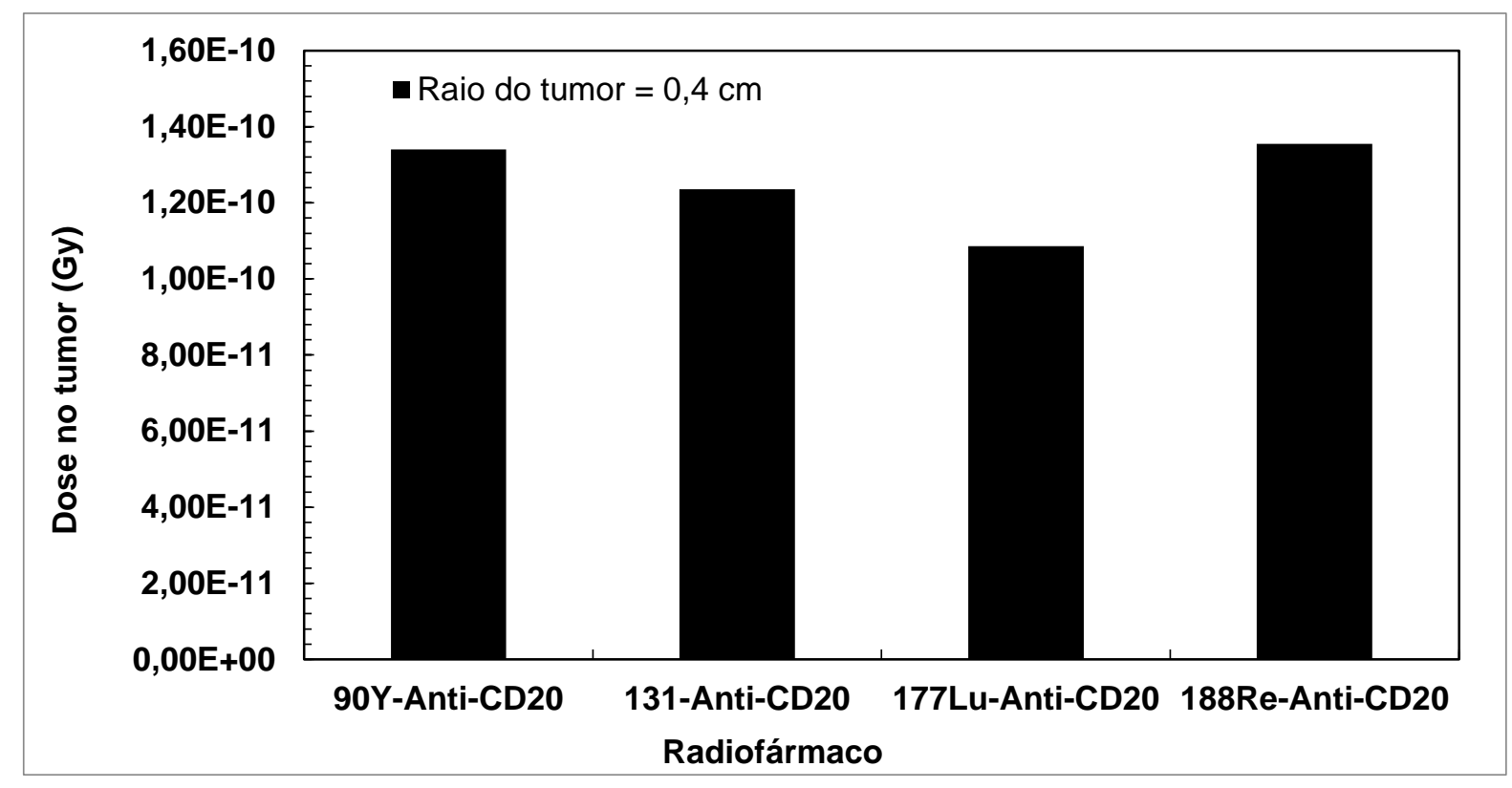

FIGURA 34 - Dose absorvida em tumores de $r=0,4 \mathrm{~cm}$, calculada por método de Monte Carlo para cada radiofármaco. Considerando $45 \%$ de captação do produto dentro do tumor e o restante distribuído no organismo do camundongo. Tempo de cada simulação: 300 minutos. Atividade simulada do radiofármaco: $85 \mathrm{~Bq}$. 
O gráfico da FIG. 33, mostra uma situação mais próxima da realidade, com radionuclídeos de menor energia de emissão são mais adequados para tratamento de tumores menores, menos volumosos, com maior eficácia de dose local. Neste caso, os radiofármacos ${ }^{131}$ I-Anti-CD20 e ${ }^{177}$ Lu-Anti-CD20 apresentaram melhores resultados.

A FIG. 34, mostra uma situação com tumores maiores, onde radionuclídeos de maiores energias de emissão foram mais adequados para tratamento de tumores maiores, de maior volume, com maior eficácia de dose local. É o caso dos radiofármacos ${ }^{90}$ Y-Anti-CD20 e ${ }^{188}$ Re-Anti-CD20 apresentaram tal concordância.

A FIG. 35 mostra a dose absorvida nos principais órgãos, com um tumor esférico de $r=0,4 \mathrm{~cm}$. As simulações foram realizadas com os quatro radiofármacos: ${ }^{90}$ Y-Anti-CD20, ${ }^{131}$ I-Anti-CD20, ${ }^{177}$ Lu-Anti-CD20 e ${ }^{188}$ Re-Anti-CD20.

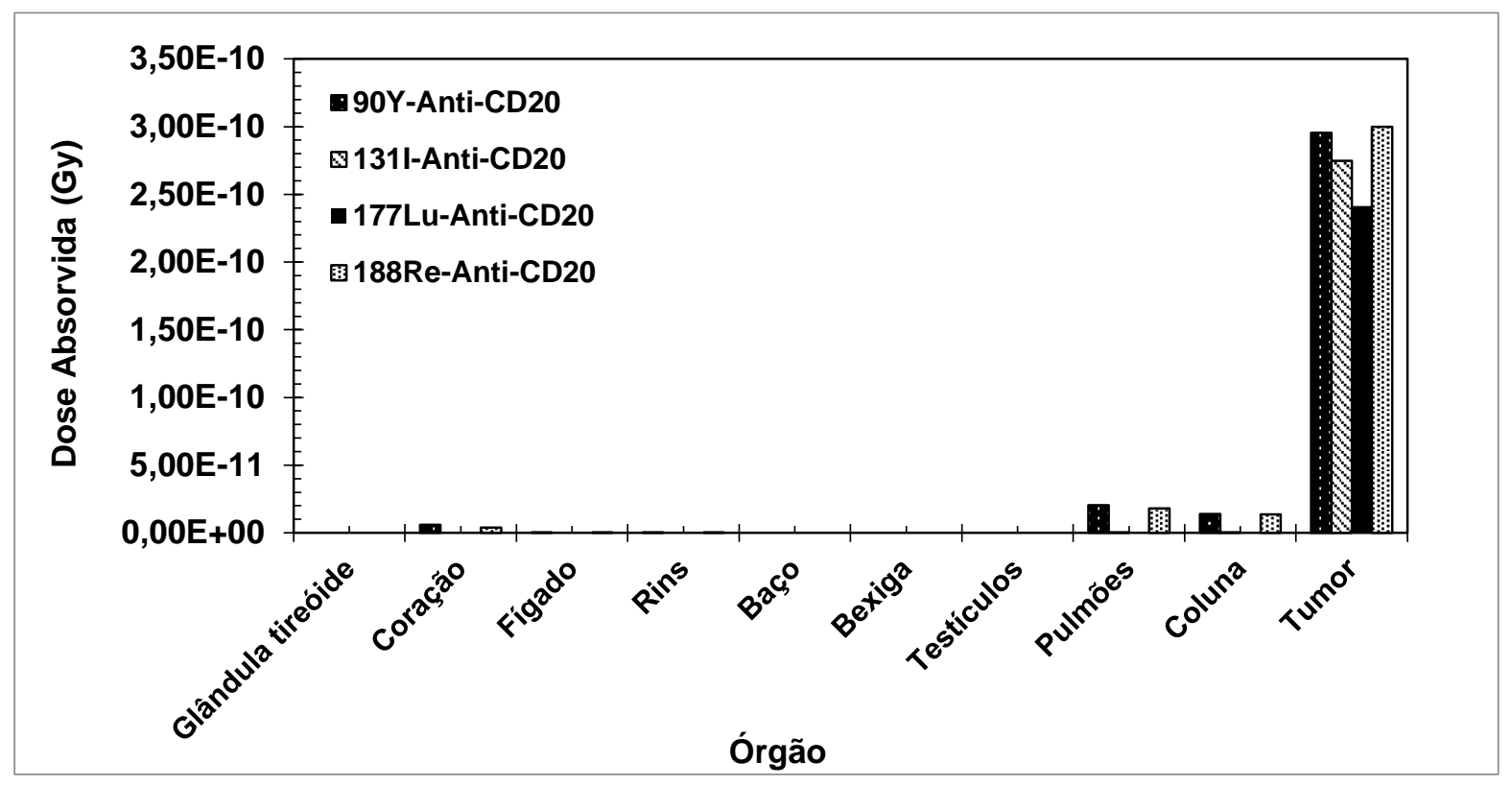

FIGURA 35 - Dose absorvida nos órgãos, considerando um tumor de $r=0,4 \mathrm{~cm}$. A simulação foi feita com cada radiofármaco, situado totalmente dentro do tumor (100\%). Tempo de cada simulação: 300 minutos. Atividade simulada do radiofármaco: $85 \mathrm{~Bq}$.

A influência da energia $\beta^{-}$da fonte/radiofármaco colocada no tumor produziu efeito similar em todos os órgãos, independente do radiofármaco considerado e da energia máxima de emissão utilizada na simulação. 
Considerando $100 \%$ de atividade dentro do tumor, a biodistribuição do ${ }^{188}$ Re-Anti-CD20 mostrou $89 \%$ da dose total absorvida pelo tumor. Os órgãos que receberam uma dose siginificativa decorrente do tumor, foram o coração $(2 \%$ da dose total emitida pelo tumor), pulmões ( $5 \%$ da dose total), e a coluna ( $4 \%$ da dose total), mesmo assim, valores pequenos e satisfatórios mediante a energia de emissão máxima do radionuclídeo de 2,12 MeV. Apesar do destaque no gráfico, as doses recebidas pelo fígado e rins não alcançaram $1 \%$, da dose total absorvida pelo tumor de $89 \%$ (doses no fígado: 0,014\% e rins: 0,0007\%).

A FIGs. 36 a 39 mostram a dose absorvida nos órgãos e no tumor em simulações por Monte Carlo com os quatro radiofármacos, em diferentes tamanhos de tumor.

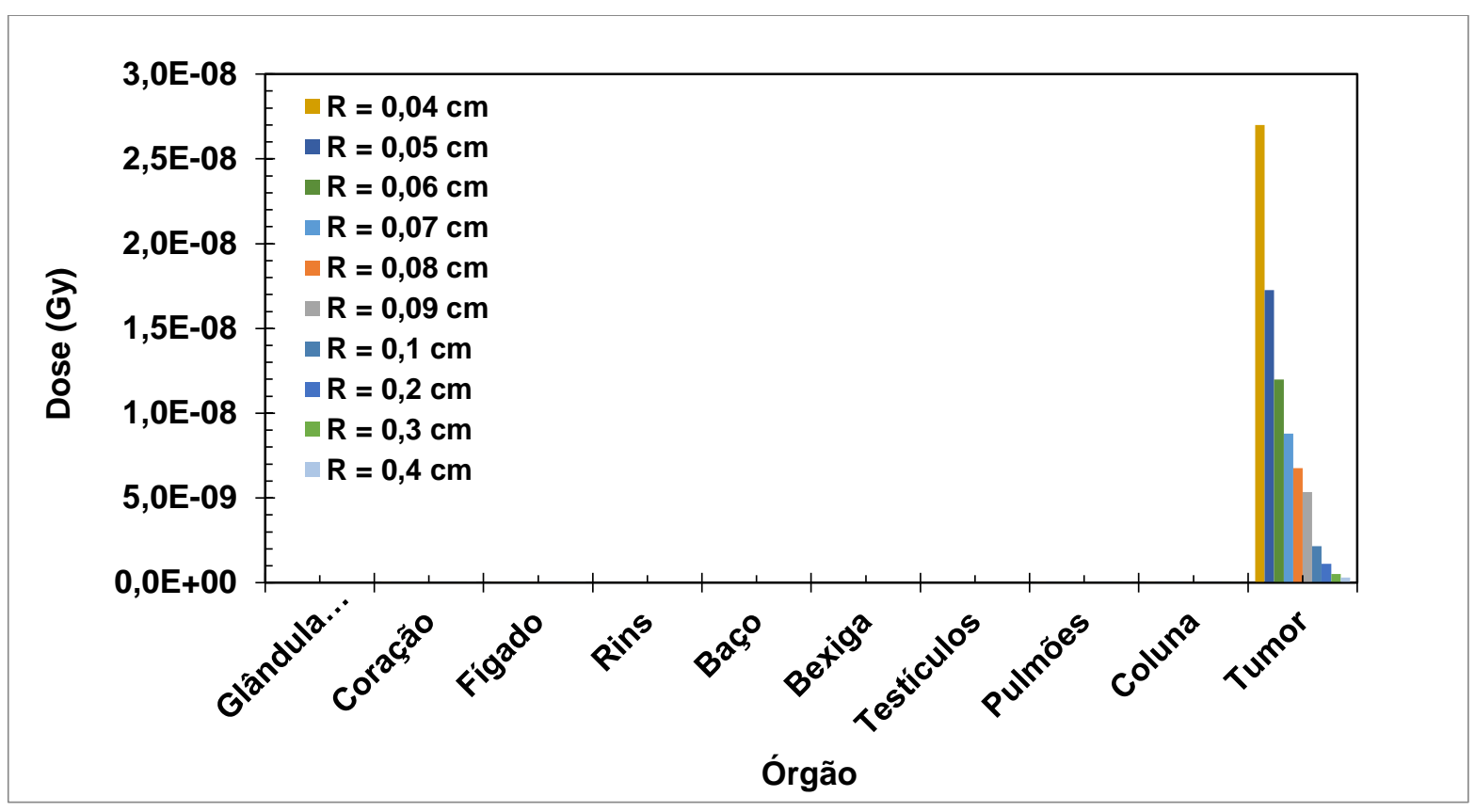

FIGURA 36 - Dose absorvida nos principais órgãos e no tumor, com simulações de diferentes dimensões de tumor, para simulações com ${ }^{188}$ Re-Anti-CD20 situado $100 \%$ dentro da região do tumor. Tempo de cada simulação: 300 minutos. Atividade simulada do radiofármaco: $85 \mathrm{~Bq}$. 


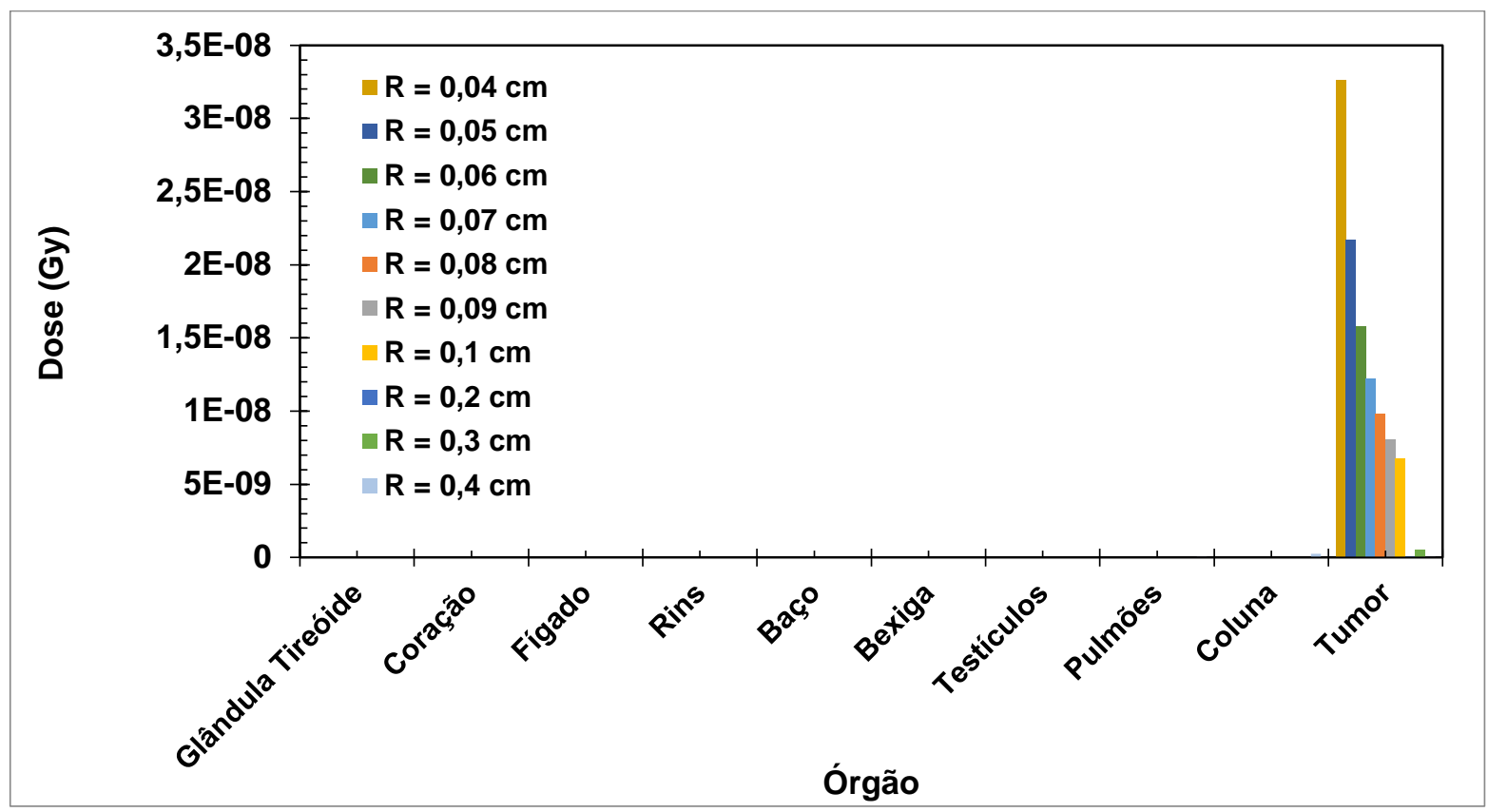

FIGURA 37 - Dose absorvida nos principais órgãos e tumor, com simulações de diferentes dimensões de tumor, para ${ }^{177}$ Lu-Anti-CD20 situado $100 \%$ dentro da região do tumor. Tempo de cada simulação: 300 minutos. Atividade simulada do radiofármaco: $85 \mathrm{~Bq}$.

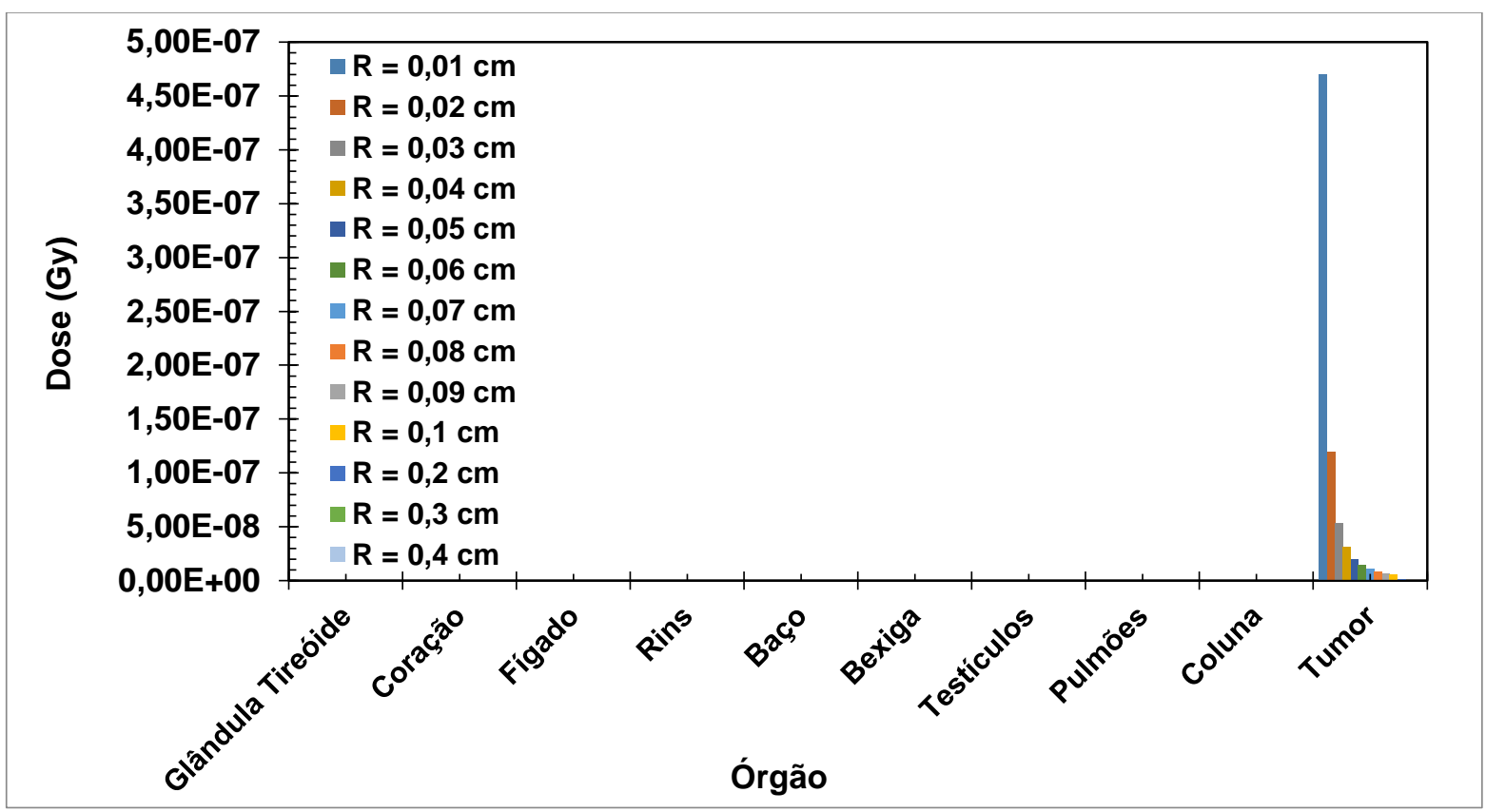

FIGURA 38 - Dose absorvida nos principais órgãos e no tumor, com simulações de diferentes dimensões de tumor, para ${ }^{131} \mid$-Anti-CD20 situado $100 \%$ dentro da região do tumor. Tempo de cada simulação: 300 minutos. Atividade simulada do radiofármaco: $85 \mathrm{~Bq}$. 


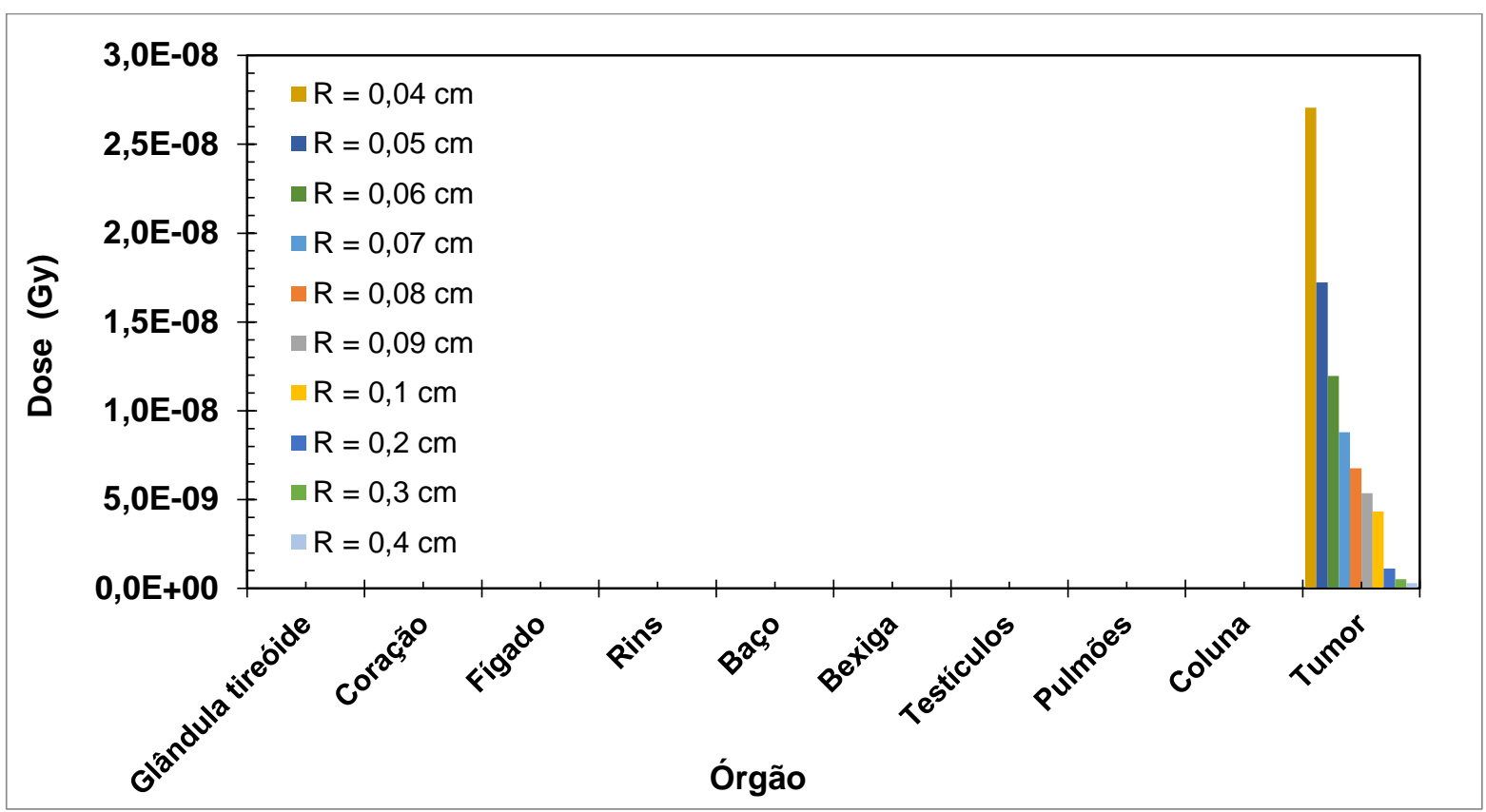

FIGURA 39 - Dose absorvida nos principais órgãos e no tumor, com simulações de diferentes dimensões de tumor, para ${ }^{90} Y$-Anti-CD20 situado 100\% dentro da região do tumor. Tempo de cada simulação: 300 minutos. Atividade simulada do radiofármaco: $85 \mathrm{~Bq}$.

De acordo com a FIG. 36 pode-se observar que a influência da energia $\beta$ do ${ }^{188} \mathrm{Re}$ no tumor ocorreu de maneira uniforme em todos os tamanhos de tumor. Independente do tamanho do tumor, considerando que na simulação todo o radiofármaco foi $100 \%$ absorvido pelo tumor, os órgãos mais expostos foram a coluna e os pulmões (doses correspondendo a $2 \%$ e $3 \%$ respectivamente da dose total). Considerando que a posição do tumor no camundongo foi próxima à glândula tireóide, esta manteve-se preservada (pelo fato da massa do órgão calculada ser muito pequena, logo, praticamente não recebeu dose alguma nas simulações) pois a coluna funcionou como uma blindagem. Pelas diferenças de densidade dos pulmões e da coluna $\left(0,3 \mathrm{~g} / \mathrm{cm}^{3}\right.$ e $1,4 \mathrm{~g} / \mathrm{cm}^{3}$ respectivamente), estes órgãos foram mais expostos à radiação, porém, suas doses encontradas corresponderam a valores inferiores a $5 \%$ da dose total (como descrito acima).

Comparado aos gráficos das Figs. 37 a 39, ${ }^{188}$ Re-Anti-CD20 apresentou comportamento similar a todos os demais radiofármacos, com doses inferiores a 0,5\% em praticamente todos os órgãos, independente da dimensão do raio do tumor.

A FIGs. 40 e 41 apresentam as doses absorvidas nos principais órgãos após realização de simulações com uma fonte esférica composta pelos 
radiofármacos ${ }^{188}$ Re-Anti-CD20, ${ }^{177}$ Lu-Anti-CD20, ${ }^{131}$ I-Anti-CD20 e ${ }^{90} \mathrm{Y}-$ Anti-CD20, com condições radiais extremas (com $R=0,01 \mathrm{~cm}$ e $R=0,4 \mathrm{~cm}$ ). A simulação foi feita com uma condição específica, para cada radiofármaco, após injeção no animal, de acordo com dados de biodistribuição extraídos de literatura. Para o ${ }^{188} \mathrm{Re}$-AntiCD20 a distribuição foi de: tumor (45\%), coração (15\%), rins (10\%), baço (15\%) e bexiga (15\%). Para o ${ }^{177}$ Lu-Anti-CD20 a distribuição foi de: coração (5\%), tireóide (4\%), bexiga (12\%), pulmão (8\%), fígado (18\%). Para o ${ }^{131} \mathrm{I}-$ Anti-CD20 a distribuição foi de: coração $(11 \%)$, rins (1\%), baço (35\%), pulmão (7\%), fígado (18\%). Para o ${ }^{90}$ YAnti-CD20 a distribuição foi de: coração (5\%), tireóide (4\%), bexiga (12\%), pulmão (8\%), fígado (18\%).
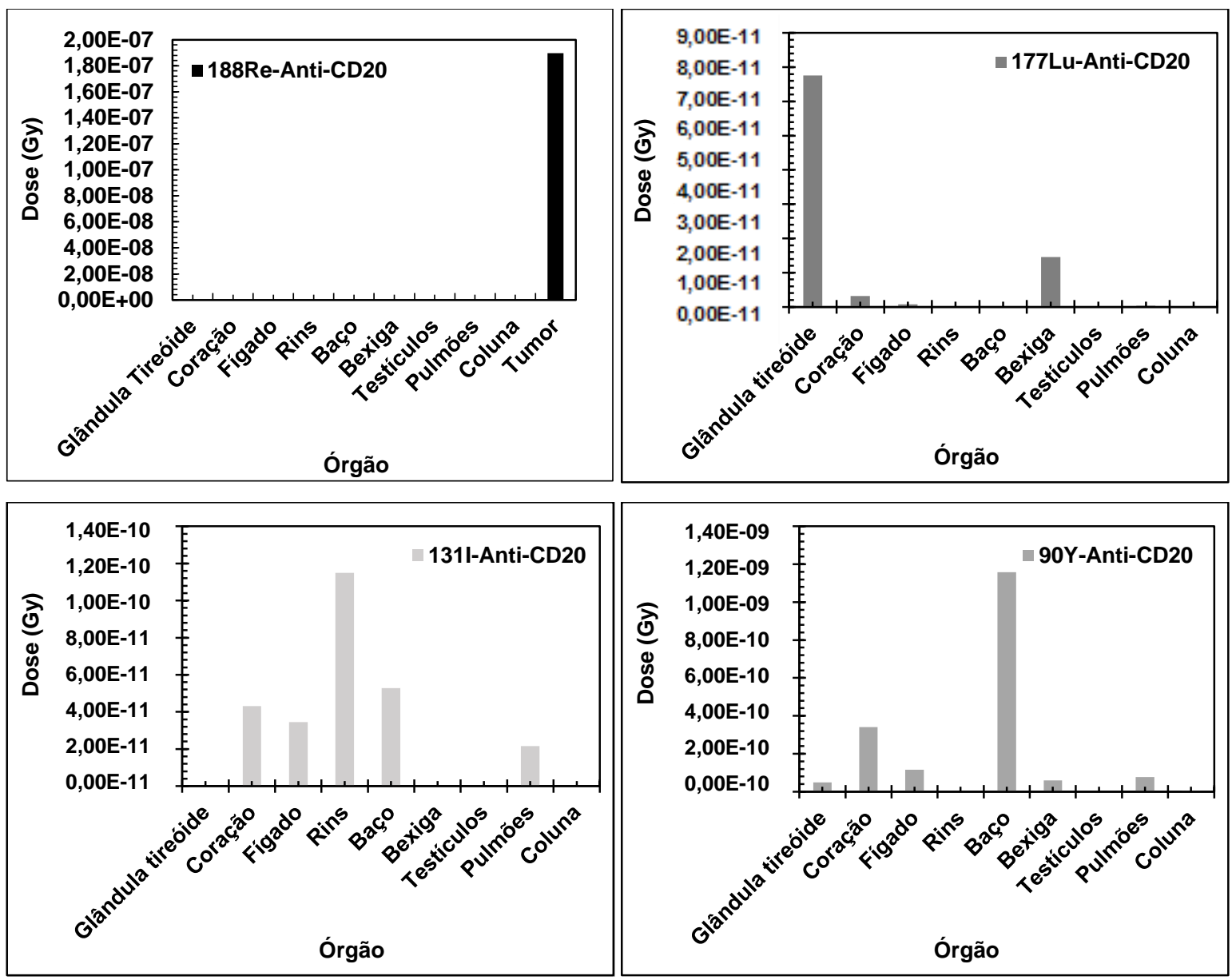

FIGURA 40 - Dose absorvida nos principais órgãos e no tumor (para $r=0,01 \mathrm{~cm}$ ) simulando uma condição em que Anti-CD20 marcado com ${ }^{90} \mathrm{Y},{ }^{131} \mathrm{I},{ }^{177} \mathrm{Lu}$ e ${ }^{188} \mathrm{Re}$, injetado no animal foi biodistribuído pelo corpo. Tempo de simulação: 300 minutos. Atividade simulada do radiofármaco: $85 \mathrm{~Bq}$. 

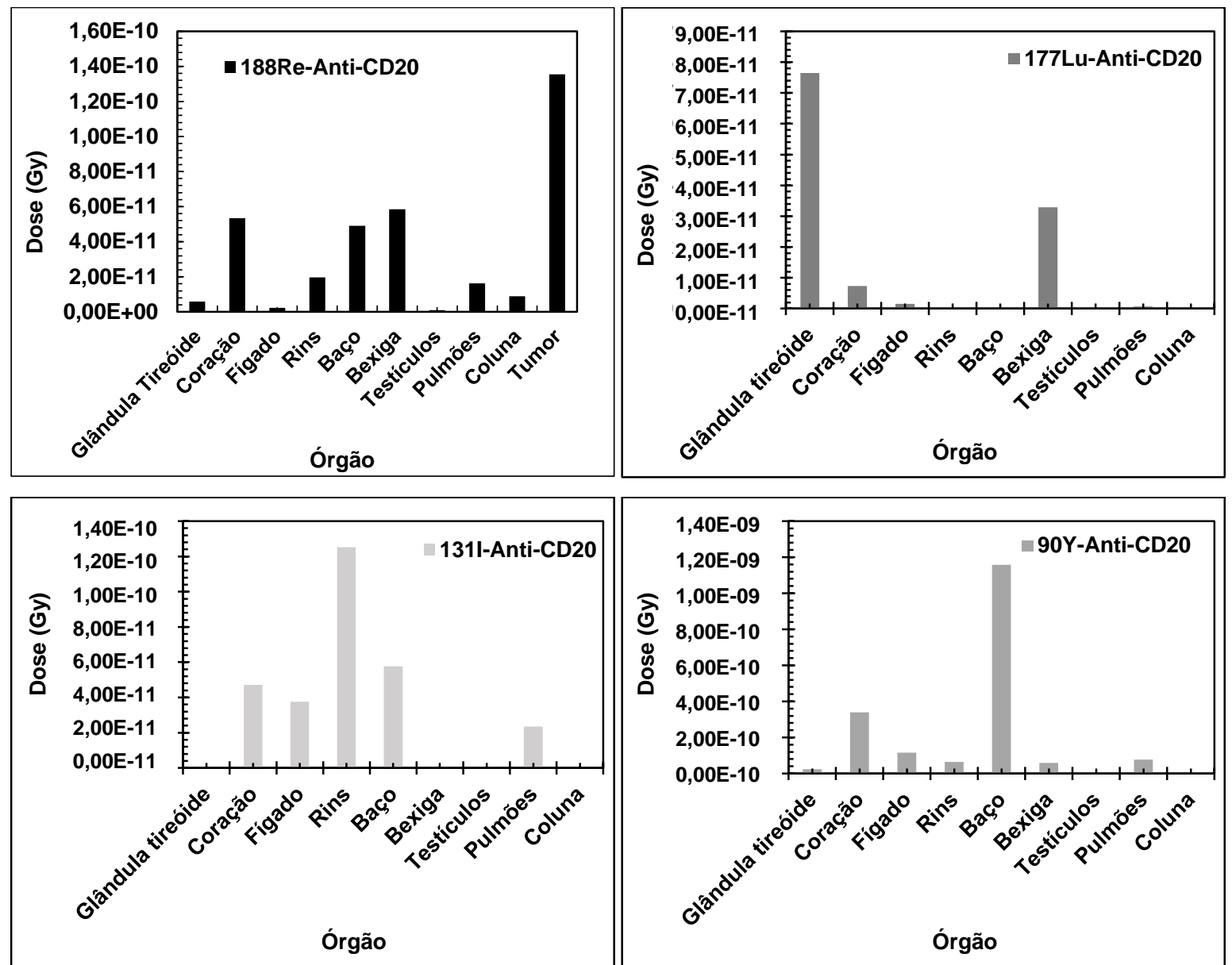

FIGURA 41 - Dose absorvida nos principais órgãos e no tumor (para $r=0,4 \mathrm{~cm}$ ) simulando uma condição em que Anti-CD20 marcado com ${ }^{90} \mathrm{Y},{ }^{131} \mathrm{I},{ }^{177} \mathrm{Lu}$ e ${ }^{188} \mathrm{Re}$ injetado no animal foi biodistribuído pelo corpo. Tempo de simulação: 300 minutos. Atividade simulada do radiofármaco: $85 \mathrm{~Bq}$.

De acordo com os resultados, simulações realizadas com tumores pequenos, a captação de ${ }^{188}$ Re-Anti-CD20 é pequena e mais uniforme nos principais órgãos do que em tumores maiores. Para a simulação com tumores maiores, a dose absorvida foi pequena para a região da coluna (que correspondeu a medula do animal). Além disso a captação do ${ }^{188}$ Re-Anti-CD20 continuou maior no tumor e a dose nos demais órgãos também foi pequena, considerando a bexiga como órgão a receber uma dose mais considerável, não apresentou altas doses absorvidas. Os demais radionuclídeos não apresentaram alteração significativa na dose absorvida, nas duas condições para as simulações realizadas, em decorrência da ausência da captação do anticorpo no tumor, não sendo realizados, por não serem presentados pela literatura. 
Os resultados da simulação computacional foram próximos a uma situação real (estudo in vivo em laboratório com animais de dimensões similares), em que após o produto ser injetado ele foi distribuído dentro do organismo.

A TAB. 23 mostra as doses absorvidas e as \%s obtidas em cada órgão e no tumor com os quatro radiofármacos, considerando simulações realizadas com biodistribuição no tumor e órgãos do produto, após a injeção do produto no animal. Para o ${ }^{188}$ Re-Anti-CD20 a distribuição foi de: tumor (45\%), coração (15\%), rins $(10 \%)$, baço (15\%) e bexiga (15\%). Para o ${ }^{177} \mathrm{Lu}$-Anti-CD20 a distribuição foi de: coração (5\%), tireóide (4\%), bexiga (12\%), pulmão (8\%), fígado (18\%). Para o ${ }^{131} \mathrm{I}-$ Anti-CD20 a distribuição foi de: coração (11\%), rins (1\%), baço (35\%), pulmão $(7 \%)$, fígado (18\%). Para o ${ }^{90}$ Y-Anti-CD20 a distribuição foi de: coração (5\%), tireóide (4\%), bexiga (12\%), pulmão (8\%), fígado (18\%). 
TABELA 23 - Doses absorvidas em cada órgão e no tumor em simulações realizadas com MCNP, com Anti-CD20 e cada um dos radionuclídeos ${ }^{188} \mathrm{Re},{ }^{177} \mathrm{Lu}$, ${ }^{131} \mathrm{I}$ e ${ }^{90} \mathrm{Y}$, para tumores de $r=0,4 \mathrm{~cm}$. Tempo para cada simulação: $300 \mathrm{~min}$. Atividade simulada do radiofármaco: $85 \mathrm{~Bq}$.

\begin{tabular}{|c|c|c|c|c|}
\hline \multicolumn{5}{|c|}{ Dose Absorvida (Gy) } \\
\hline Órgão & ${ }^{188}$ Re-Anti-CD20 & ${ }^{177}$ Lu-Anti-CD20 & ${ }^{131}$ I-Anti-CD20 & ${ }^{90} Y$-anti-CD20 \\
\hline Glândula Tireóide & $5,90.10^{-12}$ & 0 & 0 & $6,90 \cdot 10^{-12}$ \\
\hline Coração & $5,34 \cdot 10^{-11}$ & $4,33 \cdot 10^{-11}$ & $5,02 \cdot 10^{-11}$ & $5,36 \cdot 10^{-11}$ \\
\hline Fígado & $2,29.10^{-12}$ & $7,77.10^{-16}$ & $4,59 \cdot 10^{-15}$ & $2,97.10^{-12}$ \\
\hline Rins & $1,96 \cdot 10^{-11}$ & 0 & $1,56 \cdot 10^{-11}$ & $2,01 \cdot 10^{-11}$ \\
\hline Baço & $4,90 \cdot 10^{-11}$ & 0 & $4,44 \cdot 10^{-11}$ & $4,89.10^{-11}$ \\
\hline Bexiga & $5,86 \cdot 10^{-11}$ & $4,44 \cdot 10^{-11}$ & 0 & $5,89 \cdot 10^{-11}$ \\
\hline Testículos & $9,86 \cdot 10^{-13}$ & 0 & 0 & $1,34.10^{-12}$ \\
\hline Pulmões & $1,63 \cdot 10^{-11}$ & $5,57 \cdot 10^{-13}$ & $1,09.10^{-12}$ & $1,73 \cdot 10^{-11}$ \\
\hline Coluna & $8,82 \cdot 10^{-12}$ & 0 & 0 & $9,11 \cdot 10^{-12}$ \\
\hline Tumor & $1,35.10^{-10}$ & ND & ND & ND \\
\hline \multicolumn{5}{|c|}{$\%$ Dose Absorvida } \\
\hline Órgão & ${ }^{188}$ Re-Anti-CD20 & ${ }^{177}$ Lu-Anti-CD20 & ${ }^{131}$ I-Anti-CD20 & ${ }^{90} \mathrm{Y}$-anti-CD20 \\
\hline Glândula Tireóide & 1,7 & 0 & 0,0 & 3 \\
\hline Coração & 15,3 & 49 & 45 & 24 \\
\hline Fígado & 0,7 & 0 & 0 & 1 \\
\hline Rins & 5,6 & 0 & 14 & 9 \\
\hline Baço & 14,0 & 0 & 40 & 22 \\
\hline Bexiga & 16,7 & 50 & 0 & 27 \\
\hline Testículos & 0,3 & 0 & 0 & 1 \\
\hline Pulmões & 4,6 & 1 & 1 & 8 \\
\hline Coluna & 2,5 & 0 & 0 & 4 \\
\hline Tumor & 38,7 & ND & ND & ND \\
\hline
\end{tabular}

ND - Não Definido

Houve uma uniformização da dose no tumor para os radiofármaco, obtendo-se resultados em concordância com o os dados de captação dos principais órgãos sujeitos à uma maior exposição da dose (coração, baço, bexiga e o próprio tumor), que foram inseridos no programa (MCNP), indicando aproximação a um estudo real de biodistribuição in vivo. 
Estes resultados mostram a reprodutibilidade e a validade da utilização do método para avaliação de dose. Ou seja, uma vez estabelecido o modelo matemático para composição do corpo do animal, pode-se realizar inúmeros processos simulatórios com diferentes condições de dados de entrada (dados de biodistribuição do radiofármaco no corpo do animal) para determinação da dose absorvida. Desta forma, a proposta do presente trabalho pode ser considerada uma ferramenta importante nos estudos realizados com animais publicados em literatura.

A TAB. 24 mostra extrapolações realizadas para um homem de 70kg, diante dos resultados obtidos dos estudos de dosimetria pelo método de Monte Carlo, para ${ }^{188} \mathrm{Re}-A n t i-C D 20,45 \%$ do produto distribuído num tumor de 0,4 cm, e $15 \%$ no coração, baço e bexiga, e $10 \%$ do produto concentrado nos rins. Como no modelo animal, o tumor de 0,4 cm correspondeu ao maior tamanho aplicável que pudesse ser inserido no animal, foi utilizada a porcentagem de $1 \%$ da massa corpórea para definição da massa do tumor em humanos, para fazer a extrapolação dos dados de dosimetria.

TABELA 24 - Extrapolação da dose de ${ }^{188}$ Re-Anti-CD20, obtido por meio de simulações de Monte Carlo em um camundongo de $25 \mathrm{~g}$, para um homem de $70 \mathrm{~kg}$.

\begin{tabular}{|c|c|c|c|c|}
\hline \multirow[t]{2}{*}{ Órgão } & \multicolumn{2}{|c|}{$\begin{array}{c}\text { Experimental } \\
\text { Animal }(\mathrm{m}=25 \mathrm{~g})\end{array}$} & \multicolumn{2}{|c|}{$\begin{array}{c}\text { Extrapolação } \\
\text { Homem }(\mathrm{m}=70 \mathrm{~kg})\end{array}$} \\
\hline & Massa (g) & Dose (Gy) & Massa (g) & Dose (Gy) \\
\hline Glândula Tireóide & 0,002 & $5,90 \cdot 10^{-12}$ & 20 & $9,93.10^{-09}$ \\
\hline Coração & 0,124 & $5,34.10-11$ & 840 & $3,25.10^{-07}$ \\
\hline Fígado & 1,050 & $2,29 \cdot 10^{-12}$ & 1800 & $1,77.10^{-07}$ \\
\hline Rins & 0,280 & $1,96 \cdot 10^{-11}$ & 310 & $1,96.10^{-08}$ \\
\hline Baço & 0,090 & $4,90 \cdot 10^{-11}$ & 150 & $1,43.10^{-08}$ \\
\hline Bexiga & 0,065 & $5,86 \cdot 10^{-11}$ & 50 & $2,19.10^{-09}$ \\
\hline Testículos & 0,249 & $9,86 \cdot 10^{-13}$ & 35 & $2,81 \cdot 10^{-10}$ \\
\hline Pulmões & 0,135 & $1,63.10^{-11}$ & 1200 & $6,10 \cdot 10^{-07}$ \\
\hline Coluna & 0,206 & $8,82 \cdot 10^{-12}$ & 1170 & $3,79.10^{-07}$ \\
\hline Tumor & 0,268 & $1,35 \cdot 10^{-10}$ & 751 & $1,20.10^{-07}$ \\
\hline
\end{tabular}


A dose absorvida no tumor no corpo do animal não interfere na distribuição de dose nos principiais órgãos (considerando que a massa do tumor corresponde a $1 \%$ da massa total corpórea do animal). 0 resultado já era esperado e foi apresentado em resultados anteriores.

Quando as doses obtidas em animais são extrapoladas para um humano de $70 \mathrm{~kg}$ aproximadamente, a proporção da massa de cada órgão em relação à massa corpórea do humano, diferiu da proporção dos órgãos em relação a massa corpórea no animal. Com isso, a dose absorvida no tumor e distribuída nos órgãos por extrapolação acarretou em discordância nos resultados: onde a dose absorvida no tumor no animal correspondeu a $39 \%$, no homem essa captação é cerca de $7 \%$; no animal, a dose na coluna correspondeu a $2,5 \%$ da dose total, enquanto que no homem, a dose correspondente foi de $22,9 \%$. No homem, o coração recebeu cerca de $20 \%$ da dose absorvida (a massa do órgão correspondeu a cerca de $1,2 \%$ da massa total) e no animal essa dose correspondeu a 15\% (o órgão correspondeu a $0,5 \%$ da massa total).

\subsubsection{AVALIAÇÃo DA DOSE ABSORVIDA PELO MÉTODO POR FONTE PUNTIFORME DE EMISSORES $\beta$}

A construção da geometria do corpo do animal, pelo uso de equações matemáticas, foi realizada com o programa Excel, onde, cada planilha do programa, foi empregada para a construção de cada órgão (glândula tireóide, coração, pulmões, baço, fígado, bexiga, rins, testículos, coluna), no tumor e o corpo do animal.

Diferente do MCNP, que permitiu a visualização da estrutura do corpo em diferentes cortes e planos, o programa Excel permitiu ao usuário a visualização somente em cortes horizontais. A FIG. 42 mostra o resultado da junção de todas as planilhas, compondo os órgãos e o tumor dentro do corpo do animal, em um corte horizontal. 


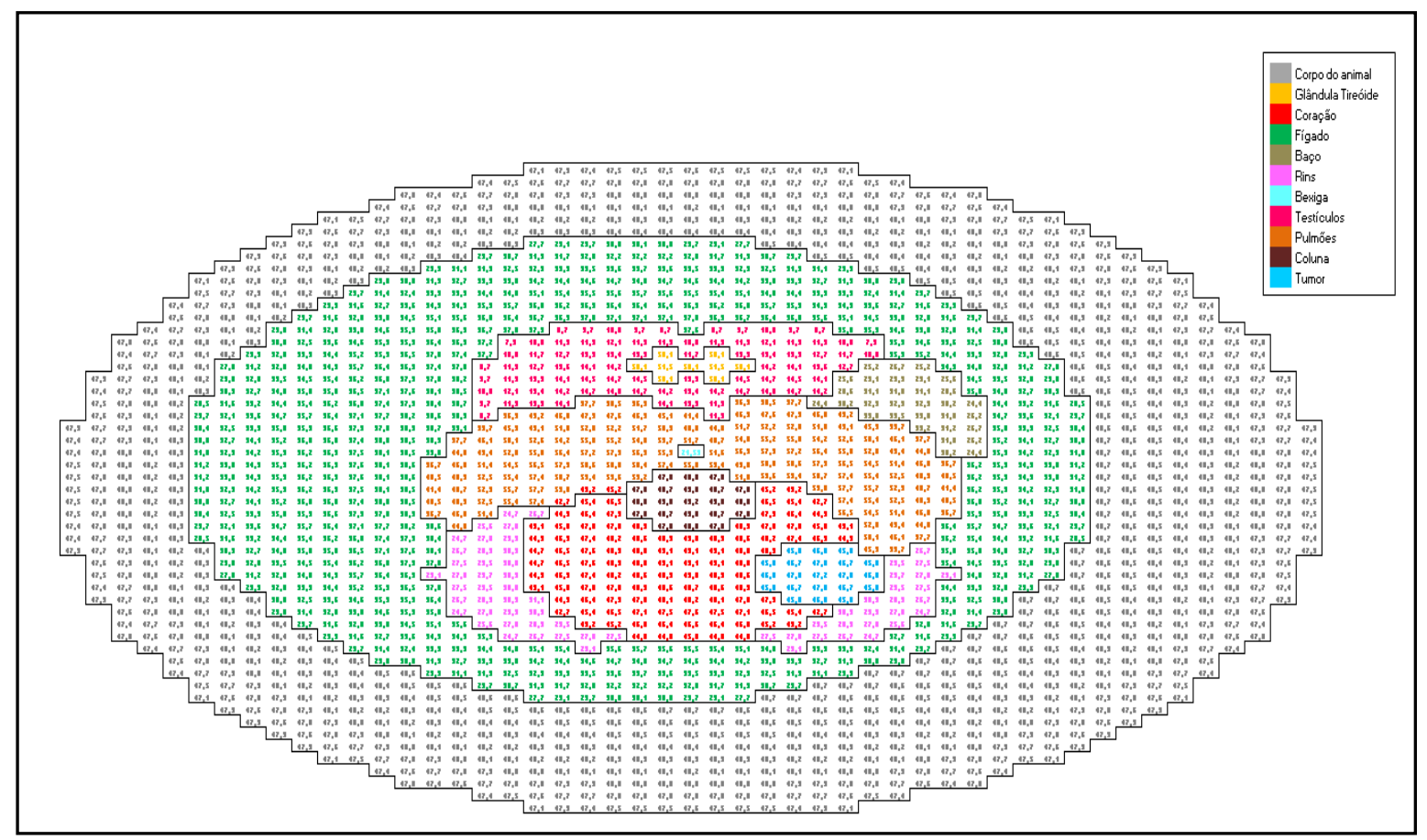

FIGURA 42 - Corte horizontal do modelo de corpo de um camundongo, construído a partir da união de diversas planilhas no programa excel, correspondendo a cada estrutura do corpo do animal, pelo uso de equações matemáticas.

No exemplo mostrado na FIG. 42, cada voxel correspondeu ao volume de uma célula, a qual foi definida pelo conjunto de equações da TAB. 10 para a construção de cada órgão e tumor dentro do corpo do animal. A posição do tumor foi a mesma utilizada na simulação de Monte Carlo (posicionada na região do dorso do animal), para não interferir nos resultados.

A FIG. 43 mostra graficamente o resultado da construção do corpo do animal, com a união de todas as planilhas, representadas por todos os órgãos e pelo tumor, mediante o uso do conjunto de equações geométricas da TAB. 10. 


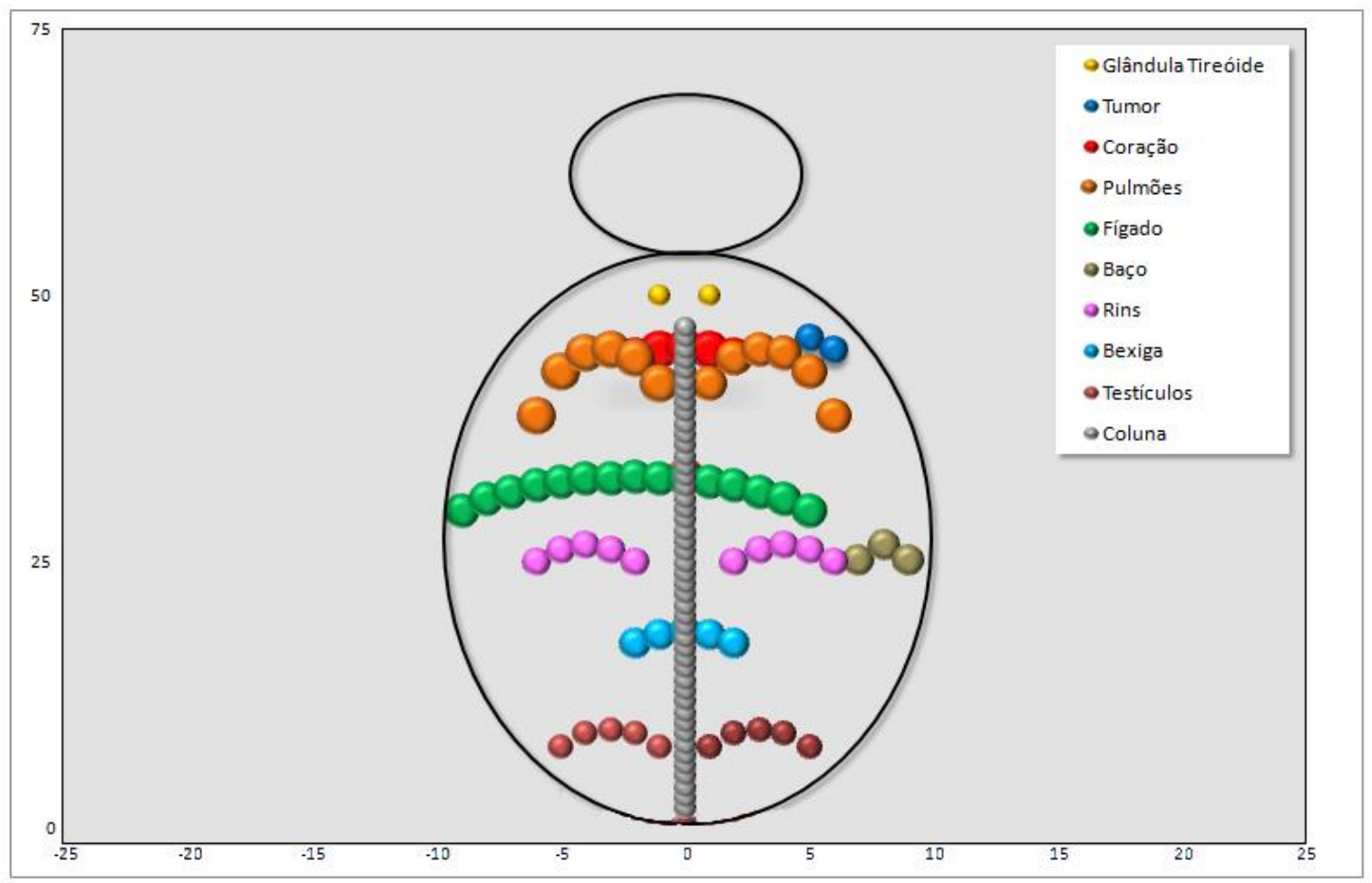

FIGURA 43 - Representação gráfica da estrutura do corpo de um camundongo construído por meio do conjunto de planilhas do excel, fazendo uso de equações geométricas, representando os órgãos e o tumor dentro do animal.

O método proposto, que visou calcular a dose absorvida para radionuclídeos emissores $\beta^{-}$apresentou diversas vantagens como: aplicação a diferentes modelos animais (não somente a camundongos, outros modelos animais e humanos); emprego de diferentes fontes geométricas e a flexibilidade de ser utilizado no programa Excel - uma ferramenta de fácil acesso e emprego.

As TABs. 25 e 26 mostram as doses e as taxas de dose calculadas nos tumores de diferentes dimensões radiais, a partir da fórmula de Loevinger para fonte puntiforme com radionuclídeos emissores $\beta$, para os radiofármacos: ${ }^{188}$ Re-AntiCD20, ${ }^{177}$ Lu-Anti-CD20, ${ }^{131}$ I-Anti-CD20 e ${ }^{90} Y$-Anti-CD20, por meio do conjunto de equações matemáticas utilizadas para construir a estrutura do corpo de um camundongo. A atividade inicial do radiofármaco considerada foi de $85 \mathrm{~Bq}$ e o tempo total da biodistribuição considerado foi de 5 horas (a mesma atividade obtida e o mesmo tempo utilizado para as simulações por Monte Carlo). 
TABELA 25 - Doses absorvidas em tumores de diferentes dimensões radiais, calculados pela fórmula de Loevinger. Atividade considerada: $85 \mathrm{~Bq}$. Tempo total considerado: 5 horas.

\begin{tabular}{|c|c|c|c|c|}
\hline \multirow{2}{*}{$\begin{array}{l}\text { Raio do Tumor } \\
\text { (cm) }\end{array}$} & \multicolumn{4}{|c|}{ Dose Absorvida (Gy) } \\
\hline & $\begin{array}{l}{ }^{188} \mathrm{Re} \\
\text { Anti-CD20 }\end{array}$ & $\begin{array}{l}177 \text { Lu } \\
\text { Anti-CD20 }\end{array}$ & $\begin{array}{l}131 \text { I } \\
\text { Anti-CD20 }\end{array}$ & $\begin{array}{l}{ }^{90} \mathrm{Y} \\
\text { Anti-CD20 }\end{array}$ \\
\hline 0,01 & $8,74.10^{7}$ & $5,86 \cdot 10^{7}$ & $6,94 \cdot 10^{7}$ & $9,88 \cdot 10^{7}$ \\
\hline 0,02 & $2,03.10^{7}$ & $1,00.10^{7}$ & $1,28.10^{7}$ & $2,31.10^{7}$ \\
\hline 0,03 & $8,41 \cdot 10^{6}$ & $3,06.10^{6}$ & $4,23.10^{6}$ & $9,62.10^{6}$ \\
\hline 0,04 & $4,40.10^{6}$ & $1,18.10^{6}$ & $1,76.10^{6}$ & $5,06.10^{6}$ \\
\hline 0,05 & $2,62.10^{6}$ & $5,19.10^{5}$ & $8,34 \cdot 10^{5}$ & $3,03.10^{6}$ \\
\hline 0,06 & $1,69.10^{6}$ & $2,47.10^{5}$ & $4,28.10^{5}$ & $1,97.10^{6}$ \\
\hline 0,07 & $1,16.10^{6}$ & $1,24.10^{5}$ & $2,33.10^{5}$ & $1,36.10^{6}$ \\
\hline 0,08 & $8,24.10^{5}$ & $6,53.10^{4}$ & $1,32.10^{5}$ & $9,71.10^{5}$ \\
\hline 0,09 & $6,06.10^{5}$ & $3,54.10^{4}$ & $7,72.10^{4}$ & $7,18.10^{5}$ \\
\hline 0,1 & $4,57.10^{5}$ & $1,97.10^{4}$ & $4,63 \cdot 10^{4}$ & $5,44.10^{5}$ \\
\hline 0,2 & $5,55.10^{4}$ & $1,13.10^{2}$ & $5,71.10^{2}$ & $7,01 \cdot 10^{4}$ \\
\hline 0,3 & $1,20.10^{4}$ & $1,16.10^{0}$ & $1,25.10^{1}$ & $1,61.10^{4}$ \\
\hline 0,4 & $3,27.10^{3}$ & $1,50.10^{-2}$ & $3,47.10^{-1}$ & $4,65.10^{3}$ \\
\hline
\end{tabular}

Os resultados indicam que quanto maior o tamanho do tumor, menor é a dose depositada e maior a chance de atingir órgãos mais críticos (como coluna, rins, fígado e coração). O comportamento da dose dos radiofármacos frente a diferentes dimensões de tumor mostrou um resultado esperado, como visto pelo método de Monte Carlo. Dentre os radiofármacos analisados, ${ }^{188} \mathrm{Re}$-Anti-CD20 e ${ }^{90} \mathrm{Y}$-Anti-CD20 mostraram-se mais adequados para tratamento de tumores maiores, destacando a vantagem de ${ }^{188}$ Re possuir uma energia $\gamma$ associada que $0{ }^{90} Y$ não possui, por ser um emissor $\beta^{-}$puro. 
TABELA 26 - Taxas de doses absorvidas no tumor de diferentes dimensões radiais, calculados pela fórmula de Loevinger. Atividade considerada: $85 \mathrm{~Bq}$. Tempo total considerado: 5 horas.

\begin{tabular}{|c|c|c|c|c|}
\hline \multirow{3}{*}{$\begin{array}{l}\text { Raio do Tumor } \\
\text { (cm) }\end{array}$} & \multicolumn{4}{|c|}{ Taxa de Dose absorvida (Gy/h) } \\
\hline & ${ }^{188} \mathrm{Re}$ & ${ }^{177} \mathrm{Lu}$ & 131| & $90 \mathrm{Y}$ \\
\hline & Anti-CD20 & Anti-CD20 & Anti-CD20 & Anti-CD20 \\
\hline 0,01 & $8,85.10^{-7}$ & $6,67.10^{-7}$ & $7,91 \cdot 10^{-7}$ & $1,11.10^{-6}$ \\
\hline 0,02 & $2,06 \cdot 10^{-7}$ & $1,14 \cdot 10^{-7}$ & $1,46 \cdot 10^{-7}$ & $2,59 \cdot 10^{-7}$ \\
\hline 0,03 & $8,51 \cdot 10^{-8}$ & $3,48 \cdot 10^{-8}$ & $4,81 \cdot 10^{-8}$ & $1,08 \cdot 10^{-7}$ \\
\hline 0,04 & $4,45.10^{-8}$ & $1,34.10^{-8}$ & $2,00.10^{-8}$ & $5,67 \cdot 10^{-8}$ \\
\hline 0,05 & $2,65.10^{-8}$ & $5,90.10^{-9}$ & $9,50 \cdot 10^{-9}$ & $3,40.10^{-8}$ \\
\hline 0,06 & $1,71.10^{-8}$ & $2,81 \cdot 10^{-9}$ & $4,88 \cdot 10^{-9}$ & $2,21.10^{-8}$ \\
\hline 0,07 & $1,17.10^{-8}$ & $1,42.10^{-9}$ & $2,65.10^{-9}$ & $1,52.10^{-8}$ \\
\hline 0,08 & $8,34 \cdot 10^{-9}$ & $7,43 \cdot 10^{-10}$ & $1,50.10^{-9}$ & $1,09 \cdot 10^{-8}$ \\
\hline 0,09 & $6,13 \cdot 10^{-9}$ & $4,03 \cdot 10^{-10}$ & $8,80 \cdot 10^{-10}$ & $8,04 \cdot 10^{-9}$ \\
\hline 0,1 & $4,62.10^{-9}$ & $2,24.10^{-10}$ & $5,27.10^{-10}$ & $6,09.10^{-9}$ \\
\hline 0,2 & $5,61 \cdot 10^{-10}$ & $1,29.10^{-12}$ & $6,50 \cdot 10^{-12}$ & $7,85.10^{-10}$ \\
\hline 0,3 & $1,21.10^{-10}$ & $1,31 \cdot 10^{-14}$ & $1,43 \cdot 10^{-13}$ & $1,80.10^{-10}$ \\
\hline 0,4 & $3,31 \cdot 10^{-11}$ & $1,70.10^{-16}$ & $3,96 \cdot 10^{-15}$ & $5,21 \cdot 10^{-11}$ \\
\hline
\end{tabular}

Pode-se analisar que a partir da obtenção da atividade acumulada (determinada pelo MCNP devido ao longo do tempo de simulação de $5 \mathrm{~h}$ para cada radiofármaco), em função da meia-vida efetiva para cada radiofármaco, para tumores menores, a taxa de dose permaneceu constante para os quatro radiofármacos. Somente para tumores maiores, radiofármacos com Anti-CD20 marcados com ${ }^{188} \mathrm{Re}$ e ${ }^{90} \mathrm{Y}$ apresentaram resultados mais satisfatórios dentre os demais, com resultados na ordem de $10^{-11} \mathrm{~Gy} / \mathrm{h}$, possibilitando um maior tempo do radiofármaco interagindo dentro do tumor, fator positivo para um tratamento em RIT.

Além das taxas de doses obtidas para os radiofármacos ${ }^{188} \mathrm{Re}$-Anti-CD20, ${ }^{177}$ Lu-Anti-CD20, ${ }^{131}$ I-Anti-CD20 e ${ }^{90}$ Y-Anti-CD20 com o uso da fórmula de Loevinger na metodologia para determinação da dosimetria no modelo de corpo de um camundongo construído com as equações geométricas (mesmas equações utilizadas para o método de Monte Carlo) no programa Excel e também no método de Monte Carlo. As FIGs. 44 a 47 mostram comparativamente as duas metodologias, com as taxas de dose obtidas em função dos diferentes tamanhos de tumor. 


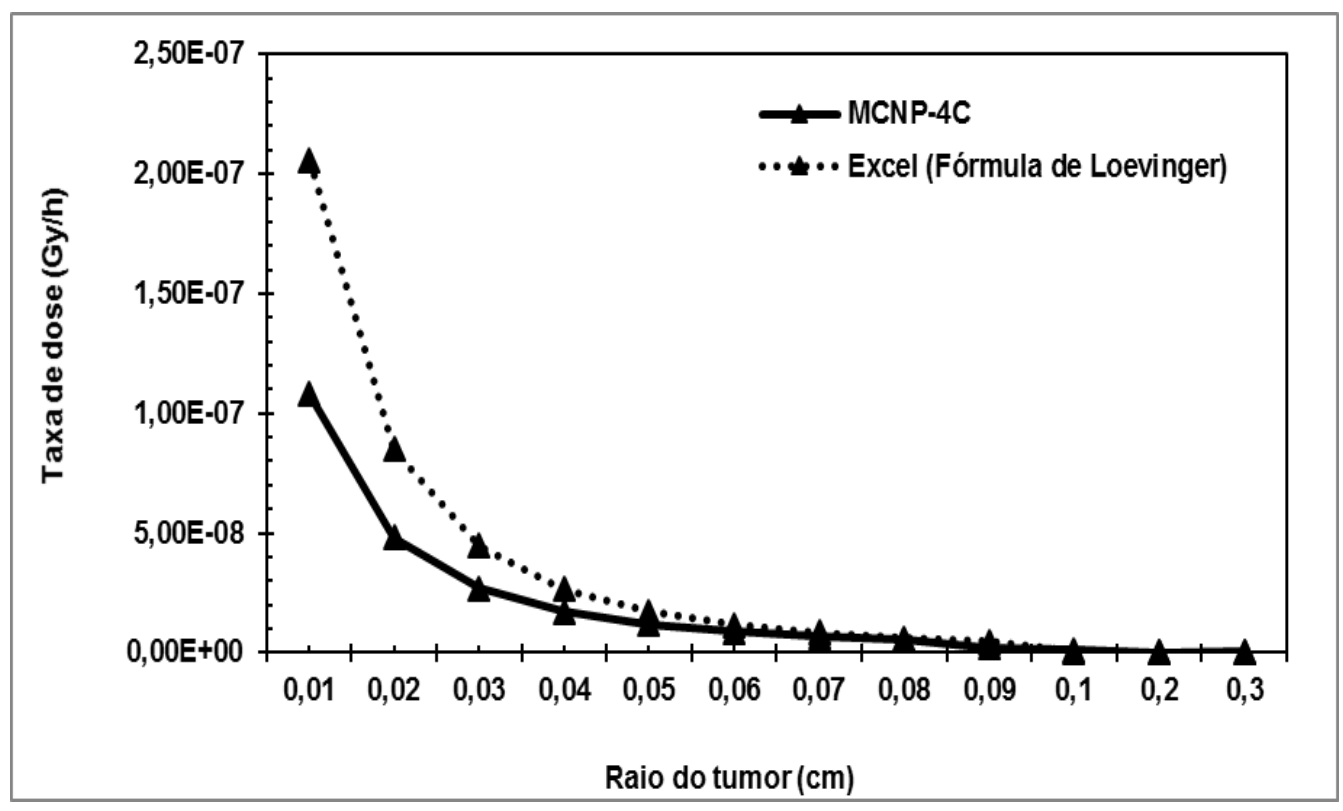

FIGURA 44 - Comparação dos resultados da taxa de dose obtidos via forma analítica (pela fórmula de Loevinger) e o método de Monte Carlo para ${ }^{188} \mathrm{Re}$-AntiCD20, em diferentes tamanhos de tumores.

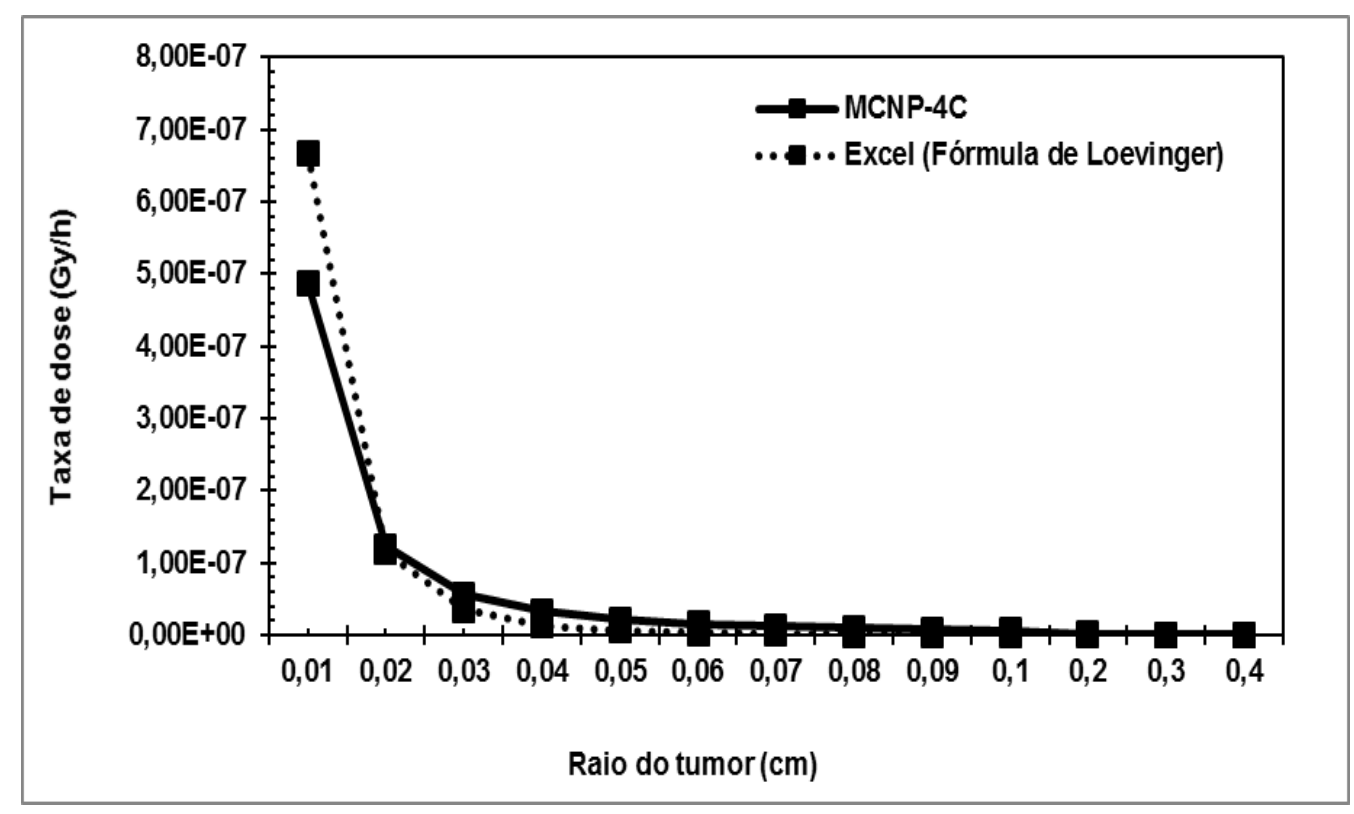

FIGURA 45 - Comparação dos resultados da taxa de dose obtidos via forma analítica (pela fórmula de Loevinger) e o método de Monte Carlo para ${ }^{177} \mathrm{Lu}$-AntiCD20, em diferentes tamanhos de tumores. 


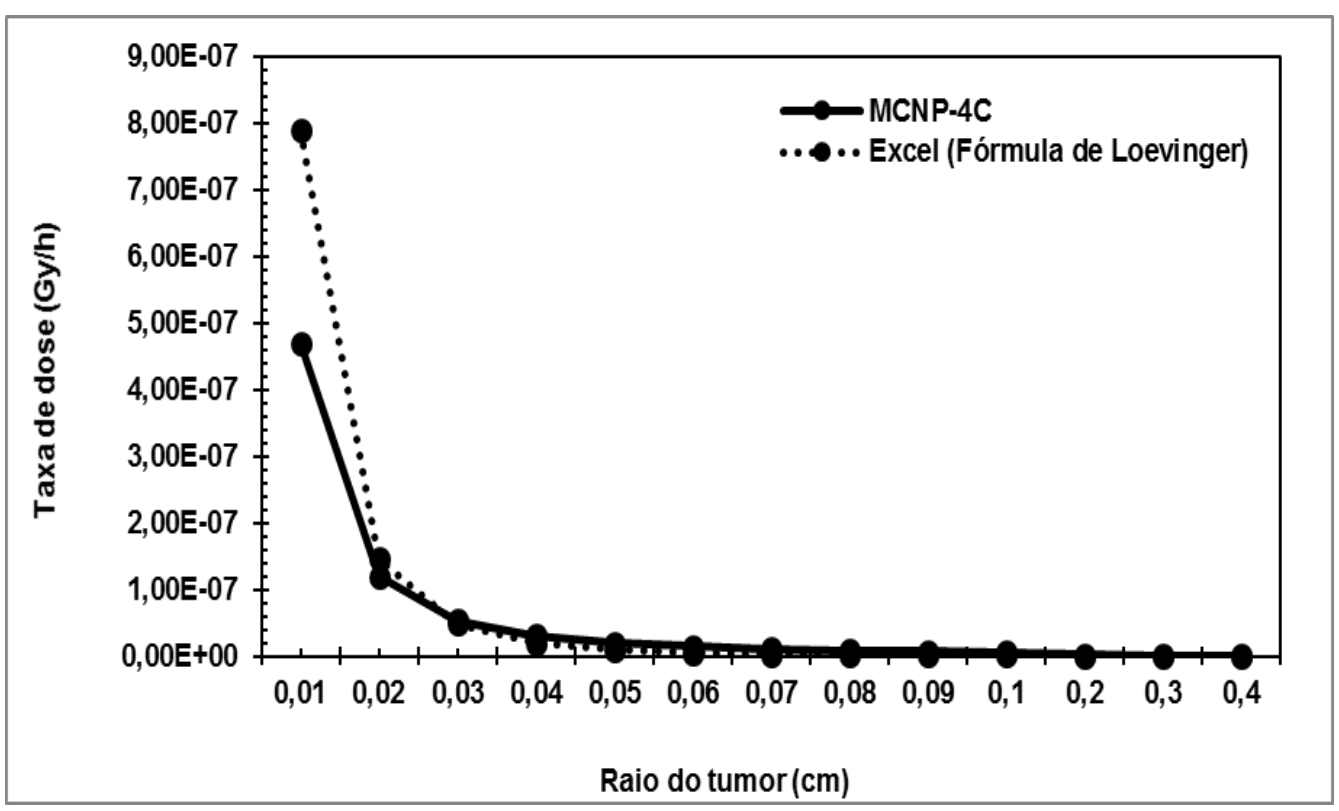

FIGURA 46 - Comparação dos resultados da taxa de dose obtidos via forma analítica (pela fórmula de Loevinger) e o método de Monte Carlo para ${ }^{131}$ I-Anti-CD20, em diferentes tamanhos de tumores.

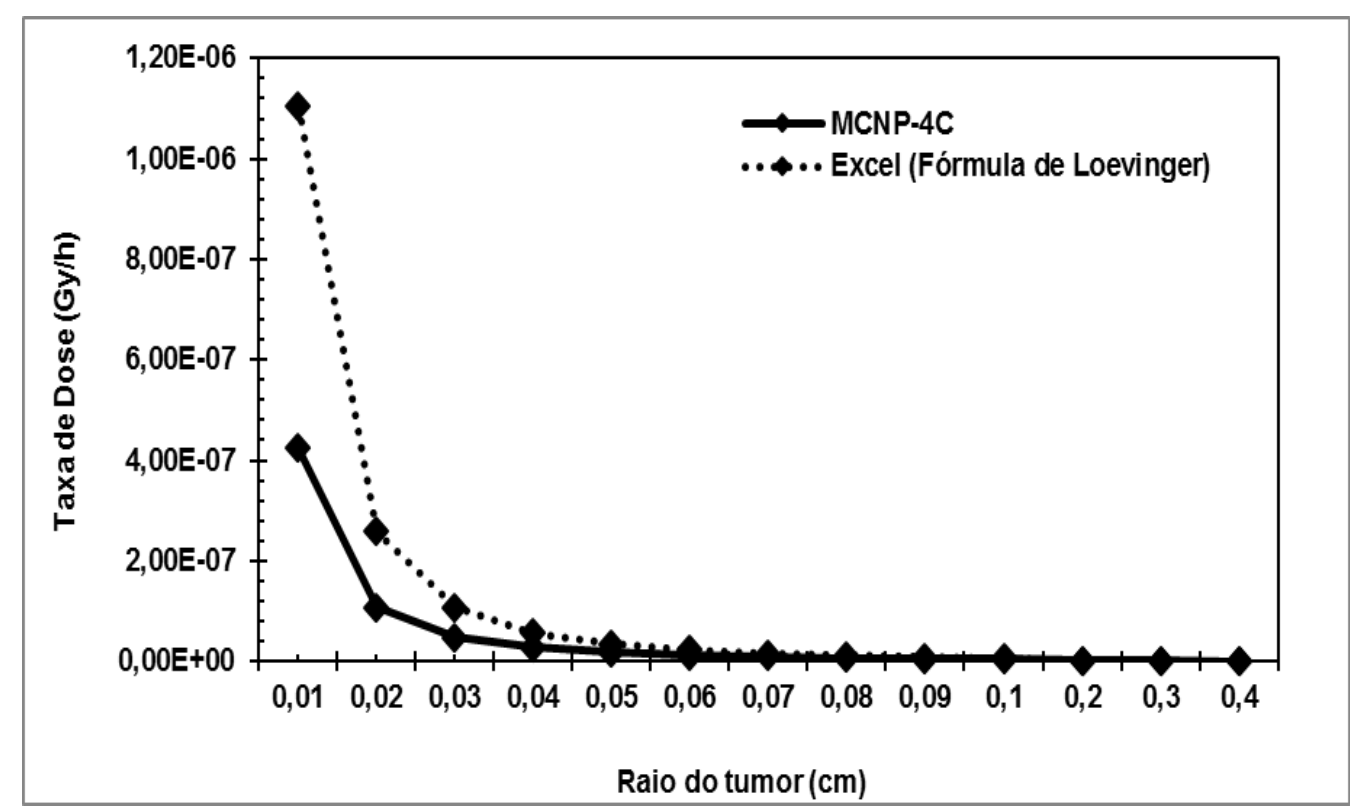

FIGURA 47 - Comparação dos resultados da taxa de dose obtidos via forma analítica (pela fórmula de Loevinger) e o método de Monte Carlo para ${ }^{90} \mathrm{Y}$-Anti-CD20, em diferentes tamanhos de tumores.

Os gráficos mostram uniformidade nos resultados de taxa de dose para todos os radiofármacos em estudo, tanto para o MCNP quanto para o Excel, sendo que o último método fez uso da equação de Loevinger para fonte pontual. 
Além disso, os resultados mostram que o uso de modelos matemáticos para estudos em animais como camundongos no método de Monte Carlo, proposto neste trabalho, é altamente viável para estudos de dosimetria em animais, comprovado pela concordância nas taxas de dose obtidas nos dois métodos em função do tamanho do tumor.

O método de Monte Carlo apresentou taxas de dose absorvida menores do que a fonte puntiforme, justificado pelo processo de simulação do código; a existência de uma biblioteca de dados, referentes a características nucleares de diversos radioisótopos, tipos e composição de materiais, proporcionando uma maior precisão nos resultados. 


\section{CONCLUSÕES}

O AcM Anti-CD20 tem sido marcado a diversos radionuclídeos utilizando métodos simples e rápidos, obtendo radioimunoconjugados química e biologicamente estáveis, com vistas ao tratamento de tumores. Possui potencialidade para aplicações clínicas como um radiofármaco terapêutico para tratamento de $\mathrm{LNH}$. As propriedades físicas do ${ }^{188}$ Re são favoráveis à RIT, quando diretamente marcado ao AcM. A energia máxima de emissão $\beta$ - de 2,12 MeV do ${ }^{188} \mathrm{Re}$ é da mesma magnitude que $0{ }^{90} \mathrm{Y}\left(\mathrm{E}_{\operatorname{máx}}=2,27 \mathrm{MeV}\right)$, exibindo ambos uma penetração similar no tecido e um cross fire em tumores volumosos, pela irradiação das células tumorais que não são ligadas ao AcM radiomarcado. Em nível celular, considerando o radiofármaco ligado à superfície da célula e o efeito cross fire, estimativas dosimétricas mostraram uma energia média específica $(\bar{z})$ para o núcleo celular de 1,34 x 10-3 Gy para ${ }^{188} \mathrm{Re}-A n t i-C D 20$ [TORRES-GARCIA et al, 2008].

O ${ }^{188} \mathrm{Re}$-Anti-CD20 possui estabilidade in vivo, segurança, e capacidade de detectar os locais dos tumores. Por causa da sua energia de radiação $\gamma$, o uso do ${ }^{188} \mathrm{Re}$ como alternativa a do ${ }^{131} \mathrm{I}$, produziria menos exposição à radiação ao paciente e ao profissional, durante e após a administração do radiofármaco.

$\mathrm{O}$ estudo quanto as propriedades físicas do ${ }^{188} \mathrm{Re}$ mostraram que $\mathrm{O}$ radionuclídeo é um excelente candidato para RIT quando marcado diretamente com Anti-CD20, principalmente quando comparado aos principais radionucídeos emissores $\beta$.

A análise farmacocinética mostrou que o método de marcação atualmente existente para obtenção do ${ }^{188}$ Re-Anti-CD20 é favorável, apresentando constantes de eliminação semelhantes quando outros radionuclídeos foram radiomarcados com o mesmo anticorpo.

O estudo de dosimetria apresentou resultados satisfatórios e uma concordância entre os resultados obtidos com os dois métodos apresentados neste trabalho. Dentre os diversos programas disponíveis e códigos sofisticados para cálculo de dose, o método de Monte Carlo (onde neste trabalho utilizou-se o MCNP4C) tornou-se de suma importância para realização de simulações e estudos de dosimetria em animais, apresentando-se como uma ferramenta no estudo e implementação de novos radiofármacos usados em Medicina Nuclear, em Institutos 
de Pesquisa, incluindo-se o Centro de Radiofarmácia. O método em que faz uso de uma fonte puntiforme, utilizando a fórmula de Loevinger para cálculos dosimétricos, pôde ser validado junto ao MCNP, apresentando resultados satisfatórios. Este método, apresentou como vantagem, características didáticas, pois faz uso de um programa de fácil utilização e disponiblidade (microsoft Excell), e desta forma pode se tornar uma ferramenta em estudos de dosimetria em Centros de Pesquisa que trabalhem com dosimetria em animais. 


\section{REFERÊNCIAS BIBLIOGRÁFICAS}

AKANJI, A. G., Estudo de marcação com iodo-131 de anticorpo monoclonal AntiCD20 usado na terapia de linfoma não-Hodgkin's. (Dissertação de Mestrado), 2006.

AGÊNCIA NACIONAL DE VIGILÂNCIA SANITÁRIA (ANVISA).

http://portal.anvisa.gov.br. Acesso em 03/08/2015.

AUDICIO, P. F., CASTELLANO G., TASSANO, M. R., REZZANO, M. E., FERNANDEZ, M., RIVA, E., ROBLES, A., CABRAL, P., BALTER, H., OLIVER, P. ${ }^{177}$ Lu-DOTA-Anti-CD20:Labeling and pre-clinical studies. Appl. Radiat. Isototopes, v. 69, p. 924-928, 2011.

AURLIEN, E., LARSEN, R. H., KVALHEIM, G., BRULAND, O. S. Demonstration of highly specific toxicity of the $\alpha$-emitting radioimmunoconjugate ${ }^{211} \mathrm{At}$-rituximab against non-Hodgkin's lymphoma cells. Br. J. Cancer., v. 83, n. 10, p. 1375-1379, 2000.

BARRIO, G. Desenvolvimento de tecnologias de preparo de geradores de ${ }^{90} \mathrm{Sr} /{ }^{90} \mathrm{Y}$ na Diretoria de Radiofarmácia do IPEN/CNEN-SP. (Dissertação de mestrado), 2010.

BOUTALEB. S., POUGET, J. P., HINDORF, C., PÈLEGRIN, A., BARBET, J., KOTZKI, P. O., BARDIÈS, M. Impact of Mouse Model on Pre-Clinical Dosimetry in Targeted Radionuclide Therapy. Proceedings of the IEEE 2009, v. 97, n. 12, p. 2076-2085, 2010.

BRIESMEISTER, J. F., MCNPTM - A general Monte Carlo n-particle transport code version 4C. Manual LA-13709-M, Los Alamos, 2000.

BUSHBERG, J. R. T., SEIBERT, J. A., LEIDHOLDT, E. M., BONNE, J. M. The Essential Physics of Medical Imaging. Second Edition. Philadelphia: Lippincott Williams and Wilkins, 2002.

BINYAMIN, L., BORGHAEI, H., WEINER, L. M., Cancer therapy with engineered monoclonal antibodies. Update on Cancer Therapeutics I, p. 147-157, 2006.

CAMPBELL, P., MARCUS, R. Monoclonal antibody therapy for lymphoma. Blood Rev., v. 17, p. 143-152, 2003. 
CARTRON, G.; WATIER, H.; GOLAY, J.; SOLAL-CELIGNY, P. From the bench to the bedside: ways to improve rituximab efficacy. Blood, v. 104, pp. $2635-2642$, 2004.

CHATAL, J.F., HOEFNAGEL, C.A. Radionuclide Therapy. Lancet, v. 354, p.931 935, 1999.

CREMONESI, M., FERRARI, M., ZOBOLI, S., et al. Biokinetics and dosimetry in patients administered with ${ }^{111}$ In-DOTA-Tyr3-octreotide: implications for internal radiotherapy with ${ }^{90}$ Y-DOTATOC. J. Nucl. Med. v. 26, p. 877-886, 1999.

DADACHOVA, E. Cancer Therapy with Alpha-Emitters Labeled Peptides. Semin. Nucl. Med., v. 40, p. 204-208, 2010.

DAS, T., BANERJEE, S. Theranostic Applications of Lutetium-177 en Radionuclide Therapy. Curr. Radioph., v. 9, p. 94-101, 2016.

DASH, A., KNAPP JR, F. F. An overview of radioisotope separation technologies for development of ${ }^{188} \mathrm{~W} /{ }^{188} \mathrm{Re}$ radionuclide generators providing ${ }^{188} \mathrm{Re}$ to meet future research and clinical demands. $\boldsymbol{R S C} \boldsymbol{A d v}$. v. 5, p. 39012-39036, 2015.

DEARLING, J. L.J., PEDLEY, R. B. Technological Advances in Radioimmunotherapy. J. Clin. Oncol., v. 19, p. 457-469, 2007.

DIAS, C. R. B. R. Estudo Comparativo da Marcação do Anticorpo Anti-CD20 com ${ }^{188} \mathrm{Re}$. (Tese de Doutorado). Instituto de Pesquisas energéticas e Nucleares de São Paulo (IPEN/CNEN-SP), 2010.

DIAS, C. R. B. R., JEGER, S., OSSO JR, J. A., MÜLLER, C., PASQUALE, C., HOHN, A., WAIBEL, R., SCHIBILI, R. Radiolabeling of rituximab with ${ }^{188} \mathrm{Re}$ and ${ }^{99 m}$ Tc using the tricarbonyl technology. Nucl. Med. Bio., v. 38, p. 19-28, 2011.

DIETZ, M.L., HOROWITZ, E.P. Improved chemistry for the production of Yttrium-90 for medical applications. Appl. Radiat. Isotopes v. 43, n. 9, p. 1093-1101, 1992.

EISENBEIS, C. F., CALIGIURI M. A., BYRD, J. C. Rituximab: converging mechanisms of action in non-Hodkin's lymphoma? Clin. Cancer Res. v. 9, p. 58105812, 2003.

EISENBERG, R., LOONEY, R. J. The therapeutic potential of Anti-CD20. What do B-cells do? Clin. Immunol., v. 117, p. 207-213, 2005.

FERRO-FLORES, G., MURPHY, C. A., Pharmacokinetics and dosimetry of ${ }^{188}$ Repharmaceuticals. Adv. Drug Deliver Rev., v. 60, p. 1389-1401, 2008. 
FISHER, D.R. From "micro" to "macro" internal dosimetry. In: Internal radiation dosimetry, Raabe, O.G. (ed.), Med. Phys. Publ., Madison, p. 61-80, 1994.

FORRER, F.; CHEN, J.; FANI, M.; POWELL, P.; LOHRI, A.; MÜLLER-BRAND, J.; MOLDENHAUER, G.; MAECKE, H.R., In vitro characterization of (177)Luradiolabelled chimeric anti-CD20 monoclonal antibody and a preliminary dosimetry study. Eur. J. Nucl. Med. Mol. Imaging.,v. 36, p. 1443-1452, 2009.

FORSTER G. J., ENGELBACH M. J., BROCKMANN J. J., et al. Preliminary data on biodistribution and dosimetry for therapy planning of somatostatin receptor positive tumours: comparison of ${ }^{86} \mathrm{Y}$-DOTATOC and ${ }^{111}$ In-DTPA-octreotide. J. Nucl. Med. v. 28, p. 1743-1750, 2001.

GAD, S. Radiation dosimetry: Instrumentation and methods. Second Edition. CRC Press, London, 2000.

GAD, S. C. The Radiopharmaceutical science of monoclonal antibodies and peptides for imaging and targeted in situ radiotherapy of malignances - Labeling mAbs and Peptides with radiometals - Yttrium Radionuclides. Handbook of Pharmaceutical Biotechnology. p. 913-915, 2007.

GLENNIE, J. M., FRENCH, R. R., CRAGG, M. S., TAYLOR, R. P. Mechanism of killing by Anti-CD20 monoclonal antibodies. Mol. Immunol., v. 44, p. 3823-3837, 2007.

HARRIS, M. Monoclonal antibodies as therapeutic agents for cancer. Lanc. Oncol., v. 5, p. 292-302, 2004.

HAMOUDEH, M., KAMLEH, M. A., DIAB, R., FESSI, H. Radionuclides delivery systems for nuclear imaging and radiotherapy of cancer. Adv. Drug Deliver Rev., v. 60, p. 1329-1346, 2008.

HELISCH A., FORSTER G. J., REBER H., et al. Pre-therapeutic dosimetry and biodistribution of ${ }^{86} \mathrm{Y}$-DOTA-Phe 1 -Tyr 3-octreotide versus ${ }^{111}$ In-pentetreotide in patients with advanced neuroendocrine tumours. J. Nucl. Med. Molec. Imag. v. 31, p. 1386-1392, 2004.

HENRIKSEN, G., HOFF, P., LARSEN, R. H. Evaluation of potential chelating agents for radium. Appl. Radiat. Isotopes, v. 56, p. 667-671, 2002.

HINDORF, C., JUNGBERG, M., STRAND, S.E. Evaluation of Parameters Influencing S Values in Mouse Dosimetry. J. Nucl. Med., v. 45, p.1960-1965, 2004. 
HOFF, J., KINETIC MODELLING. Small Animals Imaging - Basics and Practical Guide. p. 387-403, 2011.

HORTON, P, W. Radionuclide Techniques in Clinical Investigation. Medical Physics Handbooks, v. 12, 1982.

HUI, T. E., FISHER, D. R., KUHN, J. A., A Mouse Model for Calculation CrossOrgan Beta Doses from Yttrium-90-Labeled Immunoconjugates. Cancer Supp., v. 73, n. 3, p. 951-957, 1994.

IAEA. Production of Long Lived Parent Radionuclides for Generators: ${ }^{68} \mathrm{Ge}$, ${ }^{82} \mathrm{Sr},{ }^{90} \mathrm{Sr}$ and ${ }^{188} \mathrm{~W}$, p. $1-9,2010$.

ICRP PUBLICATION 89. Basic Anatomical and Physiological Data for Use in Radiological Protection: Reference Values. Annals of the ICRP., v. 32, Issues 3-4, 2002.

ICRU 1992 Photon, Electron, Proton and Neutron Interaction Data for Body Tissues ICRU Report No 46 (Bethesda, MD: ICRU), 1992.

INSTITUTO NACIONAL DE CÂNCER (INCA). http://www2.inca.gov.br. Acesso em 23/02/2015.

IZNAGA-ESCOBAR, N. Direct radiolabeling of monoclonal antibodies with rhenium188 for radioimmunotherapy of solid tumors - a review of radiolabeling characteristics, quality control and in vitro stability studies. Appl. Radiat. Isotopes, v. 54, p. 399-406, 2001.

IZNAGA-ESCOBAR, N. ${ }^{188}$ Re-Direct Labeling of Monoclonal Antibodies for Radioimmunotherapy of Solid Tumors: Biodistribution, Normal Organ Dosimetry, and Toxicology. Nucl. Med. Bio., v. 25, p. 441-447, 1998.

JACOBI, A. M., DÖRNER, T. Current aspects of Anti-CD20 therapy in rheumatoid arthritis. Curr. Opin. Pharm. v. 10, p. 316-321, 2010.

KASSIS, A. L., ADELSTEIN, J. Considerations in the selection of radionuclides for cancer therapy. Handbook Radiopharma., Radioch. Appl., Willey \& Sons, Londom, p. 767-793, 2003.

KELKAR, S. S., REINEKE, T. M. Theranostics: Combining Imaging and Therapy. Bioconjugate Chem., v. 22, 1879-1903, 2011. 
KENNEL, S. J., STABIN, YORIYAZ, H., BRECHBIEL, M., MIRZADEH, S.

Treatment of Lung Tumor Colonies with ${ }^{90} \mathrm{Y}$ Targeted to Blood Vessels: Comparsion with the $\alpha$-Particle Emitter ${ }^{213} \mathrm{Bi}$. Nucl. Med. Bio. v. 26, p. 149-157, 1999.

KEITH, M., NORWICH, K. H., WONG, W., JEEJEEBHOY, K. N. The tissue distribution of tumor necrosis factor- $\alpha$ in rats: a compartmental model. Metabolis, v. 49, No. 10, p. 1309-1317, 2000.

KNAPP, R. Comunicação Pessoal, 2006.

KOHLEN, G., MILSTEIN, C. Continuous cultures of fused cells secreting antibody of predefinided specificity. Nature. v. 256, p. 495-497, 1975.

KRUGER, P. C., COONEY, J. P., TURNER, H. lodine-131 Rituximab Radioimunotherapy with BEAM Conditioning and Autologaus Stem Cell Transplant Salvage Therapy for Relapsed/Refractory Aggressive Non-Hodgkin Lymphoma. Cancer Bioter. Radio. v. 27 (9), p. 552-560, 2012.

LASSMANN, M., EBERLEIN, U. Radiation Dosimetry Aspects of ${ }^{177}$ Lu. Curr. Radioph. v. 8, p. 139-144, 2015.

LIANG, H., YANG, Y., YANG, K., WU, Y., BOONE, J. M., CHERRY, S. R. A micro $\mathrm{PET} / \mathrm{CT}$ system for in vivo small animal imaging. Phys. Med. Biol., v. 52, p. 38813894, 2007.

LIU, A., WILLIAMS, L., LOPATIN, G., YAMAUCHI, D., WONG, J., RAUBITSCHEK, A., A radionuclide therapy treatment planning and dose estimation system. $\mathbf{J}$. Nucl. Med. v. 40, p. 1151-1153, 1999.

LIU, C., LIU, G., LIU, N., ZHANG, Y., HE, J., RUSCKOWSKI, M., HNATOWICH, D, J. Radiolabeling morpholinos with ${ }^{90} \mathrm{Y},{ }^{111} \mathrm{In},{ }^{188} \mathrm{Re}$ and ${ }^{99 \mathrm{~m} T \mathrm{~T} .}$. Nucl. Med. Bio., v. 30, p. 207-214, 2003.

LOISEL, S., OHRESSER, M., PALLARDY, M., DAYDÉ, D., BERHOU, C., CARTRON, G., WATIER, H. Relevance, advantagens and limitations of animals models used in the development of monoclonal antibodies for cancer treatment. Crit. Rev. Oncol. Hematol. v. 62, p. 34-42, 2007.

MA. D., MCDEVITT, M. R., FINN, R. D., SCHEINBERG, D. A. Breakthroughof ${ }^{225}$ AC and its radionuclide daughter from an ${ }^{225} \mathrm{Ac} /{ }^{213} \mathrm{Bi}$ generator: development of new methds, quantitative characterization, and implications for clinical use. Appl.

Radiat. Isotopes., v. 55, p.667-678, 2001. 
MACKLIS, R. M., Radioimmunotherapy as a Therapeutic Option for Non-Hodgkin's Lymphoma. Semin. Radiat. Oncol., v. 17, p. 176-183, 2007.

MAGUIRE, W. F., MCDEVITT, M. R., SMITH-JONES, P. M., SCHEINBERG, D. A. Efficient 1-Step Radiolabeling of Monoclonal Antibodies to High Specific Activity with ${ }^{225} \mathrm{Ac}$ for $\alpha$-Particle Radioimmunotherapy of Cancer. J. Nucl. Med., v. 55, p. 1492-1498, 2014.

MARCUS, R. Use of ${ }^{90}$ Y-lbritumomab Tiuxetan in Non-Hodking's Lymphoma. Sem. in Oncol. v. 32 (1), p. 36-53, 2006.

MCLAUGHLIN, P., LÓPEZ-GRILLO, A. J., LINK, B. K., LEVY, B. K., CZUCZMAN, M. S., WILLIAMS, M. E., HEYMAN, M. R., BENCE-BRUCKLER, I., WHITE, C. A., CABANILLAS, F., JAIN, V., HO, A. D., LISTER, J., WEY, K., SHEN, D., DALLAIRE, B. K.Rituximab chimeric Anti-CD20 monoclonal antibody therapy for relapsed indolent lymphoma: half of patients respond to a four-dose treatment program. $\boldsymbol{J}$. Clin. Oncol. v. 16, p. 2825-2833, 1998.

MCDEVITT, M. R., FINN, R. D., SGOUROS, G., MA D., SCHEINBERG, D. A. An ${ }^{225} \mathrm{Ac} /{ }^{213} \mathrm{Bi}$ generator system for therapeutic clinical applications: construction and operation. Appl. Radiat. Isotopes, v. 50, p. 895-904, 1999.

MCDEVITT, M. R., MA, D., SIMON, J.,FRANK, R. K., SCHEINBERG, D. A. Design and synthesis of ${ }^{225} \mathrm{Ac}$ radiopharmaceuticals. Appl. Radiat. Isotopes, v. 57, p. 841847, 2002.

MEERTEN, T, V., HAGENBEEK, A. CD-20 Targeted Therapy: The Next Generation of Antibodies. Sem. Hematol., v. 47, p. 199-210, 2010.

MIEDERER, M., SCHEINBERG, D. A., MCDEVITT, M. R. Realizing the potential of the Actinium-225 radionuclide generator in targeted alpha particle therapy applications. Adv. Drug Deliver Rev., v. 60, p. 1371-1382, 2008.

MILENIC, D. E., BRECHBIEL, M. W., Targeting of Radio-Isotopoes for Cancer Therapy. Cancer Biol. Ther. v. 3, p. 361-370, 2004.

MONOLIX. Versão 4.2.2. User Guide. Lixoft, 2013.

MULDORF, D. A., SCHEINBERG, D. A., JURCIC, J. G. The Promise of Targetes $\alpha-$ Particle Therapy. J. Nucl. Med., v. 46, p. 199S-204S, 2005. 
MÜLLER C, SCHUBIGER PA, SCHIBLI R. Isostructural folate conjugates radiolabeled with the matched pair ${ }^{99 \mathrm{~m} T c / 188} \mathrm{Re}$ : a potential strategy for diagnosis and therapy of folate receptor-positive tumors. Nucl. Med. Bio., v. 34 (6), p. 595601, 2007.

NADLER, L. M., STASHENKO P., HARDY, R. Serotherapy of a patient with a monoclonal antibody directed against a human lymphoma-associated antigen. Cancer Res. 1980. v. 40, p. 3147-3154, 1980.

NATIONAL CANCER INSTITUTE (NCl). http://www.cancer.gov/. Acesso em 23/02/2015.

NECSOIU, D., MORGAN, I. L., HUPF, H., COURTNEY, W. J., KINROSS-WRIGHT, J., BOUANANI, M. EI., DUGGAN, J. L., MCDANIEL, F. D. Monte Carlo simulations and experiments studies of yttrium-90 production using a $33 \mathrm{MeV}$ linac. Appl. Radiat. Isotopes, v. 57, p. 509-515, 2002.

OKROJ, M., OSTERBORG, A., BLOM, A. M. Effector mechanisms of Anti-CD20 monoclonal antibodies in B cell malignances. Cancer Treat. Rev., v. 39, p. 632339, 2013.

PAUWELS S., BARONE R., WALRAND S. Practical dosimetry of peptide receptor radionuclide therapy with ${ }^{90}$ Y-labeled somatostatin analogs. J. Nucl. Med. v. 46 (suppl 1), p. 92S-98S, 2005.

PARK, S. I., SHENOI, J., PAGEL, J. M., HAMLIN, D. K., WILBUR, D. S., ORGUN, N., KENOYER, A. L., FRAYO, S., AXTMAN, A., BÄCK, T., LIN, Y., FISHER, D. R., GOPAL, A. K., GREEN, D. J., PRESS, O. W. Conventional and pretargeted radioimmunotherapy using bismuth-213 to target and treat non-Hodgking lymphomas expressing CD20: a preclinical model toward optimal consolidation therapy to eradicate minimal residual disease. Blood, v. 116, n. 20, p. 4231-4239, 2010.

PALM, S., BACK, T., CLAESSON, I., DANIELSSON, A., ELGQVIST, J., FROST, S., HULTBORN, R., JENSEN, H., LINDEGREN, S., JACOBSSON, L. Therapeutic efficacy of astatine-211 labeled trastuzumab on radioresistant skov-3 tumors in nude mice. Int. J. Rad. Oncol., Biology and Physics. v. 69, n. 2, p. 572-579, 2007.

PEROSA, F., FAVOINo, E., CARAGANO, M. A., PRETE, M., DAMMACCO, F. CD20: A target antigen for immunotherapy of autoimmune diseases. Autoimmun. Rev., v. 4, p. 526-531, 2005.

PICKETT, R. D. Radiopharmacokinetics. Sampson's Textbook of Radiopharmacy. $4^{\text {th }}$ Edition. p. 219-247, 2011. 
PILLAI, M. R. A., DAS, T. Options to meet the future global demand of radionuclides for radionuclide therapy. Nucl. Med. Biol.v. 40, n. 1, p. 23-32, 2013.

PILLAI, A. M. R., KNAPP JR, F. F (R). Evolving Important Role od Lutetium-177 for Therapeutic Nuclear Medicine. Curr. Radioph, v. 8, p. 78-85, 2015.

QAIM, S.M. Therapeutic radionuclides and nuclear data. Radiochim. Acta. v. 89, p. 297-302, 2001.

RASANEH, S.RAJABI, H., BABAEI, M., H., DAHA, F., J., SALOUTI, M. Radiolabeling of trastuzumab with ${ }^{177} \mathrm{Lu}$ via DOTA, a new radiopharmaceutical for radioimmunotherapy of breast cancer. Nucl. Med. Biol., v. 36, p. 363-369, 2009.

REZVANI, A. R., MALONEY, D. G. Rituximab Resistance. Best Pract. Res. Clin. Haematol., v. 24, p. 203-216, 2011.

ROBERT, C.P., CASELLA G. Monte Carlo Statistical Methods, 2nd Edition. New York: Springer, 2004.

ROGERS, D. W. O. Fifty years of Monte Carlo simulations for medical physics. Phys. Med. Bio., v. 51, p. R287-R301, 2006.

ROSENBLAT, T. L., MCDEVITT, M. R., MULDORF, D. A., PANDIT-TASKAR, N., DIVGI, C. R., PANAGEAS, S. K., HEANEY, M. L., CHANEL, S., MORGENSTERN, A., SGOUROS, G., LARSON, S. M., SCHEINBERG, D. A., JURCIC, J. G.

Sequential Cytarabine and a-Particle Immunotherapy with Bismuth-213-Lintuzumab (HuM195) for Acute Myeloid Leukemia. Clin. Cancer Res., v. 16, p. 5303-5311, 2010.

SAHA, G.B. Fundamental of Nuclear Pharmacy - 4 edição, p. 47-64, 1998.

SCHEINFELD, N. A Review of Rituximab in Cutaneous Medicine. Dermatol Online J., Califórnia, v. 12, 2006.

SGOUROS, G. Alpha-particles for targeted therapy. Adv. Drug Deliv. Rev. v. 60, p. 1402-1406, 2008.

SHARKEY R. M., GOLDENBERG D. M. Target therapy of cancer: new prospects for antibodies and immunoconjugates. CA Cancer J. Clin. v. 56, p. 226-243, 2006.

SILVERMAN, D. H., DELPASSAND, E. S., TORABI, F., GOY, A., MCLAUGHLIN, P., MURRAY, J. L. Radiollabeled antibody therapy in non-Hodgkin's Lymphoma: radiation protection, isotope comparisons and quality of life issues. Cancer. Treat. Rev. v. 30, p. 165-172, 2004. 
SONG, E. Y., QU, C. F., RIZVI, S. M. A., RAJA, C., BERETOV, J., MORGENSTERN, A., APOSTOLIDIS, C., BUCHERTSEIFER, F., PERKINS, A., ALLEN, B. J. Bismuth-213 radioimmunotherapy with c595 anti-MUC1 monoclonal antibody in an ovarian cancer ascites model. Cancer Bio. Ther., v. 7, n. 1, p. 69-76, 2008.

STABIN, M. G. Fundamentals of Nuclear Medicine Dosimetry. Springer, 2008.

STABIN, M. G., ECKERMAN, K. F., RYMAN, J. C., WILLIAMS, L. E. Bremsstrahlung Radiation Dose in Yttrium-90 Therapy Applications. J. Nucl. Med., v. 35, p. 1377-1380, 1994.

STANLEY, J., GOLDSMITH, M. D., Radioimunotherapy of Lymphoma: Bexxar and Zevalin. Semin. Nucl. Med.v. 30, p. 122-135, 2010.

STÖCKLIN, G.; QAIM, S.M.; RÖSCH E. The Impact of Radioactivity on Medicine. Radiochim. Acta, v. 70/71, p. 249-272, 1995.

STRACHAN, T.; REED, A.P. Genética Molecular Humana. Porto Alegre (RS): ArtMed, 2.ed., 2002.

THIEME, S. AGOSTINI, S., BERGMANN, R., PIETZSCH, J., PIETZSCH, H.-J., CARTA, D., SALVARESE, N., REFOSCO, F., BOLZATI, C. Synthesis, characterization and biological evaluation of $\left[{ }^{188} \operatorname{Re}(\mathrm{N})(\mathrm{cys} \sim)(\mathrm{PNP})\right]^{+/ 0}$ mixed-ligand complexes as prototypes for the development of ${ }^{188} \mathrm{Re}(\mathrm{N})$-based target-specific radiopharmaceuticals. Nuc. Med. Bio. v. 38, p. 399-415, 2011.

THOMPSON, S., BALLARD, B., JIANG, Z., REVSKAYA, E., SISAY, N., MILLER, W. H., CUTLER, C. S., DADACHOVA, E., FRANCESCONI, L. C., ${ }^{166} \mathrm{Ho}$ and ${ }^{90} \mathrm{Y}$ labeled 6D2 monoclonal antibody for targeted radiotherapy of melanoma:

Comparsion with ${ }^{188}$ Re radiolabel. Nucl. Med. Biol., v. 41, p. 276-281, 2014.

TORRES-GARCIA, E., FERRO-FLORES, G., MURPHY, C. A., CORREAGONZALEZ, L., PICHARDO-ROMERO, P. Biokinetics and Dosimetry of ${ }^{188}$ Re-AntiCD20 in Patients with Non-Hodkings Lymphoma: Preliminary Experience. Arch. Med. Res., v. 39, p. 100-109, 2008.

VALLABHAJOSULA, S., KILLEEN, R., P., OSBORNE, J., R. Altered Biodistribution of Radiopharmaceuticals: Role of Radiochemical/Pharmaceutical Purity, Physiological and Pharmacologic Factors. Semin. Nucl. Med. v. 40, p. 220-241, 2010.

VEIT, R., ZANKL, M., PETOUSSI-HENSS, N., MANNWEILER, E., WILLIAM, G., DREXLER, G., Tomographic Anthropomorfic Models, Part I: Construction 
Technique and Description of Models of an 8 Week Old Baby and 7 Year Old Child. GSF-Report 3/89, GSF-Nat. Res. C. Environment and Health, Neuherberg, Germany, 1989.

VICINI, P., BRILL, A. B., STABIN, M. G., RESCIGNO, A. Kinetic Modeling in Support of Radionuclide Dose Assessment. Sem. Nucl. Med., v. 38, p. 335-346, 2008.

VOLKERT, W.A., HOFFMAN, T.J. Therapeutic raiopharmaceuticals. Chem. Rev., v. 99, p. $2269-2292,1999$.

WEINER, R.E., THAKUR, M.L. Metallic Radionuclides: Applications in Diagnostic and Therapeutic Nuclear Medicine. Radiochim. Acta, v. 70/71, p.273-287, 1995.

ZALUTSKY, M. R., REARDON, D. A., POZZI, O. R., VAIDYANATHAN, G., BIGNER, D. D. Targeted $\alpha$-particle radiotherapy with ${ }^{211}$ At-labeled monoclonal antibodies. Nucl. Med. Biol., v. 34, p. 779-785, 2007. 